\title{
THE ENVIRONMENTAL REGULATION OF MARINE CARBON CAPTURE AND STORAGE IN NEW ZEALAND:
}

\section{PRINCIPLES, BARRIERS AND GAPS}

\author{
BY \\ GREGORY DARREN SEVERINSEN
}

A thesis

submitted to the Victoria University of Wellington in fulfilment of the requirements for the degree of Doctor of Philosophy

Victoria University of Wellington

2017 


\begin{abstract}
This thesis concerns the regulation of a technology called carbon capture and storage (CCS). The technology is one way to mitigate anthropogenic climate change, by capturing carbon dioxide $\left(\mathrm{CO}_{2}\right)$ emissions at point sources (such as power or industrial plants) and injecting them into deep underground geological formations. Specifically, the thesis looks at the framework of public environmental law that is needed for CCS in New Zealand where injection occurs offshore in its coastal marine area and exclusive economic zone. The thesis concludes that, when tested against existing principles in New Zealand's environmental law and the requirements of international law, current provisions in domestic law contain both significant barriers and gaps. These barriers must be removed and gaps must be filled.

The thesis identifies three broad features of New Zealand's law that give rise to a range of barriers and that need to be addressed. First, there is substantial uncertainty as to how existing provisions would apply to CCS. Greater certainty is needed. Secondly, the classification of CCS as a form of marine dumping presents a significant barrier. The technology needs to be classified differently, and more positively. Thirdly, the law contains a general prohibition on considering the effects of activities on climate change. This may prevent CCS being deployed in practice, and needs to be reconsidered.
\end{abstract}

New Zealand's existing law also contains three potential gaps, which must be filled. First, there is a dearth of CCS-specific regulatory and policy provisions within existing regimes such as the Resource Management Act 1991. This means operators and regulators would be operating in a regulatory and policy vacuum. Decisions may be inconsistent, fail to impose appropriate environmental standards, or fail to give appropriate weight to relevant considerations. Secondly, there are limitations in the ability of existing regimes to regulate the positive effects of activities - such as climate change mitigation - to ensure that they are actually achieved. Thirdly, existing law does not facilitate the kind of targeted and comparative decision-making process needed for CCS. This means that it does not provide an effective process for resolving tensions between competing resource interests in the sub-seabed. 


\section{Acknowledgements}

To my supervisors, thank you for your bottomless stores of wisdom, practical advice and aid in navigating the often confusing and alarming pathways of acadaemia. To Tony Angelo, Jonathan Dempsey and support staff in the Law Faculty, thank you for all your guidance (and your printers).

To my fellow PhD friends: you are all amazing, and it has been a pleasure hanging out with you in the good times and the challenging.

To my family, particularly my darling fiancé Rochelle, my beautiful little boy Lachie and Mum and Dad: you have been constant and unfailing sources of support and love. There is no way I could have done this - or, indeed, anything else of value - without you. 


\section{Table of Contents}

I Introduction

Part 1 Normative Framework for CCS - Philosophy and Principles

II An "Inclusive Anthropocentric" Approach

III Principles of Environmental Law in New Zealand

IV Translating Principles to Marine CCS

V Marine CCS and International Law

VI Barriers in Existing Law

VII Gaps within Legislation - Targeted Instruments

VIII Gaps outside Legislation - Security of Storage

IX Other Gaps - the Relationship between Marine CCS and Petroleum Mining

X Conclusion 


\section{Detailed Table of Contents}

$\begin{array}{ll}\text { Abstract } & 3\end{array}$

Acknowledgements 5

Table of Contents $\quad 7$

Detailed Table of Contents $\quad 8$

List of Figures $\quad 11$

I Introduction 13

A Introduction: Topic and Context 13

$B$ Objectives and Thesis $\quad 15$

C Legal Barriers and Gaps 16

1 Environmental law 17

2 The injection and storage phase of marine CCS 19

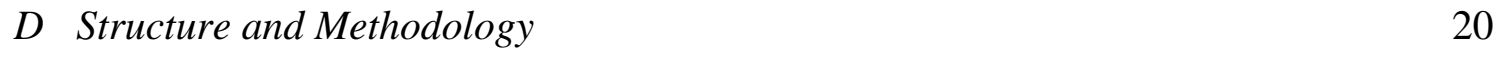

E The Development of Marine CCS 21

$F \quad$ Potential Environmental Consequences of Marine CCS 31

$G$ Summary $\quad 35$

Part 1 Normative Framework for CCS - Philosophy and Principles 37

II An "Inclusive Anthropocentric" Approach 39

A Introduction 39

$B$ Normative Approaches to the Environment 40

C An Inclusive Anthropocentric Approach 43

$D$ Conclusion $\quad 51$

III Principles of Environmental Law in New Zealand 53

A Introduction $\quad 53$

$B$ The Principle of Sustainability $\quad 54$

C The Distributive Principle $\quad 57$

$D$ Treaty of Waitangi Obligations 64

E The Public-interest Industries Principle $\quad 67$

F The Conservation-enhancement Principle 68

$G$ The Principle of Precaution $\quad 70$

H From Substantive to Procedural Principles 72

I The Participatory Principle $\quad 73$

$J$ The Decision-making Principle 76

K The Certainty-flexibility Principle $\quad 79$

$L$ The Efficiency Principle $\quad 81$

M Conclusion $\quad 82$

IV Translating Principles to Marine CCS 85

A Introduction $\quad 85$

$B$ The Principle of Sustainability $\quad 86$

C The Distributive Principle 86

D Treaty of Waitangi Obligations 89 
E The Public-interest Industries Principle 92

$F \quad$ The Conservation-enhancement Principle 97

$G$ The Principle of Precaution 102

$H$ The Participatory Principle 103

I The Decision-making Principle 104

$J$ The Certainty-flexibility Principle 105

$K$ The Efficiency Principle 106

L Conclusion 107

V Marine CCS and International Law 109

A Introduction 109

$B$ The Application of International Law to Marine CCS 110

$C$ Jurisdiction under International Law 111

D Substantive Provisions: Part 12 UNCLOS 113

1 Protection and pollution 113

2 Dumping under UNCLOS 115

E Substantive Provisions: the London Dumping Protocol 116

1 Dumping and pollution under the London Protocol 116

2 Obligations applicable to Marine CCS under the London Protocol 120

3 The relevance of the London Protocol to chapter IV conclusions 122

$F$ Other International Instruments 123

$G$ Conclusion 124

Part 2 Normative Evaluation for Marine CCS - Barriers and Gaps 125

VI Barriers in Existing Law 127

A Introduction $\quad 127$

B Crown Minerals Act $1991 \quad 128$

C Resource Management Act 1991 and EEZ Act 2012

1 Purpose: sustainable management 130

2 Regulatory restrictions on CCS 130

3 Regulatory restrictions under regulations 133

4 Policy guidance under the RMA $\quad 136$

5 Policy guidance under RMA subordinate instruments 138

6 Stocktake: why barriers arise under the RMA and EEZ Act 141

7 Climate change considerations under the RMA and EEZ Act 142

8 Leakage under the RMA and EEZ Act 146

D Climate Change Response Act $2002 \quad 150$

E Marine and Coastal Area (Takutai Moana) Act 2011

F Maritime Transport Act 1994

$G$ Hazardous Substances and New Organisms Act 1996

$H$ Legislation not Addressed $\quad 154$

I Conclusion 155

VII Gaps within Legislation - Targeted Instruments 157

A Introduction 157

$B$ The Need for Targeted Instruments 159

C Filling the Gaps in Regulatory Instruments 160 
1 Standards for $\mathrm{CO}_{2}$ purity 161

2 Other standards for injection and storage 164

3 Standards for leakage $\quad 166$

D Policy Provisions 167

1 Leveraging off international standards 167

2 Ensuring the provision of relevant information 168

3 Recognising the positive climate effects of marine CCS 169

4 Targeting the adverse effects of marine CCS 170

E Internal gaps within the Climate Change Response Act 172

F Conclusion 173

VIII Gaps outside Legislation - Security of Storage 175

$\begin{array}{ll}A \text { Introduction } & 175\end{array}$

$B$ Shortcomings of the Climate Change Response Act and the RMA/EEZ Act 176

$C$ Positive Effects, Adverse Effects and Conditions under the RMA/EEZ Act 177

$D$ Secure Storage as a Positive Effect 180

E Exceptions for the Enforcement of Positive Effects: Offsetting 182

$F$ Other Limitations of the RMA and EEZ Act 184

$G$ Filling the Gap $\quad 185$

H Authorisation of Storage 187

1 Standards for site selection, injection and site closure 188

2 Risk assessment and the exercise of discretion 190

3 Conditions and management plans 193

4 Liability for leakage 198

5 Financial security and orphaned projects $\quad 200$

I Authorisation of Closure and Transfer 202

J Conclusion 206

IX Other Gaps - the Relationship between Marine CCS and Petroleum Mining 209

A Introduction 209

B Allocating Unused Subsurface Space $\quad 210$

1 Existing allocative mechanisms 212

2 Filling the gap 216

C Resolving Conflict between New and Existing Interests 223

1 Conflict where no adverse effects arise 223

2 Risks of adverse effects on existing operations 224

3 Risks to an existing storage operation $\quad 226$

4 Risks to an existing mining operation $\quad 227$

5 Responding to adverse effects on existing operations 229

6 Third party access to storage formations 230

D Enhanced Petroleum Recovery and Carbon Capture, Utilisation and Storage 231

1 Enhanced petroleum recovery as a form of CCS 232

2 Thresholds for the application of storage law 233

$\begin{array}{ll}\text { E Conclusion } & 235\end{array}$

$\begin{array}{ll}X \text { Conclusion } & 237\end{array}$

$\begin{array}{ll}\text { Bibliography } & 247\end{array}$ 


\section{List of Figures}

Figure 1: The CCS Process $\quad 24$

Figure 2: Generic Geological Strata in CCS Operations 27

Figure 3: Carbon Capture, Utilisation and Storage 30

Figure 4: The Relationship between New Zealand's core Environmental Legal Principles 84

Figure 5: Coastal Zones and Jurisdiction under International Law 112 


\section{$\xi$}

\section{Introduction}

Warming of the climate system is unequivocal, and since the 1950s, many of the observed changes are unprecedented over decades to millennia. ${ }^{1}$

We cannot hope to tackle the scale of the climate challenge without CCS. ${ }^{2}$

\section{A Introduction: Topic and Context}

This thesis concerns the regulation of a technology called marine carbon capture and storage (marine CCS, CCS, or simply "storage"). I consider the framework of public environmental law needed for its regulation in New Zealand's offshore waters. More specifically, I recommend reforms that will produce an appropriate environmental legal framework for CCS injection and storage in New Zealand's coastal marine area, exclusive economic zone, and extended continental shelf. ${ }^{3}$

CCS is a relatively new suite of technologies designed to address anthropogenic climate change. It involves the capture of carbon dioxide $\left(\mathrm{CO}_{2}\right)$ emissions prior to their discharge to the atmosphere, their compression and transportation to a storage site, injection into a deep, natural and impermeable geological formation, and long-term stewardship of the storage site to avoid leakage. Carbon dioxide that is sequestered beneath the Earth's surface is prevented from contributing to climate change. The process has three broad phases: capture, transport and injection/storage. Where injection occurs offshore into a geological formation beneath

\footnotetext{
${ }^{1}$ IPCC "Summary for Policymakers" in Climate Change 2013: The Physical Science Basis (IPCC, Geneva, 2013) at 4.

${ }^{2}$ GCCSI The Global Status of CCS: 2015 Summary Report (GCCSI, Melbourne, 2015) at 1.

${ }^{3}$ The law is accurate as at 1 September 2016.
} 
the seabed, this can be characterised as marine CCS, in contrast to "terrestrial" CCS onshore, but the basic idea and technology is the same.

Globally, CCS deployment is in its infancy. Few commercial scale projects exist. In New Zealand it has not occurred at all, although there is interest in its development. Indeed, central government has touted CCS as a potentially important (albeit small) part of New Zealand's future emissions mitigation efforts. ${ }^{4}$ At the international level it is recognised as an integral part of a global response. ${ }^{5}$ Indeed, the most recent assessment report of the Intergovernmental Panel on Climate Change (IPCC) builds CCS technology into many of its modelling assumptions. $^{6}$

Although some attention has been paid to legal issues with CCS in New Zealand (pointing out a range of deficiencies in the law), ${ }^{7}$ the technology is not specifically regulated. Planned regulations and policies have not appeared. ${ }^{8}$ There is a risk that existing law would pose unintended barriers to deployment and create uncertainty, ${ }^{9}$ and may also contain a number of gaps. This has been a common experience internationally. ${ }^{10}$ In response, the International Energy Agency has recommended that states review and develop legal frameworks for the technology, and that uncertainties in regulation be avoided. ${ }^{11}$ Good law is essential, because

\footnotetext{
${ }^{4}$ S McCoy Carbon Capture and Storage: Legal and Regulatory Review (4 ${ }^{\text {th }}$ ed, IEA/OECD, Paris, 2014 ) at 44.

${ }^{5}$ GCCSI The Global Status of CCS: 2014 (GCCSI, Melbourne, 2014) at 8; Royal Society of New Zealand Transition to a Low Carbon Economy for New Zealand (2016) at 6, 15, 18, 83; Alberta Government Carbon Capture and Storage: Summary Report of the Regulatory Framework Assessment (Energy Alberta, Edmonton, 2013) at 27; I Havercroft and R Macrory "Pulling the Threads Together" in I Havercroft, R Macrory and RB Stewart (eds) Carbon Capture and Storage: Emerging Legal and Regulatory Issues (Hart, Oxford, 2011) at 297. ${ }^{6}$ IPCC Synthesis Report: Fifth Assessment Report of the IPCC (IPCC, Geneva, 2014) at 23, 28, 89, 99.

${ }^{7}$ Only four published academic works directly concern CCS law in New Zealand: B Barton, K Jordan and G Severinsen Carbon Capture and Storage: Designing the Legal and Regulatory Framework for New Zealand (University of Waikato Centre for Environmental, Resources and Energy Law, Hamilton, 2013); B Barton "Carbon Capture and Storage Law for New Zealand: A Comparative Study" (2009) 13 NZJEL 1; G Severinsen "Constructing a Legal Framework for Carbon Capture and Storage in New Zealand" (2014) 63 EGYPRO 6629; G Severinsen "Towards an Effective Legal Framework for the Geo-Sequestration of Carbon Dioxide in New Zealand" (2010) 16 Canta LR 330. High level analysis was also conducted in Strategic Analysis of the Global Status of Carbon Capture and Storage: Report 3: Country Studies: New Zealand (GCCSI, 2009).

${ }^{8} \mathrm{M}$ Gerstenberger and others Opportunities for Underground Geological Storage of $\mathrm{CO}_{2}$ in New Zealand: Risk Assessment Methodologies (GNS Science, Report CCS 08/10 2009/63, 2009) at 36.

${ }^{9}$ The need for clear law to promote investment certainty is a common theme in the literature. See, for example, M Granger Morgan and S McCoy Carbon Capture and Sequestration: Removing the Legal and Regulatory Barriers (RFF Press, New York, 2012) at 63; Barton and others, above n 7, at 20.

${ }^{10}$ See I Havercroft and R Purdy "Carbon Capture and Storage - A Legal Perspective" <www.un.org> at 14.

${ }^{11}$ IEA Tracking Progress in Carbon Capture and Storage (2002) at 6.
} 
"the fundamental economics, operability and commercial acceptability of CCS will be extremely sensitive to the details of how regulatory requirements are crafted". ${ }^{12}$

\section{$B \quad$ Objectives and Thesis}

The objective of the thesis is to recommend reforms that will produce an appropriate framework of public environmental law for CCS injection and storage in New Zealand's offshore waters. This is comprised of three steps: first, the establishment of our aims for regulating the technology; secondly, the identification of barriers in existing law; and, thirdly, the identification of gaps in the law. Our aims are driven by the basic way in which we see the environment and our place within it, the fundamental principles of New Zealand's environmental law, and the way in which those principles are translated to the context of CCS. I conclude that, when measured against those principles, existing law contains several barriers and gaps.

More specifically, the law has three general features that give rise to barriers, and which should be removed. First, there is uncertainty as to how some existing provisions would apply to CCS. The law should not contain any fundamental uncertainty as to whether, or how, it applies. Secondly, the law classifies CCS negatively as a form of marine dumping. Existing principle suggests that the focus of regulation should be on the technology's potential contribution to climate change mitigation, not an assumption that it is inherently harmful. Thirdly, the law contains a prohibition on considering the effects of activities on climate change when making decisions on CCS. Decision-makers need to be able to place substantial weight on the technology's climate benefits when considering applications, but are constrained in doing so.

Existing law also contains three gaps, which should be filled. First, there is an absence of CCS-specific regulatory and policy provisions within existing regimes. These are needed to address the specific adverse effects CCS could have on the local environment, to emphasise the technology's climate benefits, and to provide guidance on the relative weight to be assigned to local and global impacts. Secondly, existing regimes may lack the ability to

\footnotetext{
${ }^{12}$ N Shilling "Carbon Capture and Storage - An Equipment Manufacturer's Perspective" in Havercroft and others, above $\mathrm{n} 5$, at 25 .
} 
regulate the positive effects of activities to ensure they are achieved. This is particularly important to make sure $\mathrm{CO}_{2}$ is stored securely in the long-term. Thirdly, the law lacks a targeted and comparative decision-making process, guided by the public interest, which is capable of resolving competing sub-seabed interests in a fair and transparent manner. We also need provisions that clarify exactly when the injection of $\mathrm{CO}_{2}$ during petroleum operations becomes a form of CCS.

\section{Legal Barriers and Gaps}

This thesis seeks to identify legal barriers and gaps. What is meant by these terms is thus an important question of scope. Legal barriers are defined here as existing provisions in the law that prevent or inhibit New Zealand achieving its aims for marine CCS regulation. Similarly, legal gaps can be perceived where additional law is needed to achieve our aims. Therefore, to identify barriers and gaps, we must first identify what those aims are. This is considered in chapters 2 to 4 .

Not all barriers and gaps are of a legal character. Those in statutes and regulations are legal in nature, because they require legal intervention to remove. ${ }^{13}$ But marine CCS gives rise to many other barriers that are scientific, commercial and policy-based, and which are not addressed here. The boundary between environmental law and policy is particularly difficult to define. The legal framework developed under the Resource Management Act 1991 (RMA), for example, is characterised by a constant blurring of the lines between judicial and policy decision making, between legal submission and expert opinion, and between legal standards and policy guidance. ${ }^{14}$ Large parts of environmental law can be seen simply as a vehicle for the embodiment of central, regional and local policy preferences, ${ }^{15}$ and is not overly concerned with legal niceties. ${ }^{16}$

\footnotetext{
${ }^{13}$ Unless the context requires otherwise (for example, "legislation" versus specific subordinate "regulations"), the general terms "legal" and "regulatory" are used interchangeably. See IEA CCS Model Regulatory Framework (Paris, IEA, 2010) at 14.

${ }^{14}$ See RMA, ss 120, 293; S Elias, Chief Justice of New Zealand "Righting Environmental Justice" $\left(12^{\text {th }}\right.$ Annual Salmon Lecture, Auckland, 25 July 2013) at 14.

${ }^{15}$ For example, an activity can be prohibited through rules in a regional plan without going through a legislative process: Resource Management Act 1991 (RMA), s 87A(6).

${ }^{16}$ See Sutton v Moule (1992) 2 NZRMA 41 (CA) at 11.
} 
I exclude pure policy considerations in three ways. First, I make the assumption that marine CCS is not to be prohibited outright at a policy level. This reflects the intention of the current government, ${ }^{17}$ the bulk of international literature, ${ }^{18}$ and the principles adopted in chapter III. Secondly, those principles, which are used to guide recommendations for reform, are all enduring legal principles, and more than ephemeral expressions of government policy. ${ }^{19}$ Such principles may originate in a highly interdisciplinary context, but that does not diminish their value as principles of law. ${ }^{20}$ I do not comment on policy choices to the extent they are not driven by legal principle. I seek only to construct an appropriate legal framework for such decisions to be made. Thirdly, I consider only the regulation of - not regulation for - marine CCS. The latter concerns law that is needed to incentivise deployment (such as a higher carbon price or regulatory requirements to install capture technology), and requires difficult policy choices. ${ }^{21}$ In the literature, incentives are frequently distinguished from other aspects of the law regulating injection and storage, ${ }^{22}$ and international experience has shown that incentives for deployment are not likely to be found within frameworks regulating the technology itself. ${ }^{23}$ Regulation "of" CCS concerns only the environmental restrictions that should be imposed on a project if an applicant chose to put a project forward.

\section{Environmental law}

The scope of the thesis is limited to "environmental" law. This term is difficult to define; ${ }^{24}$ at its most basic, it is concerned with regulating the use of, and effects on, the natural and physical world. ${ }^{25}$ Here, it is taken to be the set of norms, of a legal character, that provide for

\footnotetext{
17 See Ministry of Business, Innovation and Employment (January 2016) "CCS in New Zealand" <www.mbie.govt.nz>.

${ }^{18}$ GCCSI, above n 5, at 9; McCoy, above n 4, at 44.

${ }^{19}$ See ch III. Although government policy, when legislated, may in practice override or ignore legal principle, and on occasion it may be difficult to distinguish policy from principle, these are not valid reasons to reject enduring principles as a guide to reform where they are clearly observable.

${ }^{20}$ K Bosselmann The Principle of Sustainability: Transforming Law and Governance (Ashgate, Aldershot, 2008) at 43; K Bosselmann "Sustainability and the Law" in P Salmon and D Grinlinton (eds) Environmental Law in New Zealand (Thomson Reuters, Wellington, 2015) at 97.

${ }^{21}$ For example, using tools like capital grants, production subsidies, or tax credits: see McCoy, above n 4, at 12.

${ }^{22}$ See for example Ibid at 25; Carbon Dioxide Capture and Geological Storage: Australian Regulatory Guiding Principles (MCMPR, 2005) at 10.

${ }^{23}$ IEA, above $\mathrm{n} 13$, at 35 .

${ }^{24}$ See D Grinlinton "Defining the Nature and Boundaries of Environmental Law" in Salmon and Grinlinton, above n 20.

${ }^{25}$ See generally C Warnock and M Baker-Galloway Focus on Resource Management Law (LexisNexis, Wellington, 2015) at 4-5; K Palmer "Introduction to Environmental Law" in D Nolan (ed) Environmental and Resource Management Law (5 $5^{\text {th }}$ ed, LexisNexis, Wellington, 2015).
} 
public authorities to determine how natural and physical resources are to be used or protected, and how to assess and manage the impacts of such choices. ${ }^{26}$ This does not disregard the importance of indigenous, religious and natural law foundations for environmental management. It simply recognises that such concerns are beyond the scope of a thesis concerned with regulating a new technology within an existing legal framework.

My focus is on public environmental law. Private environmental law governs how people can use resources under their control so as not to cause harm to others, and those laws continue to have important environmental consequences. ${ }^{27}$ However, I do not consider them specifically. ${ }^{28}$ For example, I do not address trespass and nuisance, questions over ownership of underground pore space and injected gas, provision for third party access to real property, or intellectual property concerns. ${ }^{29}$ Public environmental law is a more recent concept in which the state intervenes to restrict the use of both public and private resources, on the grounds that there is a public interest in responsibly managing the environment as a whole. ${ }^{30}$ It is not just about redressing harm done to private persons. ${ }^{31}$

A public law focus means that the sources of law with which the thesis is concerned are for the most part statutory. ${ }^{32}$ Discussion orbits largely around a finite number of statutes, with the RMA providing the centre of gravity. ${ }^{33}$ Even so, some boundaries remain elusive, given the wide and interconnected concept of the "environment". ${ }^{34}$ For example, human health and safety is generally not recognised in the literature as an environmental issue, and is regulated primarily under non-environmental statutes. ${ }^{35}$ However, the expansive definition of the environment in the RMA includes "people" as a constituent part of ecosystems, and effects on human health are justiciable under the Act as effects on the environment. ${ }^{36}$ For simplicity,

\footnotetext{
${ }^{26}$ Compare Grinlinton, above n 24, at 11.

${ }^{27}$ See Salmon and Grinlinton, above n 20, at 38-39; DR Keller (ed) Environmental Ethics: the Big Questions (Wiley Blackwell, West Sussex, 2010) at 2-3.

${ }^{28}$ See D Grinlinton "The Role of the Common Law" in in Salmon and Grinlinton, above n 20; Severinsen "Towards an Effective Legal Framework", above n 7; Barton and others, above n 7.

${ }^{29}$ On these subjects, see Barton and others, above n 7; I Havercroft and R Macrory Legal Liability and Carbon Capture and Storage: A Comparative Perspective (GCCSI, 2014).

${ }^{30}$ See generally P McAuslan The Ideologies of Planning Law (Pergamon Press, Oxford, 1980); Palmer, above n 25 , from 10 .

31 See generally D Grinlinton "Defining the Nature and Boundaries of Environmental Law" in Salmon and Grinlinton, above n 20, at 2; Falkner v Gisborne District Council [1995] 3 NLZR 622 (HC) at 631-632.

${ }^{32}$ Warnock and Baker-Galloway, above n 20, at 4.

${ }^{33}$ And the Exclusive Economic Zone and Continental Shelf (Environmental Effects) Act 2012 in the EEZ.

${ }^{34}$ Grinlinton, above $\mathrm{n} 24$, at 3.

${ }^{35}$ For example, the Health and Safety at Work Act 2015.

${ }^{36}$ Sections 3, 5.
} 
concerns over human health and safety are addressed to the extent they are relevant under the RMA; discussion does not extend to standards made under dedicated health and safety legislation. ${ }^{37}$ Similarly, I do not analyse indigenous law per se, such as historical claims by Māori to particular resources, or settlement processes under the Treaty of Waitangi (the Treaty). ${ }^{38}$ However, the Treaty and indigenous issues are addressed to the extent they fall within the scope of environmental statutes.

2 The injection and storage phase of marine CCS

In this thesis I consider only the injection and storage phase of marine CCS. ${ }^{39}$ This can be defined as any activity that occurs once captured $\mathrm{CO}_{2}$ reaches an injection site, or a preparatory activity that is related to those activities (such as site characterisation). The capture and transport phases are excluded from consideration. ${ }^{40}$ They give rise to different (usually less difficult) kinds of legal issues, ${ }^{41}$ are not in theory a novel activity $\left(\mathrm{CO}_{2}\right.$ is already captured and transported in New Zealand), ${ }^{42}$ and they are geographically and temporally distinct processes.

A handful of other boundaries can be mentioned briefly. The focus of the thesis is on CCS below New Zealand's coastal marine area, because this is where the most complex offshore law exists. But equivalent issues in the exclusive economic zone (EEZ) and extended continental shelf are also referenced where they arise (a number of issues are very similar despite a different legislative landscape). ${ }^{43} \mathrm{CCS}$ on land is not looked at specifically (for a variety of reasons - for example, the law applies differently, private property interests are more prominent, and public perception may well drive deployment offshore in practice). That

\footnotetext{
${ }^{37}$ Such as the Health and Safety at Work Act 2015.

${ }^{38}$ See generally K Johnston "The Treaty of Waitangi" (2008) NZ L Rev 609.

${ }^{39}$ A description of the CCS process is provided further below.

${ }^{40}$ On these, see Barton and others, above n 7, ch 8; Transfield Worley Carbon Dioxide Transport and Pipelines (July 2013).

${ }^{41}$ IEA, above n 13, at 54. See also Havercroft and Purdy, above n 10, at 15; IPCC Carbon Capture and Storage (Cambridge University Press, New York, 2005) at 69; Barton "Comparative Study", above n 7, at 5; C Hendriks, MJ Mace and R Coenraads Impacts of EU and International Law on the Implementation of Carbon Capture and Geological Storage in the European Union (European Commission, 2005) at 52; RM CuellerFranca and A Azapagic "Carbon Capture, Storage and Utilisation Technologies" (2015) 9 Journal of $\mathrm{CO}_{2}$ Utilization 82 at 90.

${ }^{42}$ New Zealand CCS Partnership CCS in New Zealand: Can Carbon Capture and Storage Deliver Value to New Zealand as we Head towards a Low Carbon Future? Summary Report (NZ CCS Partnership, 2011) at 4; Barton "Comparative Study", above n 7, at 5.

${ }^{43}$ The thesis excludes consideration of CCS beyond the extended continental shelf.
} 
said, much discussion may be transferable to the regulation of land-based CCS, and it presents a fruitful area for further research. The thesis is concerned only with geological sequestration; the law applicable to sequestration of carbon in trees, the water column, minerals and elsewhere are markedly different. ${ }^{44}$ I consider only the sequestration of $\mathrm{CO}_{2}$; the offshore injection of other greenhouse gases is prohibited under international law. ${ }^{45}$ Some have suggested that early CCS laws should be project-specific, ${ }^{46}$ but the thesis is concerned rather with general and long-term legislative solutions. ${ }^{47}$ Finally, the thesis does not attempt to answer questions of legislative design. I consider the reforms needed to remove barriers and fill gaps but do not comment on where this should be done structurally. ${ }^{48}$

\section{Structure and Methodology}

The thesis is divided into two parts of substance: identifying principles that should guide recommendations (the "normative framework" of Part 1), and analysing barriers and gaps (the "normative evaluation" of Part 2). Its methodology is linked closely to this structure.

A general "barriers and gaps" methodology follows the recommendations of the International Energy Agency and others. ${ }^{49}$ Under this approach, the first step is to determine our aims for law reform. ${ }^{50}$ As Ferré has pointed out, the use of any technology is inherently moral, so this is a necessary step. ${ }^{51}$ The next stage is to consider how existing law would apply, and if it would pose any barriers to those aims. Only then is it possible to determine if there are gaps in the law and what is required to fill them.

More specifically, in Part 1 (chapters II to IV) I produce aims for CCS regulation. Chapter II adopts a broad normative position described as an "inclusive anthropocentric" approach. This

\footnotetext{
${ }^{44}$ See IPCC, above n 41 , ch 6.

${ }^{45}$ See ch V.

46 Alberta Carbon Capture Storage and Development Council Accelerating Carbon Capture and Storage Implementation in Alberta (Interim Report, September 2008) at 19.

${ }^{47}$ See R Pritchard "Carbon Capture and Storage - A Review of the Australian Legal and Regulatory Regime" in Barton and others, above n 7, at 264.

${ }^{48}$ For example, whether new provisions should be integrated into existing laws like the RMA or Crown Minerals Act 1991, or whether stand-alone CCS legislation should be enacted (or a hybrid approach). This issue is a live one in the literature and worthy of further exploration: see Barton "Comparative Study", above n 7, at 35; Severinsen "Constructing a Legal Framework", above n 7.

${ }^{49}$ IEA, above n 13, at 23; IEA CCS Roadmap (IEA, Paris, 2009); I Havercroft and R Macrory "Pulling the Threads Together" in Havercroft and others, above n 5, at 303.

${ }^{50}$ See IEA, above n 13, at 22.

${ }^{51}$ F Ferré Philosophy of Technology (University of Georgia Press, New Jersey, 1995) at 11.
} 
sees the collective interests of humanity as the paramount moral consideration in driving law reform. That approach is elaborated on in chapter III, where I identify 10 key principles that are observable within New Zealand's existing environment law. Chapter IV then translates those principles specifically to the context of CCS, to formulate targeted aims for its regulation. Chapter V identifies international legal requirements for CCS, to which recommendations for reform must also give effect.

In Part 2 I use the conclusions of Part 1 to evaluate the adequacy of existing law, by identifying and addressing barriers and gaps. Chapter VI considers how the law currently applies to marine CCS, identifies barriers it presents and recommends solutions to remove them. Chapters VII, VIII and IX identify potential gaps in existing law and consider how they should be filled.

Within a general methodological framework of aims, barriers and gaps, the thesis uses a mixed method approach. A critical analysis of primary and secondary legal sources forms its core, and has been assisted by examples from other jurisdictions where they are useful. ${ }^{52}$ These are taken predominantly from jurisdictions that are advanced in the regulation of CCS and that share basic features of New Zealand's legal system (notably Australia and Canada). ${ }^{53}$ Some learnings are transferable from these countries' laws on terrestrial CCS, because many issues are the same as offshore.

\section{E The Development of Marine CCS}

To understand the nature of barriers and gaps, it is important to keep in mind the context in which they arise. I explore the legal context in subsequent chapters, but here I outline the political, economic, and technical context of CCS: where it is happening, why it is being deployed, and how it works.

There is now near universal recognition that anthropogenic emissions of $\mathrm{CO}_{2}$ are having adverse impacts on the world's climate. ${ }^{54}$ Yet despite this recognition, global responses have

\footnotetext{
${ }^{52}$ In the spirit of Watson's work on comparative law, this sees legitimacy in borrowing from others' laws where appropriate, despite social or cultural differences: see A Watson Legal Transplants (University of Georgia Press, 1974).

${ }_{54}^{53}$ See GCCSI, above n 2, at 9.

${ }^{54}$ IPCC, above n 1, at 4.
} 
thus far been weak. A proven effective climate agreement has yet to be achieved under the auspices of the United Nations Framework Convention on Climate Change (UN Framework Convention). ${ }^{55}$ Even if the current ambitions of states are realised, they may not be enough to constrain global temperature rises to below 3 degrees, or avoid associated environmental impacts. $^{56}$

Some climate change mitigation measures have already been taken. Notable is the use of emissions trading. ${ }^{57}$ Here, a sufficiently high "carbon" price provides an economic incentive not only to reduce atmospheric emissions, but also to develop innovative low-carbon alternatives. Only two offshore commercial projects have so far been driven solely by carbon pricing (incentivised by a Norwegian tax on offshore carbon emissions). ${ }^{58}$ But the prospect of higher carbon prices in the future, combined with substantial state investment and subsidisation, ${ }^{59}$ has led to growing interest in CCS over the last decade.

Globally, a stronger driver for CCS deployment (particularly in North America, the Middle East and China) has been the potential for $\mathrm{CO}_{2}$ injection to enhance yields of oil and gas (petroleum). ${ }^{60}$ This process, known as enhanced oil/gas/hydrocarbon/petroleum recovery (and described later in this chapter) can result in both the subsurface storage of $\mathrm{CO}_{2}$ and an extension in the life of otherwise unviable petroleum operations. In short, the financial value of increasing petroleum production from the injection of $\mathrm{CO}_{2}$ can offset the costs of an associated storage operation.

However, broad commercial deployment of CCS remains limited. Primarily this is because the cost of the technology remains higher than the price of emitting $\mathrm{CO}_{2}$, and there are few regulatory requirements to invest. ${ }^{61}$ One representative of the oil and gas industry in New

\footnotetext{
${ }^{55}$ It remains to be seen whether the Paris Agreement, recently ratified by New Zealand and based on nationally determined contributions, will be effective or not.

${ }^{56}$ GCCSI, above n 5, at 18 .

57 See, for example, Directive 2003/87/EC establishing a Scheme for Greenhouse Gas Emission Allowance Trading within the Community [2003] OJ L275/32.

${ }^{58}$ Being the Snøhvit and Sleipner projects: see GCCSI, above n 5, at 12; HC Bugge "An Overview of CCS Law and Regulation in Norway" in Barton and others, above n 7, at 338.

${ }^{59}$ For example, in the offshore context, Peterhead in Scottish waters and White Rose off the coast of Yorkshire: see McCoy, above n 4, at 21; GCCSI, above n 2, at 7.

${ }^{60}$ GCCSI, above n 5, at 11 .

${ }^{61}$ GCCSI, above n 5, at 8. A sufficient price will vary across capture and storage scenarios, but has been estimated to be in the range of $€ 60-90$ or NZ\$20-128 per tonne of $\mathrm{CO}_{2}$. See generally Barton "Comparative Study", above n 7, at 3; International ENGO Network on CCS Environmental Non-Government Organisation Perspectives on Carbon Capture and Storage (GCCSI, 2012) at 6; JJ Snyder "Obstacles to Carbon Capture and
} 
Zealand has even spoken of CCS in current conditions as "commercial suicide". ${ }^{62}$ An uncertain and unsupportive legal and policy environment has been cited as another key hurdle to commercial interest in CCS, and New Zealand has been ranked poorly on this score. ${ }^{63}$ Very few countries have implemented the targeted laws seen as necessary for deployment. ${ }^{64}$ Yet CCS is still widely considered to be an essential short-term response to climate change. ${ }^{65}$ Large-scale projects (currently 15, with 22 expected to be in operation by the end of 2017) are becoming a reality. ${ }^{66}$

In New Zealand, the emissions trading scheme has become the primary vehicle for climate change mitigation. ${ }^{67}$ The legal regime is complex, but the result is a price on carbon that currently falls far short of that needed for commercially viable CCS projects. ${ }^{68}$ Moreover, "there is no substantial record of [enhanced petroleum recovery] operations in New Zealand", ${ }^{69}$ and it appears not to be a significant driver for future CCS deployment. That said, interest has been shown in CCS by both government and industry. On a policy level, the Government has expressed a desire to progress the technology and has commissioned work on resolving legal issues. ${ }^{70} \mathrm{CCS}$ is envisaged to form a limited - but viable - part of mitigation efforts, despite the fact that New Zealand has a low "inherent CCS interest". ${ }^{71}$ GNS Science has also conducted social science research, and New Zealand continues to participate in international knowledge sharing. ${ }^{72}$ On a commercial level, the New Zealand Carbon Capture and Storage Partnership was formed in 2006 to create capability and

Sequestration by US States: Can they be Overcome?" in Havercroft and others, above n 5, at 203; McKinsey \& Co Carbon Capture \& Storage: Assessing the Economics (McKinsey, 2008).

${ }^{62}$ FJ Coyle Tackling Climate Change (Cooperative Research Centre for Greenhouse Gas Technologies, Canberra, 2014) at 56.

${ }^{63}$ GCCSI CCS Legal and Regulatory Indicator (GCCSI, 2015) at 9; McCoy, above n 4, at 11; Parliamentary Commissioner for the Environment Lignite and Climate Change (PCE, Wellington, 2010) at 22.

${ }^{64}$ GCCSI, above $\mathrm{n} 2$, at 9.

${ }^{65}$ GCCSI, above n 5, at 24-25. See also IEA Energy Technology Perspectives 2014 (IEA, Paris, 2014) at 26, 31; N Bankes "The Developing Regime for the Regulation of Carbon Capture and Storage Projects in Canada" in Barton and others, above n 7 , at 289.

${ }^{66}$ GCCSI, above $n$ 2, at 1-7.

${ }^{67}$ See Climate Change Response Act 2002.

${ }^{68}$ Barton and others, above n 7, at 241. New Zealand CCS Partnership, above n 42, at 9.

${ }^{69}$ Barton and others, above $\mathrm{n} 7$, at 159 .

${ }^{70}$ See Barton and others, above $\mathrm{n} 7$.

${ }^{71}$ Ministry of Business, Innovation and Employment, above n 17; Carbon Capture and Storage: Where are we now? (Proceedings of the International CCS Seminar, 2009) at 26. GCCSI, above n 2, at 8; MfE New Zealand's Sixth National Communication under the UNFCCC (MfE, Wellington 2013) at 84; Strategic Analysis of the Global Status of Carbon Capture and Storage: Report 3: Country Studies: New Zealand (GCCSI, 2009) at 3; IEA Carbon Capture and Storage: Legal and Regulatory Review $\left(1^{\text {st }} \mathrm{ed}\right.$, IEA, Paris, 2010) at 29.

${ }^{72}$ Coyle, above n 62; Ministry of Business, Innovation and Employment (January 2016) "CCS in New Zealand" <http://www.mbie.govt.nz>. 
understanding of CCS in a New Zealand context. ${ }^{73}$ On a technical level, investigations have been undertaken that suggest marine CCS is achievable within New Zealand's geological context and emissions profile. Potentially suitable formations have been scoped offshore. ${ }^{74}$ Several point emission sources have also been identified. ${ }^{75}$

Technically, storage is feasible, well-understood, and has been used for many years overseas with few issues. ${ }^{76}$ Many components are well-developed and deployed. ${ }^{77}$ Policy, commercial, and legal hurdles are generally considered more significant than technical challenges. ${ }^{78}$ The basic process is described below, and represented in Figure $1 .^{79}$

Figure 1: the CCS Process

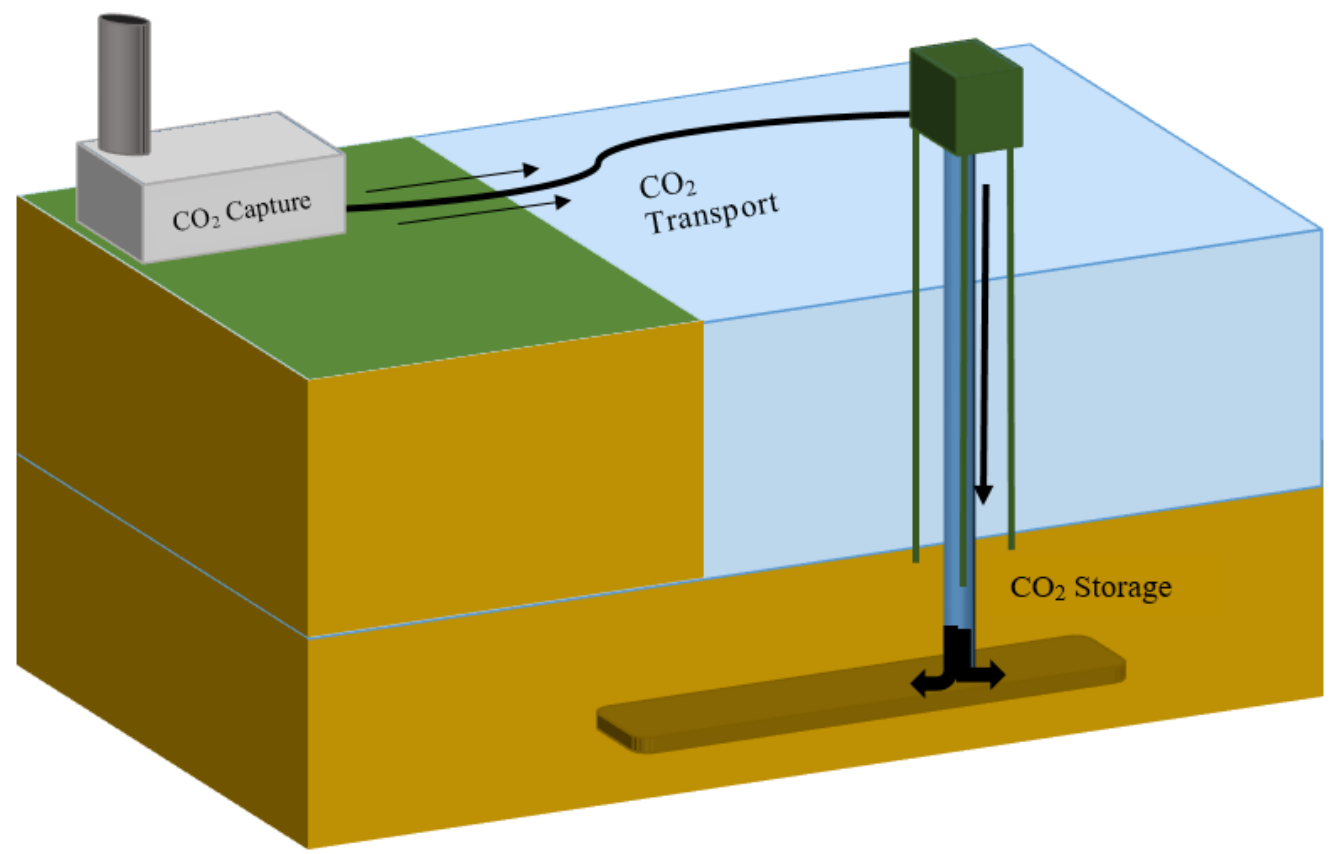

73 See NZCCS Partnership CCS in New Zealand: Case Studies for Commercial Scale Plant (2010); New Zealand CCS Partnership, above n 42.

${ }^{74}$ See PR King and others Opportunities for Underground Storage of $\mathrm{CO}_{2}$ in New Zealand: Onshore Taranaki Basin Overview (GNS Science, Report CCS 08/5 2009/58, 2008) at 92-95; B Field and others New Zealand Carbon Dioxide Storage Site Assessment: Phase 2 (Canberra, Cooperative Research Centre for Greenhouse Gas Technologies, 2009).

${ }^{75}$ Gerstenberger and others, above n 8, at 5-6; NZCCS Partnership, above n 73, at 3-6.

${ }^{76}$ Barton and others, above $\mathrm{n} 7$, at 19 .

${ }^{77}$ IPCC, above n 41, at 8; A Ingelson, A Kleffner and N Nielson "Long-term Liability for Carbon Capture and Storage in Depleted North American Oil and Gas Reservoirs" (2010) 31 Energy Law Journal 431 at 436. We have come a long way since the New Zealand Environment Court in 2003 dismissed CCS as being "decades away": see Environmental Defence Soc Inc v Auckland Regional Council [2002] NZRMA 492 (EnvC) at [67].

${ }_{78}^{78}$ Bugge, above n 58, at 339; IPCC, above n 41, at 264.

79 The technical literature on CCS is vast, and I provide a short summary only. See, for example, Energy Procedia, vols 86, 63, 51, 37, 4, 1; International Journal of Greenhouse Gas Control, vols 1-54; IPCC, above n 41. 
First, $\mathrm{CO}_{2}$ is captured from a point emission source such as a fossil fuel fired power plant or heavy industrial facility. ${ }^{80}$ This is known as the capture phase. Many emitters are compatible with capture technology. ${ }^{81}$ Three main forms are currently possible: pre-combustion, ${ }^{82}$ postcombustion and oxy-combustion. ${ }^{83}$ Natural gas fields can contain high amounts of $\mathrm{CO}_{2}$, which is usually already stripped ("sweetened") to produce a saleable product (a kind of precombustion capture). ${ }^{84}$ Special mention can also be made of bio-energy CCS (BECCS), which involves coupling CCS with the combustion of biofuels (sourced from plant materials that have themselves removed $\mathrm{CO}_{2}$ from the atmosphere) to produce energy. ${ }^{85}$ The result in such cases is net negative emissions. ${ }^{86}$

The capture phase involves considerable expense, because it generally requires large amounts of electricity (an "energy penalty" of about 10-40 per cent). ${ }^{87}$ Costs are particularly high in the energy and heavy industrial sectors. ${ }^{88}$ However, others have stressed that CCS is actually a cost-effective measure when a wider view is taken, ${ }^{89}$ because short-term mitigation is bound to be cheaper than future mitigation or adaptation measures. ${ }^{90}$ Without the use of CCS in the electricity industry, total global costs may increase by trillions of dollars. ${ }^{91}$ In some contexts capture costs may also be quite modest. For example, little additional expense may be incurred where $\mathrm{CO}_{2}$-rich natural gas must already be sweetened in order to meet market standards. $^{92}$ There, and in fertiliser and hydrogen production, capture already occurs (internationally) in a mature market. ${ }^{93}$

\footnotetext{
${ }^{80}$ For a summary of capture processes, see Cueller-Franca and Azapagic, above n 41, at 84; IPCC, above n 41, ch 3.

${ }^{81}$ Including power generation, natural gas processing, synthetic natural gas production (coal gasification), and fertiliser production.

${ }^{82}$ See GCCSI, above n 5, at 40.

${ }^{83}$ GCCSI, above $\mathrm{n} 5$, at 11 . This involves burning fossil fuels in oxygen rather than air.

${ }^{84}$ For example at Kapuni: see Barton "Comparative Study", above n 7, at 2.

${ }^{85}$ See Cueller-Franca and Azapagic, above n 41, at 87.

86 As long as such biomass is replanted at the same or higher rate than it is used. On BECCS, see IEA Combining Bioenergy with CCS (IEA, Paris, 2011).

${ }^{87}$ See IEA $\mathrm{CO}_{2}$ Capture and Storage: A Key Carbon Abatement Option (IEA, Paris, 2008), ch 3; IPCC, above n 41, at 4. N Bankes "Developing a Legal Regime for Carbon Capture and Storage in Canada" (ISEE Research Paper, December 2009) at 3.

${ }^{88}$ GCCSI, above $\mathrm{n} 5$, at $14,101$.

${ }^{89}$ GCCSI, above n 5, at 9 .

${ }^{90}$ See Executive Office of the President of the United States The Cost of Delaying Action to Climate Change (2014) at 13-14; GCCSI, above n 2, at 1.

${ }^{91}$ GCCSI, above n 5, at 25. Compare IPCC, above n 5, at 24-25.

${ }^{92}$ GCCSI, above n 5, at 14.

${ }^{93}$ IPCC, above n 41, at 5.
} 
Secondly, captured $\mathrm{CO}_{2}$ is purified (so as to remove reactive and corrosive substances like water), ${ }^{94}$ cooled and compressed (generally into a supercritical state to improve flow) ${ }^{95}$ and transported to a storage site. ${ }^{96}$ In the offshore context, transport can be achieved by pipeline or pressurised ocean tanker, although the former is more viable where storage sites are relatively close to land. ${ }^{97}$

Thirdly, supercritical $\mathrm{CO}_{2}$ streams are injected deep into the sub-seabed for permanent storage (the storage phase). ${ }^{98}$ The site is maintained and monitored to ensure the $\mathrm{CO}_{2}$ remains sequestered. There has been less practical experience with this stage, and estimated costs vary significantly depending on geological factors. ${ }^{99}$ Site selection is always crucial; a formation must be able to sequester $\mathrm{CO}_{2}$ effectively and permanently. But considerable variation in sites exists. Injection is most likely to occur in either partially depleted or dry petroleum reservoirs or into (usually much deeper) saline aquifers. ${ }^{100}$ Unmined coal seams have also been proposed as potential storage options, but their suitability remain largely untested and they are excluded from specific consideration here. ${ }^{101}$ Not all sub-seabed formations - even depleted petroleum wells - are suitable for injection. ${ }^{102}$ Three general factors are important: they must have adequate confinement (to prevent vertical migration of pressurised $\mathrm{CO}_{2}$ ), sufficient injectivity (the geologic permeability that allows a particular rate of injection to occur) ${ }^{103}$ and capacity to store $\mathrm{CO}_{2}$ (including sufficient depth). ${ }^{104}$

A storage formation (and other general terms such as "pore space") can be pictured as comprising three specific geological strata. These are represented in Figure 2. ${ }^{105}$

\footnotetext{
${ }_{95}^{94}$ Ibid; World Resources Institute (WRI) CCS Guidelines (WRI, Washington, DC, 2008) at 96.

95 A state having characteristics of both gas and liquid.

${ }^{96}$ See IPCC, above n 41 , ch 4.

${ }^{97}$ Havercroft and others, above n 5, at 7.

${ }^{98}$ For a detailed summary of the technical aspects of the storage phase, see IPCC, above n 41, ch 5.

${ }^{99}$ See IPCC, above n 41, at 261.

${ }^{100}$ Havercroft and others, above n 5, at 7; London Dumping Protocol Risk Assessment and Management Framework for $\mathrm{CO}_{2}$ Sequestration in Sub-Seabed Geological Structures (CS SSGS, LC/SG-CO2 1/7, annex 3) at 2.4-2.6.

${ }^{101}$ See Cueller-Franca and Azapagic, above n 41, at 86; IPCC, above n 41, at 3.

102 IPCC, above n 41, at 213.

${ }^{103}$ See IPCC, above $\mathrm{n} 41$, at 213.

${ }^{104}$ WRI, above $\mathrm{n} 94$, at 83.

105 See S Haszeldine "Geological Factors in Framing Legislation to Enable and Regulate Storage of Carbon Dioxide Deep in the Ground" in Havercroft and others, above n 5, at 11.
} 
Figure 2: Generic Geological Strata in CCS Operations

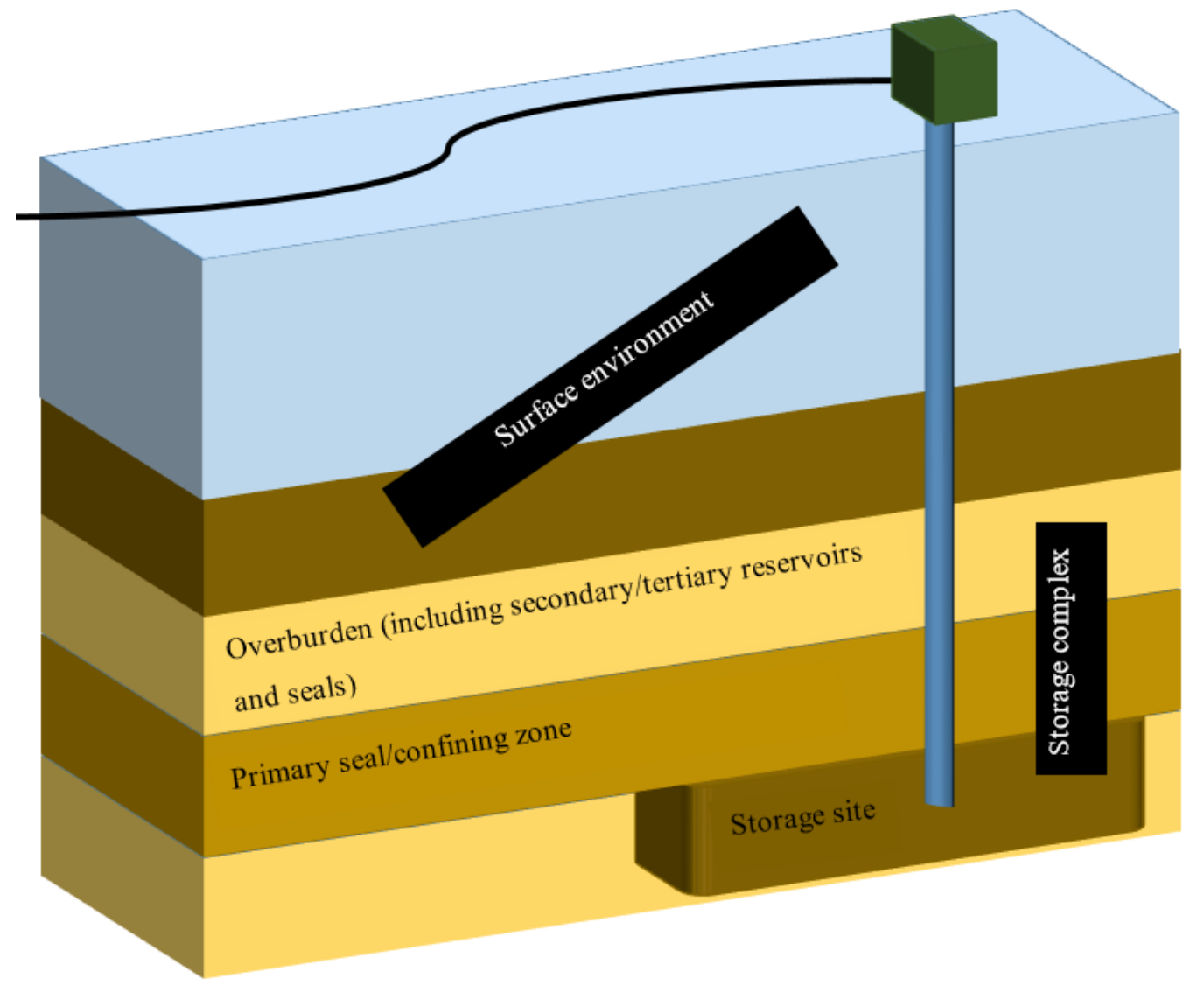

First, $\mathrm{CO}_{2}$ is injected into a storage "site". This comprises a secure and permeable primary reservoir in the subsurface rock, which contains microscopic pores (one may think of tiny holes). ${ }^{106}$ In the marine environment, a storage site will be filled with brine or petroleum. $\mathrm{CO}_{2}$ is intended to remain here. The storage site is overlain by a primary seal or cap-rock (sometimes called a confining zone). ${ }^{107}$ Secondly, above the primary seal, is an "overburden" of permeable rock, which can contain secondary and tertiary reservoirs and seals. Together with the storage site this constitutes a storage "complex", outside of which storage can no longer be considered secure. ${ }^{108}$ Thirdly, above the overburden exists the surface environment, which includes the subsurface above the storage complex along with the water column. The surface needs of injection are modest and comparable to those of petroleum operations, even though storage complexes themselves can be vast. ${ }^{109}$

\footnotetext{
${ }^{106}$ See generally GCCSI, above n 5, at 131 .

${ }^{107}$ WRI, above $\mathrm{n} 94$, at 83.

108 Directive 2009/31/EC on the Geological Storage of Carbon Dioxide [2009] OJ L140/114 (CCS Directive), art 3(3)-3(6).

${ }^{109}$ Laterally, tens of kilometres: Havercroft and others, above n 5, at 11-12. Total plume areas can be in the realm of $100 \mathrm{~km}^{2}$ : Barton and others, above $\mathrm{n} 7$, at 85 .
} 
During injection, $\mathrm{CO}_{2}$ streams remain highly pressurised, and storage complexes deeper than approximately 800 metres are under sufficient pressure for the $\mathrm{CO}_{2}$ to remain in a supercritical state. ${ }^{110}$ The period of injection can vary according to geological and commercial circumstances, but is likely to last many years. ${ }^{111}$

Once $\mathrm{CO}_{2}$ is injected, it diffuses into the pore space to form a "plume". ${ }^{112}$ This partly displaces in situ fluid (brine or petroleum), ${ }^{113}$ with the shape of a plume and rate of migration depending on local geological circumstances. ${ }^{114}$ As the plume disperses, the pressure in the complex dissipates and, from this point, the stored $\mathrm{CO}_{2}$ can be trapped in a variety of sitedependent ways. $^{115}$ Physical or structural trapping is the dominant form during and immediately after injection, where a plume is physically blocked by an impermeable geological structure such as a cap-rock. ${ }^{116}$ As time passes, this changes from physical to residual (capillary) trapping, which involves the isolation of $\mathrm{CO}_{2}$ in increasingly small pores. ${ }^{117}$ Over the course of several thousands of years, $\mathrm{CO}_{2}$ is expected to dissolve completely in formation fluids (dissolution or solubility trapping). ${ }^{118}$ As this occurs, migration rates decrease substantially. ${ }^{119}$ The final trapping mechanism, mineralisation, occurs over much longer periods (millions of years). Here, some $\mathrm{CO}_{2}$ reacts with rock to form solid, stable carbonate minerals. ${ }^{120}$

Once injection has ceased, the well is sealed and the behaviour of the plume is monitored. ${ }^{121}$ Given that storage must be secure for tens of thousands of years for the technology to be effective, it is important to prevent post-closure leakage. ${ }^{122}$ The IPCC has stated that a leakage rate of over 0.1 per cent is unacceptable. ${ }^{123}$ However, the risk of a more than

\footnotetext{
${ }^{110}$ IPCC, above n 41, at 6.

${ }^{111}$ Havercroft and others, above $\mathrm{n} 5$, at 9 .

${ }^{112}$ The "dispersing volume of $\mathrm{CO}_{2}$ in the geological formation": see CCS Directive, art 3.

${ }^{113}$ IPCC, above n 41, at 205.

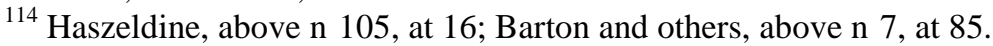

115 IEA, above n 13, at 87; WRI, above n 94, at 66; B Field and others Interaction of $\mathrm{CO}_{2}$ Storage with Subsurface Resources (IEA, Paris, 2013) from 6; SM Al-Fattah and others Carbon Capture and Storage (CRC Press, 2011), ch 5.

${ }^{116}$ Haszeldine, above n 105, at 15.

${ }^{117}$ IPCC, above n 41, at 206.

${ }^{118}$ Haszeldine, above n 105, at 15; IPCC, above n 41, at 205.

${ }^{119}$ IPCC, above n 41, at 206.

${ }^{120}$ Ibid at 206.

${ }^{121}$ Coyle, above n 62, at 165 .

122 Haszeldine, above n 105, at 7; German Advisory Council on Global Change The Future Oceans-Warming up, Rising High, Turning Sour (Special Report, 2006) at 78.

${ }^{123}$ IPCC, above n 41, at 1.6.3.
} 
negligible rate of leakage has been assessed as very low if a storage site is selected and managed well, ${ }^{124}$ and declines steadily over time. ${ }^{125}$ Once dissolution trapping begins, the fluid in the storage complex becomes denser and will sink deeper into the complex, further reducing the prospects of leakage. ${ }^{126}$ Pressures also dissipate, making cap rock fracturing and well blowouts less likely. ${ }^{127}$ Therefore careful measurement, monitoring and verification is essential to understand an evolving landscape of risk. Yet the practical ability of operators to undertake comprehensive monitoring should not be overstated. It is not viable to detect every leak in a deep sub-seabed context. ${ }^{128}$

CCS shares features in common with other industries, and can interact with them in complex ways. ${ }^{129}$ The most notable is its relationship with petroleum mining. The activities have the potential to compete for unused subsurface space, since viable oil and gas reservoirs could also be suitable for storage. CCS can also adversely impact on existing petroleum operations. ${ }^{130}$ In other cases the two operations can be compatible and mutually beneficial. As alluded to earlier, $\mathrm{CO}_{2}$ can be injected into wells for the purpose of enhanced petroleum recovery (a term that encompasses enhanced gas recovery and enhanced oil recovery, and is sometimes referred to as tertiary recovery, $\mathrm{CO}_{2}$ flooding, or enhanced hydrocarbon recovery). ${ }^{131}$ In the context of natural gas operations, $\mathrm{CO}_{2}$ is injected to re-pressurise a reservoir, forcing the gas towards a production well. ${ }^{132}$ In oil operations, an injectate of $\mathrm{CO}_{2}$ mixes with oil (they are miscible), decreasing its viscosity and making it flow more freely out of the well. ${ }^{133}$ Enhanced petroleum recovery should not be equated with hydraulic fracturing (fracking); the latter relies on fracturing rock to allow trapped gas to escape from tight shale formations (and is thus undesirable for CCS). ${ }^{134}$

\footnotetext{
${ }^{124}$ See Haszeldine, above n 105, at 14; IPCC, above n 41, at 197; Ingelson and others, above n 77, at 437.

${ }^{125}$ IPCC, above n 41, at 14, 197; Barton and others, above n 7, at 17; Granger Morgan, above n 9, at 40.

${ }^{126}$ Haszeldine, above n 105, at 15; IPCC, above n 41, ch 5.

${ }^{127}$ IEA, above n 13, at 99.

${ }^{128}$ See ch VIII.

${ }^{129}$ See Field and others, above n 115.

${ }^{130}$ M Gibbs "The Regulation of Geological Storage of Greenhouse Gases in Australia" in Havercroft and others, above n 5, at 173; J McLaren and J Fahey "Key Legal and Regulatory Considerations for the Geosequestration of Carbon Dioxide in Australia" (2005) 24 ARELJ 46 at 52-53.

${ }^{131}$ It is not yet done in New Zealand using $\mathrm{CO}_{2}$ : see Coyle, above n 62, at 159-160.

${ }^{132}$ No safeguards are put in place to ensure permanent geologic storage. See P Marston and P Moore "From EOR to CCS" (2008) 29 Energy Law Journal 421 at 424.

${ }^{133}$ See Marston and Moore, above n 132, at 427.

${ }^{134}$ See TR Elliot and MA Celia "Potential Restrictions for $\mathrm{CO}_{2}$ Sequestration Sites due to Shale and Tight Gas Production" (2012) 46 Environ Sci Technol 4223. Generally, see Parliamentary Commissioner for the Environment Evaluating the Environmental Impacts of Fracking in New Zealand (2012).
} 
Where $\mathrm{CO}_{2}$ used for enhanced petroleum recovery remains securely stored after injection, it is one example of a concept called carbon capture, utilisation and storage (CCUS), represented in Figure 3. Although other forms of CCUS are possible, ${ }^{135}$ for the purposes of this thesis the term is used to refer to permanent storage that results from an enhanced petroleum recovery operation (which is the more likely application in New Zealand). The point at which a pure enhanced petroleum recovery operation becomes a CCUS operation, and CCUS then becomes a pure storage operation, may not always be clear. It is also important to remember that not all reservoirs suitable for storage are compatible with the use of enhanced recovery techniques. ${ }^{136}$ Storage of $\mathrm{CO}_{2}$ can sometimes result in the degradation of subsurface mineral resources. ${ }^{137}$

Figure 3: Carbon Capture, Utilisation and Storage

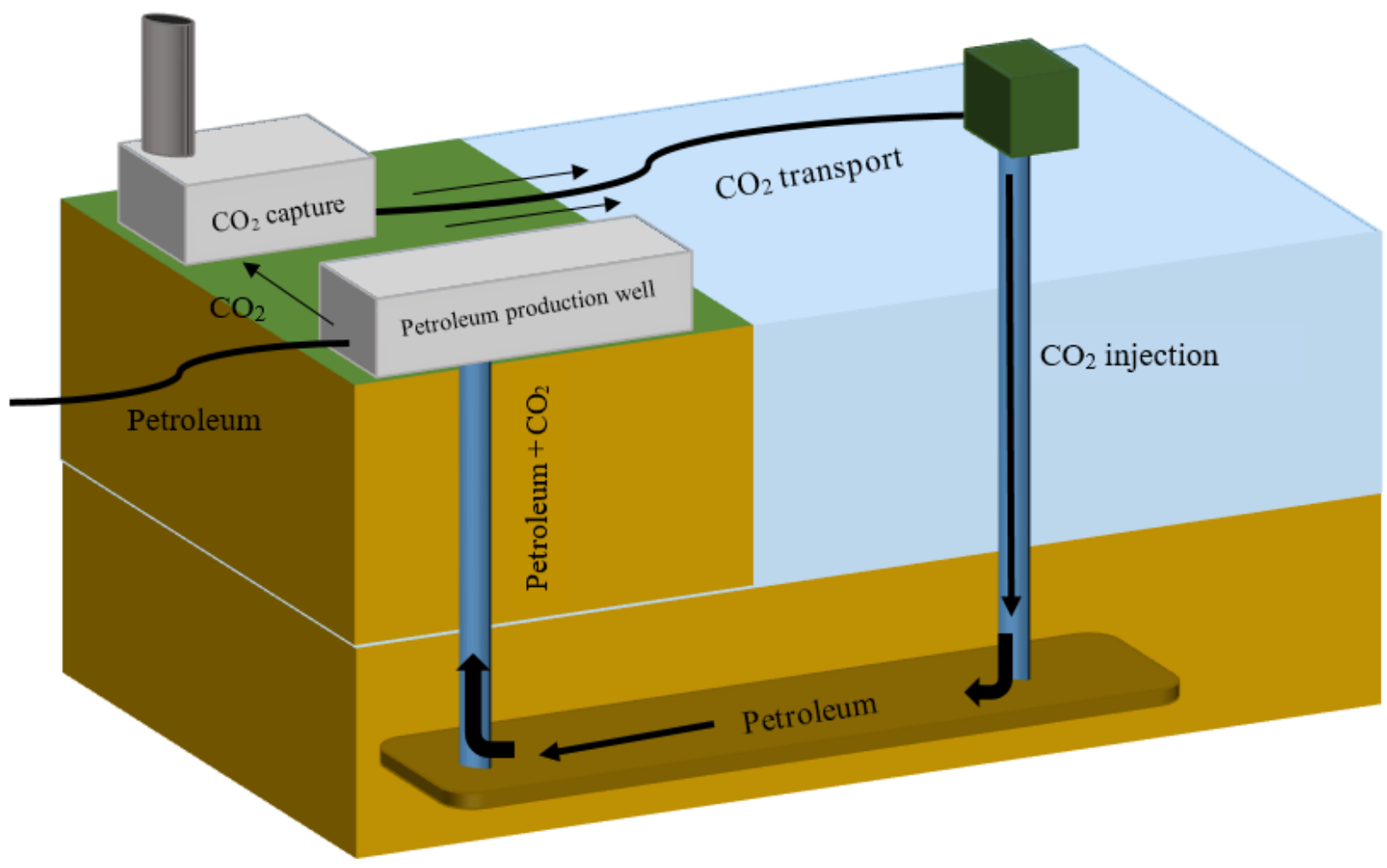

CCS also has a regulatory relationship with petroleum mining. The latter provides potential analogues for regulation, because of its physical similarities. ${ }^{138}$ Conventional petroleum

\footnotetext{
${ }^{135}$ For example, as a circulation fluid in geothermal operations: see B Freifeld and others "Geothermal Energy Production Coupled with CCS" (2013) 37 EGYPRO 6595.

${ }^{136}$ IPCC, above n 41, at 216; Gibbs, above n 130, at 173.

${ }^{137}$ WRI, above $\mathrm{n} 94$, at 82.

${ }^{138}$ Generally, see IPCC, above n 41, from 211; Alberta Government, above n 6, at 22.
} 
mining utilises deep sub-seabed formations and requires similar expertise and knowledge. ${ }^{139}$ Enhanced petroleum recovery, hydraulic fracturing, temporary geological storage of natural gas, and acid-gas disposal have even more obvious similarities because they involve the injection of fluid into the subsurface. ${ }^{140}$ Overseas, their regulation has provided useful blueprints for CCS law. ${ }^{141}$ However, legal regimes for them are under-developed in New Zealand. ${ }^{142}$ There are also crucial differences in the purposes and processes of these activities (as explained in chapter IV). As such, they contribute little to a first-principles analysis of marine CCS law. ${ }^{143}$

\section{F Potential Environmental Consequences of Marine CCS}

CCS has the potential to cause a range of adverse effects on the local environment. These can be divided into three broad categories: effects on a storage site, impacts on the general subsurface environment, and surface effects. Overall, the risks of geological storage have been considered to be low and similar to those of petroleum activities. ${ }^{144}$

Carbon dioxide itself is relatively innocuous. ${ }^{145}$ It occurs naturally both above and below ground, forms an essential part of the carbon cycle and it is neither flammable nor explosive. In its gaseous form and in concentrations found in nature, it is colourless, odourless and not harmful to humans or the environment. That said, when mixed with water, $\mathrm{CO}_{2}$ forms a weak (carbonic) acid. ${ }^{146}$ In confined spaces or concentrated volumes it can also displace oxygen and act as an asphyxiant and toxin. ${ }^{147}$

In a storage site, injection can cause both direct physical effects and communication effects. The former arise from the movement of plumes, which may result in the lateral migration of $\mathrm{CO}_{2}$ outside an approved area. This could increase the risk of leakage by transporting plumes

\footnotetext{
${ }^{139}$ IPCC, above n 41, at 6.

${ }^{140}$ See T Lairer and H Obro "Environmental and Safety Monitoring of the Natural Gas Underground Storage at Stenile, Denmark" in DJ Evans and RA Chadwick (eds) Underground Gas Storage (London, Geological Society, 2009) at 81-92. Hydraulic fracturing involves the injection of high pressure fluid to induce fracturing in rock (often shale), releasing additional methane gas.

${ }^{141}$ GCCSI, above n 2, at 9; Marston and Moore, above n 132, at 425.

142 See Crown Minerals (Petroleum) Regulations 2007, reg 34B; Barton and others, above n 7, at 162.

${ }^{143}$ Gerstenberger and others, above n 8, at 15 .

${ }^{144}$ IPCC, above n 41, at 12.

${ }^{145}$ See Barton and others, above n 7, at 17. See also IPCC, above n 41, Annex 1.

${ }^{146}$ IEA, above $\mathrm{n} 13$, at 52.

${ }^{147}$ See Gerstenberger and others, above n 8, at 15 .
} 
along unmapped migration pathways. Lateral migration may also have negative effects on the extraction of nearby petroleum resources. ${ }^{148}$ However, migration is not always adverse (many effective storage scenarios rely on non-physical trapping mechanisms rather than lateral barriers). ${ }^{149}$

Communication effects are those caused by the pressure wave from injection into a sealed or partially sealed formation. Due to this pressure wave and a slow rate of subsurface dissipation (over several decades), ${ }^{150}$ excessive injection rates could fracture an overlying seal, producing potential leakage pathways out of a storage site. ${ }^{151}$ Injection may also increase pressures in hydraulically connected formations, which may affect their storage capacity and thus future viability. ${ }^{152}$

Injection may impact on the subsurface environment more generally. ${ }^{153}$ Increased pressures can force subsurface brine into overlying potable groundwater reservoirs and mobilise harmful metals and minerals. ${ }^{154}$ Storage may interfere with or prevent the future use of formations for other purposes (such as petroleum extraction ${ }^{155}$ or natural gas storage). ${ }^{156}$ Impurities in streams can also impact on the effectiveness of the injection and storage process itself, and affect the flow of fluids within a storage site. ${ }^{157}$

A project will involve the occupation of an area of the seabed, and the physical disturbance of the seabed. Unintended leakage also poses risks to the local surface environment. Perfect containment cannot be guaranteed, and leakage can occur in many ways (for example, from well-heads, faults, or ineffective seals). ${ }^{158}$ The remoteness of the deep subsurface and the peculiarities of local geology mean it will never be possible to understand completely how a

\footnotetext{
${ }^{148}$ Haszeldine, above n 105, at 11; WRI, above n 94, at 75.

149 See IPCC, above n 41, at 209; F Orr "Storage of Carbon Dioxide in Geological Formations" (2004) 56 Journal of Petroleum Technology 90 at 94.

${ }^{150}$ Haszeldine, above n 105 , at 16.

151 Ibid; N Swayne and A Phillips "Legal Liability for Carbon Capture and Storage in Australia" (2012) 29 Environmental and Planning Law Journal 189.

152 Ibid.

${ }^{153}$ See NR Hoffman "The Feasibility of Applying Strict Liability Principles to Carbon Capture and Storage" (2009-2010) 49 Washburn LJ 527 from 529.

${ }^{154}$ Ibid; Coyle, above n 62, at 162; IEA, above n 13, at 91.

${ }^{155}$ Barton "Comparative Study", above n 7, at 23.

${ }^{156}$ Haszeldine, above n 105, at 11. See generally Field and others, above n 115.

157 IPCC, above n 41, at 220; E Wilson, A Klass and S Bergan "Assessing a Liability Regime for Carbon Capture and Storage" (2009) 1 EGYPRO 4575 at 4576.

${ }^{158}$ IPCC Guidelines for National Greenhouse Gas Inventories (IPCC, 2006) at 5.12.
} 
storage site will perform until injection commences. ${ }^{159}$ However, the risk of an escape to the atmosphere has been modelled to be very low if a primary seal is intact and properly assessed. ${ }^{160}$ Experience has corroborated this conclusion: no unintended leakage has been recorded at the oldest marine CCS sites at Sleipner and Snøhvit. ${ }^{161}$

Furthermore, by no means could all injected $\mathrm{CO}_{2}$ escape to the atmosphere. As secondary trapping mechanisms occur, they reduce potential leakage volumes. ${ }^{162}$ As such, the greatest risk is present at the injection well during and immediately after injection error. That said, other risks do exist. For example, leakage pathways can be created by the fracturing of a primary seal, an increase in pressure caused by seismic activity or by the presence of poorly closed legacy wells, and $\mathrm{CO}_{2}$ can escape along undetected leakage pathways. ${ }^{163}$

If a surface leak did occur, its environmental effects would depend on the character of the leak. ${ }^{164}$ Any leakage would to a degree contribute to global climate change, but local effects are likely to be modest. ${ }^{165}$ A controlled rapid release of $\mathrm{CO}_{2}$ from a wellhead at-the Otway pilot project in Victoria, for example, simply resulted in the formation of a large deposit of dry ice. ${ }^{166}$ In reality, any escape from a storage complex would not be catastrophic in nature once injection had been completed. ${ }^{167}$ Carbon dioxide stored in microscopic pore space in rock several kilometres deep cannot physically escape at such a rate. ${ }^{168}$ A rapid escape from a well-head is possible, although unlikely where operations are well managed. Effects would be contained to a relatively small area and be modest (compared to a blowout from an oil well). However, within this area there may be some danger of asphyxiation to marine animal life. ${ }^{169}$ The vapour density of $\mathrm{CO}_{2}$ is relatively high, so can in some cases accumulate at ground level (including lakes on the seabed). ${ }^{170}$ Research continues into the behaviour and effects of large

\footnotetext{
${ }^{159}$ Shilling, above n 12 , at 33.

${ }^{160}$ See Ingelson, above n 90, at 437.

${ }^{161}$ Shilling, above n 12, at 29; Gerstenberger and others, above n 8, at 8 .

${ }^{162}$ Haszeldine, above n 105 , at 18.

${ }^{163}$ Haszeldine, above n 105, at 19; Coyle, above n 62, at 161; IPCC, above n 41, at 13.

${ }^{164}$ Generally, see IPCC, above n 41.

${ }^{165}$ Barton and others, above n 7, at 17; Granger Morgan, above n 9, at 41.

${ }^{166}$ Coyle, above n 62, at 118 .

${ }^{167}$ Haszeldine, above n 105, at 18; Coyle, above n 62, at 161. IPCC, above n 41, at 211.

${ }^{168}$ Haszeldine, above $\mathrm{n} 105$, at 18 .

${ }^{169}$ IEA, above n 13, at 52.

${ }^{170}$ Ibid at 52; IPCC, above n 41, at 391.
} 
escapes of the gas, ${ }^{171}$ but it is thought that the risk of blowouts can be managed by conventional means. ${ }^{172}$

New Zealand's marine environment is rich in biodiversity, and slow leakage from the seafloor into the water column may affect marine life in different ways. ${ }^{173}$ Guidance under the OSPAR Convention and London Dumping regime recognises that the effects of leakage on the local environment are primarily related to biological sensitivities. ${ }^{174}$ Hazards may be posed to benthic and pelagic species as $\mathrm{CO}_{2}$, incidentally stored substances, and mobilised substances moved through benthic sediments into the water column. ${ }^{175}$ In particular, high $\mathrm{CO}_{2}$ concentrations can cause acidosis (lowering of $\mathrm{PH}$ in body fluids), hypercapnia (increased blood concentration of $\mathrm{CO}_{2}$ ) and asphyxiation (impaired oxygen transport). ${ }^{176}$ Particularly at risk are corals, shellfish and groups of phytoplankton, which can face stunted growth, reproductive issues and increased mortality. ${ }^{177}$ The magnitude of effects depends on the rate of leakage, the chemical buffering capacity of the receiving environment, and patterns of local dispersion. ${ }^{178}$ In some cases, small leaks may actually enhance the growth of marine flora. ${ }^{179}$ If a leak occurs, it may be difficult to detect and remediate given the likely extent of most sites, cost of access, and limitations in the sensitivity of monitoring equipment. $^{180}$

Induced seismicity and ground heave on a relatively minor scale is another potential effect of storage, as it is of other activities involving the pressurisation of the subsurface. ${ }^{181}$ Fortunately, this can be closely monitored and there is low risk of more than minor seismicity. ${ }^{182}$ There may, however, be particular social sensitivities around this risk in parts of New Zealand following the Canterbury earthquakes. Due to its novelty, public concern over environmental risks may be greater than is supported by scientific evidence.

\footnotetext{
${ }^{171}$ GCCSI, above n 5, at 126.

${ }^{172}$ Haszeldine, above n 105, at 18.

${ }^{173}$ Ibid at 9; Risk Assessment and Management Framework, above n 100, at 4.4-4.11.

${ }^{174}$ OSPAR Framework for Risk Assessment and Management of Storage of $\mathrm{CO}_{2}$ Streams in Geological Formations (2007-12) (OSPAR FRAM), at 4.5; Specific Guidelines for the Assessment of Carbon Dioxide for Disposal into Sub-Seabed Geological Formations (LC34/15, 2012), Annex 8 at 7.

${ }^{175}$ OSPAR FRAM, above n 174, at 4.3; Specific Guidelines, above n 174, Annex 8 at 7.2.

${ }^{176}$ OSPAR FRAM, above n 174, at 4.5; IPCC, above n 41, at 391.

${ }^{177}$ OSPAR FRAM, above n 174 , at 4.5 .

${ }^{178}$ Ibid at 4.5; Risk Assessment and Management Framework, above n 100, at 1.6, 1.12.

${ }^{179}$ See Barton and others, above $\mathrm{n} 7$, at 19.

${ }^{180}$ IPCC, above n 41, at 255.

${ }^{181}$ IEA, above n 13, at 91; WRI, above n 94, at 74 .

${ }^{182}$ See Bankes, above n 65, at 307; WRI, above n 94, at 74.
} 
Despite the above focus on adverse effects, it should not be forgotten that CCS also has substantial positive effects. These are primarily environmental (mitigation of climate change) but others may be economic and social (such as the provision of employment). Moreover, local opposition to terrestrial CCS may mean that the marine form is pursued as the less risky path commercially. Public concerns over storage on land have proved fatal to large-scale CCS projects in Europe. ${ }^{183}$

\section{G Summary}

In this chapter I have outlined the objectives, methodology, and structure of the thesis, as well as introducing the technical, commercial and policy context of marine CCS and summarising its key environmental impacts. Internationally, the technology is a reality on a large scale, and has a good track record of environmental sustainability and operational success. Despite some risks, it continues to be touted as an essential component of a global climate change response.

183 See D Langlet "Exporting $\mathrm{CO}_{2}$ for Sub-Seabed Storage" (2015) 30 International Journal of Marine and Coastal Law 395 at 400; Coyle, above n 62, at 72, 130; Havercroft and Purdy, above n 10, at 1, 26. 


\section{Part 1}

Normative Framework for CCS - Philosophy and Principles 


\section{$\xi$}

\section{II}

\section{An "Inclusive Anthropocentric" Approach}

\section{A Introduction}

The objective of this thesis is to recommend an appropriate environmental legal framework for marine CCS, by removing barriers and filling gaps. What an "appropriate" framework means, and what a "barrier" or "gap" is, are normatively charged questions, to which different people may give different answers. They depend on our aims; barriers and gaps only exist if current law would fail to achieve what we want it to.

In chapters II to V (Part 1) I identify a series of aims for marine CCS law. I do so in three stages. In this chapter, I outline the broad normative framework adopted in the thesis: an inclusive anthropocentric approach. It describes the basic way in which we see the environment, and our place within it. ${ }^{1}$ In chapter III I then develop, within this approach, a series of more specific principles of environmental law targeted to the New Zealand context. In chapter IV I apply these principles to marine CCS, to construct a series of aims for regulating the technology. Those, along with the requirements of international law identified in chapter $\mathrm{V}$, are then used to identify and address barriers and gaps.

\footnotetext{
${ }^{1}$ On the philosophical nature of "environment" and related terms see DR Keller (ed) Environmental Ethics: the Big Questions (Wiley Blackwell, West Sussex, 2010) at 2-3.
} 


\section{B Normative Approaches to the Environment}

A normative legal theory is one that outlines what the law should be. ${ }^{2}$ Normative approaches to environmental law are therefore linked intimately to ethical discussions of what is right and wrong. ${ }^{3}$ Indeed, foundational discourse for environmental law can be traced ultimately to ethical and philosophical works and axiological assumptions. ${ }^{4}$ At its most basic, we need to decide how humans "should best live their lives in their earthly home." 5

The environment is a particularly difficult area of ethics. Despite collective technological efforts to improve the efficiency of resource use, the planet has a finite carrying capacity that must at some point be reached. The attainment of morally good "development" must at some point be met by the incurring of morally "bad" environmental harm. The opportunity cost of using resources will often be the benefit that can come only from protecting them from use, and vice versa.

A universal ethic that attributes absolute moral superiority to one or other of these ends is disingenuous and fanciful. Experience in a fragile world of finite resources shows we cannot maximise both at the same time. ${ }^{6}$ It is therefore tempting to see the ethical quandary as intractable, in that there can be no right and wrong. But it is more helpful to recognise that there is a range within which an ethically "right" outcome can exist. Serious theories of environmental ethics seek only a method to strike and defend a particular balance between resource use and environmental protection. ${ }^{7}$ The normative question is essentially where that balance is to be struck.

\footnotetext{
2 SJ Burton "Normative Legal Theories: The Case for Pluralism and Balancing" (2012-2013) 98 Iowa L Rev 535 at 537.

${ }^{3}$ K Bosselmann, D Grinlinton and P Taylor (eds) Environmental Law for a Sustainable Society (2 ${ }^{\text {nd }}$ ed, New Zealand Centre for Environmental Law, Auckland, 2013) at viii.

${ }^{4}$ See generally Keller, above n 1; K Bosselmann The Principle of Sustainability: Transforming Law and Governance (Ashgate, Aldershot, 2008) at 9, 91; A Kiss and D Shelton International Environmental Law $\left(3^{\text {rd }}\right.$ ed, New York, Transnational Publishers, 2004), at 1-26; see also S Coyle and K Morrow The Philosophical Foundations of Environmental Law (Hart, Oxford, 2004); A Gillespie International Environmental Law, Policy and Ethics (2 ${ }^{\text {nd }}$ ed, OUP, Oxford, 2014); HA Rolston A New Environmental Ethics (Routledge, 2012).

${ }^{5}$ Keller, above n 1 , at 2 .

${ }^{6}$ Bosselmann, above n 4 , at 1 .

7 See generally C Warnock and M Baker-Galloway Focus on Resource Management Law (Lexis Nexis,Wellington, 2015) at 28. "Resource use" encompasses both the use of resources for human betterment as well as "using" receiving environments to pollute.
} 
Different normative theories of environmental ethics (and therefore law) provide different answers to this question. Some (economic approaches such as the "Coase theorem") ${ }^{8}$ favour resource use, while others (such as eco-centric theories) favour protection. All require the benefits and costs of use and protection to be weighed, but built into the weighing process are inevitable value judgements that some benefits and costs are more significant than others. For example, while no one would seriously claim that the leaching of chemicals into a river is morally praiseworthy in its own right, some may argue it is worth doing if it enhances a deprived community's economic well-being. Recognising the importance of "balance" is not necessarily an invitation to ecological disaster, as some have characterised it. ${ }^{9}$ In balancing multiple considerations we can, and often do, choose to given substantial weight to environmental protection above and beyond the need to retain the basic or "bottom line" regenerative capacity of ecosystems. We do this frequently by, for example, imposing heavy restrictions on most human activities in conservation areas. ${ }^{10}$

Balancing exercises do not occur in the abstract. The relative significance we give to an effect is determined not by the effect per se, but by the character of the person or thing affected. In other words, the question of "what weight do we place on the various benefits and costs of this decision?" can be rephrased as "what relative importance do we place on the persons or things for whom this decision has benefits and costs?" For example, some may feel compelled to prevent pollution in low socio-economic areas where residents cannot afford healthcare. The key differences between normative approaches are therefore not so much about whether they favour use or protection per se, but rather whose interests are to be valued more or less. ${ }^{11}$

The pool of those affected by environmental decision-making can be divided into competing interest-groups in four different ways. First, benefits and costs must be distributed somehow between different people presently alive. This is often characterised as a distributional issue (when allocating resource use rights) or one of environmental justice (when costs are unevenly allocated along racial or socio-economic lines). ${ }^{12}$ Secondly, benefits and costs must

\footnotetext{
${ }^{8}$ R H Coase "The Problem of Social Cost" (1960) 3 Journal of Law and Economics 1.

${ }^{9}$ Bosselmann, above n 4, ch ; see M Wissenburg "An Extension of the Rawlsian Savings Principle to Liberal Theories of Justice in General" in A Dobson (ed) Fairness and Futurity (OUP, Oxford, 1999).

${ }^{10}$ See, for example, Conservation Act 1987, long title and s 17U.

${ }^{11}$ See P Salmon "Access to Environmental Justice" (1998) 2 NZJEL 1 at 2.

${ }^{12}$ K Bosselmann "The Concept of Sustainable Development" in Bosselmann, Grinlinton and Taylor, above $\mathrm{n} 3$, at 106 .
} 
be distributed between those alive now and those not yet born. This is a problem of intergenerational equity/justice. ${ }^{13}$ Thirdly, benefits and costs need to be distributed between private persons and the wider notion of the "public". ${ }^{14}$ The "public" good is not simply an aggregation of private interests. Fourthly, benefits and costs must be distributed between people and the "non-human" concept of nature. ${ }^{15}$ This is often characterised as an issue of ecological justice. ${ }^{16}$

Other features of environmental decision-making make this exercise even more complicated. First, environmental decisions are future-focused. There is inherent uncertainty in future events and we often lack knowledge of environmental processes. In some cases, predictions may be possible as to how likely an effect is, but in others (such as those involving the deep seabed) we may simply "not know what we do not know". ${ }^{17}$ Treatment of risk and uncertainty are therefore key components of environmental decision-making. ${ }^{18}$

Secondly, there may be legitimate dispute over whether a consequence is actually a "benefit" or a "cost". For example, while the wanton destruction of a rare ecosystem would be considered morally reprehensible, there may be disagreement over whether the preservation of a common wetland in its natural state is beneficial. Some might advocate for its transformation into a more aesthetically pleasing recreational lake, where biodiversity is managed and improved, arguing that it provides a benefit to both nature and people. Establishing an "objective" standard for measuring costs and benefits is challenging.

Thirdly, every environmental decision is inherently unique. What is ethically sound in one context may not be so in a slightly different scenario. Ethics may also evolve over time as new dangers and understandings arise, ${ }^{19}$ and it is difficult to pin down a set of inflexible commandments. At the same time, ethics have little value if not applied in practice. We are led inexorably to the importance of a common process as a mechanism for crystallising

\footnotetext{
${ }^{13}$ Bosselmann, above $\mathrm{n} 12$, at 106.

${ }^{14}$ See D Grinlinton "The Context of Environmental Law" in P Salmon and D Grinlinton (eds) Environmental Law in New Zealand (Thomson Reuters, Wellington, 2015) at 37-42.

${ }^{15}$ Bosselmann, above n 4, at 29.

${ }^{16}$ Bosselmann, above n 12, at 106.

${ }^{17}$ See G Severinsen "Letting our Standards Slip?" (2014) 18 NZJEL 173; C Iorns and G Severinsen "Diving in the Deep End" (2015) 13 NZJPIL 201; G Severinsen "Bearing the Weight of the World" (2014) 26 NZULR 375.

${ }^{18}$ See generally J Jones "Regulatory Design for Scientific Uncertainty" (2007) 19 J Environmental Law 347.

${ }^{19}$ See G Hardin "The Tragedy of the Commons" (1968) 162 Science 1243 at 1245.
} 
environmental ethics in any given scenario. A focus on process gives rise to other important issues: the role that science, democracy and judicial pronouncement should play in shaping ethics, the extent to which decision makers should enjoy discretion in their choices, and the level of community (local, regional or national) at which decisions should be made.

Fourthly, despite often being represented as such, the ethical question may not always be one involving a stark trade-off between the "economic" value of resource use and the "environmental" value of protection. Protection can provide economic benefits (such as the sustainable harvesting of native timber and fish stocks), while the use of resources may in some cases protect the environment (for example, CCS uses the subsurface but seeks to mitigate climate change). An ethical system therefore needs to assign value between different aspects of environmental well-being. ${ }^{20}$ It may also have to assign value as between different aspects of economic or social well-being, by allocating scarce resources to different socioeconomic groups.

\section{An Inclusive Anthropocentric Approach}

In this thesis I adopt an "inclusive anthropocentric" view of the environment. This envisages a system in which a wide range of human values (in particular, the public interest) ought to drive environmental decision-making.

Normative approaches can be divided loosely into two camps: those that are anthropocentric (human-focused), and those that are eco-centric (nature-focused). ${ }^{21}$ The story of environmental ethics as a whole can be seen as critiques or defences of the anthropocentric philosophy upon which western society has developed. ${ }^{22}$ Under the umbrella of anthropocentrism, we can observe a further distinction between economic approaches (those that, generally speaking, focus on efficiency and social welfare, and seek to place a dollar value on environmental goods) ${ }^{23}$ and non-economic approaches (those that focus on human

\footnotetext{
${ }^{20}$ See M Montini and E Orlando "Balancing Climate Change Mitigation and Environmental Protection Interests in the EU Directive on Carbon Capture and Storage" (2012) 3 Climate Law 165 at 179.

${ }^{21}$ See Bosselmann, above n 12, at 102; see also E Hargrove Foundations of Environmental Ethics (Prentice Hall, New Jersey, 1989); K Palmer "Introduction to Environmental Law" in D Nolan (ed) Environmental and Resource Management Law ( $5^{\text {th }} \mathrm{ed}$, LexisNexis, Wellington, 2015) at 7-8.

${ }^{22}$ See Keller, above n 1, at 1.

${ }^{23}$ On approaches that can broadly be characterised as economic, see M Pickford "Economic Efficiency and the Resource Management Act" (2014) 18 NZJEL 149 at 153; D Pearce "Optimal Prices for Sustainable Development" in D Collard, D Pearce and D Ulph (eds) Economics, Growth and Sustainable Environments
} 
values rather than monetary quantification). Eco-centricity can also be divided into a number of categories (for example, those with spiritual or indigenous flavours, ${ }^{24}$ or those focused on animal rights). ${ }^{25}$ These are convenient terms for understanding various perspectives, but in reality a wide range of theories exist in a complex matrix between strict economic approaches and strict eco-centric ones. ${ }^{26}$

The inclusive anthropocentric approach adopted here is a brand of non-economic anthropocentrism. It is focused on the importance of the environment (both its use and protection) for the public interest, being a concept that is determined through a process of human discourse. The approach rests upon work by scholars like Mark Sagoff and William Grey, who have adopted an anthropocentric perspective with wide normative aims (hence my label "inclusive"). ${ }^{27}$ It is also generally consistent with Habermas' theory of discourse ethics. ${ }^{28}$ In short, while human interests remain central, the approach recognises that the public interest in environmental matters is often not a simple aggregation of the interests of private consumers. ${ }^{29}$ What we want as economic actors is not necessarily who we are as citizens of an environmentally aware society, ${ }^{30}$ and public values are not a "mechanistic, mimicking recalculation based on private behaviour". 31 It rejects the idea that natural valuation can be achieved by measuring people's willingness to pay. ${ }^{32}$ The approach

(Springer, 1988); L Kaplow and S Shavell Fairness versus Welfare (Harvard University Press, 2009); M Bramley and J McNeill "Up the Creek and Down the River: In-stream Ecological Values and Property Rights under the RMA" in K Bosselmann and V Tava (eds) Water Rights and Sustainability (New Zealand Centre for Environmental Law, Auckland, 2011) at 175. For critiques of narrow economic approaches, see RL Revesz Foundations of Environmental Law and Policy (OUP, New York, 1997) at 3; W Lippman Essays on the Public Philosophy (Hamish Hamilton, London, 1955) at 109; M Sagoff The Economy of the Earth (Cambridge University Press, Cambridge, 2008).

${ }^{24} \mathrm{See}$, for example, A Tunks "One Indigenous Vision for Sustainable Development Law" in Bosselmann, Grinlinton and Taylor, above n 3; U Klein "Belief Views on Nature" (2000) 4 NZJEL 81.

${ }^{25}$ For eco-centric approaches generally, see C Stone "Should Trees have Standing?" (1972) 45 S Cal LR 450; P Taylor and J Kleinig Valuing Life (Princeton University Press, 1991); P Burdon "Wild Law: A Proposal for Radical Social Change" (2015) 13 NZPIL 157; P Singer Animal Liberation (Random House, 2015); P Taylor Respect for Nature (Princeton University Press, 1986); C Stone Earth and Other Ethics (Harper and Row, New York, 1987).

${ }^{26}$ See Keller, above n 1 , ch 1.

${ }^{27}$ Revesz, above n 23, at 18; W Grey "Anthropocentrism and Deep Ecology" (1993) 71(4) Australasian Journal of Philosophy 463.

28 J Habermas Between Facts and Norms: Contributions to a Discourse Theory of Law and Democracy (Cambridge, Polity Press, 1996) at 127-131.

${ }^{29}$ Compare R von Ihering Law as a Means to an End (Macmillan, New York, 1924) at 220. Note that this is consistent with what some have presented as "economic" approaches, on the grounds that interests are still assigned "value" through deliberative and participatory processes: see M Christensen "Valuation of Natural Assets under the Resource Management Act" (2013) 17 NZJEL 291 at 298, 318.

${ }^{30}$ M Sagoff "The Economy of the Earth" in Revesz, above n 23, at 19-22.

${ }^{31}$ S Kelman "Cost-Benefit Analysis: an Ethical Critique" in Revesz, above n 23, at 95.

${ }^{32}$ See S Beder "Costing the Earth" (2000) 4 NZJEL 227 at 234-235. 
encompasses the interests of future generations as an expression of a public ethic, although (due to its anthropocentricity) stops short of recognising that nature has interests or a voice divorced from the value that humanity sees in it.

The methods of an inclusive anthropocentric approach are not as limited as those of a narrow economic perspective. Cost-benefit analyses are rejected as an absolute measure of ethics, as is efficiency or equity. We are social, cultural, political and moral actors as well as economically rational and self-interested agents. ${ }^{33}$ Valuing the environment does not necessarily bring with it a wish to possess it in an economic sense, and market failure is not seen as the sole basis of social regulation. ${ }^{34}$ Environmental issues involving other life forms and future generations pose ethical aims beyond the maximisation of resource consumption, no matter how "sustainable" that consumption may be.

This means that the approach is pluralist rather than monist in nature, in that many potentially competing values must be weighed to reach a right answer. ${ }^{35}$ Neither social welfare, nor economic value, nor the "anthropocentric reductionism" of environmental human rights are determinative. ${ }^{36}$ Instead, the approach seeks to weigh a much wider range of society's values through human discourse. A spectrum of individual and collective rights may emerge as norms from that discourse, but they are not presumed to drive it.

In emphasising the centrality of a legitimate process in determining the weight of such values, the approach can be characterised loosely as positivist. ${ }^{37}$ Environmental laws are legitimate and enforceable if the process is followed, despite inevitable moral objections from some sectors of society as to their effect. This is not surprising in an anthropocentric approach; after all, legal positivism has grown hand-in-glove with the neo-liberal anthropocentrism that has defined modern western systems of law. That said, inclusive

\footnotetext{
${ }^{33}$ M Sagoff The Economy of the Earth (Cambridge University Press, Cambridge, 1988) from 66.

${ }^{34}$ Sagoff, above n 30, at 22.

35 See Burton, above n 2; A Brennan "Moral Pluralism and the Environment" (1992) 1 Environmental Values 15; Stone Earth and Other Ethics, above n 25.

${ }^{36}$ Bosselmann, above $\mathrm{n}$ 4, at 6, 111, 114. See also T Daya Winterbottom "The Role of Administrative Law" in Salmon and Grinlinton, above n 14, at 206; S Glazebrook "Human Rights and the Environment" (2009) 40 VUWLR 293 at 350.

${ }^{37}$ On positivism and natural law generally, see M Freeman Lloyd's Introduction to Jurisprudence (Sweet and Maxwell, 2014).
} 
anthropocentrism is a hybrid approach. In contrast to strict theories of legal positivism, ${ }^{38}$ it does not claim that the law's legitimacy is completely divorced from the morality of its content. Indeed, the method used in this thesis, in which I measure barriers and gaps against the "principles" identified in chapter III, requires me to consider their ethical foundation above and beyond the content of specific rules that have emerged from them. ${ }^{39}$

The approach sees environmental law as founded in high level indisputable norms or grundnorms, ${ }^{40}$ such as the broad concept of sustainability, ${ }^{41}$ and the legal process as a mechanism for determining the correct ethical balance of values held by society at any given time within the broad boundaries set by those norms. Essentially, it acknowledges the existence of a natural law "envelope" defined by grundnorms. Within that envelope, there is a constant search for moral validation from the participant community. The exact meaning of those norms, and the resolution of the many tensions they contain, only emerges from that exercise.

In the sense that ethical positions on environmental questions can be "discovered" at any point in time with reference to observable public values emerging from that discourse, inclusive anthropocentrism has further echoes of natural law. ${ }^{42}$ But while the need for environmental protection as a whole (grundnorms like sustainability) may resemble natural law thinking, ${ }^{43}$ and the generation of specific binding rules by government can be explained by positivist theory, neither alone adequately captures the complex relationship between power, process and ethics in the environmental space. For example, although a specific decision to allow the use of 1080 poison in the conservation estate for pest management purposes cannot be justified by a natural law conception of universal morality, it nevertheless has a substantial moral foundation (the idea that indigenous ecosystems deserve protection from introduced species like possums). If possums became an endangered species overnight, the morality of that action would be called into question. Choices are therefore not made in a

\footnotetext{
38 See HLA Hart The Concept of Law ( ${ }^{\text {rd }}$ ed, OUP, Oxford, 2012); JW Harris Legal Philosophies (Butterworths, London, 1980) at 16.

${ }^{39}$ Bosselmann, above n 4, at 49.

40 Similar to Kelsen's grundnorm; see JW Harris Legal Philosophies (Butterworths, London, 1980), ch 6; H Kelsen Pure Theory of Law (University of California Press, 1978).

${ }^{41} \mathrm{~K}$ Bosselmann "Sustainability and the Law" in Salmon and Grinlinton, above n 14, at 98-99.

${ }^{42}$ For a natural law justification of environmental law, see Coyle and Morrow, above $\mathrm{n}$ 4, at 9-58.

${ }^{43}$ Bosselmann, above n 4, at 113, 114.
} 
positivist "waste-land of rational and ethical nihilism". ${ }^{44}$ Within a high level envelope of natural law grundnorms, it may be more apt to describe an inclusive anthropocentric approach as a form of dialogical theory, under which, according to Habermas, ethics (and laws) are valid if those with values affected by decisions participate in rational discourse leading to them. ${ }^{45}$

The primary reason for adopting an inclusive anthropocentric approach is practicality. I do not set out to question the normative basis upon which environmental law is made in New Zealand, or to test a particular theory of environmental philosophy. It would be of less practical value to adopt dogmatically a theory that did not fall within the bounds of political or social reality, and "we must chasten our goals by adjusting them to economic, legal, scientific, and political realities". 46 This is not intended to dismiss alternative theories, particularly variants of eco-centrism, as undesirable. It is simply to say that the thesis is designed to make an original contribution to academic legal scholarship in a way that is capable of yielding practical recommendations for law and policy makers in New Zealand. Its basic approach must therefore have not only normative power (providing clear direction for law reform) but also explanatory power (accounting for the existence of fundamental principles that underpin existing laws). It is a deliberate rejection of Hume's is-ought divide. ${ }^{47}$ Since our main concern is adopting an approach that best accounts for principles observable within New Zealand's law, there is limited value in analysing various jurists' theories at length - because none will do so perfectly. We can incorporate useful ideas from theorists like Kelsen, Habermas and Sagoff because they allow us to move on to a closer consideration of New Zealand's principles under a broad umbrella of inclusive anthropocentrism.

The flexibility and robust pluralism of an inclusive anthropocentric approach best accounts for the range of principles observable in New Zealand's existing law. Admittedly, it does not do so perfectly; in New Zealand "economic values co-mingle with eco-centric values". ${ }^{48}$ However, it has greater explanatory power than strict economic and eco-centric approaches.

\footnotetext{
${ }^{44} \mathrm{P}$ Allott "The Globalisation of Philosophy and the Philosophy of Globalisation" in R MacDonald and D Johnston (eds) Towards World Constitutionalism (Martinus Nijhoff, 2007).

${ }^{45}$ See Habermas, above n 28, at 126-131; Bosselmann, above n 4, at 49; R Eckersley The Green State (MIT Press, Cambridge, 2004) at 141.

${ }^{46}$ Sagoff, above n 30, at 26.

${ }^{47}$ See Keller, above n 1, at 379.

${ }^{48}$ B Gordon "Treaty of Waitangi and Māori Issues in Environmental Law" in Salmon and Grinlinton, above n 14, at 322; K Bosselmann When Two Worlds Collide: Society and Ecology (RSVP Publishing, Auckland, $1995)$ at $130-133$.
} 
New Zealand's law goes further than simply remedying market failures or providing for methods of economic valuation. ${ }^{49}$ The central normative provisions of the RMA are laden with wider "public" values that require authorities to reach judgements based on contextual judgments rather than the mechanical outcomes of economic analyses. ${ }^{50}$ The public interest is treated as greater than the sum of private interests, which can be seen in, for example, the need for Environment Court approval of private settlements reached through the appeal process. ${ }^{51}$ Legislation applicable to conservation areas is also based on the premise that the public interest in protection in some areas is absolute, and, in a sense, priceless. Existing law even accepts that there is a public interest in how private land is used, rejecting the libertarian view that landowners can do as they please. ${ }^{52}$ Moreover, the origins of the RMA can be traced back to concerns with the well-being of future generations (who are not market actors), arising from international events that illustrated the fragility and scarcity of natural resources. ${ }^{53}$

Similarly, some existing provisions reflect strong eco-centric assumptions and ambitions. ${ }^{54}$ For example, the law recognises the intrinsic value of ecosystems and water, ${ }^{55}$ which exist alongside more traditional instrumental concepts of resource management. ${ }^{56}$ But the system as a whole is inconsistent with the overall ethos of eco-centrism. ${ }^{57}$ For example, the recognition in the RMA of the "intrinsic value" of ecosystems in s 7 does not lead to a presumption that all life is to be protected from humans. ${ }^{58}$ Nowhere can one perceive a set of rules governing when the interests of the natural world must override those of humans. ${ }^{59}$ The fact that native trees are subject to robust protections, yet it is considered desirable to fell wilding pines, is evidence enough that the law does not adopt an approach whereby all living organisms are respected as teleological centres of life. Guardians or proxies of specific

\footnotetext{
${ }^{49}$ It is an error of law to reduce landscape values solely to economic cost-benefit analysis: see; Meridian Energy Ltd v Central Otago District Council [2010] NZRMA 477 (HC) at [116].

${ }^{50}$ See Christensen, above n 29; Meridian Energy Limited v Central Otago District Council [2011] 1 NZLR 482 (HC) at [107]-[111].

${ }^{51}$ See Hurunui Water Project Ltd v Canterbury Regional Council [2015] NZHC 3098, [2016] NZRMA 71 at [26]; Environment Court of New Zealand Practice Note (2014) at 4.12.

${ }^{52}$ See D Young Values as Law (VUW Institute of Policy Studies, Wellington, 2001), at vi.

${ }^{53}$ Ibid at 3-5.

${ }^{54}$ For example, the existence of the Animal Welfare Act 1999 demonstrates a psychocentric acceptance that cruelty to animals is morally deplorable in its own right.

${ }^{55}$ RMA, ss 7(d), 199.

${ }^{56}$ Bosselmann, above $\mathrm{n}$ 4, at 93, 105.

${ }^{57}$ Ibid at 103 .

${ }^{58}$ Canterbury Regional Council v Selwyn District Council (1996) 2 ELRNZ 395 (EnvC) at 406.

${ }^{59}$ Contrast theorists such as Taylor, above n 25.
} 
resources might have legal standing, ${ }^{60}$ and large areas are managed as conservation estate, but nature itself is not generally granted legal personality in the sense envisaged by Stone. ${ }^{61}$ Nor (unfortunately) does the law impose ecological bottom lines in most situations; more often it balances multiple social, cultural, economic and ecological concerns. ${ }^{62}$ As Louka has opined, and Bosselmann has accepted with regret, ${ }^{63}$ "the deep-ecology approach is based on different philosophical assumptions than those shared by the majority of people in the world today". ${ }^{64}$ We can add also that eco-centrism (such as Bosselmann's "ecological core" approach to sustainability) ${ }^{65}$ does little to account for the normative direction of important non-natural components of our environmental law, such as the management of heritage sites and urban design. $^{66}$

Rejecting eco-centrism in favour of anthropocentrism does not lead to an assumption that we must strike a balance in favour of resource use. ${ }^{67}$ Human interests need not be equated to the rapacious use of resources. Nor does the exclusion of the natural world from the community of justice itself damn the environment to destruction. ${ }^{68}$ Inclusive anthropocentrism can still be ecologically sound, and potentially equally so. ${ }^{69}$ The anthropocentric notions of the public interest and inter-generational equity already encapsulate the idea that nature has noneconomic value, now and in the future. Much depends on the principles that are produced by community discourse, which may in practice draw an anthropocentric theory much closer to eco-centric principles. For example, while the conservation of the kiwi is clearly not recognised as a fundamental element of "justice" in New Zealand, it nevertheless receives unwavering support in law because it has been firmly embedded through the community's

\footnotetext{
${ }^{60}$ For example, under s 13 of Fiordland (Te Moana o Atawhenua) Marine Management Act 2005.

${ }^{61}$ Stone, above $\mathrm{n} 25$. Although a recent exception is that Te Uruwera, formerly a national park, is a now legal entity in its own right under the Te Uruwera Act 2014. See T Daya Winterbottom "Water Management" in Salmon and Grinlinton, above n 14, at 693.

${ }^{62}$ North Shore City Council v Auckland Regional Council [1997] NZRMA 59 (EnvC) at 92-94; Genesis Power Ltd v Franklin District Council [2005] NZRMA 541 (EnvC) at [53]; note also Environmental Defence Society v New Zealand King Salmon Co Ltd [2014] NZSC 38, [2014] NZRMA 195; KPF Investments Ltd v Marlborough District Council [2014] NZEnvC 152, (2014) 18 ELRNZ 367; G Severinsen "Consenting to a Bottom Line in the RMA?" (2014) 10 BRMB 192.

${ }^{63}$ Bosselmann, above $\mathrm{n} 4$, at 103 .

${ }^{64}$ E Louka International Environmental Law (Cambridge University Press, Cambridge, 2006) at 17. See also P Taylor "The Global Perspective: Convergence of International and Municipal Law" in Bosselmann, Grinlinton, and Taylor, above n 3, at 155 .

${ }^{65}$ Bosselmann, above $\mathrm{n} 4$, at 53 , ch 3 .

${ }^{66}$ See RMA, ss 187-198.

${ }^{67}$ W Beckerman and J Pasek "The Concept of Intrinsic Values" in Keller, above n 1, at 86-87.

${ }^{68}$ See D Tladi "Of Course for Humans: A Contextual Defence of Intergenerational Equity" (2007) 9 South African Journal of Environmental Law and Policy 177.

${ }^{69}$ Grey, above n 27, at 473 .
} 
ethical discourse. Similarly, the approach does not reject economic concerns or the use of economic tools to achieve a wider set of aims. ${ }^{70}$

David Young's description of the RMA ("a complex set of values enshrined in law") is also an apt snapshot of the highly pluralist approach I have adopted. ${ }^{71}$ Pluralism is a strength, because it gives the law the agility to respond to changing natural and social environments. It is also a weakness. Pluralism gives rise to greater uncertainty, subjectivity and argument. It is can be simpler to make decisions based on monist values such as social welfare or the interests of the natural world. As the High Court has pointed out, a "degree, even a relatively high degree, of subjectivity is virtually inevitable" in assessing aspects of the environment like landscape values. ${ }^{72}$ The act of weighing different effects is like "comparing apples and oranges". ${ }^{73}$ The approach does not provide the predictability that is generally considered a desirable attribute of the law, because plural values are often discordant and incommensurable. ${ }^{74}$ However, the New Zealand experience of pluralism is hardly the kind of random theory-switching or moral relativism that has been criticised. ${ }^{75}$ Our principles have proved remarkably consistent over time. ${ }^{76}$ Furthermore, a pluralist approach recognises an inescapable fact that more dogmatic economic and eco-centric approaches tend to conceal: at some point subjective judgments must be made by a community as to the true value of environmental costs and benefits. Human values are always present, whether or not they are explicitly acknowledged or quantified. ${ }^{77}$

The way in which an inclusive anthropocentric approach is made more certain in this thesis is not by introducing theoretical refinements, but rather by analysing the legal principles that have actually arisen from community discourse in the New Zealand context (explored in chapter III). The use of a highly pluralist normative approach that can accommodate a variety of existing values is also capable of elaboration by looking at those values. This is vital, since the thesis aims to make pragmatic recommendations by working within, rather than creating anew, the principles of New Zealand's environmental law.

\footnotetext{
${ }^{70}$ See M Faber "How to be an Ecological Economist" (2008) 66 Ecological Economics 1 at 2.

${ }^{71}$ Young, above n 52, at 85.

${ }^{72}$ Meridian Energy, above n 50, at [110]. See generally P Brosnahan and V Rive "Landscape and Visual" in D Nolan (ed) Environmental and Resource Management Law $\left(5^{\text {th }} \mathrm{ed}\right.$, LexisNexis, Wellington, 2015).

${ }^{73}$ JF Investments Ltd v Queenstown Lakes District Council EnvC Christchurch C48/06, 27 April 2006 at [37].

${ }^{74}$ Burton, above n 2, at 544, 561; Hardin, above n 19, at 1244.

75 See JB Callicott "The Case against Moral Pluralism" (1990) 12 Environmental Ethics 99, at 112.

${ }^{76}$ See ch III.

${ }^{77}$ Salmon, above n 11, at 2.
} 


\section{Conclusion}

In this chapter I have described the normative framework adopted in the thesis: an inclusive anthropocentric approach. It recognises that while people's values, expressed through a process of community discourse, are paramount in determining how resources are used and protected, that does not mean environmental outcomes need be negative. Economic considerations need not receive greater weight than eco-centric ones, and the public interest is something distinct from the sum of private interests. Above all, the approach best accounts for the plural principles that we can observe in New Zealand's existing law. An important next step, before the approach is applied to the regulation of marine CCS, is to explore the more specific principles underpinning New Zealand's existing environmental law. 


\section{Principles of Environmental Law in New Zealand}

\section{A Introduction}

In this chapter I identify a series of 10 principles that underpin New Zealand's existing environmental law. Six of them are substantive: the sustainability principle, distributive principle, Treaty obligations, public-interest industries principle, conservation-enhancement principle, and precautionary principle. The other four are procedural: the participatory principle, decision-making principle, certainty-flexibility principle, and efficiency principle. The term "principle" is not used in a technical sense, and is intended to be broad enough to encompass any enduring norm of a legal character observable in New Zealand law. ${ }^{1}$ Although many have substantial moral content, that does not mean they are legally insignificant: "if [their] moral dimension is resonant with a legal dimension, then there is reason to recognize [their] legal nature". ${ }^{2}$ Principles will be used as a guide to law reform in Part 2 of the thesis. ${ }^{3}$

The principles of New Zealand's existing environmental law are plural. In achieving a balance between resource use and protection, the law seeks to place relative value on the interests of various groups: between different groups within present day society, between present and future generations, and between private and public interests. The exact location

\footnotetext{
${ }^{1}$ On the meaning of a legal "principle" see K Bosselmann The Principle of Sustainability: Transforming Law and Governance (Ashgate, Aldershot, 2008) at 44.

${ }^{2}$ Bosselmann, above $\mathrm{n} 1$, at 49 .

${ }^{3}$ This is not intended to be a comprehensive account or critique of all principles.
} 
of this balance defies meaningful expression at an abstract level, ${ }^{4}$ but substantive and procedural principles are extremely important in resolving tensions. It is useful to engage with legal principles rather than just legal rules (in the positivist sense of Hart and Austin), ${ }^{5}$ because such rules may not always fully reflect underlying principles when applied to novel contexts like $\mathrm{CCS}^{6}$

The basic normative content of New Zealand's environmental legal principles has proved remarkably consistent since the resource management law reforms of the early 1990s. ${ }^{7}$ Many reflect principles that have developed internationally, ${ }^{8}$ but the touchstone for discussion is how they have been implemented in New Zealand.

\section{B The Principle of Sustainability}

Sustainability is the core, overarching framework principle in New Zealand's environmental law, setting the broad parameters within which other principles operate. It demands the holistic and integrated consideration of a wide range of impacts on a broadly defined environment, according to the specific effects of a proposal.

In the last few decades, sustainability has become a byword for responsible environmental management. ${ }^{9}$ New Zealand environmental statutes embrace various forms of the principle. ${ }^{10}$ However, most debate has centred on the term "sustainable management", which is the normative touchstone for decision-making under the Resource Management Act 1991

\footnotetext{
${ }^{4}$ SJ Burton "Normative Legal Theories: The Case for Pluralism and Balancing" (2012-2013) 98 Iowa L Rev 535 at 550 .

${ }^{5}$ Dworkin draws a useful distinction between rules, which require inflexible outcomes, and principles, which guide decisions: R Dworkin Taking Rights Seriously (Bloomsbury, London, 1997) at 41-45.

${ }^{6}$ See generally Bosselmann, above n 1, at 44.

${ }^{7}$ On the reforms, see D Grinlinton "Natural Resources Law Reform in New Zealand - Integrating Law, Policy and Sustainability" (1995) AJNRLP 1; G Palmer "The Making of the Resource Management Act" in G Palmer Environment - The International Challenge (Victoria University Press, Wellington, 1995), ch 5.

${ }^{8}$ See generally N de Sadeleer Environmental Principles (OUP, Oxford, 2002); P Sands and others Principles of International Environmental Law ( $3^{\text {rd }}$ ed, Cambridge University Press, Cambridge, 2012), pt II; P Birnie, A Boyle and C Redgwell International Law and the Environment ( $3^{\text {nd }} \mathrm{ed}$, OUP, Oxford, 2009).

9 D Grinlinton "Integrating Sustainability into Environmental Law and Policy in New Zealand" in K Bosselmann, D Grinlinton and P Taylor (eds) Environmental Law for a Sustainable Society (2 $2^{\text {nd }}$ ed, New Zealand Centre for Environmental Law, Auckland, 2013) at 26; Bosselmann, above n 1, ch 1.

${ }^{10}$ For example, see Fisheries Act 1996, s 10; Civil Defence Emergency Management Act 2002, s 3; Local Government Act 2002, s 14(1)(h).
} 
(RMA), and the Exclusive Economic Zone and Continental Shelf (Environmental Effects) Act 2012 (EEZ Act). ${ }^{11}$ Sustainable management is defined in s 5 of the RMA as:

managing the use, development, and protection of natural and physical resources in a way, or at a rate, which enables people and communities to provide for their social, economic, and cultural well-being and for their health and safety while-

(a) sustaining the potential of natural and physical resources (excluding minerals) to meet the reasonably foreseeable needs of future generations; and

(b) safeguarding the life-supporting capacity of air, water, soil, and ecosystems; and

(c) avoiding, remedying, or mitigating any adverse effects of activities on the environment.

Arguably this definition does not add much to an inclusive anthropocentric approach or its call to establish some ethical balance between use and protection according to the values of a community. There have been numerous observations to that effect. ${ }^{12}$ It is above all a framing or umbrella principle, setting out various potentially conflicting matters that need to be reconciled through the operation of subordinate principles. ${ }^{13}$ It is not itself an operative provision or a "rule". ${ }^{14}$ This reflects Lowe's understanding of sustainable development, which he sees as of only "interstitial normativity" and as "pushing and pulling the boundaries of true primary norms". ${ }^{15}$ As such, the basic idea of sustainability contains a useful degree of normative agility (its true meaning can change through subordinate instruments as the relative values within society shift) but in itself it provides few absolute bottom lines or clarifications as to where a balance is to be struck. ${ }^{16}$ Most of New Zealand's experience with sustainable management has been characterised by a relatively vague balancing of conflicting interests

\footnotetext{
${ }^{11}$ RMA, s 5; EEZ Act s 10; see also Reith v Ashburton District Council [1994] NZRMA 241 (PT); Grinlinton, above $\mathrm{n} 9$, at 27.

${ }^{12}$ See D Young Values as Law (VUW Institute of Policy Studies, Wellington, 2001) at 31; Mangakahia Māori Komiti v Northland Regional Council [1996] NZRMA 193 (PT) at 215; Auckland Regional Council v North Shore City Council (1995) 1B ELRNZ 426 (CA) at 429; B Harris "Sustainable Management as an Express Purpose of Environmental Legislation" (1993) 8 Otago Law Review 51; D Grinlinton "Does the RMA Need More Reform?" [1997] 2 BRMB 49 at 50. Compare E Louka International Environmental Law (Cambridge University Press, Cambridge, 2006) at 38.

${ }^{13}$ See Environmental Defence Society Inc v New Zealand King Salmon Co Ltd [2014] NZSC 38, [2014] NZRMA 195 at [14], [24]; Royal Forest and Bird Protection Society of New Zealand v Buller District Council [2013] NZHC 1324, [2013] NZRMA 275 at [8].

${ }^{14}$ King Salmon, above n 13, at [151]; K Bosselmann "Sustainability and the Law" in P Salmon and D Grinlinton Environmental Law in New Zealand (Thomson Reuters, Wellington, 2015) at 97.

${ }^{15}$ V Lowe "Sustainable Development and Unsustainable Arguments" in A Boyle and D Freestone (eds) International Law and Sustainable Development (OUP, Oxford, 1999) at 31.

${ }^{16}$ For example, see Re Meridian Energy Ltd [2013] NZEnvC 59 at [190].
} 
(an "overall broad judgment") rather than the imposition of clear ecological bottom lines. ${ }^{17}$ That said, sustainable management allows, even if it seldom demands, the imposition of bottom lines. $^{18}$

Some useful normative elements can be seen within the principle of sustainability in New Zealand, notably under the RMA. First, the scope of the principle is wide. It contemplates almost all effects of activities on a broadly defined "environment", including the social, economic and cultural condition of communities. ${ }^{19}$ It is concerned with impacts on both private property and public values, although (subject to safeguards) it also recognises that the wider public interest in environmental protection can override narrow private (including property) rights and interests. ${ }^{20}$ Secondly, it embraces a universal duty to avoid, remedy or mitigate any adverse effects of activities on the environment. ${ }^{21}$ Addressing potentially unforeseen harm is therefore seen, in theory, as more important than the transparency and certainty provided by specific controls. Thirdly, at least under the RMA, the principle aims to ensure an appropriate degree of environmental protection in the face of resource use (enabling use), not to promote or pursue the benefits of resource use itself. This idea is explored further below under the concept of distributional equity.

Fourthly, sustainability encourages holistic, ${ }^{22}$ integrated, future-focused and ecosystem and effects-based assessment ${ }^{23}$ rather than the imposition of artificial boundaries, arbitrary

\footnotetext{
${ }^{17}$ See North Shore City Council v Auckland Regional Council [1997] NZRMA 59 (EnvC) at 92-94; Genesis Power Ltd v Franklin District Council [2005] NZRMA 541 (EnvC) at [53]. Contrast early "bottom-line" cases such as Campbell v Southland District Council PT Wellington W114/94, 14 December 1994; and more recently King Salmon, above n 13, at [24]; but compare KPF Investments Ltd v Marlborough District Council [2014] NZEnvC 152, (2014) 18 ELRNZ 367 at [196]-[202]; Board of Inquiry Final Report and Decision of the Board of Inquiry into the Basin Bridge Proposal (29 August 2014) at [176]-[188]; Royal Forest and Bird Protection Society v Buller District Council [2013] NZHC 1346, [2013] NZRMA 293 at [53]. See generally D Grinlinton "Sustainability in New Zealand Law and Policy" in Salmon and Grinlinton, above n 14, at 115-116; G Severinsen "Consenting to a Bottom Line in the RMA?" (2014) 10 BRMB 192; B Armstrong "Time for a More Eco-Centric Approach to Resource Management in New Zealand" (August 2014) RMJ 7 at 9, 11; G Hewison "The Resource Management Act 1991" in Salmon and Grinlinton, above n 14, at 121, 542-543; Elias CJ "Righting Environmental Justice" (12 ${ }^{\text {th }}$ Annual Salmon Lecture, Auckland, 25 July 2013) at 8.

${ }^{18}$ King Salmon, above n 13, at [150]; Auckland Regional Council, above n 12.

${ }^{19}$ RMA, s 2; Zdrahal $v$ Wellington City Council [1995] 1 NZLR 700 (HC). Contrast the narrower focus on the natural environment in the EEZ Act, s 4.

${ }^{20}$ West Coast Regional Council v Royal Forest and Bird Protection Soc Inc [2007] NZMRA 32 (HC) at [73]; Falkner v Gisborne District Council [1995] NZRMA 462 (HC) at 478; Springs Promotions Ltd v Springs Stadium Residents Assn Inc [2006] 1 NZLR 846 (HC) at [77]; Christchurch International Airport Ltd v Christchurch City Council (1996) 3 ELRNZ 96 (HC) at 98; RMA, s 85; C Warnock and M Baker-Galloway Focus on Resource Management Law (LexisNexis, Wellington, 2015) at 29-30.

${ }^{21}$ RMA, ss 5, 17; EEZ Act, s 25; Fisheries Act 1996, s 8(2).

${ }^{22}$ See generally T Daya Winterbottom "Resource Management Act 1991 Issues" in B Barton, K Jordan and G Severinsen Carbon Capture and Storage: Designing the Legal and Regulatory Framework for New Zealand
} 
standards, and detailed control of development that were characteristics of the pre-RMA approach. ${ }^{24}$ Decisions are not fully integrated, and some resources continue to be managed across multiple regulatory regimes,${ }^{25}$ but we can observe an intention to achieve integrated management as far as practicable. ${ }^{26}$

\section{The Distributive Principle}

The distributive principle guides more specifically how we assign weight to various interests when making environmental decisions. Weight must be assigned between the interests of groups within present day society, between present and future generations, and between public and private interests. ${ }^{27}$ The principle encompasses six key concepts: environmental justice, distributional equity, polluter-pays, anthropocentric valuation, subsidiarity, and intergenerational equity. I conclude that, in New Zealand, environmental justice and distributional equity are weak. Concepts of anthropocentric valuation, subsidiarity and inter-generational equity are stronger. New Zealand also applies the concept of polluter-pays, but not strictly. It can be broadened to a concept of "user-pays" and even "beneficiary-pays".

The concept of environmental justice seeks to protect certain groups (such as those who are disadvantaged socio-economically) more than others from the costs of resource use. ${ }^{28}$ It involves an equitable imposition of risk. ${ }^{29}$ Distributional/intra-generational equity/justice seeks to ensure that the benefit of resource use rights, are distributed equitably. ${ }^{30}$ Under an

(University of Waikato Centre for Environmental, Resources and Energy Law, Hamilton, 2013) at 359; D Grinlinton "Integrated Resource Management - A Model for the Future"(1992) 9 EPLJ 4.

${ }^{23}$ M Bramley "Institutional and Governance Structures of Environmental Law" in Salmon and Grinlinton, above n 14 , at 398.

24 (4 July 1991) NZPD 3019; G Palmer "The Resource Management Act - How we got it and what Changes are being made to it" (2014) RM Theory\&Practice 22 at 30. On integrated environmental management, see Warnock and Baker-Galloway, above n 21, at 16-18; Grinlinton, above n 7. See also Batchelor v Tauranga District Council (No 2) (1992) 1A ELRNZ 221 (HC) at 224; JF Investments Ltd v Queenstown Lakes District Council EnvC Christchurch C48/06, 27 April 2006 at [18].

${ }^{25}$ For example under the Crown Minerals Act 1991 (CMA), Forests Act 1949, and Fisheries Act 1996. See Bramley, above n 23, at 410; Grinlinton, above n 9, at 34; M van Kampen and B Matheson "Minerals and Petroleum" in D Nolan (ed) Environmental and Resource Management Law $\left(5^{\text {th }}\right.$ ed, LexisNexis, Wellington, $2015)$ at 553.

${ }^{26}$ See RMA, ss 91, 104(1)(a), sch 4; Te Runanga-a-Iwi O Ngati Kahu v Far North District Council (2011) 16 ELRNZ 708 (HC) at [126]; Far North District Council v Te Runanga-a-Iwi O Ngati Kahu [2013] NZCA 221 at [43]; U Klein “Integrated Resource Management in New Zealand” (2001) 5 NZJEL 1.

${ }^{27}$ See generally B Preston "The Effectiveness of the Law in Providing Access to Environmental Justice" in P Martin and others (eds) In Search of Environmental Justice (Edward Elgar, 2015).

${ }^{28}$ See V Been "What's Fairness Got to do with it?" (1993) 78 Cornell Law Review 1001.

${ }^{29}$ See ibid; Bosselmann, above n 1, ch 3.

${ }^{30}$ DR Keller (ed) Environmental Ethics: the Big Questions (Wiley Blackwell, West Sussex, 2010) at 418. 
anthropocentric approach, the concepts are not about protecting the environment per se, only about the ways in which the costs and benefits arising from use are allocated. Internationally, they have been described as the social dimension of sustainability. ${ }^{31}$

However, within New Zealand's environmental law the concept of distributional equity has proved weak. ${ }^{32}$ The economic rationalism that underpins the RMA sees the market, not equity or justice, as the primary determinant for how and by whom most resources are used. ${ }^{33}$ The concept of sustainable "development", prominent in international fora and promoted in the Brundtland Report, ${ }^{34}$ was intentionally eschewed in the RMA due to its association with rights to socio-economic development and the distribution of wealth. ${ }^{35}$ As such, the RMA does not allow limitless interventions on environmental and social grounds or seek to allocate property rights. ${ }^{36}$ Specific questions of allocation are not generally regulated for (except, to some extent, allocation to Māori). ${ }^{37}$ The result in practice is that most resources are allocated on a first in time basis through consenting processes, which do not usually consider opportunity cost or speculate as to alternative uses for those resources that may arise in the future. ${ }^{38}$ The focus is on the acceptability of adverse effects, not planning for or maximising public benefits. ${ }^{39}$ Instead, trust is placed in the market for efficient allocative choices. As the Minister for the Environment said on the Resource Management Bill's second reading, as long as adverse effects are acceptable, "what people get up to is their own affair". ${ }^{40}$ Recent

\footnotetext{
${ }^{31}$ Bosselmann, above n 1 , at 9 .

${ }^{32}$ E Hudspith "Freshwater Management in New Zealand" (2013) 16 NZJEL 277 at 285; contrast K Bosselmann "A Legal Framework for Sustainable Development" in Bosselmann and others, above n 9, at 178. See also Barton and others, above n 22, at 28; SD Upton "Purpose and Principle in the Resource Management Act" (1995) 3 Wai L Rev 17 at 24.

${ }^{33}$ See Meridian Energy Limited v Central Otago District Council [2011] 1 NZLR 482 (HC) at [119]; Young, above n 12, at 32; Springs Promotions, above n 20, at [79].

${ }^{34}$ K Palmer "Resource Management Act 1991" in Nolan, above n 25, at 111-112; World Commission on Environment and Development Our Common Future (OUP, Oxford, 1987) at 43.

${ }^{35}$ Report of the Review Group on the Resource Management Bill (MfE, Wellington, 1991) at [3.3]; St Columba's Environmental House Group v Hawkes Bay Regional Council [1994] NZRMA 560 (PT) at 528; Grinlinton, above n 9, at 28; Armstrong, above n 17, at 6. Sustainable development appears in the Local Government Act 2002, but has a much more limited application.

${ }^{36}$ See Armstrong, above n 17, at 12; Falkner, above n 20, at 480.

37 Carter Holt Harvey Ltd v Waikato Regional Council [2011] NZEnvC 380 at [435]; contrast Marine and Coastal Area (Takutai Moana) Act 2011 (MCAA).

${ }^{38}$ See Cullen v Kaipara District Council EnvC Auckland A015/99, 17 February 1999 at [27]-[28]; Fleetwing Farms Ltd v Marlborough District Council [1997] 3 NZLR 257 (CA) at 264; M Pickford "Economic Efficiency and the Resource Management Act" (2014) 18 NZJEL 149 at 158. Alternatives can be considered in only limited situations: see Maniototo Environmental Society Inc $v$ Central Otago District Council EnvC Christchurch C103/2009, 28 October 2009 from [702]; Lower Waitaki River Management Society Inc v Canterbury Regional Council EnvC Christchurch C080/09, 21 September 2009 at [201].

${ }^{39}$ Lower Waitaki, above n 38, at [199]-[201]; Upton, above n 32, at 41.

40 (4 July 1991) 516 NZPD 3018.
} 
case law has suggested (although not confirmed) an erosion of this approach, ${ }^{41}$ and the RMA (and more narrow legislation) now contains some provisions that can allocate specific resources in other, more structured and considered, ways. ${ }^{42}$ But, ultimately, the challenge of social and economic justice has proved been too great to incorporate allocative questions fully into law designed to protect the bio-physical environment. ${ }^{43}$

The concept of environmental justice is also fairly weak within New Zealand's law. Although effects on social, economic and cultural well-being of people and communities are justiciable effects on the "environment", the law does not specifically require that certain socioeconomic groups be insulated from adverse effects more than others. ${ }^{44}$ An exception is that impacts on Māori cultural interests are strongly safeguarded. ${ }^{45}$ Furthermore, in practice, effects on vulnerable communities may be valued particularly negatively, and treated as being of greater magnitude. ${ }^{46}$ In contrast, we can discern no real expression of inter-species or ecological justice.

The concept of polluter-pays provides that the costs of pollution should be internalised to those responsible for producing it or who reap its benefits. ${ }^{47}$ A broader concept of "userpays" can be observed in New Zealand's law. Pollution is simply one example of using a resource (a receiving environment). The concept can be seen in, for example, the establishment of a carbon market under the New Zealand emissions trading scheme, the fact that financial contributions and administrative charges can be imposed on resource users as a quid pro quo for using or impacting on public resources, ${ }^{48}$ and the fact that financial return to the Crown is a key consideration in granting mining permits. ${ }^{49}$ Moreover, resource users must pay for direct interference with others' real property rights; compulsory acquisition invariably leads to monetary compensation, ${ }^{50}$ as do forced access agreements under the CMA. ${ }^{51}$

\footnotetext{
${ }^{41}$ See ch IX.

${ }^{42}$ For example, RMA, pt 7A, ss 14(3), 30(1)(fa)-(fb); CMA, s 24; Fisheries Act 1996, pt 4.

${ }^{43}$ See Bosselmann, above $\mathrm{n} 1$, at 12.

${ }^{44}$ S Beder "Costing the Earth" (2000) 4 NZJEL 227 at 236.

${ }^{45}$ For example, see RMA, ss 85A, 104(3)(c)(iv).

46 See generally D Sheppard "The Resource Management Act - from Principles to Practice" in T Daya Winterbottom (ed) Frontiers of Resource Management Law (Thomson Reuters, Wellington, 2012) at 233. Compare (albeit with different reasoning) J Milligan "Equity in the Resource Management Act" (2000) 4 NZJEL 245 at 253.

${ }^{47}$ See Machinery Movers Ltd v Auckland Regional Council (1993) 1A ELRNZ 411 (HC) at 416.

${ }^{48}$ RMA, ss 36(4), 108; LGA, pt 8; Machinery Movers, above n 47, at 416-417.

${ }^{49}$ CMA, s $1 \mathrm{~A}(2)(\mathrm{d})$.

${ }^{50}$ See Forest and Bird, above n 17, at [58]; RMA, ss 85, 86(3), 185-186.

${ }^{51}$ CMA, s 76.
} 
This does not mean that people have a right to pollute or use resources if they pay. ${ }^{52}$ Regulation, not the market, usually determines if adverse effects are acceptable. ${ }^{53}$ Yet the true costs of resource use are not fully internalised in New Zealand's application of the concept. ${ }^{54}$ For example, the law does not require that compensation be paid for a failure to avoid, remedy or mitigate the wider adverse effects of an activity on the environment or persons (unless there is a formal expropriation). ${ }^{55}$ It does not require that charges be imposed for the use of public resources. ${ }^{56}$ A low price on carbon emissions under the emissions trading scheme effectively shifts a large portion of the costs of climate change from emitters to wider society. ${ }^{57}$ Degrading one aspect of the environment while enhancing another can be acceptable ${ }^{58}$ as can the degradation of the environment in the interests of other nationally important agendas. ${ }^{59}$ The intention of the RMA to place the costs on a change-maker, rather than the community, has been achieved only in a narrow sense of some procedural costs. ${ }^{60}$ Ultimately, pragmatism wins over strict principle. The public interest in enabling private use of resources is seen as more important than their perfectly fair distribution or a complete internalisation of environmental costs.

In some cases this may produce inequities. But in others, New Zealand law may simply reflect a broader take on the concept - one of beneficiary-pays. Here, some of the costs of private activities having wider benefits for society can also justifiably be borne by the society that benefits. It is sometimes implicit. For example, substantial weight is usually placed on the public benefits generated by key industrial activities like electricity generation, relative to its adverse impacts. ${ }^{61}$ The concept can also be seen in a more concrete sense under the RMA,

\footnotetext{
${ }^{52}$ See generally C Warnock "Global Atmospheric Pollution: Climate Change and Ozone" in Salmon and Grinlinton, above n 14, at 808-809.

${ }^{53}$ For example, see RMA, ss 104-104D, 87A(6); contrast Climate Change Response Act 2002 (CCRA), s 63.

${ }^{54}$ See Auckland Regional Council v Auckland City Council [1997] NZRMA 205 (EnvC), at 61; Meridian, above n 33, at [618]; Warnock and Baker-Galloway, above n 20, at 20.

${ }^{55}$ See RMA, s 108; Forest and Bird, above n 17, at [58]; See Colonial Homes Ltd v Queenstown Lakes District Council EnvC Wellington W104/95, 28 August 1995 at 4.

${ }^{56}$ A Hayward "Freshwater Management: Water Markets and Novel Pricing Regimes" (2006) 10 NZJEL 215 at 245; Machinery Movers, above n 47, at 416-417; I Leersnyder "Free for All or User Pays?" (2008) 12 NZJEL 65.

${ }^{57}$ G Palmer "New Zealand's Defective Law on Climate Change" (2015) 13 NZJPIL 115 at 131.

${ }^{58}$ See Forest and Bird, above n 17.

${ }^{59}$ New Zealand Rail Ltd v Marlborough District Council [1994] NZRMA 70 (HC) at [86]; JF Investments, above n 24, at [27]; Forest and Bird, above n 17, at [52].

${ }^{60}$ Young, above n 12, at 24; P Salmon "Access to Environmental Justice" (1998) 2 NZJEL 1 at 12-13; RMA, ss 36, 360(1)(b).

${ }^{61}$ For example, see Maniototo, above n 38, at [331]-[346], [732].
} 
where administrative charges can only be imposed on persons to the extent that they benefit over and above the wider community. ${ }^{62}$

Where resource use is unauthorised, it is generally subject to a more strict application of polluter/user-pays. Here, the principle can result not only in internalisation of costs (compensation and remediation), but also in punitive action (prosecution) for harming the broader public interest. ${ }^{63}$ Only in limited cases does the law not pursue the full internalisation of costs. Again, this is usually where a risk of unauthorised harm stems from an activity in which the public has a substantial interest. ${ }^{64}$

A particular variant of polluter-pays underpinning New Zealand's environmental law is that of common but differentiated responsibility. ${ }^{65}$ This is most prominent in the climate change context. $^{66}$ It provides that, while all states have common responsibility for global environmental problems, it would be inequitable to require identical responses given the different historical contributions of states to the problem and varying capabilities to respond. ${ }^{67}$ As a developed state, New Zealand has recognised that it should bear a relatively greater burden for climate mitigation measures than the developing world. ${ }^{68}$ In that context the concept demands that meaningful action be taken to mitigate climate change, including the enhancement and protection of carbon sinks. ${ }^{69}$ It highlights the need for us all to bear the burdens of a global ecological citizenship. ${ }^{70}$

The concept of anthropocentric valuation is also significant in New Zealand law. It recognises that "positive" or "adverse" effects (and their significance) depend on human

\footnotetext{
${ }^{62}$ RMA, s 36(4)(b)(i).

${ }^{63}$ RMA, ss 338-339.

${ }^{64}$ For example, see B Marten "Limitation of Liability in Maritime Law and Vessel-source Pollution" (2013) 9 NZ L Rev 199.

${ }^{65}$ See Bosselmann, above n 1, at 59-60.

${ }^{66}$ See, for example, United Nations Framework Convention on Climate Change 1771 UNTS 107 (signed 9 May 1992, entered into force 21 March 1994) (UNFCCC), art 3.1; Warnock, above n 52, at 793.

${ }^{67}$ See generally D Shelton "Using Law and Equity for the Poor and the Environment" in Y Le Bouthillier and others (eds) Poverty Alleviation and Environmental Law (Edward Elgar, Cheltenham, 2012).

${ }^{68}$ UNFCCC, art 3.1, Annex I. See generally C Warnock "The Climate Change Regime" (2004) 8 NZJEL 88. On New Zealand's contribution to climate change, see A Arthur-Young "Climate Change" in Nolan, above n 25, at 1120 .

${ }^{69}$ UNFCCC, arts 3.3, 4; CCRA, s 64.

${ }^{70}$ Bosselmann, above $\mathrm{n} \mathrm{1,} \mathrm{at} \mathrm{6.} \mathrm{See} \mathrm{generally} \mathrm{P} \mathrm{Taylor} \mathrm{"Heads} \mathrm{in} \mathrm{the} \mathrm{Sand} \mathrm{as} \mathrm{the} \mathrm{Tide} \mathrm{Rises"} \mathrm{(2000)} 19$ UCLA Journal of Environmental Law and Policy 247; P Taylor "The Business of Climate Change: What's Ethics got to do with it?" (2007) 20 Pacific McGeorge Global Business and Development Law Journal 161.
} 
attitudes towards them. ${ }^{71}$ While the "adverse" character of change may be obvious in many scenarios (such as the dumping of toxic waste or destruction of habitats), in others it is less clear (such as debate over amenity values, ${ }^{72}$ or whether an organism is "unwanted"). ${ }^{73}$ Environmental change is not automatically considered to be an adverse change, and can be neutral or positive depending on how closely it impacts on human values. ${ }^{74}$ Such questions are usually resolved in the development and review of normatively charged policies by elected representatives. ${ }^{75}$

The concept of subsidiarity provides that decisions should be made closest to, and in line with the values of, those most affected by them (the relevant community of interest). ${ }^{76} \mathrm{~A}$ decision (for example, authorising a power station) can affect national interests (a positive impact on energy supply) in very different ways to local interests (amenity impacts). It can be difficult to determine where the appropriate community of interest lies, because many communities have legitimate and conflicting interests. In New Zealand, the result of this is often highly devolved decision-making by local government, because positive and adverse impacts of most resource uses (and protection) are felt locally and regionally. ${ }^{77}$ However, the law provides for this default position to shift if national interests emerge or become more prominent. ${ }^{78}$ Because subsidiarity is closely related to the question of who should make decisions (not just the values that should determine them) a fuller discussion is deferred later in this chapter under the decision-making principle.

The concept of inter-generational equity is much more prominent in existing law than intragenerational equity. ${ }^{79}$ It concerns the relative weight we place on the interests of current and future generations, providing that the latter should be safeguarded. It is a morally charged

\footnotetext{
${ }^{71}$ K Bosselmann "The Concept of Sustainable Development" in Bosselmann and others, above n 9, at 101.

${ }^{72}$ See RMA, ss 2, 7(c); Pigeon Bay Aquaculture Ltd v Canterbury Regional Council [1999] NZRMA 209 (EnvC); Wakatipu Environmental Society Inc v Queenstown Lakes District Council [2000] NZRMA 59 (EnvC); Meridian Energy Ltd v Central Otago District Council [2011] 1 NZLR 482 (HC).

${ }^{73}$ Biosecurity Act 1993, s 2.

${ }^{74}$ See RMA, s 3.

${ }^{75}$ For example, see RMA, pt 5.

${ }^{76}$ Compare A Arthur-Young "Climate Change" in Nolan, above n 25, at 1150.

${ }^{77}$ See RMA, ss 59-77; B Gussen "Subsidiarity as a Constitutional Principle in New Zealand" (2014) 12 NZJPIL 123.

${ }^{78}$ See RMA, ss 43-58A.

79 K Palmer "Origins and Guiding Ideas of Environmental Law" in Bosselmann and others, above n 9, at 16; RMA, s 5(2)(a); Conservation Act 1987, ss 2, 6(c); Local Government Act 2002, s 14(1)(h)(iii).
} 
obligation to future generations to act prudently, ${ }^{80}$ a direction not to consider cumulative, long-term effects as inconsequential, ${ }^{81}$ and an exhortation to live off the dividends of, rather than erode, our natural capital. ${ }^{82}$ Edith Brown Weiss in her seminal work has seen in this concept three key components: conserving the diversity of our resource base, maintaining the quality of our planet, and providing equitable access to our legacy. ${ }^{83}$ The market alone may not provide for the interests of future generations, because the economic actors within it may not act in the interests of those who are not yet born.

New Zealand's environmental law does not necessarily seek to provide equal weight to future interests. The RMA, for example, requires only that the reasonably foreseeable needs of future generations are met, not that they are accorded the same ability to provide for their well-being as present generations. ${ }^{84}$ As in international law, the "needs" of future generations is an amorphous concept and notoriously difficult to predict. ${ }^{85}$ Furthermore, while particular regard must be had to any finite characteristics of resources, this does not necessarily require their protection. ${ }^{86}$ In some cases, such as the rate of mineral extraction, the law effectively encourages resource use for the benefit of present generations. ${ }^{87}$

However, a central concern of the law is to ensure that future people are not deprived of the essential biophysical components of the environment that are necessary for life. ${ }^{88}$ Although two generations has been seen as a minimum time horizon for planners, this does not constrain the concept of the "future", which is to be determined according to the nature of the

\footnotetext{
${ }^{80}$ On the principle generally, see E Brown Weiss In Fairness to Future Generations (Tokyo, United Nations University Press, 1989); E Agius "Towards a Relational Theory of Inter-Generational Ethics" in S Busuttil and others (eds) Our Responsibilities to Future Generations (1990); Sands, above n 8, at 209.

${ }^{81}$ See G Winter "A Fundament and Two Pillars: The Concept of Sustainable Development 20 Years after the Brundtland Report" in HC Bugge and C Voigt (eds) Sustainable Development in International and National Law (Europe Law Publishing, Amsterdam, 2008) at 28.

${ }^{82}$ Bosselmann, above n 1 , at 34.

${ }^{83}$ E Brown Weiss "Intergenerational Justice and International Law" in Busuttil and others, above n 80, from 98.

${ }^{84}$ Section 5(2)(a).

${ }^{85}$ Bosselmann, above n 1, at 31. See generally R Treumann "Global Problems, Globalization and Predictability" (1991) 31 World Futures 14.

${ }^{86}$ RMA, s 7(g).

${ }^{87}$ RMA, s 5(2)(a); CMA, s 1 A.

${ }^{88}$ Compare Bosselmann, above n 1, at 98. See also B Norton "The Ignorance Argument" in Keller, above n 30 , from 534 .
} 
threat. ${ }^{89}$ Long-term, severe and irreparable environmental (including climate) damage is to be given significant weight. ${ }^{90}$

\section{Treaty of Waitangi Obligations}

The special place of Māori within New Zealand's ethical and legal frameworks influences the aims of its environmental law. ${ }^{91}$ One can perceive a general aim for law to be consistent with principles that have been recognised by Parliament and developed by the Courts as reflecting the spirit of the Treaty of Waitangi, even though its specific content is not itself directly enforceable in domestic law. ${ }^{92}$ These principles have "become part of the fabric of New Zealand law." ${ }^{93}$ Many are directly concerned with rights to use and manage natural resources, and most environmental statutes recognise them in some way. ${ }^{94}$ In all legislation, the Treaty must be considered as an aid to statutory interpretation. ${ }^{95}$ Treaty principles impact upon distributional questions (rights of Māori to use particular resources, and for their interests to be protected from others' uses), but are also concerned more generally with how the environment is managed. ${ }^{96}$

The principles themselves can be described broadly as follows: ${ }^{97}$ a duty on both Māori and the Crown to act reasonably and in good faith (including a duty to consult); ${ }^{98}$ the active protection of Māori interests by the Crown (a fiduciary duty, and to some extent including

\footnotetext{
${ }^{89}$ Canterbury Regional Council v Christchurch City Council EnvC Christchurch C217/2001, 6 December 2001 at [18].

90 Environmental Defence Soc Inc v Auckland Regional Council [2002] NZRMA 492 (EnvC) at [65]; New Zealand Coastal Policy Statement 2010, pol 24.

${ }^{91}$ On Māori world views, see U Klein "Belief-View on Nature" (2000) 4 NZJEL 81.

${ }^{92}$ See Treaty of Waitangi Act 1975, s 8; Ashby v Minister of Immigration [1981] 1 NZLR 222 (CA) at 224; B Gordon "Treaty of Waitangi and Māori Issues in Environmental Law" in Salmon and Grinlinton, above n 14, at 325; New Zealand Māori Council v Attorney-General [1994] 1 NZLR 513 (PC) at 515.

${ }^{93}$ Huakina Development Trust $v$ Waikato Valley Authority [1987] 2 NZLR 188 (HC) at 210.

${ }^{94}$ Treaty of Waitangi Act 1975, sch 1. For example, see RMA s 8; EEZ Act s 12, Conservation Act 1987 s 4 , CCRA, s 3A. See generally R Boast "The Treaty of Waitangi and Environmental Law" in R Harris (ed) Handbook of Environmental Law (Royal Forest and Bird Protection Society of New Zealand, Wellington, 2004) at 513 .

${ }^{95}$ Huakina, above n 93, at 210.

${ }^{96}$ See R Beverley "The Incorporation of the Principles of the Treaty of Waitangi into the Resource Management Act 1991" (1997) 1 NZJEL 125; P Majurey and C Whata "Maori and Environmental Law" in Nolan, above n 25.

${ }^{97}$ See generally Gordon, above $\mathrm{n}$ 92, at 328, 554-555; M Palmer The Treaty of Waitangi in New Zealand's Law and Constitution (Victoria University Press, Wellington, 2008); Carter Holt Harvey Ltd v Te Runanga o Tuwharetoa ki Kawerau [2003] 2 NZLR 349 (HC) at [27].

${ }^{98}$ Waitangi Tribunal Radio Spectrum Management and Development (Brookers, Wellington, 1999) at 38-39.
} 
interests in resources that could not be exploited at the time of signing) ${ }^{99}$ the making of informed decisions by the Crown; the remediation of past grievances; ${ }^{100}$ and the right of the Crown to govern by pursuing its policies in the interests of the whole community. ${ }^{101}$ The Waitangi Tribunal has also seen the basic principle as being one of reciprocity, where governance or sovereignty has been exchanged for rangitiratanga or control over resources. ${ }^{102}$ It is also worth bearing in mind the powerful words of Cooke $\mathrm{P}$ in the Lands case, to the effect that the principles are always evolving: they "should not be approached with the austerity of tabulated legalism". ${ }^{103}$

The principles of the Treaty, and the Māori values that they protect, do not necessarily shift the balance between resource use and protection in either direction. This is because the Treaty is as much about recognising Māori rights to use resources as it is about protecting the environment from use. ${ }^{104}$ For example, customary rights to continue traditional practices are protected despite general restrictions in the RMA. ${ }^{105}$ Rather than seeking to presuppose or codify a "protective" Māori environmental ethic, many regimes tend to shift decision making powers to Māori or enhance their participation, as part of a movement towards partnership in governance. $^{106}$ A local authority under the RMA may even elect to transfer resource management powers to iwi authorities, subject to certain criteria. ${ }^{107}$ Other specific statutes grant compensation or return control of particular resources to Māori via the granting of property or resource use rights, as a result of Treaty settlements. ${ }^{108}$ Some of these interact with general environmental laws like the RMA to address distributive issues, ${ }^{109}$ but it is difficult to discern general legal principles above the political desire to redress past wrongs.

\footnotetext{
${ }^{99}$ Waitangi Tribunal Te Maunga Railways Land Report (Brookers, Wellington, 1994) at 67-68.

${ }^{100}$ See Boast, above n 94, at 517.

${ }^{101}$ On their first detailed formulation, see New Zealand Māori Council v Attorney-General [1987] 1 NZLR 641 (CA) (Lands Case).

${ }^{102}$ Waitangi Tribunal The Ngai Tahu Report (Brookers, Wellington, 1991) at 236.

${ }^{103}$ Lands Case, above n 101, at 655; Mason-Riseborough v Matamata-Piako District Council EnvC Auckland A143/97, 11 December 1997 at 17.

${ }^{104}$ See Cook Island Community Centre Soc (HB) Inc v Hastings District Council (1993) 1B ELRNZ 205 (PT); Treaty Tribes Coalition v Urban Māori Authorities [1997] 1 NZLR 513 (PC) at 517; Majurey and Whata, above n 96, at 953.

${ }^{105}$ MCAA, s 52.

106 See MCAA ss 66-70; Conservation Act; s 6X(1A); CCRA, s 3A; RMA, s 36D; EEZ Act, s 59(3)(c); Helmbright v Environment Court [No 1] [2005] NZRMA 118; J Vince "Maori Consultation under the Resource Management Act and the 2005 Amendments" (2006) 10 NZJEL 295.

${ }^{107}$ RMA, s 33.

${ }^{108}$ For example, see Māori Fisheries Act 2004, preamble.

${ }^{109}$ For example, see RMA, s 165W.
} 
All settlements are different, and are a process of negotiation. ${ }^{110}$ RMA processes can be used as a tool to implement them, but not as an avenue to create them. ${ }^{111}$

Outside of specific distributional questions, the active protection of Māori values has had a protective flavour. ${ }^{112}$ This is because of the way in which such values have been expressed in statutes, because the Māori world view is closer to western eco-centrism, and because Māori thus far have been most prominent as submitters in opposition to developments. The RMA provides for, as a matter of national importance, the "relationship of Māori and their culture and traditions with their ancestral lands, water, sites, waahi tapu, and other taonga", 113 and requires decision makers to have particular regard to kaitiakitanga as a principle of wider environmental management. This protective concept of kaitiakitanga, akin to the idea of stewardship, has been described as "the overriding Māori environmental ethic". ${ }^{114}$ Moreover, the principles of the Treaty are to be taken into account in their own right under the RMA. ${ }^{115}$ Central to these are active protection, good faith consultation, a need for principles to adapt to changing times, mutual benefit, partnership and a right for Māori to manage resources consistently with tikanga. ${ }^{116}$ The Conservation Act recognises the Māori concept of a rahui, or ban, on the use of at risk resources. ${ }^{117}$ Furthermore, geographically-specific legislation implements protective Māori values to varying degrees, either in a way that integrates with or stands alongside more general legislative regimes. ${ }^{118}$ This includes an increasing use of cogovernance arrangements. ${ }^{119}$

Therefore, although the active protection of Māori values in environmental law is not absolute, ${ }^{120}$ it is a key aim. The Privy Council has observed that decision-makers, at least

\footnotetext{
${ }^{110}$ For examples, see Gordon, above n 92, at 377-385.

${ }^{111}$ See Boast, above n 94, at 515; Haddon v Auckland Regional Council [1994] NZRMA 49 (PT).

${ }^{112}$ See, for example, RMA, ss 6(e), 7(a), 58(b), 104(3)(c)(i).

${ }^{113}$ RMA, s 6. See Aqua King Ltd v Marlborough District Council EnvC Wellington W71/97, 30 June 1997.

${ }^{114}$ A Tunks "Tangata Whenua Ethics and Climate Change" [1997] 1 NZJEL 67 at 84. See the definition in s 2 of the RMA: "the exercise of guardianship by the tangata whenua of an area in accordance with tikanga Māori in relation to natural and physical resources; and includes the ethic of stewardship". See generally S Hayes "Defining Kaitikaitanga and the Resource Management Act 1991" (1998) 8 Auckland U L Rev 893.

115 Section 8

${ }^{116}$ See Carter Holt Harvey, above n 97, at [27].

117 Section 27A.

${ }^{118}$ For example, Waikato-Tainui Raupatu Claims (Waikato River) Settlement Act 2010.

${ }^{119}$ See Salmon and Grinlinton, above n 14, at 691, 380-381; RMA sch 11.

${ }^{120}$ See Community Centre, above n 104, at 212; McGuire v Hastings District Council [2000] UKPC 43, [2002] 2 NZLR 577 at [21]; see also Watercare Services Ltd v Minhinnick (1997) 3 ELRNZ 511 (CA) at 514.
} 
under the RMA, must have particular sensitivity to Māori issues, given that the law contains "strong directions" concerning them. ${ }^{121}$

\section{E The Public-interest Industries Principle}

The public-interest industries principle recognises that, where the use of resources delivers vital societal outcomes, we must recognise their importance and ensure they are delivered when making environmental decisions. It stands in contrast to the principles discussed above, which tend to promote the protection of resources from use (such as inter-generational equity), or are neutral (such as sustainability). Those are generally consistent with the laissezfaire tradition of New Zealand's environmental law, within which specific resource choices are not determined (only enabled). But the public-interest industries principle recognises that where a use is necessary to realise the public interest, the law should play a greater role in driving its deployment. ${ }^{122}$

The principle is manifested in the law in three key ways: mandating or incentivising the deployment of industries having publicly important outcomes (such as supporting mining, fishing, and renewable electricity, and requiring the provision of public infrastructure such as roads and sewerage systems by public authorities); ${ }^{123}$ in partly overcoming environmentally protective provisions in other legislation; ${ }^{124}$ and in ensuring activities occur in a way that achieves publicly important outcomes once they commence. ${ }^{125}$ These outcomes tend to be either economic or social, although some (such as the provision of parks, landfills and renewable electricity generation) may have an environmental flavour. The principle applies not only to public bodies, but also to private actors conducting activities that provide an element of public good (such as electricity transmission).

\footnotetext{
${ }^{121}$ McGuire, above n 120, at [21]; P Beverley "The Mechanisms for the Protection of Māori Interests under Part II of the Resource Management Act 1991" (1998) 2 NZJEL 121 at 123; K Keith "The Treaty of Waitangi in the Courts" (1990)1 4 NZULR 37 at 56.

${ }^{122}$ Compare K Palmer "The Sources and Institutions of Environmental Law" in Nolan, above n 25, at 43-44.

${ }^{123}$ CMA, s 1A; LGA, s11A; Fisheries Act 1996, s 8; New Zealand Recreational Fishing Council Inc v Sanford Ltd [2009] NZSC 54, [2009] 3 NZLR 438 at [39]; RMA, s 7(j); Land Transport Management Act 2003 (LTMA), s 95.

${ }^{124}$ In relation to mining, see RMA, s 5(1)(a). In relation to housing supply, see Housing Accords and Special Housing Areas Act 2013 (HASHA Act). In relation to designations for key infrastructure, see RMA, s 172.

${ }^{125}$ Gas Act 1992, ss 1A(a), 37, 43F, 45; Electricity Act 1992, ss 1A, 36; Electricity Industry Act 2010, ss 32(1), 42; Telecommunications Act 2001, ss 2, 70. See also Barton and others, above n 22, at 28, 95; JF Investments, above n 24, at [25].
} 
Because the principle is limited to resource use in particular sectors in which there is a high public interest, it tends to be expressed through resource-specific statutes rather than general effects-based regimes such as the RMA. This means that any new public-interest industries tend not to be caught by those statutes, and must be legislated for specifically. ${ }^{126}$ For those industries, a key question is whether there is sufficient public interest to warrant intervention, above and beyond their adverse effects, in a regulatory environment that usually relies on market-forces to provide the social benefits of resource use. Thus the statement of Barton and others that "it can be strongly argued that environmental legislation should not be used to regulate an industrial activity: the two are essentially different"127 can be accepted in the spirit in which it is offered - that general effects-based regimes like the RMA are concerned with the management of adverse impacts, not the regulation of specific industrial activities to ensure they achieve positive aims. ${ }^{128}$

The public-interest industries principle does not demand that such industries are to be nurtured at any environmental cost. It simply provides an incentive to make applications, a robust counterweight that may shift the balance towards resource use, ${ }^{129}$ and an impetus to ensure that activities successfully deliver publicly important outcomes once they are authorised.

\section{F The Conservation-enhancement Principle}

The conservation-enhancement principle provides that, in some scenarios, the protection of the environment from use should be accorded particularly strong and sometimes overriding weight. This is often in specific areas of high natural value, but includes coastal and marine areas more generally. It also emphasises that we should actively enhance our environment, including through the minimisation of waste.

A balance between resource use and environmental protection is not struck equally in all geographical areas. In some contexts (like national parks and other Crown-owned conservation estate) the principle of conservation requires that protection be emphasised more absolutely. In this sense, it responds to calls for the state to act as guardian of the

\footnotetext{
${ }^{126}$ Non-social housing supply is a recent example, which has been addressed through the HASHA Act.

127 Barton and others, above n 22, at 39.

${ }^{128}$ See Queenstown Central v Queenstown Lakes DC [2013] NZHC 815 at [79].

${ }^{129}$ See JF Investments, above n 24, at [25].
} 
ecological values of public areas under the public trust doctrine, and recognises that a public interest in the existence of wilderness areas is something other than an aggregation of private interests. ${ }^{130}$ The principle can also be observed in a less pronounced form outside these specific geographical areas. ${ }^{131}$ For example, some protections attach to specific animals rather than locations where they may live. ${ }^{132}$ The protection of the coastal marine area as a whole (and the intrinsic value of water, associated ecosystems, and natural character) is also emphasised comparatively strongly. ${ }^{133}$ The avoidance of local impacts on the coast is not absolute, and is partly to secure recreational and scientific usage, ${ }^{134}$ but protection is still valued very highly. ${ }^{135}$

In some contexts, the principle requires us to go further and improve the existing environment. ${ }^{136}$ This requires substantial investment and is therefore mainly achieved through the efforts of government agencies with public funding and statutory mandates. ${ }^{137}$ Private persons cannot generally be compelled to improve the environment unless it relates somehow to the adverse effects of that person's activity. ${ }^{138}$ That said, a general desire for enhancement can also be observed in aspirational statements contained in environmental legislation and associated planning instruments, even if they have no direct regulatory effect. $^{139}$

A pertinent example for this thesis is the general aspiration to reduce the generation and disposal of waste and pollution, particularly in the marine environment. ${ }^{140}$ This is more ambitious than responding to the adverse effects of waste/pollution once it occurs. "Waste" is

\footnotetext{
${ }^{130}$ See generally J Sax "The Public Trust Doctrine in Natural Resources Law" (1970) 68 Michigan Law Review 471; PH Sands "Sovereignty Bounded" (2004) 4 Global Envtl Pol 47.

${ }^{131}$ For example, see the Forests Act 1949, pt 3A.

${ }^{132}$ See P Wallace "Integrated Conservation Management" (2011) 15 NZJEL 185 at 191; Marine Mammals Protection Act 1978.

${ }^{133}$ For example, see RMA, ss 15A-15B, 38, 57(1), 60(1), 64(1), 64(3), 12, 3(a); New Zealand Coastal Policy Statement, pol 3. See D Nolan "The Coastal Environment" and P David "Marine Pollution" in Nolan, above n 25 , at $400-402,645-650$.

${ }^{134}$ See Marine Reserves Act 1971, s 3(2); Conservation Act, s 6; Nolan, above n 133, at 452-453.

${ }^{135}$ See generally New Zealand Rail Ltd v Marlborough District Council [1994] NZRMA 70 (HC); Trio Holdings Ltd v Marlborough District Council [1997] NZRMA 97 (PT); King Salmon, above n 13, at [21]-[45], [96].

${ }^{136}$ See Conservation Act 1987; National Parks Act 1980; Marine Reserves Act 1971, s 3(1); Sugar Loaf Islands Marine Protected Area Act 1991, ss 3-4; Hauraki Gulf Marine Park Act 2000, s 8. See generally See J Ruru "Managing our Treasured Home" (2004) 8 NZJEL 243; Harrison v Tasman District Council [1994] NZRMA 193 (PT); JF Investments, above n 24, at [28].

${ }^{137}$ For example, Conservation Act, s 6.

${ }^{138}$ See ch VIII.

${ }^{139}$ RMA ss 7(f), 45; New Zealand Coastal Policy Statement, pol 1.1.5.

${ }^{140}$ RMA, s 15A-15B; Waste Minimisation Act 2008 (WMA), s 3; EEZ Act, s 10(1)(b).
} 
conceived of broadly in New Zealand's legislation, and includes anything disposed of or discarded (essentially, abandoned). ${ }^{141}$ "Disposal" requires that a "waste" be deposited for the long-term in a place set apart for that purpose (or incinerated). ${ }^{142}$ The definition is therefore partly circular and there remains an inherent subjectivity in how we define waste (and terms like pollution) in any given case. ${ }^{143}$ We need only consider the example of animal effluent, which some may dispose of in landfill and others may treasure as a way to return nutrients to the soil. Storing carbon in trees would also not generally be seen as the disposal of a waste, but it could be. Such labels are not dependent on any defined attributes of a substance, but rather human attitudes towards it and its effects. ${ }^{144}$

\section{G The Principle of Precaution}

Because the future is inherently unknowable, the precautionary principle reminds us to err on the side of environmental protection where we face risk or uncertainty. It is important both when fact-finding (identifying risks) and making judgments (assessing and managing risks). Risk is a product of an effect's likelihood and magnitude, whereas uncertainty refers to the degree of understanding and information upon which an assessment of risk is based. ${ }^{145}$ At its most basic, precaution provides that where it is unclear whether an adverse effect will occur, that does not excuse a lack of action to address the effect. ${ }^{146}$ In layman's terms, it is better to be safe than sorry.

Precaution is central to New Zealand's environmental law. ${ }^{147}$ Many statutes are, in a sense, inherently precautionary, because they take an approach whereby risky activities cannot

\footnotetext{
${ }^{141}$ WMA, s 5; CCRA, s 4; Carter Holt Harvey v North Shore City Council [2007] NZCA 420, [2008] 1 NZLR 744 at 749.

${ }^{142}$ WMA, s 6; CCRA, s 4.

${ }^{143}$ See S Schofield "Waste Management Law in New Zealand" (2010) 14 NZJEL 223 from 226.

${ }^{144}$ See H Wagener "The Waste Minimisation Act 2008 and the Ability of Territorial Authorities to Manage Solid Waste" (2009) 13 NZJEL 295 at 328.

${ }^{145}$ Sometimes characterised as epistemic uncertainty (relating to knowledge and its degree of validation).

146 See UNFCCC, art 3.3: "Where there are threats of serious or irreversible damage, lack of full scientific certainty should not be used as a reason for postponing such measures ....". On precaution generally, see Bosselmann, above n 1, at 60; D Freestone "International Fisheries Law since Rio: The Continued Rise of the Precautionary Principle" in A Boyle and D Freestone (eds) International Law and Sustainable Development (OUP, Oxford, 1999) 135.

147 See A Gillespie "Precautionary New Zealand" (2011) 24 NZULR 364 at 365; G Severinsen "Letting our Standards Slip?" (2014) 18 NZJEL 173; C Iorns Magallanes and G Severinsen "Diving in the Deep End" (2015) 13 NZJPIL 201.
} 
occur unless expressly authorised. ${ }^{148}$ We do not wait to clean up the mess afterwards. But we can go further. Under New Zealand's take on precaution, identifying and managing risk require different approaches. Risk identification must be objective, evidence-based and scientifically (or at least factually) determined, often involving the close assessment of detailed evidence to assess uncertainties in information. ${ }^{149}$ Identifying what risks exist (what could happen) does not require overt normative or political judgments (what should happen). ${ }^{150}$

Different regimes take different approaches to risk identification. Some simply require ministers to take evidence-based decisions based on reasonableness and relevance. ${ }^{151}$ In other regimes, such as the RMA, some have sought to read in more specific legal criteria precautionary standards and evidential burdens of proof - for establishing risks. ${ }^{152}$ This "legalisation" of future fact-finding has proved controversial for a variety of reasons, and (rightly or wrongly) increasingly appears to be giving way to an approach whereby decisionmakers have a wide evaluative discretion to conclude whether, and what, risk exists. ${ }^{153}$ Either way, the main concern of the courts has been to prevent low probability risks being artificially excluded from consideration. Precaution can be observed elsewhere in the fact finding process; for example, an applicant generally bears responsibility for providing sufficient information (in an assessment of environmental effects) to allow a merits assessment to occur, ${ }^{154}$ and bears a tactical (rather than legal) burden to convince a decision maker to grant an authorisation. ${ }^{155}$

In contrast to the identification of risk, epistemic criteria can play little role in determining questions of risk assessment or management. Value judgments are needed to determine what should happen in response to the risks identified. ${ }^{156}$ Under several key statutes, these

\footnotetext{
${ }^{148}$ For example, see RMA, pt 3; Te Aroha Air Quality Protection Appeal Group v Waikato Regional Council (1993) 1A ELRNZ 399 (PT) at 409.

149 Shirley Primary School v Christchurch City Council [1999] NZRMA 66 (EnvC) at [136]; Long Bay-Okura Great Park Soc Inc v North Shore City Council EnvC Auckland A078/08, 16 July 2008 at [314].

${ }^{150}$ Severinsen, above n 147, at 196.

${ }^{151}$ Fisheries Act 1986, s 10(c).

${ }^{152}$ For example, see McIntyre v Christchurch City Council (1996) 2 ELRNZ 84 (PT) at 105-106.

153 Shirley, above n 149, at [136]; Director General of Conservation v Marlborough District Council EnvC Christchurch C113/2004, 17 August 2004 at [44].

${ }^{154}$ RMA, s 88, sch 4; Affco v Far North District Council (No 2) (1994) 1B ELRNZ 101 at 113-114.

155 G Severinsen "Bearing the Weight of the World" (2014) 26 NZULR 375 at 389; Warnock and BakerGalloway, above n 20, at 20.

${ }^{156}$ See J Forret "Scientific Evidence and Environmental Litigation in New Zealand" (1998) 2 NZJEL 39 at 60; Telecom v Christchurch City Council EnvC Wellington W165/96, 15 November 1996.
} 
judgements must specifically be informed by the need for precaution. ${ }^{157}$ Even under the RMA, which does not overtly refer to precaution, case law has built in fairly robust requirements to make decisions in a precautionary manner. ${ }^{158}$ This does not require the elimination of risk, ${ }^{159}$ but New Zealand's approach is fairly protective compared to international formulations. ${ }^{160}$ For example, while precautionary responses are proportionate to the probability and magnitude (including irreversibility and significance) of potential effects, ${ }^{161}$ there is no requirement that harm be serious, irreversible or likely. As a risk's probability and magnitude increase, so too does the action required become more robust (including, in extreme cases, the imposition of prohibited activity status). ${ }^{162}$ Whether remaining (unmitigated) risks are acceptable cannot be answered in the abstract; it depends largely on value-driven policies relating to the kinds of effects and locations in question. ${ }^{163}$ The magnitude of risk is determined by its significance to the things people value. For example, a high chance of a substantial effect on a resource we value very little would receive low weight compared to a low risk of an impact on a resource we value highly (such as the life-supporting capacity of the oceans or atmosphere).

It is also important to remember that the acceptability of risk may be considered in light of positive effects. Under an "overall judgement" approach, risks can be worth taking if an activity offers substantial countervailing benefits, and in some contexts, residual risks may also be managed through adaptive management conditions, rather than avoided altogether. ${ }^{164}$

\section{H From Substantive to Procedural Principles}

The principles discussed above guide, at a high level, where the balance between use and protection is to be struck. Seldom do they prescribe specific outcomes; they usually require more specific policy positions to be adopted to "operationalise" them. The law must facilitate

\footnotetext{
${ }^{157}$ EEZ Act, s 34(2); Fisheries Act 1996, s 10(c); Hazardous Substances and New Organisms Act 1996, s 7.

${ }^{158}$ Palmer, above n 79, at 17. See Coromandel Watchdog of Hauraki Inc v Ministry of Economic Development [2007] NZCA 473, [2008] 1 NZLR 562 (CA), at [30].

${ }^{159}$ Contact Energy Ltd v Manawatu-Wanganui Regional Council [2010] NZEnvC 406, [2011] NZRMA 155 at [71].

${ }^{160}$ Contrast UNFCCC, art 3; Offshore Petroleum and Greenhouse Gas Storage Act 2008 (Vic), s 61(2)(g).

${ }^{161}$ Gillespie, above n 147, at 373.

${ }^{162}$ For example, see Resource Management (Pollution Regulations) 1998, reg 4(1).

${ }^{163}$ Usually contained in plans and policy statements

164 See North Shore, above n 17, at 92-94; Sustain our Sounds Inc v New Zealand King Salmon Co [2014] NZSC 40, [2014] 1 NZLR 673.
} 
a process to allow that to happen. ${ }^{165}$ In New Zealand, we can observe a series of four procedural legal principles that guide how, when and by whom substantive principles are applied: the participatory principle, the decision making principle, the certainty-flexibility principle, and the efficiency principle.

\section{The Participatory Principle}

The participatory principle provides broadly that people should have the opportunity to be involved in environmental decision-making to the extent that they are affected. This means that rights to be involved are not absolute, but requirements for transparency, fairness, and access to information are more robust.

In New Zealand, public participation is a procedural cornerstone of environmental law ${ }^{166}$ and is related closely to broader notions of human rights, natural justice, and deliberative democracy. ${ }^{167}$ This does not mean that individual decisions are democratic, although decision-makers are often elected and the notified consenting process can be described as a way of "democratising expertise". ${ }^{168}$ The law generally aims for all relevant views to be considered, for choices to be informed by local knowledge, ${ }^{169}$ to provide catharsis for genuinely held values, ${ }^{170}$ and to ensure that a balance between use and protection reflects the wider values of communities. ${ }^{171}$ As Louka has observed more generally, "communityoriented participation discourses ... are an important means of defining and legitimizing local interests" $" 172$ and Barton and others have considered that robust participatory rights under the RMA "reflect a social consensus that goes back long before 1991 ". ${ }^{173}$ Wide participation is a

\footnotetext{
${ }^{165}$ See Young, above n 12, at 50.

${ }^{166}$ See generally Westfield (New Zealand) Ltd v North Shore City Council [2005] NZSC 17, [2005] NZRMA 337 at [25]; Waitakere City Council v Brunel [2007] NZRMA 235 (HC) at [56]-[58]; King Salmon, above n 13, at [15]; L Toomey "Public Participation in Resource Management" (2012) 16 NZJEL 117 at 120-121.

${ }^{167}$ Generally, see B Barton, "Underlying Concepts and Theoretical Issues in Public Participation in Resources Development" in D Zillman, A Lucas and G Pring (eds) Human Rights in Natural Resources Development (OUP, Oxford, 2002); JF Investments, above n 24, at [41].

168 FJ Coyle Tackling Climate Change (Cooperative Research Centre for Greenhouse Gas Technologies, Canberra, 2014) at 8; Central Plains Water Trust v Ngai Tahu Properties Ltd [2008] NZCA 71, [2008] NZRMA 200 (CA) at [57].

${ }^{169}$ Salmon, above n 60, at 6; Beverley, above n 121, at 131.

${ }^{170}$ Murray, $v$ Whakatane District Council [1997] NZRMA 433 at 467; Parliamentary Commissioner for the Environment (PCE) "Public Participation in Environmental Decision Making: Discussion paper" (Wellington, February 1996) at A15-16.

${ }^{171}$ See Watercare, above n 120, at 525.

${ }^{172}$ Louka, above n 12, at 18.

${ }^{173}$ Barton and others, above n 22, at 78.
} 
safeguard in a regime that can impact significantly on property rights, and in New Zealand can be seen as a backlash to the marginalisation of public involvement in "think-big" legislation of the early 1980 s. $^{174}$

In New Zealand the principle generally operates on the assumption that people can participate to the extent that their interests are affected (although what this means in practice can change over time). ${ }^{175}$ As such, broad participatory rights are particularly noticeable when producing plans, policy statements and regulations under the RMA and EEZ Act (and plans under the Local Government Act 2002) where objectives, policies, rules/regulations and other provisions can affect a wide range of people. ${ }^{176}$ Under the RMA there is provision for public notification, a right to make submissions, and a chance to appeal on the merits of decisions (with some restrictions). ${ }^{177}$ Participation is more constrained at the project (consenting) stage, because a narrower range of people may be affected. For example, applications can be limited notified (to those directly affected) or non-notified under the RMA depending on the extent of potential effects. ${ }^{178}$ Full public involvement is generally warranted even at the project stage where effects on the environment are more than minor, recognising that the environment is a shared resource in which wider society has an interest. ${ }^{179}$

However, participation is not an absolute principle. ${ }^{180}$ If a submission is frivolous, vexatious or discloses no reasonable case, it can be struck out. ${ }^{181}$ Moreover, although a degree of advance consultation is required for rules and policies of general application, ${ }^{182}$ the law generally imposes no duty on an applicant to consult prior to the lodgement of a specific consent application. ${ }^{183}$ The vast majority of consent applications remain non-notified, ${ }^{184}$ and some rights have been eroded in recent times. ${ }^{185}$ In addition, the law seeks to avoid excessive

\footnotetext{
${ }^{174}$ See Palmer, above n 24.

175 See Sheppard, above n 46, at 226.

${ }^{176}$ Ibid at 225; Barton, above n 167, at 101; RMA, sch 1; LGA, s 93A.

${ }^{177}$ RMA, sch 1.

${ }^{178}$ RMA, ss 95-95B; EEZ Act, s 29D. See generally T Daya Winterbottom "The Role of Administrative Law" in Salmon and Grinlinton, above n 14, at 226-227; Discount Brands Ltd v Westfield (New Zealand) Ltd [2005] NZSC 17, [2005] 2 NZLR 597.

${ }^{179}$ RMA, s 95A(2).

${ }^{180}$ See PCE, above n 176; A Brower "The ECan Act, Parliamentary Sovereignty and Environmental Law" (2010) 8 BRMB 144.

${ }^{181}$ RMA, s 41C(7).

${ }^{182}$ RMA, sch 1, cls 3-3A.

${ }^{183}$ RMA, s 36A.

${ }^{184}$ Grinlinton, above n 9, at 41; Ministry for the Environment Resource Management Act: Survey of Local Authorities 2010/2011 (2011) at 16; D Young Keeper of the Long View (PCE, Wellington, 2007) at 66.

${ }^{185}$ C Whata "Environmental Rights in Times of Crisis" [2013] RM Theory \& Practice 42; RMA, pt 6A.
} 
duplication of opportunities for participation. For example, public involvement in the national policy statement (NPS) process is complemented by the power to bypass further participation when an NPS is being translated into lower level instruments. ${ }^{186}$ Participatory rights are less robust where the purpose of legislation is to achieve a narrow outcome already deemed to be in the public interest (such as the protection of conservation areas or the exploitation of minerals). ${ }^{187}$ Hearings and appeals are seen to be more important in regimes such as the RMA that seek to balance a multiplicity of interests and values (including property rights).

Additional participatory rights are generally accorded to Māori. ${ }^{188}$ In many contexts, Māori are treated more as partners in governance and rangatira (chiefs/leaders) than a sector of the public. ${ }^{189}$ For example, in preparing RMA plans, councils are obliged to consult (in addition to ministers of the Crown and other local authorities) iwi authorities and customary marine title groups. ${ }^{190}$ Regional coastal plans specifically must be prepared by a regional council in consultation with Māori. ${ }^{191}$ Similarly, iwi authorities are the only organisations from which the Minister for the Environment must seek comment prior to preparing an NPS. ${ }^{192}$ Many other provisions recognise the special status of Māori. ${ }^{193}$ This does not mean that Māori interests will trump others, only that Māori involvement is an important end in its own right. ${ }^{194}$

Related to participatory rights are rights concerning access to information, fair judicial process, and transparency. ${ }^{195}$ Such procedural rights are often spoken of in the same breath as environmental justice. ${ }^{196}$ In New Zealand, most information concerning environmental decision-making is subject to official information legislation, ${ }^{197}$ reporting on key indicators is

\footnotetext{
${ }^{186}$ RMA, s 55.

${ }^{187}$ See CMA, s 18(3)-(4); Conservation Act, ss 17F-17G.

${ }_{188}$ Beverley, above n 121, at 129-130; Mason-Riseborough, above n 103, at 18.

189 Beverley, above n 121, at 131. See also M Palmer The Treaty of Waitangi in New Zealand's Law and Constitution (Victoria University Press, Wellington, 2008).

${ }^{190}$ RMA, sch 1, cl 3.

${ }^{191}$ RMA, sch 1, cl 2.

192 RMA, s 46(a).

${ }^{193}$ EEZ Act, s 18; CCRA, s 3A; CMA, s 17(1)(b); Greenpeace v Minister of Energy [2012] NZHC 1422.

${ }^{194}$ Beverley, above n 121, at 133; Wellington International Airport Ltd $v$ Air New Zealand [1993] 1 NZLR 671 (CA) at 675.

${ }^{195}$ See Elias CJ, above n 17, at 2-3. Compare Alberta Government Carbon Capture and Storage: Summary Report of the Regulatory Framework Assessment (Energy Alberta, Edmonton, 2013) at 53.

${ }^{196}$ Salmon, above n 60, at 2.

197 Official Information Act 1982; Local Government Official Information and Meetings Act 1987; Daya Winterbottom, above n 178, at 212.
} 
mandatory, ${ }^{198}$ and rights of appeal (at least on points of law) exist for many environmental decisions. ${ }^{199}$ Judicial review is also available when appeal rights are not. ${ }^{200}$

\section{J The Decision-making Principle}

The decision-making principle is concerned with the question of who makes decisions on environmental matters. ${ }^{201}$ Generally speaking, it provides that decisions on high level norms should be made by politically accountable decision-makers, with more emphasis on independence where norms are being applied to particular projects. Decisions should also be made by those who represent the relevant community of interest (those most affected).

When making decisions, political, judicial and technical actors can bring with them different values and varying degrees of independence. ${ }^{202}$ So can local, regional and national ones. The question of who makes decisions is therefore partly a "procedural" expression of the subsidiarity principle described earlier in this chapter (whose values should determine a decision). In New Zealand, different kinds of decision-makers are used in different contexts, leveraging off their respective attributes while mitigating their risks. For example, political decision-making is capable of distorting facts and playing on fears more than scientific or judicial decision-making. ${ }^{203}$ There is a risk that politicians fail to "deliberate about ... interests", and respond "mechanically to constituent pressures". ${ }^{204}$ Yet, on the other hand, epistemology, scientists and judges have no particular moral claim to tell us what we should do, and are less accountable to communities for their choices. ${ }^{205}$ History has shown us that there can be a vast chasm between scientific rationality and environmental wisdom. ${ }^{206}$

In New Zealand there is no dogmatic adherence to democratic, scientific or judicial processes, nor complete reliance on local, regional or national decision makers. Overall, we

\footnotetext{
${ }^{198}$ Environmental Reporting Act 2015.

199 RMA, s 120, sch 1. On these kinds of issues more generally, see R Macrory and M Woods Modernising Environmental Justice (UCL, 2003).

${ }^{200}$ Judicature Amendment Act 1972. See K Palmer "The Sources and Institutions of Environmental Law" Nolan, above n 25, at 52-53.

${ }^{201}$ See generally Salmon and Grinlinton, above n 14, chs 9-10.

${ }^{202}$ Salmon, above n 60, at 5 .

203 Although on the "myth of objectivity" in science, see Forret, above n 161, at 48; B Evar "Conditional Inevitability" (2011) 39 Energy Policy 3414 at 3417.

${ }^{204}$ M Sagoff The Economy of the Earth (1988) in R L Revesz Foundations of Environmental Law and Policy (OUP, New York, 1997) at 22.

${ }^{205}$ Keller, above n 30, at 379.

${ }^{206}$ Bosselmann, above n 1, at 16.
} 
observe that broadly applicable rules/regulations and policies are informed by democratically-determined values (that is, decided by elected and accountable politicians). This recognises that the generation of norms, in instruments like regional/district plans, is ultimately an expression of community discourse rather than expert assessment. As Louka has observed, "most decisions on environmental matters have to be made based on political considerations". ${ }^{207}$ Such values are also determined according to the concept of subsidiarity: decisions are devolved to those representing the relevant community of interest (be it local, regional or national). ${ }^{208}$ Thus, legislation under which normative matters are decided centrally (such as the EEZ Act, Conservation Act 1987 and Climate Change Response Act 2002) can be explained as addressing a national (or global) community of interest in oceans, conservation areas, and the climate. ${ }^{209}$ The RMA, which addresses a wider range of environmental issues, provides for political decision-making power at the planning level to shift as the relevant community of interest changes. ${ }^{210}$ The Act contains a statutory presumption in favour of devolved decision making at first instance (district and regional councils are tasked with producing plans), ${ }^{211}$ but the power to determine communities of interest ultimately resides with central government. It can choose to promulgate national direction (to which effect must be given in regional and district planning instruments) ${ }^{212}$ and intervene in local planning processes. $^{213}$ Furthermore, rights of appeal exist to the Environment Court on the merits of local and regional (but not national) planning decisions, which can override normative choices by local government even where a community of interest is local. ${ }^{214}$ This judicial supervision of value-laden planning decisions, which goes further than the judiciary's usual function of interpreting and applying the law and resolving disputes, ${ }^{215}$ can be seen as central to the operation of the Act. ${ }^{216}$ In essence, the law recognises that national interests should not be defeated by the defence of local interests, and that central and judicial oversight is more important than unfettered local democracy. ${ }^{217}$ It is

\footnotetext{
${ }^{207}$ Louka, above n 12, at 19.

${ }^{208}$ Bramley, above n 23, at 398.

${ }^{209}$ Others include fisheries, forestry, and biosecurity: see Bramley, above n 23, at 398.

${ }^{210}$ See RMA, pt 6A, ss 43-58A.

${ }^{211}$ RMA, ss 63-77. The Minister of Conservation has final decision-making power on regional coastal plans.

${ }^{212}$ RMA, ss 62(3), 67(3), 75(3).

${ }^{213}$ RMA, s 25A.

${ }^{214}$ RMA, sch 1, cl 27; Forest and Bird, above n 17, at [45]-[46].

${ }^{215}$ See Canterbury Regional Council v Apple Fields Ltd [2003] NZRMA 508 (HC).

${ }^{216}$ See I Carlman "The Resource Management Act 1991 through External Eyes" (2007) 11 NZJEL 181 at $203-$ 204; J McLean "New Zealand's Resource Management Act 1991: Process with Purpose?" (1992) 7 Otago LR 538.

${ }^{217}$ For criticism of this feature, see Ministry for the Environment Improving our Resource Management System (MfE, Wellington, 2013) at 13.
} 
overly simplistic to claim that New Zealand's resource management system is defined by decentralisation.

A desire for greater (although not absolute) ${ }^{218}$ political independence, through judicial and expert decision-making, is noticeable at the project (consenting) level. This stage is more about objectively (as far as possible) applying a balance of politically-determined norms in context, rather than generating new norms. Value judgments and discretion remain (including the "overall judgment" under the RMA, which persists in resource consenting even after the Supreme Court judgment in King Salmon), ${ }^{219}$ but they do not seek to alter the overall normative environment. For example, the RMA and EEZ Act provide for the EPA, Environment Court, boards of inquiry, independent commissioners and requiring authorities to have roles in deciding consents and notices of requirement. All these bodies are apolitical and operate at a distance from central and local government, but are still required to assign weight to the norms in existing planning instruments.

The concept of subsidiarity can be seen equally at the project level, in that even independent decision-makers tend to reflect the relevant community of interest. For example, the national level EPA is charged with making consenting decisions under the EEZ Act, while independent commissioners under the RMA are generally selected by the relevant council. Requiring authorities represent concerns that transcend those of local communities. ${ }^{220}$ However, again, central government has power to determine what the relevant community of interest $i s$. It can choose to "call in" proposals of national significance under the RMA to remove decision-making power from local government, in favour of decision by a board of inquiry or the Environment Court. ${ }^{221}$ As in the planning context, rights of appeal exist to the Environment Court on the merits of many consenting and designation decisions. ${ }^{222}$

Some legislation grants Māori the power to make legally-binding decisions. This is particularly noticeable in relation to water and coastal resources. ${ }^{223}$ For example, holders of

\footnotetext{
${ }^{218}$ For example, elected councils and ministers make various permitting decisions under the RMA and other acts.

${ }^{219}$ King Salmon, above n 13; Genesis, North Shore, and KPF, above n 17. Compare Gisborne District Council v Eldamos Investments Ltd HC Gisborne CIV-2005-485-1241, 26 October 2005 at [42].

${ }^{220}$ See generally M Casey "Land Use" in Salmon and Grinlinton, above n 14, at 635-636.

${ }^{221}$ RMA, pt 6AA.

${ }^{222}$ RMA, ss $120,174$.

${ }^{223}$ For example, see Waikato-Tainui Raupatu Claims (Waikato River) Settlement Act 2010.
} 
customary marine title recognised under the Marine and Coastal Area (Takutai Moana) Act 2011 are given the power to grant RMA "permission rights" within a title area, without which an activity requiring a coastal permit cannot proceed. ${ }^{224}$ In most cases, these powers remain subject to at least some considerations of the wider public interest. ${ }^{225}$ Such powers may to some extent erode legal certainty, transparency, and scientific rationality in favour of cultural discretion, but this is seen to be justified to recognise an important and separate Māori community of interest that exists alongside - rather than below - national and local communities.

\section{K The Certainty-flexibility Principle}

The certainty-flexibility principle recognises that environmental decision-making requires both certainty and flexibility for users. Clarity as to the meaning and applicability of law is vitally important, but rules need not (and should not) be prescriptive where decisions require close contextual assessment. Predictability can be provided by clear policy guidance, not just rules. Regulators should have the ability to alter authorisations to protect the environment, but they should not be able to derogate from one grant in favour of alternative uses.

Most fundamentally, New Zealand law aims to minimise uncertainty as to the meaning of legal provisions themselves. Conditions of specific authorisations should be clear, understandable, and enforceable. ${ }^{226}$ On the other hand, absolute certainty as to legal outcomes is not possible where discretionary decisions must respond to infinitely variable contexts. A degree of flexibility is needed for both regulators and those conducting activities to respond to changing environmental and commercial circumstances. Regulators generally have substantial flexibility to change regulatory and policy provisions, whether for the purpose of protecting or using resources. For example, central government can simply choose to implement national direction under the RMA as long as it complies with the purpose of the Act and administrative law. At the regional and local levels, councils can also introduce, remove or change rules and policies, although this is subject to a more involved appeal

\footnotetext{
${ }^{224}$ MCAA, s 68; see also N Tomas "Māori Land Law: The Marine and Coastal Area (Takutai Moana) Act 2011" [2011] NZ L Rev 381.

${ }^{225}$ MCAA, ss 64-65.

${ }^{226}$ Ferguson v Far North District Council [1999] NZRMA 238 at 246; J Raz The Authority of Law (2 ${ }^{\text {nd }}$ ed, OUP, Oxford, 2009) at 222.
} 
process and change is constrained by the content of instruments higher in the planning hierarchy. ${ }^{227}$

Regulations and policies can be specific or general. This determines how certain or flexible the outcomes of particular applications are. Regulations that are detailed, prescriptive or proscriptive (such as permitted and prohibited activity rules), and policies that are highly targeted and directive ("rule-like" policies), ${ }^{228}$ predetermine outcomes and provide greater certainty. They are used in New Zealand, ${ }^{229}$ but more noticeable is the use of discretion to apply policy guidance to the context of particular applications. ${ }^{230}$ Arguably the RMA is about "dialogue rather than dictat". ${ }^{231}$ Generally, regulation is prescriptive/proscriptive only where there is a high degree of community consensus over the values at stake, ${ }^{232}$ where specific geographical context is not particularly important, ${ }^{233}$ or where it would be inefficient to relitigate the same value questions repeatedly at the project level. ${ }^{234}$ Such certainty is desirable where possible. But as the values involved become more balanced, so too does the law recognise the need for increased discretion through contextualisation and bespoke conditions. Targeted policy provisions are desirable to guide discretion and provide a degree of predictability. $^{235}$

Regulators also enjoy flexibility to alter specific authorisations (such as resource consents), but only where necessary to protect the environment from adverse effects. For example, consent authorities have the ability to impose review conditions, require renewals, or remove rights for non-compliance. ${ }^{236}$ A general duty to avoid, remedy and mitigate adverse effects applies to all persons, even consent-holders. ${ }^{237}$ Conditions can also build in flexibility by referring to general requirements that may change over time (such as "best practicable option"). ${ }^{238}$

\footnotetext{
${ }^{227}$ RMA, ss 65, 67(3).

${ }^{228}$ See A Aarnio "Taking Rules Seriously" (1990) 42 ARSP 180.

${ }^{229}$ See King Salmon, above n 13, at [106]-[148].

${ }^{230}$ Young, above n 12, at 59.

${ }^{231}$ Ibid at 90.

${ }^{232}$ For example, a wide prohibition on marine dumping.

${ }^{233}$ Such as climate change.

${ }^{234}$ For example, radiation issues from telecommunications facilities.

${ }^{235}$ Louka, above n 12, at 66; Young, above n 12, at 58.

${ }^{236}$ RMA, ss 108, 128, pt 12.

${ }^{237}$ RMA, s 17.

${ }^{238}$ For example, RMA, s 138A(2).
} 
However, regulators do not generally have the flexibility to alter, frustrate or erode existing authorisations for the purposes of re-allocating resource rights to others. This is usually referred to as non-derogation. ${ }^{239}$ It recognises that specific grants confer valuable rights to use resources, which are arguably akin to proprietary rights and upon which private investment relies, and should not be derogated from. ${ }^{240}$ It can also be understood through a public law lens as a form of substantive legitimate expectation. ${ }^{241}$ Either way, we observe that because the market generally determines the use to which resources are put under New Zealand's take on the distributive principle, the law then protects those market choices.

Resource users have some, but generally less, flexibility to alter the terms of their own authorisation. This provides assurance to the public that activities' adverse environmental effects will remain acceptable. For example, an applicant can apply to vary the conditions of resource consent, but this requires a process much the same as applying for a new consent (including participatory requirements where relevant). ${ }^{242}$ However, the use of management plans for complex projects is now common, and conditions may allow such plans to be amended without formal variation procedures if they are capable of certification according to clear and objective standards. ${ }^{243}$ Adaptive management conditions can also be used, enabling proposals to proceed that may otherwise not have received consent. ${ }^{244}$ Moreover, requiring authorities (who make decisions on resource uses having substantial public benefit) enjoy greater powers to alter the conditions of their own designations. ${ }^{245}$

\section{The Efficiency Principle}

Running through New Zealand's environmental law is a desire for efficiency, both in terms of administrative process and the efficient use of resources. ${ }^{246}$ As Louka has observed, it is

\footnotetext{
${ }^{239}$ See Aoraki Water Trust v Meridian Energy Ltd [2005] 2 NZLR 268 (HC) at [36]; Dart River Safaris Ltd v Kemp [2000] NZRMA 440 (HC) at [27]; Southern Alps Air v Queenstown Lakes District Council [2008] NZRMA 47 (HC).

${ }^{240}$ See D Grinlinton "The Nature of Property Rights in Resource Consents" (2007) 7 BRMB 37; L Fraser "Property Rights in Environmental Management" (2008) 12 NZJEL 145.

${ }^{241}$ See B Barton "The Nature of Resource Consents" in Environmental Law: National Issues Intensive (NZLS, 2009) at 54.

${ }^{242}$ RMA, s 127(3).

${ }^{243}$ Mount Field Ltd v Queenstown Lakes District Council [2012] NZENVC 262, [76]-[83]; Board of Inquiry decision on applications for designation and resource consents by the New Zealand Transport Agency for the Mackays to Peka Peka Expressway, Final Report Volume 2: Conditions, conditions DC.7A, DC.9.

${ }^{244}$ Sustain our Sounds, above n 164.

${ }^{245}$ RMA, s 181.

${ }^{246}$ RMA, s 7(b) RMA; Hudspith, above n 32, at 284.
} 
"hard to characterize an excessively wasteful system as effective". ${ }^{247}$ The concern can be seen generally in provisions seeking to streamline decision-making processes in the RMA, ${ }^{248}$ and in the integration of decision-making in the Act (compared to previously fragmented legislation). ${ }^{249}$ Efficiency is a matter to which particular regard must be had under the RMA, and the use of comparable units of measurement is encouraged where possible. ${ }^{250}$ Planning evaluations and an applicant's assessments of environmental effects are not required to be perfect or exhaustive. ${ }^{251}$ The cost and effort incurred must generally match the scale and significance of relevant effects. ${ }^{252}$ For example, when considering applications for consent under the EEZ Act the EPA must base decisions on the best information available without unreasonable cost, effort or time. ${ }^{253}$

However, efficiency is not the primary concern of New Zealand's environmental law. It generally gives way to the public interest that exists in having robust environmental controls, as well as bending to the inevitable costs of public participation. Decisions are not reduced to cost-benefit analyses in the strict economic sense, ${ }^{254}$ and efficiency is only one matter to which particular regard must be had under the RMA. ${ }^{255}$ Moreover, efficiency is not the same as cost-reduction. An efficient approach simply compares the cost of inputs with the value of outputs, and is therefore inextricably linked to the broader, anthropocentric, value we choose to place on environmental outcomes. ${ }^{256}$ A costly system can still be an efficient one.

\section{Conclusion}

In this chapter I have identified 10 broad principles of New Zealand's existing environmental law, and their key features:

\footnotetext{
${ }^{247}$ Louka, above n 12, at 65.

${ }^{248}$ Resource Management (Simplifying and Streamlining) Amendment Act 2009; RMA, s 80, pts 6A, 7A; Central Plains Water Trust v Synlait Ltd [2009] NZCA 609, [2010] 2 NZLR 363.

${ }^{249}$ Young, above n 12, at 15; Warnock and Baker-Galloway, above n 20, at 16.

${ }^{250}$ RMA, s 32(2)(b); M Christensen "Valuation of Natural Assets under the Resource Management Act" (2013) 17 NZJEL 291 at 294.

${ }^{251}$ RMA, s 32, sch 4.

${ }^{252}$ RMA, sch 4, cl 2(3)(c), s 32(1)(c); EEZ Act, s 39(2).

${ }^{253}$ EEZ Act, s 61(5).

${ }^{254}$ Meridian Energy Ltd v Central Otago District Council HC Dunedin CIV-2009-412-000980,16 August 2010 at [107]; Geotherm Group Ltd v Waikato Regional Council EnvC Auckland A151/06, 19 November 2006 at [48]; Christensen, above n 250, at 292.

${ }^{255}$ RMA, ss 7(b) and s 32. See also Pickford, above n 38, at 152; Lower Waitaki, above n 39, at [201].

${ }^{256}$ Christensen, above n 250, at 293, 303; JR Jackson "The Role of Economics in the RMA" (1999) 3 NZJEL 19 at 32.
} 
- the sustainability principle;

- the distributive principle;

- Treaty obligations;

- the public-interest industries principle;

- the conservation-enhancement principle;

- the precautionary principle;

- the participatory principle;

- the decision making principle;

- the certainty-flexibility principle; and

- the efficiency principle.

A number of concepts have been discussed within each. Unfortunately, we have no metaprinciple to unify these principles, and law reform for marine CCS must therefore operate within a highly pluralist regime. One commentator has aptly described the RMA as a "confusion of market, conservation and Māori perspectives within a formal regulatory regime." ${ }^{257}$ Nonetheless, the principles provide a workable foundation for law reform, and define a fairly stable field within which environmental decisions can be regarded as ethically defensible in a New Zealand context. A pictorial summary of the relationship between these principles is represented in Figure 4 below.

${ }^{257}$ J Kelsey The New Zealand Experiment - A World Model for Structural Adjustment? (Auckland University Press, Auckland, 1995) at 110. 
Figure 4: The Relationship between New Zealand's core Environmental Legal Principles

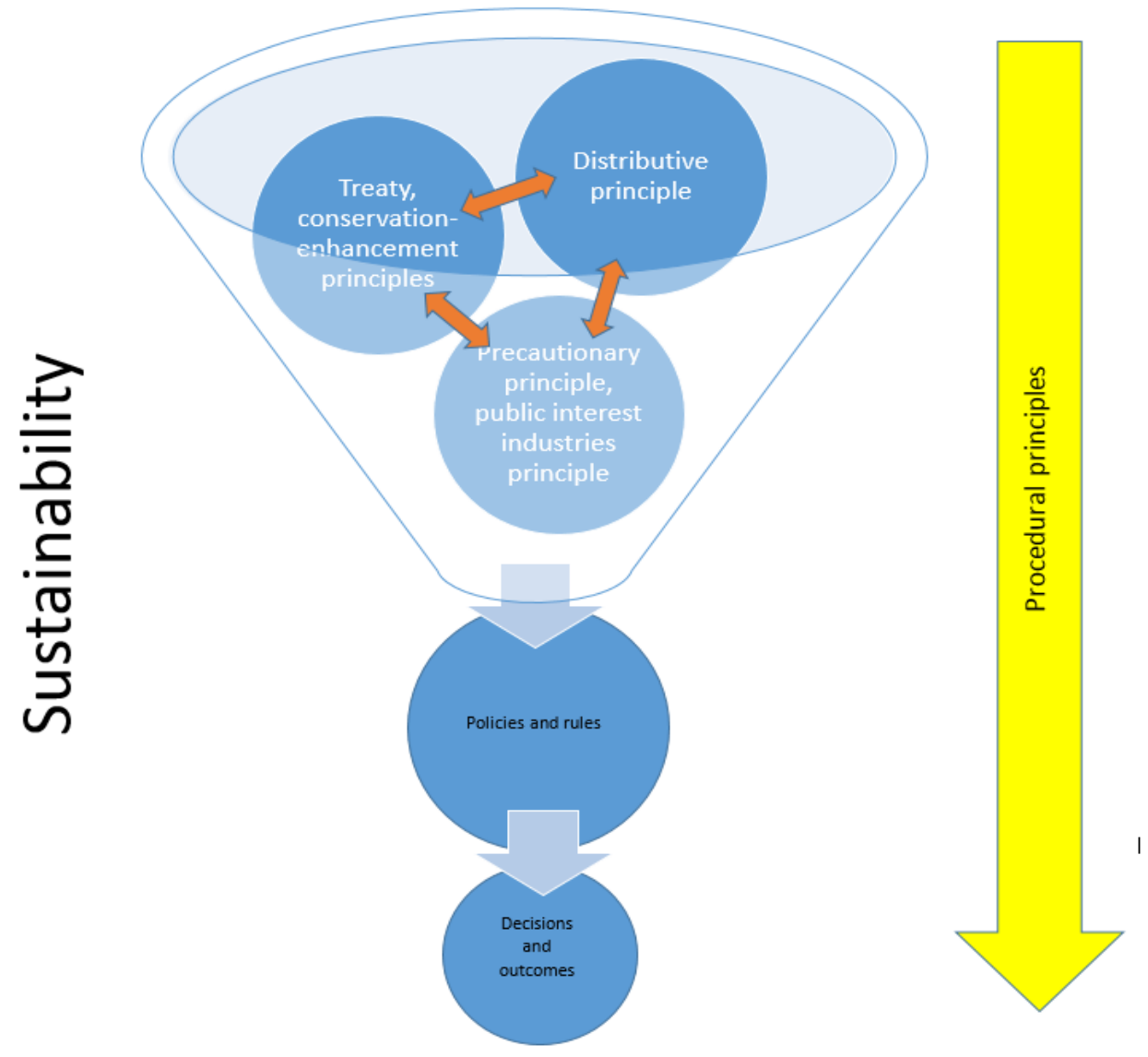


IV

\section{Translating Principles to Marine CCS}

\section{A Introduction}

In this chapter I translate the principles identified in the previous chapter to marine CCS, in order to generate specific aims for regulating the technology. ${ }^{1}$ It is an important step, because we cannot assume that existing laws perfectly reflect legal principles when applied to a new technology. How we frame the aims of CCS law - positively or negatively - is also crucial in shaping project level decisions and public perception. ${ }^{2}$ The latter may be based on misinformation and thus is not itself an appropriate guide for law reform. ${ }^{3}$

Like all environmental laws, the ultimate task of CCS law is to strike an ethical balance between resource use and environmental protection, by placing value on the interests of various groups in accordance with legal principle. Most principles can be translated to CCS fairly easily. However, aspects of some are not as obvious, ${ }^{4}$ and it is on these that $\mathrm{I}$ focus in this chapter.

\footnotetext{
${ }^{1}$ Compare the "contextual drivers" discussed in IEA Carbon Capture and Storage Model Regulatory Framework (IEA, Paris, 2010) at 22.

${ }^{2} \mathrm{M}$ Gerstenberger and others Opportunities for Underground Geological Storage of $\mathrm{CO}_{2}$ in New Zealand: Risk Assessment Methodologies (GNS Science, Report CCS 08/10 2009/63, 2009) at 33; See S McCoy Carbon Capture and Storage: Legal and Regulatory Review ( $4^{\text {th }}$ ed, IEA/OECD, Paris, 2014) at 11.

${ }^{3}$ Gerstenberger and others, above $\mathrm{n} 2$, at 31 .

${ }^{4}$ See MJ Mace, C Hendriks and R Coenraads "Regulatory Challenges to the Implementation of Carbon Capture and Geological Storage within the European Union under EU and International Law" (2007) 1 International Journal of Greenhouse Gas Control 253 at 254.
} 
It is essential that CCS be conducted sustainably. ${ }^{5}$ It is fairly simple to apply most of the principle's features: for example, decisions should be integrated, holistic, and effects-based. However, one aspect of sustainability is more difficult: whether CCS itself amounts to a resource use or a protective measure. Most environmental debates tend to be framed as a dichotomous tension between the socio-economic benefits of use and the environmental benefits of protection. ${ }^{6}$ In contrast, CCS can be seen as an activity that uses resources (storage formations as receptacles for $\mathrm{CO}_{2}$ ) or a measure intended to protect the global atmosphere from climate change. It could both sustain the life-supporting capacity of air while at the same time threatening the life-supporting capacity of the seabed. ${ }^{7}$

Ultimately, we need to recognise that sustainability is not that simplistic. An activity can be both exploitative and protective, providing protection through use. ${ }^{8}$ More common examples are wind farms and the re-forestation of land (which have climate benefits, but also environmental costs). We do not only balance economy with environment; we must also balance different aspects of environmental well-being. ${ }^{9}$ In itself, this conclusion is not earthshattering. It is recognised in the wide definition of "environment" and "effect" in the RMA. But it highlights that the key question is actually distributive: which aspects of the environment we value more highly.

\section{The Distributive Principle}

The distributive principle tells us how to assign relative weight to various interests within the broad parameters of sustainability. It tells us not only which, but also whose, interests are to

\footnotetext{
${ }^{5}$ See, for example, Greenhouse Gas Geological Sequestration Act 2008 (Vic) (GGGSA), ss 7(a)-(d), 8; Offshore Petroleum and Greenhouse Gas Storage Act 2010 (Vic) (OPGGSA(Vic)), s 61; C Hendriks, MJ Mace and R Coenraads Impacts of EU and International Law on the Implementation of Carbon Capture and Geological Storage in the European Union (European Commission, 2005) at 2.

${ }^{6}$ B Armstrong "Time for a More Eco-Centric Approach to Resource Management in New Zealand" (2014) August RMJ 7 at 14.

${ }^{7}$ See similar difficulties in applying the Biodoversity Convention to marine CCS: Mace and others, above $\mathrm{n} 4$, at 135 .

${ }^{8}$ See Canterbury Regional Council v Selwyn District Council (1996) 2 ELRNZ 395 (EnvC) at 407.

${ }^{9}$ For example, renewable energy development also is a resource use, but is one that has environmental benefit: see I Boisvert "Lifting the Looking Glass" (2011) 15 NZJEL 1 at 39.
} 
be valued more or less. ${ }^{10}$ Without knowing whose interests we value more, other principles (such as sustainability and precaution) fail to formulate clear aims for CCS. Overall, I contend that the distributive principle (and the more specific concepts within it) demand that the law place substantial weight on the beneficial global, atmospheric and future effects of marine CCS.

New Zealand's laissez-faire take on distributional equity and environmental justice means that particular groups in present day society need not necessarily be specifically shielded from the costs of, or granted disproportionate benefits from, an operation. ${ }^{11}$ In practice, particularly vulnerable groups may be shielded on a case by case basis if adverse effects are substantial; impacts on Māori cultural interests should also be specifically protected (discussed below under Treaty principles).

The concept of common but differentiated responsibility - in the context of climate change is more directive. It favours a generally receptive regulatory environment for a technology that could in part address New Zealand's responsibility for historical emissions and reflect its relative capability to respond. ${ }^{12}$ We cannot simply claim that global impacts of carbon emissions are "not our problem". ${ }^{13}$ Furthermore, the principle of anthropocentric valuation demands that positive and adverse effects are valued according to human perceptions of their significance. It does not prevent us emphasising adverse impacts on the environment that do not directly affect humans (such as the existence value of nature), but only if we choose to value those aspects. In the context of CCS, this suggests that the prevention of adverse effects on the climate should be valued more highly than the prevention of changes to the deep subsurface. When anthropocentrically valued, physical and chemical changes to the deep subseabed are not, in themselves, "adverse" at all, unless they pose risks to subsurface resources we value (like petroleum or potable water) or the surface environment (impacts of leakage on

\footnotetext{
${ }^{10}$ C Clarke "Long-Term Liability for CCS: Some Thoughts About Specific Risks, Multiple Regimes and the EU Directive" in I Havercroft, R Macrory and RB Stewart (eds) Carbon Capture and Storage: Emerging Legal and Regulatory Issues (2011, Hart, Oxford) at 180.

${ }_{11}^{11}$ Contrast OPGGSA(Vic), s 61(2)(b); GGGSA(Vic), s 8(b).

${ }^{12}$ See generally P Ekanayake, P Moriarty and D Honnery "Equity and Energy in Global Solutions to Climate Change" (2015) 26 Energy for Sustainable Development 72; B Barton, K Jordan and G Severinsen Carbon Capture and Storage: Designing the Legal and Regulatory Framework for New Zealand (University of Waikato Centre for Environmental, Resources and Energy Law, Hamilton, 2013) at 16, 24.

${ }^{13}$ BJ Doody, JS Becker and FJ Coyle What should we do about $\mathrm{CO}_{2}$ ? (GNS Science, Report 2012/27, 2012) at 50-51.
} 
the biosphere or atmosphere). That is where most debate has centred internationally. ${ }^{14}$ Barton has recognised this, in suggesting that subsurface change per se is not the kind of concern underlying the RMA unless it interferes with freshwater or surface features. ${ }^{15}$ Thus the law should not presume that the sub-seabed injection of $\mathrm{CO}_{2}$ for storage is an environmentally harmful activity.

The polluter/user-pays principle suggests that we should seek to internalise the environmental costs of CCS to those creating pollution or using resources. For reasons explained further below, injection itself should not be seen as "pollution", but it is the use of a subsurface resource. As a resource user, an injector could be expected to bear responsibility for a project's success and its effects. ${ }^{16}$ That said, under the beneficiary-pays principle, ${ }^{17}$ its broader costs (such as risks to the local environment) can also justifiably be spread more widely across a society that has an interest in its success. ${ }^{18}$ Storage has important climate benefits for New Zealand society as a whole, not just financial benefits for an injector.

Under the concept of subsidiarity, the risks of storage may also justifiably be spread disproportionately across society. This is because the community of interest in CCS is national, in that the benefits it provides (as with activities like electricity generation) are national. ${ }^{19}$ Moreover, there is a strong national interest in managing the adverse effects of offshore activities, reflected in the active role of central government in this space. ${ }^{20}$ The law recognises that a national community of interest should not always be defeated by the defence of local interests, and should be given substantial weight. ${ }^{21}$ Relying on regionally and locallyspecific approaches to regulation would undermine investment certainty, potentially produce unintended and confusing distinctions in terminology and application, and take variable

\footnotetext{
${ }^{14}$ Ibid at 38-39, 57.

${ }^{15}$ B Barton "Carbon Capture and Storage Law for New Zealand: A Comparative Study" (2009) 13 NZJEL 1 at 33.

${ }^{16}$ A Ingelson, A Kleffner and N Nielson "Long-term Liability for Carbon Capture and Storage in Depleted North American Oil and Gas Reservoirs" (2010) 31 Energy Law Journal 431 at 465; See also E Wilson, A Klass and S Bergan "Assessing a Liability Regime for Carbon Capture and Storage" (2009) 1 EGYPRO 4575 at 4581.

${ }^{17}$ See Ingelson and others, above n 16, at 466; Mace and others, above n 4, at 45.

${ }^{18}$ See World Resources Institute (WRI) CCS Guidelines (WRI, Washington, DC, 2008) at 80.

19 See New Zealand CCS Partnership CCS in New Zealand: Can Carbon Capture and Storage Deliver Value to New Zealand as we Head towards a Low Carbon Future? Summary Report (NZ CCS Partnership, 2011) at 15; Between a Rock and a Hard Place (Commonwealth of Australia, Canberra, 2007) at 99.

${ }^{20}$ For example, see RMA, ss 57(1), 64(3), 117.

${ }^{21}$ Meridian Energy Ltd v Wellington City Council EnvC Wellington W31/07, 14 May 2007 at [456]-[459].
} 
amounts of time to implement. ${ }^{22}$ In contrast, once injection has occurred, national and local interests in preventing leakage align, and tensions are less noticeable.

The existence of a national community of interest in CCS, and the need for weight to be given to its long-term benefits, is supported by the concept of inter-generational equity. The science concerning climate change is now sufficiently certain for us to conclude that climate measures are necessary to protect the basic interests of future people. ${ }^{23}$ The Environment Court has described climate change as a phenomenon that engages the idea of intergenerational equity: an "insidious threat that scientists tell us threatens to improperly deprive future generations of their ability to meet their needs". ${ }^{24}$ The concept suggests, therefore, that the basic survival and dignity of future generations should at least be capable of a higher valuation than the present. That means not only that storage should be seen in a positive regulatory light, but also that there must be robust safeguards to prevent long-term leakage.

Under the distributive principle as a whole, we are effectively asking three questions about how we allocate relative value to environmental effects: between local and global impacts, between sub-surface and atmospheric impacts, and between present and long-term impacts. ${ }^{25}$ It tells us that, when making decisions on CCS, global, atmospheric and future effects should be assigned substantial (although not always overriding) value compared to its local, subsurface and short-term effects. ${ }^{26}$ Chris Clarke has captured a similar idea in simpler terms, in his assertion that storage, while having risks, is contributing to a "greater" good. ${ }^{27}$

\section{Treaty of Waitangi Obligations}

Arguably the principles of the Treaty of Waitangi do not demand a particular blanket normative treatment of CCS, only the close involvement of, and advance consultation with,

\footnotetext{
${ }^{22}$ Barton and others, above n 12 , at 36 .

${ }^{23}$ K Bosselmann The Principle of Sustainability: Transforming Law and Governance (Ashgate, Aldershot, 2008) at 10.

${ }^{24}$ Genesis Power Ltd v Franklin District Council [2005] NZRMA 541 (EnvC) at [224]. On the adverse impacts of climate change on the future environment and people, see A Baghaki "The Inequitable Connections between Environmental Degradation, Climate Change and Poverty" (2014) 18 NZJEL 1; compare Royal Society of New Zealand Climate Change Implications for New Zealand (2016).

${ }^{25}$ Reflected also in the views of Ingelson and others, above n 16, at 465.

${ }^{26}$ Grinlinton's valid concerns over the relative lack of weight given to cumulative local landscape impacts of wind farms is much less of a concern for marine CCS. See D Grinlinton "Property Rights, the 'Public Interest' and Global Considerations" (2007) 7 BRMB 62.

${ }^{27}$ Clarke, above n 10, at 186.
} 
Māori in the decision-making process and monitoring programmes. ${ }^{28}$ Māori rights of governance, and rights to make decisions, should not be removed unless essential to the wider public good.

Where substantive Māori values have been emphasised in environmental legislation, they tend to focus on the protection of local aspects of the environment with cultural value. For example, comparatively high value has been accorded to the protection of taonga, waahi tapu, ${ }^{29}$ and ancestral Māori relationships with the environment. ${ }^{30}$ These are not protected absolutely, but the principle of active protection suggests that the law should take a much more restrictive approach to storage, and require the consideration of alternatives, ${ }^{31}$ to the extent that risks affect local Māori interests.

Where Māori do not have significant interests in particular areas, Treaty principles do not demand that CCS be approached in a negative way or presuppose that Māori decision-makers will do so. Many Māori values are intertwined with intangible or spiritual relationships (whanaunga) with the environment, ${ }^{32}$ which have been described as an intricate and interconnected web with foundations in a complex cosmology of familial celestial relationships. ${ }^{33}$ The law must provide "an ungrudging response" to such Māori values as they evolve. ${ }^{34}$ But how they apply to modern contexts is not always clear, and they can adapt to new technologies in novel ways. ${ }^{35}$ The legal treatment of storage under Treaty principles will therefore depend on how it is perceived culturally and spiritually by Māori under tikanga. For example, if it is seen as a form of pollution, by its very nature it may be seen as threatening the relationship of Māori with the natural environment. ${ }^{36}$ If it is seen instead as a "green"

\footnotetext{
${ }^{28}$ See V Toki "Treaty of Waitangi Issues in Respect of Carbon Capture and Storage" in Barton and others, above n 12, at 378; Haddon v Auckland Regional Council [1994] NZRMA 49 (PT); B Gordon "Treaty of Waitangi and Māori Issues in Environmental Law" in P Salmon and D Grinlinton (eds) Environmental Law in New Zealand (Thomson Reuters, Wellington, 2015) at 349.

${ }^{29}$ On waahi tapu, see Winstone Aggregates Ltd v Franklin District Council EnvC Auckland A080/02, 17 April 2002.

${ }^{30}$ See RMA, s 6(e); Toki, above n 28, at 378.

${ }^{31}$ See McGuire v Hastings District Council [2000] UKPC 43, [2002] 2 NZLR 577 at [21]; Te Runanga O Taumarere v Northland Regional Council (1996) 2 ELRNZ 41 (PT) at 61.

${ }^{32}$ See Friends and Community of Ngawha Inc v Minister of Corrections [2002] NZRMA 401 (HC), [2003] NZRMA 272 (CA); Bleakley v Environmental Risk Management Authority [2001] 3 NZLR 213 (HC); Gordon, above $\mathrm{n} 28$, at 331 .

${ }^{33}$ See A Tunks "Tangata Whenua Ethics and Climate Change" [1997] 1 NZJEL 67 at 71, from 73.

${ }^{34}$ Helmbright v Environment Court [2005] NZRMA 118 (HC) at [25].

${ }^{35}$ Gordon, above n 28, at 328. For example, radio waves have been seen as a taonga rather than a form of pollution, even though they amount to a "contaminant" under s 2 of the RMA.

${ }^{36}$ Some have suggested that storage is an activity that fundamentally conflicts with tikanga "in that it, for instance, seeks to alter the tapu nature of the whenua": see Toki, above n 28, at 378.
} 
technology that enhances the status of Māori as kaitiaki, it may be seen as the opposite. ${ }^{37}$ Little evidence exists as to what Māori perceptions of storage may be, and there may be no suitable analogies in historic cultural practice. ${ }^{38}$ The situation is not as straightforward as others on which the courts have pronounced. ${ }^{39}$ Different kaitiaki may also have different views.

It is at least arguable that kaitiakitanga supports the principle of inter-generational equity, which in turn supports a positive normative treatment of storage. Valmaine Toki has seen storage as fundamentally inconsistent with tikanga and thus the principle of active protection, ${ }^{40}$ but it is telling that she has also recognised the potential for $\mathrm{CO}_{2}$ itself to move outside the realms of "waste" and be seen instead as a taonga to be treasured. ${ }^{41}$ Even if it is considered as a waste, from a national perspective it could arguably be seen as a way to be responsible for our own waste as kaitiaki. ${ }^{42}$ Finally, it is worth reiterating that the application of Treaty principles does not prevent the Crown governing in the broader public interest, with which CCS is imbued. ${ }^{43}$

A positive narrative is further supported by Māori views on anthropogenic climate change, which adversely impacts on spiritual entities responsible for maintaining the lower heavens, exposes the Earth mother Papatuanuku to harm, and depletes the Earth's mauri (life force). ${ }^{44}$ Bio-energy CCS (BECCS) is a way to remove these already dangerous emissions from the atmosphere. Playing a part in global climate action also accords with the Māori view of the environment as holistic and interconnected. ${ }^{45}$

\footnotetext{
${ }^{37}$ Doody and others, above n 13 , at 50 .

${ }^{38}$ As the High Court has stated, "it is only kaitiaki who can tell the Court what they consider kaitiakitanga requires": see Ngawha, above n 32, at [70].

${ }^{39}$ For example, it was reasonably clear in Te Runanga O Taumarere v Northland Regional Council (1996) 2 ELRNZ 41 (PT) that a proposed sewage outfall would itself be culturally adverse.

${ }^{40}$ See Toki, above n 28, at 378 .

${ }^{41}$ Ibid at $374,379$.

42 FJ Coyle Tackling Climate Change (Cooperative Research Centre for Greenhouse Gas Technologies, Canberra, 2014) at 70-71, 107.

${ }^{43}$ See ch III.

${ }^{44}$ See Tunks, above n 33, at 77-81.

45 A Tunks "One Indigenous Vision for Sustainable Development Law" in K Bosselmann, D Grinlinton and P Taylor (eds) Environmental Law for a Sustainable Society $\left(2^{\text {nd }}\right.$ ed, New Zealand Centre for Environmental Law, Auckland, 2013) at 126.
} 


\section{E The Public-interest Industries Principle}

I contend that CCS is an industry in which there is substantial public interest. The law should therefore play an active role in ensuring its purpose, secure storage, is achieved. I argue that this should not come at the expense of support for longer-term solutions to the climate problem, and the public interest should guide the resolution of conflict between CCS and other activities.

The core challenge in translating the public-interest industries principle to private CCS operations is determining whether the technology is sufficiently affected with a public interest to warrant intervention. ${ }^{46}$ Most examples of public-interest industries in New Zealand law provide social or economic benefits (such as mining, telecommunications, or energy) rather than environmental benefits. ${ }^{47}$ But environmental outcomes are equally imbued with a public interest - they have just traditionally been achieved by imposing broad statutory obligations on public authorities rather than on private persons, or by preventing human activities so the natural world can be left to regenerate itself..$^{48}$ In fact, there is a strong case that CCS is a public-interest industry, because of the urgency and extent of climate change, where a balance between resource use and protection must give way to more directive approaches. ${ }^{49}$ Storage offers one way in which real gains can be made; a power plant equipped with capture technology emits a significant 80-90 percent less $\mathrm{CO}_{2}$ than one without it. ${ }^{50}$ It offers mitigation across a wide range of emitting industries. ${ }^{51}$

The literature is replete with references to CCS as being beneficial, urgent, and in the public interest. $^{52}$ This includes the findings of the IPCC in its most recent assessment report, ${ }^{53}$ and

\footnotetext{
${ }^{46}$ See M Sagoff The Economy of the Earth in R L Revesz Foundations of Environmental Law and Policy (OUP, New York, 1997) at xx.

${ }^{47}$ For example, see Crown Minerals Act 1991 (CMA), s 1A; Minerals Programme for Petroleum (2013) at 7.

${ }^{48}$ For example, see Conservation Act 1987, s 6, pt 3B.

49 See Bosselmann, above n 23, at 77. On the value of regulatory intervention for infrastructure projects achieving climate outcomes, see S Nolan "Facilitating Infrastructure Development" (2012) RM Theory\&Practice 97.

${ }^{50}$ IPCC Carbon Capture and Storage (Cambridge University Press, New York, 2005) at 4.

${ }^{51}$ Such as electricity generation (coal, oil and gas), steel, cement, and chemical production: GCCSI The Global Status of CCS: 2015 Summary Report (GCCSI, Melbourne, 2015) at 3.

${ }^{52}$ See I Havercroft and R Purdy "Carbon Capture and Storage - A Legal Perspective" <www.un.org> at [1]; Barton, above $\mathrm{n} \mathrm{15}$, at 36; M Lewis and $\mathrm{N}$ Westaway "Public Participation in UK CCS Planning and Consent Processes" in Havercroft and others, above n 10, at 277; GCCSI The Global Status of CCS: 2014 (GCCSI, Melbourne, 2014), at 20; IEA Technology Roadmap: Carbon Capture and Storage (IEA, Paris, 2013) at 1; Parliamentary Advisory Group on CCS Lowest Cost Decarbonsation for the UK (2016) at 4.

${ }^{53}$ For a summary of these, see Bellona Brief: IPCC $5^{\text {th }}$ Climate Assessment Report (2015).
} 
the policy material underpinning many countries' approaches to regulation. ${ }^{54}$ The International Energy Agency, for one, has stated that storage is a public good. ${ }^{55}$ It is a sentiment shared by Barton and others in the context of removing impediments to terrestrial CCS, who have drawn comparisons with ports, roads and electricity distribution. ${ }^{56}$ Even many environmental groups perceive storage positively, as a necessary, albeit regrettable, measure. ${ }^{57}$ Studies have shown that, generally, public support also increases as people's understanding of the technology's actual benefits and risks improves. ${ }^{58}$ As an activity imbued with a high degree of public interest, the law plays a legitimate role in ensuring that storage is effective. $^{59}$ Jurisdictions active in regulating CCS have recognised this, imposing specific provisions targeted at the achievement of secure storage (the prevention of leakage). ${ }^{60}$

It is worth dwelling on this finding for a moment. An aim of preventing leakage is a much more stringent normative position than under existing legislation concerning the climate, where emitters must simply pay for emissions. ${ }^{61}$ This disconnect in aims can be justified on several grounds. First, in some cases leakage should be prevented because it poses risks to the local marine environment that are not posed by sources that emit directly to the atmosphere. ${ }^{62}$ Secondly, even if local risks were de minimis, taking a more lenient approach to leakage would undermine the carbon market under the emissions trading scheme, where credits are granted on the basis that $\mathrm{CO}_{2}$ is sequestered permanently. ${ }^{63} \mathrm{We}$ could, admittedly, simply oblige an injector to pay for leakage (surrender units), but accurate measurements in a vast sub-surface storage site would be much more challenging than measuring point source emissions. Moreover, if a corporate injector ceased to exist, no one would be responsible for $\mathrm{CO}_{2}$ discharged from a leaking storage site. This would be inconsistent with the polluter-pays principle, and suggests that prevention must be a core normative concern from the site selection stage.

\footnotetext{
${ }^{54}$ See UK Department of Energy and Climate Change CCS Roadmap (2012) at 13; European Commission Energy Roadmap 2050 (EU, Luxembourg, 2012) at 8.

${ }^{55}$ IEA, above $\mathrm{n} 1$, at 35 .

${ }^{56}$ Barton and others, above n 12, at 95. Compare Ingelson and others, above n 16, at 463-465.

${ }^{57}$ International ENGO Network on CCS Environmental Non-Government Organisation Perspectives on Carbon Capture and Storage (GCCSI, 2012) at 3; C Smith An Insight into why Environmental Groups Support CCS (2014). Contrast Greenpeace False Hope: Why Carbon Capture and Storage won't Save the Climate (Greenpeace International, Amsterdam, 2008).

${ }^{58}$ See Gerstenberger and others, above n 2, at 31.

${ }^{59}$ See Barton and others, above n 12, at 64; Directive 2009/31/EC on the Geological Storage of Carbon Dioxide [2009] OJ L140/114 (CCS Directive), art 1; WRI, above n 18, at 83.

${ }^{60}$ For example, Victoria, Queensland, and the Australian Commonwealth. See ch VIII; IEA, above n 1, at 54.

${ }^{61}$ Climate Change Response Act 2002, s 3.

${ }^{62}$ See ch I.

${ }^{63}$ See chs 6 and 8.
} 
Thirdly, it is more important, on public interest grounds, to take a strict approach to leakage than conventional emissions. This is because, once $\mathrm{CO}_{2}$ is sequestered, the substantial cost and effort of injection has already been incurred. This would be an inefficient use of resources, if leakage occurred. It may even be practically impossible to return large volumes of $\mathrm{CO}_{2}$ to the subsurface once released. Costs are likely to have already been passed on to a class of consumers broad enough to represent the "public" (those consuming goods produced by carbon-intensive industries). ${ }^{64}$ Furthermore, a substantial amount of extra $\mathrm{CO}_{2}$ may have been produced to generate the energy required for the capture process; allowing this to leak may mean a storage project actually contributes to the problem it was designed to solve. ${ }^{65}$ Suitable offshore geological formations, potentially rare, are also "public" resources, and the public has an interest in seeing them used to achieve public good outcomes.

In recognising that marine CCS is affected with a substantial public interest, we cannot ignore the relative public interest in other industries with which it may conflict. If storage became substantially cheaper than the cost of atmospheric emissions, it may incentivise capture at the expense of other climate change mitigation measures, and encourage the utilisation of fossil fuels rather than the development of renewable energy. ${ }^{66}$ While this is largely a question of policy rather than legal principle, some observations can be made. CCS has important co-benefits that strict emission reductions do not. It enables the gradual phasing out of carbon-intensive resource uses that remain socially and economically important in the short-term, ${ }^{67}$ the efficient utilisation of existing industrial infrastructure (such as petroleum mining facilities), ${ }^{68}$ and the continuation of important industries in which carbon-neutral processes are not yet available. ${ }^{69}$ It also has wider climate benefits than renewable electricity generation, because it can be applied outside the stationary energy sector. ${ }^{70}$ This is key in New Zealand, where renewables are already dominant. In fact, it is forecast to be the only effective measure that will enable the transition to carbon-neutrality in industries like steel,

\footnotetext{
${ }^{64}$ See IPCC, above n 50, at 10. Compare Machinery Movers Ltd v Auckland Regional Council (1993) 1A ELRNZ 411 (HC) at 416.

${ }^{65} \mathrm{P}$ Zakkour Choices for Regulating $\mathrm{CO}_{2}$ Capture and Storage in the EU (European Commission, Amsterdam, 2007) at 2.

${ }^{66} \mathrm{~N}$ Bankes "Developing a Legal Regime for Carbon Capture and Storage in Canada" (ISEE Research Paper, December 2009) at 2; L Smith "Carbon Capture and Storage" in Key Issues for the New Parliament 2010 (House of Commons Library Research) at 100.

${ }^{67}$ See Havercroft and Purdy, above n 52, at 13. IPCC, above n 50, at 67.

${ }^{68}$ D Langlet "Safe Return to the Underground?" (2009) 18 RECIEL 286 at 288.

${ }^{69}$ See ch I; IEA Technology Roadmap: Carbon Capture and Storage (IEA, Paris, 2013) at 8.

${ }^{70}$ GCCSI, above n 51, at 3.
} 
iron and cement. ${ }^{71}$ Representative concentration pathways (models used by the IPCC in forecasting climate change scenarios) ${ }^{72}$ assume geological storage is used, with most of these relying on fast and widespread deployment (including the use of BECCS). ${ }^{73}$

In the short-term CCS has substantial value as a public-interest industry. But we must not overstate the importance of storage as a long-term solution. To do so would neither be sustainable nor serve the public interest. ${ }^{74}$ Even in the global context, the International Energy Agency has suggested that storage should account for roughly 14 percent of emissions reductions, ${ }^{75}$ while renewable generation and end use energy efficiency combined should account for a much larger 68 percent. ${ }^{76}$ The IPCC has echoed this feeling, considering CCS to be part of a portfolio of mitigation measures (responsible for 15-55 percent of total reductions). ${ }^{77}$ In the long-term, clean technologies and changing social expectations around energy consumption are crucial, ${ }^{78}$ and the spirit of inter-generational equity does not support the use of permanent technological band aids. ${ }^{79} \mathrm{We}$ must emphasise that storage is a "bridging" technology rather than a quick or permanent fix,${ }^{80}$ but at the same time ensure it is not disadvantaged in the short term as part of a wider, agile, portfolio of climate measures. ${ }^{81}$

CCS may also conflict in a more tangible sense with petroleum operations (see chapter I). Petroleum mining is currently treated as having a substantial public interest. ${ }^{82}$ Preferences

71 GCCSI, above n 52, at 25; IEA Energy Technology Perspectives (IEA, Paris, 2014) at 50; European Commission Report on Review of Directive 2009/31/EC on the Geological Storage of Carbon Dioxide (Brussels, 2015) at 3; ENGO Network, above n 57, at 3; Royal Society of New Zealand Transition to a Low Carbon Economy for New Zealand (2016) at 127.

${ }^{72}$ See IPCC "Summary for Policymakers" in Climate Change 2013: The Physical Science Basis (IPCC, Geneva, 2013 ) at 29.

${ }^{73}$ IPCC Synthesis Report: Fifth Assessment Report of the IPCC (IPCC, Geneva, 2014) at 28; IPCC "Summary for Policymakers" in Climate Change 2014: Mitigation of Climate Change (IPCC, Geneva, 2013) at 532-533, from 753; Royal Society, above $\mathrm{n} 71$, at 83.

74 IPCC, above n 50, ch 5; C Armeni, 'Carbon Capture and Storage in the Sub-Seabed and Sustainable Development: Please Mind the Gap' (2013) 27 Ocean Yearbook 1 at 15.

${ }^{75} \mathrm{McCoy}$, above n 2, at 4.

${ }^{76}$ Ibid.

${ }^{77}$ IPCC, above n 50, at 3, 353 .

${ }^{78}$ See Ekanayake and others, above n 12, at 78.

${ }^{79}$ Mace and others, above n 4, at 42; Coyle, above n 42, at 69; Doody and others, above n 13, at 58.

${ }^{80}$ CCS Directive, preamble at (4); IPCC, above n 50, at 257; R Purdy "The Legal Implications of Carbon Capture and Storage Under the Sea" (2006) Sustainable Development Law \& Policy 22 at 22; P Marston and P Moore "From EOR to CCS" (2008) 29 Energy Law Journal 421 at 432; I Havercroft and R Macrory "Pulling the Threads Together" in Havercroft and others, above n 10, at 297.

${ }^{81}$ IPCC, above n 50, at 67; CCS Directive, preamble at (4); NZCCS Partnership, above n 19, at 15. See also Lewis and Westaway, above n 52, at 286-287; B Praetorious and K Schumacher "Greenouse Gas Mitigation in a Carbon Constrained World" (2009) 37 Energy Policy 5081 at 5091-5092.

${ }^{82}$ See CMA, s 1 A. 
between CCS and mining are largely ones of policy, but inter-generational equity suggests that the former should not be disadvantaged. The key normative driver must, however, be an assessment of the public interest in the context of a particular conflict. Moreover, the publicinterest industries principle suggests that mutually compatible operations should be facilitated, and that a highly risk-averse approach be taken to secure storage once injection has commenced.

We would do well to remember that the normative drivers of CCS and mining are very different, ${ }^{83}$ despite some close technical similarities (see chapter I). ${ }^{84}$ Similarities arise by chance rather than design. ${ }^{85}$ Most fundamentally, CCS aims primarily for climate benefits from injection ${ }^{86}$ whereas mining aims for economic outcomes from extraction ${ }^{87}$ and may, eventually, contribute to the climate problems that storage seeks to address. Pure enhanced petroleum recovery usually aims to minimise the volumes of $\mathrm{CO}_{2}$ stored. ${ }^{88}$ Extractive regimes are also less concerned with how geological structures are connected, because preventing leakage is not a priority. ${ }^{89}$ Thus simply because the law may already provide for extraction to be successful does not mean it is adequate to realise the climate aims of storage. ${ }^{90}$ Some jurisdictions have declined to recognise this normative and practical disconnect, continuing to regulate storage as a branch of petroleum or energy laws. ${ }^{91}$ Others have embraced a distinction. ${ }^{92}$

Similarly, it is important that the aims of CCS not be conflated with the aims of the emitting industries from which $\mathrm{CO}_{2}$ is captured. The public interest in CCS is in its ability to mitigate

\footnotetext{
${ }^{83}$ See Barton and others, above n 12, at 150. See also NETL Carbon Dioxide Enhanced Oil Recovery (2010) at 18; A Regulatory Framework for the Long-term Underground Geological Storage of Carbon Dioxide in Victoria (Victoria Department of Primary Industries, Melbourne, 2008) at 11.

${ }^{84}$ GCCSI, above n 52; IPCC, above n 50, at 259; Havercroft and others, above n 10, at 10; Barton, above n 15 , at 24 ; Doody and others, above $\mathrm{n} 13$, at 18 .

${ }^{85}$ For example, operations can occur in saline aquifers that do not have any association with petroleum. See GCCSI, above n 52, at 12; NZCCS Partnership, above n 19, at 6; M Gibbs "The Regulation of Geological Storage of Greenhouse Gases in Australia" in Havercroft and others, above n 10, at 165.

${ }^{86}$ IEA, above $\mathrm{n} 1$, at 35 .

87 Alberta Government Carbon Capture and Storage: Summary Report of the Regulatory Framework Assessment (Energy Alberta, Edmonton, 2013) at 8; Barton, above n 15, at 26; IEA, above n 1, at 35.

${ }^{88}$ IEA, above n 1, at 114; see also WRI, above n 18, at 93-94; N Bankes, J Poschwatta and EM Shier "The Legal Framework for Carbon Capture and Storage in Alberta" (2008) 45 Alta L Rev 585 at 594.

${ }^{89}$ Havercroft and others, above n 10, at 10.

${ }^{90}$ Barton and others, above $\mathrm{n} 12$, at 50 .

91 See Mines and Minerals Act 2000 (Alb), ss 114-124; Oil and Gas Conservation Act 2000 (Alb); OPGGSA(Cth); HC Bugge "An Overview of CCS Law and Regulation in Norway" in Barton and others, above n 12, at 342; Parliament of the Commonwealth of Australia Offshore Petroleum Amendment (Greenhouse Gas Storage) Bill 2008: Revised Explanatory Memorandum (2008), Attachment A, at 8-10.

${ }^{92}$ For example, in Victoria under the GGGSA(Vic).
} 
climate harm, ${ }^{93}$ not to perpetuate other forms of harm that could result from the continuation of specific emitting activities. For example, in many other jurisdictions CCS has been perceived as a "clean coal" technology, ${ }^{94}$ and debates have been diverted into broader questions of the desirability of burning coal and other fossil fuels (such as impacts on energy security, effects on local air quality and amenity, and inter-generational impacts of mineral use). ${ }^{95}$ The perpetuation of coal may be the practical result of CCS in some cases, but such arguments should be resolved through laws targeted at those issues rather than being artificially transplanted into the CCS debate. CCS is about protecting the climate from $\mathrm{CO}_{2}$ emissions from many different sources, ${ }^{96}$ which in New Zealand could include but is unlikely to be focused on coal. ${ }^{97}$

\section{F The Conservation-enhancement Principle}

My key argument under the conservation-enhancement principle is that CCS may legitimately be subject to robust restrictions in areas of high natural value, but should also be recognised more broadly as a valuable mechanism for enhancing the global environment. It should not be subject to blanket negative normative classifications like waste or pollution.

The principle applies to marine CCS in three important ways. First, it suggests that where protection of the local environment is emphasised in defined geographical areas (such as marine reserves), these concerns should remain pre-eminent. ${ }^{98}$ The benefit from publicinterest industries does not generally override the more absolute public interest in protecting defined areas of high natural value from human interference. ${ }^{99}$ CCS would amount to a significant non-natural intrusion. The principle also suggests that robust local protections

\footnotetext{
${ }^{93}$ See GGGSA(Vic), s 1; CCS Directive, art 1.

${ }^{94}$ See GCCSI, above n 51, at 3; AM Arranz "Carbon Capture and Storage: Frames and Blind Spots" (2015) 82 Energy Policy 249 at 256; Between a Rock and a Hard Place (Commonwealth of Australia, Canberra, 2007) at 8-9.

95 See Marston and Moore, above n 80, at 432; JJ Snyder "Obstacles to Carbon Capture and Sequestration by US States: Can they be Overcome?" in Havercroft and others, above n 10, at 203; ENGO Network, above n 57 , at 6,16; Greenpeace, above n 57; Doody and others, above n 13, at 46.

${ }^{96}$ ENGO Network, above n 57, at 2; IEA Energy Technology Perspectives 2014 (IEA, Paris, 2014) at 495.

${ }^{97}$ See McCoy, above n 2, at 44; NZCCS Partnership CCS in New Zealand: Case Studies for Commercial Scale Plant (2010); Barton and others, above n 12, at 17.

${ }^{98}$ Compare GGGSA(Vic), s $12(2)(\mathrm{a})$.

${ }^{99}$ See Pigeon Bay Aquaculture v Canterbury Regional Council EnvC Christchurch C179/2003, 17 June 2004 at [26].
} 
should be imposed in the marine environment more generally, although these need not be absolute. ${ }^{100}$

Secondly, the principle supports the public-interest industries principle in suggesting that we should embrace bio-energy CCS (BECCS) as a way to improve the global environment (remove $\mathrm{CO}_{2}$ from the atmosphere). Atmospheric concentrations of $\mathrm{CO}_{2}$ are already at a level that may mean climate change is inevitable unless some is removed, ${ }^{101}$ so support for BECCS is needed to enhance the status quo. ${ }^{102}$

Thirdly, the conservation-enhancement principle aims to minimise, reduce and discourage waste and pollution. Disposal or dumping of such substances are viewed through a particularly negative normative lens. ${ }^{103}$ Whether $\mathrm{CO}_{2}$ falls into these morally charged categories is therefore central to how it is treated under the principle, and deserves close attention. $^{104}$

An exhortation to minimise waste and pollution does not in itself determine whether a class of activity amounts to one or the other. ${ }^{105}$ It is, in fact, possible to classify storage in a range of ways, which can be negative, positive, or neutral. ${ }^{106}$ It can be seen as the dumping, discharge or disposal of a waste, pollutant, or contaminant, ${ }^{107}$ as the use of a geological resource, ${ }^{108}$ as the prevention of climate harm, or as the storage of a resource or byproduct. ${ }^{109}$ Other jurisdictions continue to grapple with similar issues of classification. ${ }^{110}$ The commonly used moniker "carbon capture and storage" is itself notable, in that it has not

\footnotetext{
${ }^{100}$ See ch III.

${ }^{101}$ See Baghaki, above n 24, at 35.

${ }^{102}$ GCCSI, above n 51, at 3; Compare Genesis, above n 24, at [220]. As explained at p 25, BECCS involves the capture and storage of emissions sourced from the combustion of biomass, which has itself removed $\mathrm{CO}_{2}$ from the atmosphere.

${ }^{103}$ See ch III. Doody and others, above n 13, at 12.

104 The point is not to examine whether CCS falls within the ambit of particular statutory regimes or definitions, only its general treatment under the principle.

${ }^{105}$ See ch III; Attorney-General's Reference (No 5 of 2000) [2001] Env LR 129 (UK); J Pike, "Waste Not Want Not" (2002) 14 Journal of Environmental Law 197 at 207.

${ }^{106}$ For an equivocal view see D Langlet "Exporting $\mathrm{CO}_{2}$ for Sub-Seabed Storage" (2015) 30 International Journal of Marine and Coastal Law 395 at 397; IEA Legal Aspects of Storing $\mathrm{CO}_{2}$ (IEA, Paris, 2007) at 28-29.

107 IEA, above n 1, at 25; Snyder, above n 95, at 203; TA Campbell, RA James and J Hutchings "Carbon Capture and Storage Project Development" (2007-2008) 38 Tex Envtl LJ 169 at 181.

${ }^{108}$ McCoy, above n 2, at 18, 22.

${ }^{109}$ Gerstenberger and others, above n 2, at 37.

${ }^{110}$ McCoy, above n 2, at 36; K Robertson, J Findsen, and S Messner International Carbon Capture and Storage Projects (DOE/NETL, 2006) at 8; J Glazewski, A Gilder and E Swanepoel Carbon Capture and Storage: Towards a Regulatory and Legal Regime in South Africa (IMEL, Cape Town, 2012) at 18-19.
} 
captured the public imagination as carbon "dumping" or "disposal". 111 However, the movement of gaseous or liquid substances into an uncontained receiving environment - in an "unnatural place"112 - has historically been perceived as a matter of pollution control. ${ }^{113}$ This tends also to be the initial perception of the lay person. ${ }^{114}$ Indeed, storage bears many similarities to more conventional forms of waste disposal like landfilling. ${ }^{115}$

At the global level, parties to the London Dumping Protocol have accepted that marine CCS is a form of dumping, to be regulated under a regime aimed squarely at controlling the adverse effects of pollution, rather than one emphasising the need for climate outcomes to be realised. ${ }^{116}$ Valmaine Toki has also recognised that the "orthodox view" of $\mathrm{CO}_{2}$ is a waste that contributes to climate change, ${ }^{117}$ and a report on CCS in South East Asia has recommended that $\mathrm{CO}_{2}$ needs to be classified as waste or pollution in order to make use of existing regulations. ${ }^{118}$

In contrast, Western Australia does not consider $\mathrm{CO}_{2}$ to be a "pollutant". ${ }^{119}$ Similarly, the EU has developed a targeted directive for the technology, ${ }^{120}$ despite many member states being party to international treaties that characterise it as dumping. ${ }^{121}$ Previously, $\mathrm{CO}_{2}$ had fallen within the scope of "waste" under the EU Waste Framework Directive, bringing with it the need to comply with relatively onerous requirements. ${ }^{122}$ A New Zealand study has shown that the public may in fact conceive of storage rather paradoxically as both the disposal of waste and the use of a resource, ${ }^{123}$ and a UK study concluded that public perceptions of the technology can change once it is placed firmly within its climate change context. ${ }^{124}$ The

\footnotetext{
${ }^{111}$ Mace and others, above n 4, at 117.

${ }^{112}$ Doody and others, above n 13 , at 58.

${ }^{113}$ IEA, above $\mathrm{n} 1$, at 22.

${ }^{114}$ IPCC, above n 50, at 257.

${ }^{115}$ Havercroft and others, above n 10, at 21; Zakkour, above n 65, at 11.

116 See C Armeni "Legal Developments for Carbon Capture and Storage under International and Regional Marine Legislation" in Havercroft and others, above n 10, at 145.

${ }^{117}$ Toki, above n 28, at 379.

${ }^{118}$ Prospects for Carbon Capture and Storage in South East Asia (Asian Development Bank, 2013) at 63.

${ }^{119}$ Robertson and others, above n 110 , at 28

${ }^{120}$ CCS Directive.

${ }^{121}$ Some have observed that it also applies many pollution-centric features to CCS: Havercroft and Macrory, above $\mathrm{n} 80$, at 300 .

${ }^{122}$ Havercroft and Purdy, above n 52, at 16; Zakkour, above n 65, at 9-10; CCS Directive, art 35.

${ }^{123}$ Coyle, above n 42 , at 68, 106-107.

${ }^{124}$ IPCC, above n 50, at 257.
} 
IPCC has also left the question open, pointing out that analogues could be as diverse as nuclear waste disposal and temporary natural gas storage. ${ }^{125}$

The story of CCS opposition should be seen for what it (largely) is: a marketing or communications failure. ${ }^{126}$ It is not a fundamental flaw of the technology. As some commentators have put it, CCS has effectively been picked as a "loser" compared to energy efficiency and renewable electricity measures, ${ }^{127}$ and "has undermined its own credibility" because of how it is perceived. ${ }^{128}$ Yet a positive narrative around storage is not out of reach. ${ }^{129}$ This has been the case with "clean, green" - but also environmentally harmful renewable energy projects. ${ }^{130}$ Under the principle of anthropocentric valuation, terms like "waste" and "disposal" (as with terms like "harm" and "risk") ${ }^{131}$ are ultimately human constructs rather than inherent features of particular substances or actions, describing our attitudes towards something and its effects rather than a thing or action itself. ${ }^{132}$ Many regimes simply assume we will recognise waste when we see it, and based on how we handle it. ${ }^{133}$ Biological sequestration of $\mathrm{CO}_{2}$ (in trees) is certainly not perceived or treated as the dumping or disposal of carbon, although it arguably could be if we defined it by action rather than outcome. ${ }^{134}$ Classifying marine CCS streams negatively based on their origin, commercial valuation, or an abstract assessment of the nature of $\mathrm{CO}_{2}{ }^{135}$ is therefore not helpful unless that classification assists in achieving the results we desire. ${ }^{136}$

Do we wish to discourage, minimise and reduce the use of CCS through a negative normative classification? The distributive principle suggests that we do not. ${ }^{137}$ It demands that weight be given to the global, atmospheric and inter-generational impacts of the technology relative to

\footnotetext{
${ }^{125}$ Ibid at 69. Compare Bankes and others, above n 88, at 598.

${ }^{126}$ Doody and others, above n 13 , at 54, 60 .

${ }^{127}$ ENGO Network on CCS Moving CCS Forward in Europe (GCCSI, 2013) at 7.

128 Ibid at 4.

${ }^{129}$ Norwegian perception is largely positive: see E Heiskanen Snohvit $\mathrm{CO}_{2}$ Capture and Storage Project (2006) at 15 .

${ }^{130}$ Ibid at 4; Maniototo Environmental Society Inc v Central Otago District Council EnvC Christchurch C103/2009, 28 October 2009 from [386]; New Zealand Energy Strategy 2011-2021 (Ministry of Economic Development, 2011) at 6.

${ }^{131}$ Mace and others, above n 4, at 5.

${ }^{132}$ See Clarke, above n 10, at 186; Robertson and others, above n 110, at 8

${ }^{133}$ See Mace and others, above n 4, at 137; see also ch III.

${ }^{134}$ Doody and others, above n 13, at 29.

${ }^{135}$ IEA, above $\mathrm{n} 1$, at 25.

${ }^{136}$ E Wilson, A Klass and S Bergan "Assessing a Liability Regime for Carbon Capture and Storage" (2009) 1 EGYPRO 4575 at 4577; S Schofield "Waste Management Law in New Zealand" (2010) 14 NZJEL 223 at 227; Carter Holt Harvey v North Shore City Council [2006] 2 NZLR 787 (HC) at [90].

${ }^{137}$ See also Havercroft and Purdy, above n 52, at 13.
} 
its local, geological and short-term effects. The climate imperative is to increase deployment (especially BECCS). ${ }^{138}$ Deep geological change is, at worst, normatively neutral, while reducing atmospheric $\mathrm{CO}_{2}$ is positive. This is consistent with the conclusions of Macrory and others that $\mathrm{CO}_{2}$ streams used for enhanced petroleum recovery are not waste under EU law because they serve a useful function, ${ }^{139}$ and Marston and Moore's prediction that pure storage streams may have value in the future. ${ }^{140}$ The public-interest industries principle also demands that the benefits of CCS be realised; regimes concerned with dumping, discharges, pollution and waste are invariably focused on the prevention of adverse effects rather than the obtainment of positive effects. ${ }^{141}$

Authorised storage should therefore not fall within classes of activity that the law generally seeks to reduce or assumes to be harmful. It is not intellectually dishonest to reject terms like "disposal", as some have implied. ${ }^{142}$ As Louka has stated more generally, "redefining wastes as potential sources for other material and energy production [is] important in changing ... perceptions", ${ }^{143}$ and Barton and others have emphasised that CCS can be seen as "an effort to protect the environment rather than harm it". ${ }^{144}$ The choice of language here is significant, ${ }^{145}$ and the literature is replete with exhortations to provide a supportive legal environment for the technology. ${ }^{146}$ Negative public perceptions are often based on misunderstandings of the climate role of storage and exaggerations of its risks rather than well-considered ethical positions. ${ }^{147}$ The law must respond to principle, not perception.

In contrast, this logic does not apply to leakage. The distributive and public-interest industries principles demand that leakage be treated as a pollutant (or other negatively charged term) for precisely the same reason that storage should not. Leakage poses both climatic and local

\footnotetext{
${ }^{138}$ See GCCSI, above n 51, at 3.

$139 \mathrm{R}$ Macrory and others, Legal Status of $\mathrm{CO}_{2}$-Enhanced Oil Recovery (UCL Carbon Capture Legal Programme, 2013) at 23.

${ }^{140}$ Marston and Moore, above n 80, at 428.

${ }^{141}$ See also ch VIII.

142 See E Wilson and A Gibbons "Deploying Carbon Capture and Storage in Europe and the United States" (2007) 5 JEEP 343 at 347.

${ }^{143}$ E Louka International Environmental Law (Cambridge University Press, Cambridge, 2006) at 106.

${ }^{144}$ Barton and others, above n 12, at 239.

${ }^{145}$ WRI, above n 18, at 54; Doody and others, above n 13.

${ }^{146}$ See Prospects for Carbon Capture and Storage, above n 118, at 61; GCCSI, above n 51, at 8.

${ }^{147}$ Gerstenberger and others, above n 2, at 32.
} 
risks. It thus triggers the application of the polluter-pays principle, as it does under the EU Waste Framework Directive. ${ }^{148}$

\section{G The Principle of Precaution}

I contend that the risks that CCS poses to the local environment should not be viewed in isolation, and need to be set against the technology's potential to improve the climate. CCS itself ought to be recognised as a precautionary measure.

Most aspects of precaution apply to marine CCS as they would to any other industrial activity. Robust risk identification must occur before authorising a project, ${ }^{149}$ be objective and informed by evidence, and encompass risks of low probability. Risks of adverse effects need not be eliminated, ${ }^{150}$ but must be managed by responding in a way that errs on the side of environmental protection and is proportionate to the probability and magnitude (including significance) of the risk. In the context of seabed mining activities in particular, recent decisions have strongly emphasised the importance of protecting the local marine environment from the risk of harm. ${ }^{151}$ Each application will pose its own risks and have varying degrees of uncertainty for which a response is required, and in many we may have information that is far from perfect. ${ }^{152}$ But generally speaking, the magnitude and probability of local risks are likely to be low as long as operations are sited appropriately. ${ }^{153}$ There is no reason to believe a precautious approach should be synonymous with the ex ante prohibition of all storage operations.

Some commentators assume that a conservative approach consistent with precaution is one in which we give the local environment primacy. ${ }^{154}$ These arguments may be prominent in the

\footnotetext{
${ }^{148}$ Clarke, above n 10, at 194.

149 N Durrant "Carbon Capture and Storage Laws in Australia: Project Facilitation or a Precautionary Approach?" (2010) 18 Environmental Liability Journal 148 at 154.

${ }^{150}$ Ibid.

${ }^{151}$ Environmental Protection Authority Trans-Tasman Resources Ltd Marine Consent Decision (June 2014) at [116], [139]; Environmental Protection Authority Decision on Marine Consent Application: Chatham Rock Phosphate Limited (February 2015) at [823]; C Iorns and G Severinsen "Diving in the Deep End" (2015) 13 NZJPIL 201 at 209, from 222.

${ }^{152}$ See Barton and others, above n 12, at 69.

153 See ch I.

${ }^{154}$ Implicit in Mace and others, above n 4, at 40; Durrant, above n 149, at 157, 169.
} 
context of particular sites. ${ }^{155}$ But in a world where the specific effects of climate change remain uncertain, one can regard marine CCS itself as a precautionary measure - as acting responsibly in the face of uncertainty. ${ }^{156}$ The principle conceptually encompasses the need for comparative risk assessment (including the risks of failing to act), not just the need to respond to potential adverse effects. ${ }^{157}$ Both are important. In fact, the IPCC has highlighted BECCS projects as being particularly precautious. ${ }^{158}$ As under the principle of sustainability, the balance between different kinds of risk must be determined with reference to the distributive principle. This demands that substantial weight be placed on the potential for global, atmospheric and long-term climate benefits.

\section{H The Participatory Principle}

I contend that the public should be involved in most steps of decision-making concerning CCS. However, wide participatory rights should not be ongoing, and it would be inefficient to duplicate them across multiple decision-making frameworks.

The participatory principle demands wide public involvement at the strategic decisionmaking level for industrial activities like CCS (for example, when formulating rules and policies). In contrast, at the project level, public notification and associated rights are generally conferred where there is a risk of significant or more than minor effects on the environment. ${ }^{159}$ The local risks of storage are generally thought to be low, but it is unclear whether they should or should not be regarded as sufficiently high to warrant full public participation at the project level. Proposals do not inherently involve low risk, and much depends on context. But several factors suggest that public involvement is important, and that notification should at least be presumed. ${ }^{160}$ The extent of potential effects (such as leakage) may become apparent only when detailed evidence is presented (after a decision on notification has been made). In a marine context where data may be incomplete, submitters

\footnotetext{
${ }^{155}$ See J Desbarats (ed) Review of the Public Participation Practices for CCS and non-CCS Projects in Europe (Institute for European Environmental Policy, 2010) at 3; GCCSI, above n 52, at 154.

${ }^{156}$ Doody and others, above n 13, at 57; J Heinrich Legal Implications of $\mathrm{CO}_{2}$ Ocean Storage (MIT, Cambridge, 2002) at 3; F Bowen "Carbon Capture and Storage as a Corporate Technology Strategy Challenge" (2011) 39 Energy Policy 2256 at 2258.

${ }^{157} \mathrm{See}$ ch III.

${ }^{158}$ IPCC, above n 50, at 67

${ }^{159}$ See ch III. On notification generally, see G Hewison "The Resource Management Act 1991" in Salmon and Grinlinton, above n 28, at 586-588.

${ }^{160}$ Compare OPGGSA(Vic), s 61(2)(j); GGGSA(Vic), s 8(2)(j).
} 
may have much value to add to a consent authority's information base. Furthermore, other activities that involve extensive seabed drilling, the discharge or deposit of large volumes of matter, or large-scale industrial operations in the marine environment are generally publicly notified. ${ }^{161}$ There is a substantial public interest in climate measures more generally. ${ }^{162}$ Treaty obligations also require the provision of robust and targeted consultative and participatory mechanisms for Māori in particular. ${ }^{163}$

The corollary of this is that there is less need for duplication of full participatory processes in other regimes requiring authorisation for storage, particularly where they are guided by clearer normative direction not requiring the balancing of multiple values (as in conservation areas). It would be inefficient and potentially confusing to provide for two avenues of robust public participation for the same activity.

Some have seen additional value in requiring pre-application consultation with affected communities. ${ }^{164}$ International experience shows that early engagement can remove substantial roadblocks to deployment, by allowing a community to shape an acceptable proposal and by dispelling public fears that are based on a lack of understanding. ${ }^{165}$ However, the participatory principle generally disavows obligations to consult before a formal application process has commenced, instead embracing a more adversarial, one-off model of engagement. ${ }^{166}$ Social license to operate is generally not required under the principle for a legal license to operate, even though early engagement would be good commercial practice.

The Decision-making Principle

Most aspects of the decision making principle described in chapter III require no further discussion. Clarification is mainly needed, under the concept of subsidiarity, as to where the relevant community of interest should lie. This will determine by whom, and according to

\footnotetext{
${ }^{161}$ See RMA, ss $95 \mathrm{~A}(2)$.

${ }^{162} \mathrm{~K}$ Bosselman and others Climate Change in New Zealand: Scientific and Legal Assessments (NZCEL, Auckland, 2002) at 92.

${ }^{163}$ See Coyle, above n 42, at v.

${ }^{164}$ Havercroft and Macrory, above n 80, at 302; World Resources Institute CCS and Community Engagement (WRI, 2010) at 68; Coyle, above n 42; P Ashworth and C Cormick "Enabling the Social Shaping of CCS Technology" and S Forbes and others "Regulatory Requirements for Public Engagement around Carbon Capture and Storage Demonstrations" in Havercroft and others, above n 10, from 208.

${ }^{165}$ IEA, above n 1, at 48; ENGO Network, above n 57, at 6; Barton and others, above n 12, at 239; UK Department of Energy and Climate Change, above n 54, at 36; Gerstenberger and others, above n 2, at 38.

${ }^{166}$ See ch III.
} 
whose interests, decisions are made. There is a compelling argument that storage in offshore waters has a national community of interest. Most adverse effects can be characterised as local or regional, but the benefits of storage would be global (and, by extension, national). If left to local governance only (particularly in the politically-driven policy development stage), local risks may often be seen as outweighing global benefits, which may, in many cases, fail to reflect the distributive principle. As with many public-interest industries, decisions need to be located at the national level. ${ }^{167}$ Barton and others have concluded that storage decisions should be centralised for more practical reasons, notably that central government is better resourced to assess proposals. ${ }^{168}$

\section{J The Certainty-flexibility Principle}

My key conclusion under the certainty-flexibility principle is that a regulatory regime for CCS should allow substantial, although not absolute, flexibility for regulators and operators to change operations over their long life-spans. Certainty is also needed as to the basic meaning of legal provisions concerning CCS, even if specific outcomes are not predetermined. ${ }^{169}$ The law should be applied consistently; specific rules and standards targeted at the technology provide desirable certainty where they are generalisable across all contexts in which CCS could occur. ${ }^{170}$ Where specific standards are not generalisable, clear and transparent policy guidance is desirable to scaffold discretionary decision making, ${ }^{171}$ while still retaining the flexibility to respond to contextual factors.

A desire for certainty should not prevent change at the strategic level (changes to plans and policies). This is needed to response to new issues or to meet existing challenges in new ways. At the project level, flexibility should also be prominent where the public interest requires authorities to amend specific authorisations. The prevention of serious unanticipated adverse effects should not be defeated by the presence of existing resource use rights. But under the concept of non-derogation, the reasons for such alterations should not be the re-

\footnotetext{
167 For example, decisions concerning the management of minerals and fisheries, and large infrastructure projects subject to ministerial call-in powers under the RMA. Compare NZCCS Partnership CCS in New Zealand: Case Studies for Commercial Scale Plant (2010) at 45.

${ }^{168}$ Barton and others, above n 12, at 80 .

${ }^{169}$ See Mace and others, above n 4, at vi.

${ }^{170}$ Compare Langlet, above n 68, at 299-300.

${ }^{171}$ Barton and others, above n 12, at 64.
} 
allocation of resource rights from one private user to another, ${ }^{172}$ which could seriously undermine investment certainty. ${ }^{173}$ Certainty concerning the rights that are being conferred by sub-surface authorisations, and when they are infringed, is needed.

Usually the principle demands that less flexibility be accorded to an applicant to change the terms of an authorisation. Under the participatory principle, the public has an interest in being involved in significant variations to conditions that would, if consent had not been granted already, require a full public participatory process. In the context of CCS, however, this is set against the considerable public interest in having operational changes made to ensure storage is effective, under the public-interest industries principle. Given the rapidity with which storage technologies and methods are developing, numerous changes in operational approaches may be required over the long life of a project. ${ }^{174}$ Requiring a full participatory process each time would be onerous, and may hamper the long-term viability of injection. International experience has supported the need for flexibility and, on balance, so too does existing principle - as long as the changes are needed to realise the public interest in a healthy climate. $^{175}$

\section{K The Efficiency Principle}

The efficiency principle supports the above conclusion that clear standards and policies for CCS should be imposed where they can be generalised across multiple storage scenarios. More generally, CCS law should aim to streamline decision-making procedures as far as possible without undermining the value of public participation, subsidiarity and informed decision-making. The financial costs of ensuring decisions are informed should be borne by an applicant, ${ }^{176}$ and guided by what is reasonable in light of the scale and significance of effects, but under the precautionary principle this should not prevent decision-makers from declining applications on the basis of inadequate or uncertain information.

Furthermore, while we ought to recognise the efficiency value of using comparable units of measurement to quantify effects, the effects of marine CCS should not be artificially reduced

\footnotetext{
${ }^{172}$ Compare Alberta Government, above n 87, at 71.

${ }^{173}$ On the value of investment certainty for CCS, see European Commission, above n 71, at 6.

${ }^{174}$ IEA, above n 1, at 16, 24. Compare Barton and others, above n 12.

${ }^{175}$ IEA, above n 1, at 59; Carbon Dioxide Capture and Geological Storage: Australian Regulatory Guiding Principles (MCMPR, 2005) at 10.

${ }^{176}$ See, for example, RMA, s 88(2)(b).
} 
to monetary units where this does not reflect their true public value. For example, the high public interest in storage and the prevention of leakage may not be reflected in the price of emissions under the emissions trading scheme.

Finally, the principle supports the efficient use of resources. It is compelling to see CCS as an efficient use of subsurface space. The total costs of outputs - the mitigation of (or adaptation to) climate change - are expected to be much higher if it is not deployed. It has been estimated that without storage the total cost of emissions reductions (necessary to restrict atmospheric concentrations of $\mathrm{CO}_{2}$ to below 450 parts per million) increases by up to 70 percent globally, ${ }^{177}$ a cost which will fall on future generations.

\section{Conclusion}

In chapter IV I have translated the general principles identified in chapter III to marine CCS. This has established a broad normative foundation - our aims - for regulating the technology. Some aims do not add much colour to the generic principles in chapter III, but others provide valuable clarification. Crucial among these are that CCS law should place substantial weight on the global, atmospheric and long-term effects of storage, recognise that storage is both a resource use posing risks and a protective and precautionary measure, and continue to place overriding value on local environmental protections in conservation areas. The law should also recognise the importance of Māori decision-making roles within culturally significant areas, the centrality of Māori participation more generally, and the importance of substantive Māori values in relation to the marine environment. We must ensure that the positive climate effects of CCS are achieved once injection has occurred, by preventing leakage. We must also recognise that marine CCS is an important transitional measure, and one among a portfolio of measures, to address climate change - not an absolute or long-term solution.

It is important that CCS law resolve conflict between sub-seabed industries on the basis of the public interest, and facilitate mutually beneficial outcomes. Yet we should not conflate storage with the wider effects or character of associated activities. The law should also refrain from characterising storage as an inherently negative activity, while ensuring any that leakage

\footnotetext{
${ }^{177}$ IEA, above n 1, at 13; IEA Energy Technology Perspectives 2010 (IEA, Paris, 2010) at 494. A more modest estimate of 30 percent has been made in 2005 by the IPCC, above n 50, at 12 .
} 
is approached negatively. Standards should be generalised across projects where possible, but to the extent they cannot, targeted policies are desirable.

Translating general principles to marine CCS is crucial to the barriers and gaps analysis that follows. This is because a "barrier" exists only if existing provisions are inconsistent with such principles, and a gap can be perceived only if existing environmental law as a whole fails to achieve the aims embedded in them. 


\section{$\xi$}

$\mathbf{V}$

\section{Marine CCS and International Law}

\section{A Introduction}

In this chapter I consider what international environmental law requires of New Zealand's domestic law on marine CCS. It is possible to consider compliance with international law as a "principle" of domestic law, and a continuation of the previous chapter. However, it warrants separate treatment because it often involves concrete rules rather than the more general guidance associated with principles.

I conclude that, while New Zealand must meet a number of obligations, none are fundamentally inconsistent with the principles described in chapter IV. A coherent set of criteria for law reform is therefore possible. I also find that, although some global treaties impose only high level obligations (such as framework conventions like the United Nations Convention on the Law of the Sea (UNCLOS)), ${ }^{1}$ others are quite specific in their requirements. For example, the London Dumping Protocol has been used as a site for the development of fairly detailed prohibitions, rules, and guidelines specifically concerning marine CCS. In this chapter I assume that New Zealand will honour its international obligations by legislating in a manner consistent with them, even though international law is not directly enforceable in domestic courts. ${ }^{2}$

\footnotetext{
${ }^{1}$ United Nations Convention on the Law of the Sea 1833 UNTS 3 (opened for signature 10 December 1982, entered into force 16 November 1994) (UNCLOS).

${ }^{2}$ Teddy v Police [2014] NZCA 422, from [59]; St Columba's Environmental House Group v Hawkes Bay Regional Council [1994] NZRMA 560 (PT); New Zealand Law Commission A New Zealand Guide to International Law and its Sources (NZLC R34, 1996) at 10.
} 
The focus of chapter $\mathrm{V}$ is treaty law. This does not dismiss customary international environmental law as unimportant. In fact, it is very important, given that (unlike treaty law) it applies directly in New Zealand without express incorporation into domestic law (unless it is inconsistent with it). ${ }^{3}$ It simply recognises that custom is general and principles-based, does not easily translate into specific obligations on private persons (such as CCS operators), and in the marine context does not add much to the more detailed provisions of treaty law or the domestic principles already discussed in chapter IV. Many of the latter find their own genesis in principles of international environmental law. ${ }^{4}$ Furthermore, most accepted principles of custom have focused on inter-state relations, such as duties to prevent trans-boundary harm, ${ }^{5}$ and are of limited relevance to CCS in a geographically isolated context like New Zealand. ${ }^{6}$

There are two kinds of treaties relevant to marine CCS: those that seek to address climate change by incentivising mitigation action, and those that seek to protect the marine environment from that action. The United Nations Framework Convention on Climate Change (UN Framework Convention) and the Kyoto Protocol form the centre of gravity of the former. ${ }^{7}$ These regimes are generally supportive or at least facilitative of technological measures like $\mathrm{CCS}^{8}{ }^{8}$ But they have not been used as a site for the detailed regulation of CCS other than imposing obligations on states to report emissions (or where projects occur in developing states). Thus they are relevant mainly to the question of how CCS is to be incentivised (regulation for, not regulation of CCS), and beyond the scope of the thesis. Even

\footnotetext{
${ }^{3}$ T Dunworth "The Influence of International Law in New Zealand: Some Reflections" in C Morris, J Boston and P Butler (eds) Reconstituting the Constitution (Springer, New York, 2011) 319 at 327.

${ }^{4}$ See B Gordon "Treaty of Waitangi and Māori Issues in Environmental Law" in P Salmon and D Grinlinton (eds) Environmental Law in New Zealand (Thomson Reuters, Wellington, 2015) at 271.

${ }^{5}$ See generally U Beyerlin and T Marauhn International Environmental Law (Hart, Oxford, 2011) at 285-286.

${ }^{6} \mathrm{C}$ Hendriks, MJ Mace and R Coenraads Impacts of EU and International Law on the Implementation of Carbon Capture and Geological Storage in the European Union (European Commission, 2005) at 25. Although the principle of prevention supports the concept of common but differentiated responsibility for climate impacts. ${ }^{7}$ United Nations Framework Convention on Climate Change 1771 UNTS 107 (signed 9 May 1992, entered into force 21 March 1994) (UNFCCC); Protocol to the United Nations Framework Convention on Climate Change 37 ILM 22 (signed 11 December 1997, entered into force 16 February 2005) (Kyoto Protocol).

${ }^{8}$ For example, see IPCC "Summary for Policymakers" in IPCC Climate Change 2014: Mitigation of Climate Change (IPCC, Geneva, 2014) at 12; Hendriks and others, above n 6, at 117; See UNFCCC, art 4(1)(c); GCCSI The Global Status of CCS: 2015 Summary Report (GCCSI, Melbourne, 2015) at 13; C Armeni, 'Carbon Capture and Storage in the Sub-Seabed and Sustainable Development: Please Mind the Gap' (2013) 27 Ocean Yearbook 1 at 13; R Purdy and R Macrory Geological Carbon Sequestration: Critical Legal Issues (Tyndall Centre, London, 2004) at 16.
} 
where carbon accounting does have implications for restricting leakage, ${ }^{9}$ New Zealand's emissions trading scheme (for now) operates largely independently of international emissions trading. ${ }^{10}$

Treaties that aim to protect the marine environment warrant closer attention. There have been no serious efforts to develop a treaty with the regulation of marine CCS at its heart. ${ }^{11}$ Instead, efforts have been directed at removing barriers from existing maritime treaties to allow domestic laws to do so. ${ }^{12}$ Arguably, few significant obstacles remain in the international space, ${ }^{13}$ although treaties still impose fairly stringent safeguards around the use of CCS offshore compared to onshore.

\section{Jurisdiction under International Law}

It is reasonably clear that international law provides sufficient jurisdiction for New Zealand to regulate marine CCS in its offshore waters. This can be seen in the provisions of UNCLOS. ${ }^{14}$ Jurisdiction varies according to geographical distance from a country's land mass, ${ }^{15}$ with the most important provisions for the purposes of storage provided in pts 2,5 and 6 of the Convention. These divide coastal waters, broadly speaking, into four zones, depending on their distance from a geographically determined baseline (see the generalised schematic in Figure 5). These are internal waters (on the landward side of the baseline), the territorial sea (extending from the baseline to 12 nautical miles), the contiguous zone (an overlay on the exclusive economic zone (EEZ) extending to 24 nautical miles from the baseline) and the EEZ (which extends to 200 nautical miles from the baseline). ${ }^{16}$

\footnotetext{
${ }^{9}$ See chs 6, 9.

${ }^{10}$ See C Warnock "Global Atmospheric Pollution: Climate Change and Ozone" in Salmon and Grinlinton, above n 4, ch 15; A Arthur-Young "Climate Change" in D Nolan (ed) Environmental and Resource Management Law ( $5^{\text {th }}$ ed, LexisNexis, Wellington, 2015) at 1143.

11 I Havercroft, R Macrory, and RB Stewart (eds) Carbon Capture and Storage: Emerging Legal and Regulatory Issues (Hart, Oxford, 2011) at 1.

12 IPCC Carbon Capture and Storage (Cambridge University Press, New York, 2005) at 254; generally Carbon Capture Legal Programme CCS Offshore $\mathrm{CO}_{2}$ Storage (UCL).

${ }^{13}$ See I Havercroft and R Purdy "Carbon Capture and Storage - A Legal Perspective" <www.un.org> at 17.

${ }^{14}$ See generally G Haver and HC Bugge "Transboundary Chains for CCS" (2007) 4 Journal for European Environmental and Planning Law 367 at 371.

${ }^{15}$ MN Shaw International Law (6 ${ }^{\text {th }}$ ed, Cambridge University Press, Cambridge, 2008) at 553.

${ }^{16}$ UNCLOS, arts 3, 8, 33, 57.
} 
Figure 5: Coastal Zones and Jurisdiction under International Law

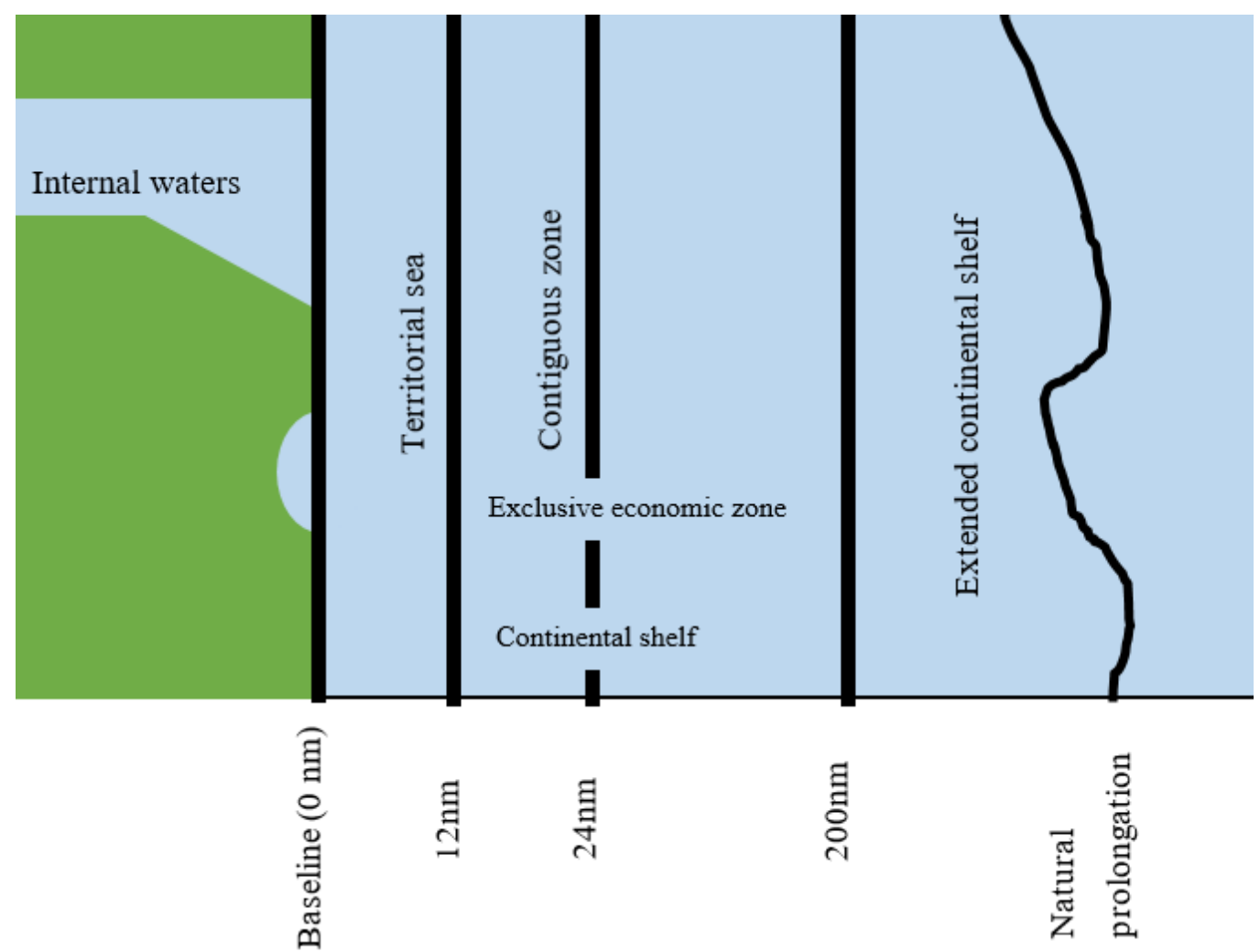

Article 2 of UNCLOS provides that a coastal state's sovereignty extends to its territorial sea, which includes its seabed and subsoil, but that such sovereignty is subject to the Convention. Similarly, arts 56 and 77 confer on a coastal state sovereign "rights" in the EEZ and underlying continental shelf (as well as its extended continental shelf), ${ }^{17}$ to exploit, conserve and manage natural resources. Geological storage formations fall within the scope of a natural resource. ${ }^{18}$ The Convention also provides a right of innocent passage through the territorial sea, and freedom of navigation in the EEZ, to the vessels of other states. ${ }^{19}$ In the EEZ, other states have additional rights to lay pipelines and cables. ${ }^{20}$ To the extent that storage unlawfully impinged on these rights, a state would be in breach of international law. However, normal operations seem unlikely to do so. The exploitation of the extended

\footnotetext{
${ }^{17}$ Under art 76, the submerged natural prolongation of a state's land mass beyond 200 nautical miles from the baseline, on which the Commission on the Limits of the Continental Shelf has made a recommendation.

${ }^{18}$ See MA De Figueiredo The Liability of Carbon Dioxide Storage (Cambridge, MIT, 2007) at 106; B Milligan "Planning for Offshore $\mathrm{CO}_{2}$ Storage" (2014) 48 Marine Policy 162 at 163; M Lassen "Sub-seabed storage in the Maritime Zones of the 1982 Law of the Sea Convention" (2014) 29 International Journal of Marine and Coastal Law 381 at 391; KN Scott "The Day After Tomorrow: Ocean $\mathrm{CO}_{2}$ Sequestration and the Future of Climate Change" (2005) 18 Geo Int'l Envtl L Rev 57 at 66-67.

${ }^{19}$ Articles 17-26, 58.

${ }^{20}$ Article 79.
} 
continental shelf is subject to an additional obligation to make payment to the International Seabed Authority, although it is unclear how a calculation based on "production" would apply to a non-extractive activity like CCS. ${ }^{21}$ More significantly, and as explored below, pt 12 of the Convention requires that the marine environment be protected and preserved. Both sovereignty and sovereign rights are contingent on compliance with $\mathrm{pt} 12 .^{22}$

\section{Substantive Provisions: Part 12 UNCLOS}

The substantive requirements of pt 12 of UNCLOS do not pose specific or insurmountable barriers to domestic law reform that seeks to enable sub-seabed CCS. ${ }^{23}$ As such, UNCLOS does not present any significant barriers to jurisdiction. Its broad provisions impose general obligations that are applicable to the technology, ${ }^{24}$ and enable more detailed international rules to be developed on aspects of environmental protection. ${ }^{25}$

\section{Protection and pollution}

Under pt 12 of UNCLOS, the injection and storage of $\mathrm{CO}_{2}$ likely does not amount to pollution itself unless, at the point of injection, subsequent leakage were likely to occur. States have a general obligation under art 192 of the Convention to protect and preserve the marine environment. A more precise direction is contained in art 195, which provides that, in taking measures to prevent, reduce and control pollution of the marine environment, states shall act so as not to transfer, directly or indirectly, damage or hazards from one area to another or transform one type of pollution into another. ${ }^{26}$ If $\mathrm{CO}_{2}$ amounts to "pollution" under the Convention, then injecting it under the ground arguably infringes the obligation not to transfer one type of pollution (emissions to the air) into another (injection to the ground). Some may interpret the Convention in this way, seeing storage as illegal and "morally

\footnotetext{
${ }^{21}$ Article 82. See De Figueiredo, above n 18, at 107. Note also that CCS cannot currently occur under international law beyond the extended continental shelf.

${ }^{22}$ Article 193.

${ }^{23}$ Lassen, above n 18, at 389; C Redgwell "International Legal Responses to the Challenges of a Lower-carbon Future" in D Zillman and others (eds) Beyond the Carbon Economy: Energy Law in Transition" (OUP, Oxford, 2008) at 108.

${ }^{24}$ R Purdy "The Legal Implications of Carbon Capture and Storage under the Sea" (2006) Sustainable Development Law \& Policy 22 at 22. See generally Strategic Analysis of the Global Status of Carbon Capture and Storage: Report 3: Policies and Legislation Framing Carbon Capture and Storage Globally (GCCSI, 2009) from 81.

${ }^{25}$ Article 197.

${ }^{26}$ Hendriks and others, above n 6, at 25.
} 
abhorrent". ${ }^{27}$ However, others have disagreed, and the obligation has not been treated in this way by states in practice. ${ }^{28}$ The injection of $\mathrm{CO}_{2}$ likely does not meet the definition of pollution in art 1.4:

the introduction by man, directly or indirectly, of substances or energy into the marine environment, including estuaries, which results or is likely to result in such deleterious effects as harm to living resources and marine life, hazards to human health, hindrance to marine activities, including fishing and other legitimate uses of the sea, impairment of quality for use of sea water and reduction of amenities.

The definition is constrained in a number of ways. It is largely anthropocentric, and does not recognise any effects that $\mathrm{CO}_{2}$ might have on the deep subsurface. If done properly, the injection of $\mathrm{CO}_{2}$ would also not be "likely" to result in the kinds of effects contemplated - a high probabilistic threshold. Similarly, a group tasked with analysing whether the OSPAR Convention (a regional marine protection agreement applying to the north-east Atlantic) presented a barrier to storage concluded that the precautionary approach in that treaty would apply if there was the possibility of pollution from a project. ${ }^{29}$ The implication in this conclusion is that injection itself is not pollution, at least under OSPAR. The logic is transferable to UNCLOS, given their materially identical definitions of pollution. ${ }^{30}$

This position is not necessarily beyond legal challenge, particularly if at the time of permitting a project $\mathrm{CO}_{2}$ were considered both likely to escape from a formation and likely to cause the kinds of effects contemplated in the definition of pollution. Carbon dioxide discharged into the water column could potentially could cause harm to marine life. ${ }^{31}$ The risk of an indirect introduction of $\mathrm{CO}_{2}$ to the surface environment (leakage) therefore colours whether injection itself can be regarded as pollution in any given case, since the assessment required is not whether a substance is a "pollutant" in the abstract but rather whether it would cause pollution. ${ }^{32}$ Thus there can be no blanket conclusion as to whether or not CCS would

\footnotetext{
${ }^{27}$ See Purdy, above n 24, at 26.

${ }^{28}$ De Figueiredo, above n 18, at 107. For an equivocal view, see D Langlet "Safe Return to the Underground?" (2009) 18 RECIEL 286 at 292.

${ }^{29}$ OSPAR Commission Report from the Group of Jurists and Linguists on Placement of Carbon Dioxide in the OSPAR Maritime Area (2004) at [9].

${ }^{30}$ OSPAR, art 1(d).

${ }^{31}$ IPCC, above n 12, at 243. See ch I.

${ }^{32}$ See Purdy and Macrory, above n 8, at 18.
} 
amount to pollution under UNCLOS. ${ }^{33}$ In cases where storage were secure, the more persuasive argument is that it would not (in contrast, leakage is likely to amount to pollution).

Consistent with this conclusion, injection from offshore installations or ships has been treated as a form of dumping under the Convention, rather than pollution from "seabed activities" or "offshore installations" addressed in art 208. Even if CCS were, in some cases, captured by art 8 as a form of pollution, this provides only a general obligation that states shall adopt laws to "prevent, reduce and control" it. As such, there has been little appetite to specify that storage does not amount to pollution. ${ }^{34}$

A general monitoring provision in art 204(2) of UNCLOS requires that a coastal state keep under surveillance the effects of any activities that it allows, in order to determine whether these are likely to pollute the marine environment. Thus, even though geologically stored $\mathrm{CO}_{2}$ is unlikely to amount to pollution, surveillance is needed to monitor the risks of leakage. States are also required to provide relief in respect of damage caused by pollution of the marine environment within their jurisdiction. ${ }^{35}$

\section{Dumping under UNCLOS}

CCS is classified as a form of dumping under UNCLOS, but this brings with it very few specific obligations. Most relevant to marine CCS is art 210. This directs states to prevent, reduce and control "pollution" by dumping, and to some extent it is implicit that the two terms are closely connected (that an item dumped becomes "pollution"). Yet the article also contains provisions that are relevant to the act of dumping more generally. These are fairly weak obligations by the standards of domestic law, but it is significant that art 210(5) specifically requires states not to treat dumping as a permitted activity (express approval is required). ${ }^{36}$

Most significantly, art 210(6) imposes an obligation to regulate dumping in a manner no less effective than the relevant "global rules and standards". The direction links UNCLOS to the

\footnotetext{
${ }^{33}$ See Havercroft and Purdy, above n 13, at 3.

${ }^{34} \mathrm{C}$ Armeni "Legal Developments for Carbon Capture and Storage under International and Regional Marine Legislation" in Havercroft and others, above n 11, at 157.

${ }^{35}$ Article 235.

${ }^{36}$ Compare Armeni, above n 34, at 147.
} 
London Dumping regime, to which New Zealand is party. It is not immediately clear whether it is the London Convention or the Protocol that is being referred to. ${ }^{37}$ However, the question is largely irrelevant for present purposes, given New Zealand is party to the London Protocol and is therefore bound by its higher standards anyway.

\section{E Substantive Provisions: the London Dumping Protocol}

The London dumping regime has become the focus of marine CCS regulation at international law. While technically a protocol to the London Convention, as of its entry into force in 2006 the London Protocol effectively replaced its parent convention for New Zealand. ${ }^{38}$ As such, the below discussion focuses on the Protocol.

I find below that CCS is a form of non-prohibited dumping under the London Protocol, although that status need not be replicated verbatim in domestic law. A CCS stream must be comprised overwhelmingly of $\mathrm{CO}_{2}$, no other matters may be added for the purposes of disposal, and various procedural requirements must be met under Annex II of the Protocol. There are some exceptions: domestic law need not impose these requirements on carbon capture, utilisation and storage projects (involving enhanced petroleum recovery), or where $\mathrm{CO}_{2}$ is stripped from offshore natural gas deposits and reinjected.

\section{Dumping and pollution under the London Protocol}

The London Protocol implements a strongly precautionary approach to dumping, by requiring parties to prohibit the dumping of waste and other matter into the sea or seabed unless a substance is contained within an exhaustive list in Annex 1. This is sometimes described as a "reverse" or "white" list. "Waste and other matter" is defined broadly as materials of any kind, form or description, and encompasses $\mathrm{CO}_{2}$ irrespective of its source. ${ }^{39}$ Parties are obliged to require a permit even for the dumping of Annex 1 substances. ${ }^{40}$

\footnotetext{
${ }^{37}$ Convention on the Prevention of Marine Pollution by Dumping of Wastes and Other Matter 1046 UNTS 120 (signed 29 December 1972, entered into force 30 August 1975) (London Convention); 1996 Protocol to the Convention on the Prevention of Marine Pollution by Dumping of Wastes and Other Matter 36 ILM 1 (signed 7 November 1996, entered into force 24 March 2006) (London Protocol).

${ }^{38}$ London Protocol, art 23.

${ }^{39}$ Article 1.8 .

${ }^{40}$ Article 4.
} 
As under UNCLOS, the primary focus of the Protocol is on dumping that causes pollution, rather than dumping per se. "Pollution" is defined in a materially identical way to UNCLOS (for present purposes). ${ }^{41}$ As such, it is unlikely that injection itself would amount to pollution, and likely that leakage would. But the importance of "pollution" under the Protocol is actually limited. Its core restrictions apply to any dumping irrespective of whether it would constitute pollution.

Presently, CCS is regarded as a non-prohibited form of dumping under the Protocol. Its restriction on dumping in art 4(4), and the operation of the stringent reverse list, do not require a dumped substance also to be a pollutant (it need only be "matter"). ${ }^{42}$ Nor does the definition of dumping require an activity to cause pollution. Article 4 provides simply that "contracting Parties shall prohibit the dumping of any wastes or other matter with the exception of those listed in Annex 1" and that "the dumping of wastes or other matter listed in Annex 1 shall require a permit". The act of dumping is defined as including: ${ }^{43}$

1. any deliberate disposal into the sea of wastes or other matter from vessels, aircraft, platforms or other man-made structures at sea; and

2. any storage of wastes or other matter in the seabed and the subsoil thereof from vessels, aircraft, platforms or other man-made structures at sea; but excluding

3. the placement of matter for a purpose other than the mere disposal thereof, provided that such placement is not contrary to the aims of this Protocol.

The definition presents some potential limitations on the scope of the Protocol's restrictions. It includes "storage", but expressly excludes the placement of matter for a purpose other than mere disposal. (Storage is therefore viewed as a form of disposal.) Although there are valid

\footnotetext{
${ }^{41}$ Article 1(10).

${ }^{42}$ See R Macrory and others Legal Status of $\mathrm{CO}_{2}$-Enhanced Oil Recovery (UCL Carbon Capture Legal Programme, 2013) at 9.

${ }^{43}$ Article 1.
} 
arguments on both sides, ${ }^{44}$ the international community has accepted that marine CCS does amount to mere disposal, and not another purpose. ${ }^{45}$

Injection of $\mathrm{CO}_{2}$ would be deliberate. It would also occur from man-made structures "at sea", ${ }^{46}$ which includes the underlying seabed and subsoil. ${ }^{47}$ Arguments that the "sea" may not include storage sites because they are too deep ${ }^{48}$ are unconvincing. ${ }^{49}$ The fact that "sub seabed repositories accessed only from land" need to be expressly excluded suggests that they are ordinarily within the scope of the Protocol; geological formations quite comfortably fall within the plain and ordinary meaning of "sub seabed repository". ${ }^{50}$ Most importantly, the express provisions in Annex 1 relating to marine CCS, as of amendments in 2006, now clearly show that the Protocol applies to storage in such formations.

One point of contention should be mentioned specifically. Some have suggested that injection occurring from remotely controlled devices on the seafloor, rather than from injection platforms (as at the Snøhvit project in the Barents Sea), does not amount to "dumping" under the Protocol. ${ }^{51}$ It would therefore not be subject to the safeguards in Annexes 1 and 2. The reason given is that the definition of "sea" expressly excludes subsea repositories accessed only by land. ${ }^{52}$ Such a view could, in the future, encourage the use of seafloor devices to avoid internationally accepted standards on storage. Again, we see that this confusion has arisen from adopting a regulatory regime for CCS that is not targeted at the climate benefits of storage, ${ }^{53}$ but rather one that perpetuates states' reluctance to impose meaningful international restrictions on land-based sources of pollution. Some have, quite rightly, questioned the rationale for fundamentally different treatment of activities having the same

\footnotetext{
44 See D Langlet "Exporting $\mathrm{CO}_{2}$ for Sub-Seabed Storage" (2015) 30 International Journal of Marine and Coastal Law 395 at 402; M Brus, 'Challenging Complexities of CCS in Public International Law' in MM Roggenkamp and E Woerdman (eds) Legal Design of Carbon Capture and Storage (Intersentia, Antwerp, 2009) at 37; J Friedrich "Carbon Capture and Storage: A New Challenge for International Environmental Law" 67 Zeitschrift fur auslandisches offentliches Recht und Volkerrecht (2007) 211 at 219; Purdy, above n 24, at 23; Purdy and Macrory, above n 8, at 23.

${ }^{45}$ Resolution LP.3(4) on the Amendment to Article 6 of the London Protocol (adopted 30 October 2009). Compare OSPAR Commission, above n 29, at [20].

${ }^{46}$ Article 1(4.1).

${ }^{47}$ Article 1(7).

${ }^{48}$ Havercroft and Purdy, above n 13, at 3; Langlet, above n 44, at 402.

${ }^{49}$ Purdy, above n 24, at 24.

${ }^{50}$ Article 1(7).

${ }^{51}$ Friedrich, above n 44, at 219; de Figueiredo, above n 18, at 137; IEA Legal Aspects of Storing $\mathrm{CO}_{2}$ (IEA, Paris, 2007) at 64; Havercroft and Purdy, above n 13, at 4; Purdy, above n 24, at 24.

${ }^{52}$ London Protocol, art 1(7).

${ }^{53} \mathrm{~J}$ Heinrich Legal Implications of $\mathrm{CO}_{2}$ Ocean Storage (MIT, Cambridge, 2002) at 2.
} 
positive and adverse impacts on the environment, based only on a choice of method or technology. ${ }^{54}$ A more persuasive view is that the use of seabed injection devices means that access to a sub-seabed repository is no longer "only" via a land-based pipeline, and is therefore subject to the Protocol. Some have sensibly suggested that the existence of a pipeline itself may be enough for an injection stream not to be "land" based. ${ }^{55}$

The London Protocol specifically excludes some other activities from its restrictions. The disposal or storage of matter directly arising from, or related to, the exploration, exploitation and associated off-shore processing of seabed mineral resources is not restricted. ${ }^{56}$ Injected $\mathrm{CO}_{2}$ itself is not a mineral, nor is it a seabed mineral, so pure storage is not excluded. However, carbon capture, utilisation and storage (CCUS) in the form of $\mathrm{CO}_{2}$ enhanced petroleum recovery would likely not be subject to the Protocol, because it would relate to the exploitation of a seabed mineral. ${ }^{57}$ Nor would a scenario where $\mathrm{CO}_{2}$ that had been stripped from natural gas were reinjected, such as at the Sleipner project in the North Sea. There too, the disposal of $\mathrm{CO}_{2}$ relates to the offshore processing of a seabed hydrocarbon mineral. ${ }^{58}$ New Zealand is under no obligation to apply the Protocol in such scenarios.

Pure storage, however, falls within the ambit of dumping under the Protocol. Originally, $\mathrm{CO}_{2}$ was not included in Annex 1, so the Protocol essentially prohibited such CCS deployment offshore. In response, in 2006, amendments were adopted to Annex 1 of the Protocol to include the dumping of $\mathrm{CO}_{2}$ streams, subject to: $:^{59}$

1. $\mathrm{CO}_{2}$ being streams from $\mathrm{CO}_{2}$ capture processes for sequestration;

2. disposal being into a sub-seabed geological formation;

3. gas streams consisting overwhelmingly of carbon dioxide (they may contain incidental associated substances derived from the source material and the capture and sequestration processes used); and

4. no wastes or other matter being added for the purpose of disposing of those wastes or other matter.

\footnotetext{
${ }^{54}$ Hendriks and others, above n 6, at 37; OSPAR Commission, above n 29, at [33].

${ }^{55}$ Macrory and others, above n 42, at 9.

${ }^{56}$ Article 1(4.3).

${ }^{57}$ See IPCC, above n 12, at 255.

${ }^{58}$ De Figueiredo, above n 18, at 129-130; Havercroft and Purdy, above n 13, at 4; IPCC, above n 12 , at 36.

59 London Protocol, Annex 1(4). See generally R Purdy and I Havercroft "Carbon Capture and Storage: Developments under European Union and International Law" (2007) 5 JEEP 353 at 356.
} 
The Protocol therefore restricts, but no longer prohibits, storage. It does not prevent states parties from prohibiting, or implementing additional restrictions on forms of marine CCS that are not prohibited under the Protocol. ${ }^{60}$

\section{Obligations applicable to Marine CCS under the London Protocol}

Annex 2 to the Protocol covers an additional list of general restrictions that are applicable to all dumping operations. These include obligations around dump-site selection, characterisation of injection streams, assessments of effects, monitoring, and permitting. They have been expanded upon in non-binding guidance material produced under the Protocol. ${ }^{61}$ In particular, under cls 9 and 10 of Annex 2, parties are required to set up a national action list and upper and lower levels for dumping, and categorise waste into one of categories according to such levels. Guidance material in this context focuses not on the nature of $\mathrm{CO}_{2}$ itself, but on an assessment of the kinds of impurities contained within an injection stream. ${ }^{62}$ Annex 2(11) of the London Protocol also requires the consideration of certain kinds of information when selecting dumping sites:

1. physical, chemical and biological characteristics of the water-column and the seabed; ${ }^{63}$

2. location of amenities, values and other uses of the sea in the area under consideration; ${ }^{64}$

3. assessment of the constituent fluxes associated with dumping in relation to existing fluxes of substances in the marine environment; and

4. economic and operational feasibility.

Clauses 12-16 of Annex 2 address the requirements for assessments of environmental effects and monitoring. ${ }^{65} \mathrm{CCS}$ is also subject to the requirements of art 9 , under which contracting parties must establish permitting regimes for dumping, keep records of matter dumped, monitor the condition of the sea, and report information.

\footnotetext{
${ }^{60}$ Article 4(2).

${ }^{61}$ London Dumping Protocol Specific Guidelines for the Assessment of Carbon Dioxide for Disposal into SubSeabed Geological Formations (LC34/15, 2012), Annex 8.

62 Ibid at 5 .

${ }^{63}$ Ibid at 6.2. Such as storage depth, capacity, injectivity, permeability, integrity, tectonic setting, leakage pathways and potential environmental effects of leakage.

${ }^{64}$ Ibid at 6.7. Such as environmentally, scientifically, culturally and historically important features, shipping lanes, military zones, and other uses of the seafloor.

${ }^{65}$ Ibid at 7. These should be comprehensive, clearly described and/or quantified, and based on robust risk assessment and impact hypothesis that considers changing risk profiles over time.
} 
The inclusion of marine CCS as a "white listed" form of dumping (rather than excluding it from the Protocol altogether) produces some curious questions. This is because CCS does not fit the traditional model of dumping. One is presented by the requirement in art 4(1) that, in granting permits, particular attention must be paid to opportunities to avoid dumping in favour of "environmentally preferable alternatives". It reflects the assumption that ordinarily, the dumping of waste in the oceans is seen as a last resort. That position is not beyond debate for marine CCS. What exactly a "preferable" alternative would be in the case of storage is not made clear, although presumably the secure storage of $\mathrm{CO}_{2}$ below ground may be justified as environmentally preferable to an atmospheric discharge. ${ }^{66}$ A similar issue arises from the wording of Annex 2(6), which provides that:

A permit to dump wastes or other matter shall be refused if the permitting authority determines that appropriate opportunities exist to re-use, recycle or treat the waste without undue risks to human health or the environment or disproportionate costs.

"Re-use" and "recycling" would be largely inapplicable considerations in the context of storage, unless large-scale uses for captured $\mathrm{CO}_{2}$ became common. ${ }^{67}$ Yet on occasion it might be possible and cost-effective to "re-use" anthropogenic emissions as fluid for enhanced petroleum recovery, and the London Protocol's explicit preference for re-use over storage is curious. Without some guarantee that enhanced petroleum recovery would result in permanent storage, it may be more harmful to the environment than CCS.

An equally curious question is presented by art 3, which provides that parties shall not "transfer, directly or indirectly, damage or likelihood of damage from one part of the environment to another or transform one type of pollution into another". This mirrors the provision in UNCLOS identified above. As discussed under UNCLOS, it is likely that the injection of $\mathrm{CO}_{2}$ into the subsurface does not amount to "pollution" under the London Protocol, unless an escape of gas were considered likely. If it were, it may be that harm is transferred from the atmosphere to a localised area of the water column. ${ }^{68}$ Although some

\footnotetext{
${ }^{66}$ Langlet, above n 28, at 293.

${ }^{67}$ Ibid at 3.3-3.4.

${ }^{68}$ De Figueiredo, above n 18, at 107.
} 
damage (seabed disturbance) would result from drilling, it seems unlikely the mere presence of $\mathrm{CO}_{2}$ in the subsurface could itself be classified as "damage". 69

An issue that has received much recent international attention is presented by art 6 . This prohibits parties from exporting matter, including $\mathrm{CO}_{2}$, to other countries for dumping at sea. ${ }^{70}$ An amendment has been introduced to overcome this barrier, but ratifications have been too few for it to come into force. ${ }^{71}$ However, while it may be of concern in other jurisdictions, ${ }^{72}$ cross-border transportation has little relevance in the geographically isolated context of New Zealand and is not explored further.

Finally, Annex 2(1) of the Protocol stipulates that "the acceptance of dumping under certain circumstances shall not remove the obligations under this Annex to make further attempts to reduce the necessity for dumping." 73 States remain obliged to reduce the need for storage by focusing on emissions reductions, mirroring the findings in chapter IV that CCS is not a longterm solution.

3 The relevance of the London Protocol to chapter IV conclusions

While the London Protocol is not designed to regulate specific industries, it has become the de facto location for the most detailed international regulation on marine CCS. Best practice guidelines have been developed under its auspices, which contain considerations that are vital in issuing permits (such as site selection, CCS stream characterisation, risk assessment, and ongoing monitoring and maintenance). ${ }^{74}$ To some extent, and somewhat ironically, the adoption of the London regime as the "home" for CCS-specific guidance is because it has presented the most substantial regulatory obstacles to the technology. ${ }^{75}$ It has been a choice

\footnotetext{
${ }^{69}$ On CCS and international liability for damage, see C Armeni, 'Carbon Capture and Storage in the Sub-Seabed and Sustainable Development: Please Mind the Gap’ (2013) 27 Ocean Yearbook 1.

${ }^{70}$ See generally T Dixon, J Garrett and E Kleverlaan "Update on the London Protocol" (2014) 63 EGYPRO 6623 at 6626; A Nollkaemper "Transboundary Movement of Hazardous Waste for the Purpose of Dumping at Sea" (1991) 22 Marine Pollution Bulletin 377.

${ }^{71}$ See IEA Fourth IEA International CCS Regulatory Network Meeting (IEA, Paris, 2012) at 5; IEA Carbon Capture and Storage Legal and Regulatory Review (3 ${ }^{\text {rd }}$ ed, IEA, 2012) at 24.

72 See Langlet, above n 44, at 399; IEA Carbon Capture and Storage and the London Protocol (IEA, Paris, 2011).

${ }^{73}$ See also Specific Guidelines, above n 61, Annex 8 at 1.5 .

${ }^{74}$ Specific Guidelines, above n 61; London Dumping Protocol Risk Assessment and Management Framework for $\mathrm{CO}_{2}$ Sequestration in Sub-Seabed Geological Structures (CS SSGS, LC/SG-CO2 1/7, Annex 3 ).

${ }^{75}$ See Langlet, above n 28, at 298.
} 
based largely on convenience, not principle; no other existing regimes are suitable. ${ }^{76}$ As a result, it is less than targeted, and contains some curious provisions. ${ }^{77}$

Most importantly, its normative roots are in the reduction of marine pollution, not in the facilitation and regulation of a climate change mitigation technology. ${ }^{78}$ This seems inconsistent with the conclusion in chapter IV that marine CCS should be treated as an activity in its own right, not painted with the negative normative brush of "dumping", "pollution" or "waste". Fortunately, the Protocol does not require municipal law to define storage as a form of dumping. It simply requires parties to implement the standards and considerations contained within it. Therefore its binding directions remain consistent with the conclusions of chapter IV.

\section{F $\quad$ Other International Instruments}

Other international instruments with relevance to marine CCS can be mentioned more briefly. New Zealand is party to the regionally-specific Noumea Convention and its Protocol on marine dumping, ${ }^{79}$ the latter of which generally mirrors the London Dumping regime. However, in its current form the Protocol would not restrict CCS over and above the requirements of the London Protocol, because the former takes a more permissive approach. ${ }^{80}$ It is also generally accepted that the Basel Convention, ${ }^{81}$ which governs the disposal and trade of hazardous wastes (including disposal to the seabed), does not apply to streams of $\mathrm{CO}_{2}$ for geological storage unless triggered by the presence of hazardous impurities. ${ }^{82}$ This is because the Convention largely refers to domestic legal requirements concerning disposal, and (as shall be seen), $\mathrm{CO}_{2}$ is not regarded as hazardous waste in New Zealand. ${ }^{83}$ In any case,

\footnotetext{
${ }^{76}$ See Langlet, above n 44 , at 401.

${ }^{77}$ For example, guidelines concede that waste prevention audits under Annex 2 of the London Protocol are not relevant to storage applications, and that "benefits" of this form of dumping need to be maximised: Specific Guidelines, above n 61, at 2.2 and 9.1.

${ }^{78}$ IPCC, above n 12 , at 254.

${ }^{79}$ Convention for the Protection of Natural Resources and Environment of the South Pacific Region [1986] PITSE 15 (signed 24 November 1986, entered into force 22 August 1990); Protocol for the Prevention of Pollution of the South Pacific Region by Dumping [1986] PITSE 16 (signed 24 November 1986, entered into force 22 August 1990).

${ }^{80}$ See art 4, Annex I. Only listed substances are prohibited, and $\mathrm{CO}_{2}$ does not fit into those categories. Amendments have been adopted that would, when in force, align the Noumea Dumping Protocol with the London Protocol as described above.

${ }^{81}$ Convention on the Control of Transboundary Movements of Hazardous Wastes and their Disposal 1673 UNTS 57 (opened for signature 22 March 1989, entered into force 5 May 1992).

${ }^{82}$ Hendriks and others, above n 6, at 79-80; Armeni, above n 34, at 157.

${ }^{83}$ See ch VI.
} 
it is primarily about exporting hazardous waste, which is unlikely to occur in the geographical context of New Zealand, and does not impose any strict prohibitions. ${ }^{84}$ Most other conventions directly applicable to marine CCS are regional in scope and do not bind New Zealand. ${ }^{85}$

\section{G Conclusion}

In this chapter I have considered what international environmental law requires of domestic CCS law. Combined with the aims in chapter IV, this presents a complete normative picture for identifying and addressing barriers and gaps in New Zealand law. In short, UNCLOS provides a robust jurisdictional foundation to regulate the technology, and imposes high level obligations concerning the protection of the marine environment. As a framework treaty, it contemplates the development of more detailed requirements elsewhere, which has been achieved mainly through the London Dumping regime. Despite some normative shortcomings, the London Protocol now allows CCS, and in the same breath imposes a variety of standards, processes and considerations. It has also served as an incubator for best practice guidelines to emerge.

\footnotetext{
${ }^{84}$ Macrory and others, above n 42, at 11.

${ }^{85}$ See, for example, Hendriks and others, above n 6 , at 83 .
} 
Part 2

Normative Evaluation for Marine CCS - Barriers and Gaps 


\section{$\xi$ \\ VI \\ Barriers in Existing Law}

\section{A Introduction}

In Part 2 I undertake a barriers and gaps analysis of New Zealand's environmental law. In this chapter I consider how the law would apply to CCS in the coastal marine area, and identify potential barriers that arise. I also refer to equivalent barriers that arise in the simpler regimes governing the exclusive economic zone (EEZ) and extended continental shelf. A barrier is a provision that prevents or inhibits the achievement of the aims described in chapter IV, and includes non-compliance with international obligations described in chapter V. It has not been uncommon for existing law to present such barriers in other jurisdictions. ${ }^{1}$ Chapter VI is structured according to key environmental statutes relevant to CCS. The most significant barriers are presented by the Resource Management Act 1991 (RMA), the Climate Change Response Act 2002 (CCRA), and the Marine and Coastal Area (Takutai Moana) Act 2011 (MCAA).

My basic proposition is that New Zealand's existing law poses a number of barriers, but that most of these arise from just three characteristics of that law. First, even law of a general and effects-based nature is often uncertain when applied to the technology, because it was not drafted with it in mind. Such fundamental uncertainty is in itself a significant barrier. Secondly, the law treats most forms of marine CCS as a kind of dumping, bringing with it inappropriately negative normative baggage that is inconsistent with the distributive principle. To address this, we could make changes to particular provisions that are unsuitable,

\footnotetext{
${ }^{1} \mathrm{P}$ Zakkour Choices for Regulating $\mathrm{CO}_{2}$ Capture and Storage in the EU (European Commission, Amsterdam, 2007) at 20 .
} 
but the better course of action would be to recognise the root cause by removing CCS from the scope of negatively charged classifications. Thirdly, existing law prohibits most climate change mitigation considerations being taken into account when authorities are making regulatory decisions on CCS. This means that the global, atmospheric and future benefits of CCS, essential under the distributive principle, may receive no or little weight in the decisionmaking process. I recommend that these barriers be removed through relatively minor legislative amendments and the development of subordinate legislative instruments.

\section{B Crown Minerals Act 1991}

Given technical similarities between CCS and mining, we might expect that the Crown Minerals Act 1991 (CMA) (and, beyond the coastal marine area, the Continental Shelf Act 1964) would apply to CCS. ${ }^{2}$ It is important to dispel such expectations. The CMA applies only to activities related to extraction, and is not a tool for wider sub-surface resource management. ${ }^{3}$ The scope of Continental Shelf Act under s 3 is wider, but its few operative provisions are also focused on mining. While their inapplicability contributes to the existence of legal gaps (considered in chapter IX), it also means that they do not pose barriers. They are therefore not considered in detail. ${ }^{4}$

In short, the CMA (most of which is incorporated by reference into the Continental Shelf $A c t)^{5}$ requires express authorisation to prospect for, explore for and mine Crown owned minerals, which is granted in accordance with minerals programmes. ${ }^{6}$ The scope of a "mineral" is able to change over time, ${ }^{7}$ but $\mathrm{CO}_{2}$ could not fit within the Act's definition. ${ }^{8}$ Nor does the Act directly allow the management of depleted petroleum reservoirs themselves (and

\footnotetext{
${ }^{2}$ See generally B Barton, K Jordan and G Severinsen Carbon Capture and Storage: Designing the Legal and Regulatory Framework for New Zealand (University of Waikato Centre for Environmental, Resources and Energy Law, Hamilton, 2013) from 44; G Severinsen "Towards an Effective Legal Framework for the GeoSequestration of Carbon Dioxide in New Zealand” (2010) 16 Canta LR 330.

${ }^{3}$ Crown Minerals Act 1991 (CMA), s 2; B Barton "Carbon Capture and Storage Law for New Zealand: A Comparative Study" (2009) 13 NZJEL 1 at 7; Severinsen, above n 2, at 335-336; Barton and others, above n 2 , at $45-52$.

${ }^{4}$ On minerals law generally, see M van Kampen and B Matheson "Minerals and Petroleum" in D Nolan (ed) Environmental and Resource Management Law ( $5^{\text {th }}$ ed, LexisNexis, Wellington, 2015).

${ }^{5}$ See ss 4, 5AA.

${ }^{6} \mathrm{CMA}$, ss 8, 25.

${ }^{7}$ See Shire of Wannon v Riordan [1955] VLR 413.

${ }^{8}$ Section 2 defines a mineral as " a naturally occurring inorganic substance beneath or at the surface of the Earth ... and includes ... all non-metallic minerals".
} 
CCS projects may utilise saline formations entirely unrelated to such reservoirs). ${ }^{9}$ The purpose of the Act highlights its normative shortcomings: "to promote prospecting for, exploration for, and mining of Crown owned minerals for the benefit of New Zealand". 10 Non-extractive activities are within its scope (such as exploration, enhanced petroleum recovery and natural gas storage), but only to the extent they are incidental to extraction. ${ }^{11}$

\section{Resource Management Act 1991 and EEZ Act 2012}

The RMA applies to CCS in the coastal marine area in a number of ways. This section considers how its purpose, regulatory restrictions, processes, and subordinate regulatory and policy instruments apply to the technology and give rise to barriers. The Exclusive Economic Zone and Continental Shelf (Environmental Effects Act) 2012 (EEZ Act) performs a similar function beyond the coastal marine area, and its equivalent provisions are cited throughout discussion of the RMA.

In short, the RMA has a wide scope, and restricts/regulates most activities that have risks of adverse environmental effects. ${ }^{12}$ As a generalisation, the core of the Act operates by providing for the creation of, and requiring compliance with, various regulatory instruments (such as rules in plans), ${ }^{13}$ and by providing for discretionary decision-making, guided by policy instruments, once regulatory provisions trigger the need for specific authorisations like resource consent. ${ }^{14}$ Regional councils have primary responsibility for the regulation of activities in the coastal marine area, through the development of rules and policies in regional coastal plans and the determination of consent applications. ${ }^{15}$ This includes responsibility for regulating discharges and dumping in the coastal marine area. ${ }^{16}$ Central government has an active role, primarily through the policies contained in the New Zealand Coastal Policy Statement (NZCPS) to which effect must be given in regional coastal plans. ${ }^{17}$

\footnotetext{
${ }^{9}$ Section 8 .

${ }^{10}$ Section $1 \mathrm{~A}$.

${ }^{11}$ Sections 23, 2 (definition of "mining").

${ }^{12}$ RMA, pt 3. On the operation of the RMA generally, see G Hewison "The Resource Management Act 1991" in P Salmon and D Grinlinton (eds) Environmental Law in New Zealand (Thomson Reuters, Wellington, 2015), ch 11.

${ }^{13}$ Sections 43A, 67-68, 75-76.

${ }^{14}$ Generally, see Environmental Defence Society v New Zealand King Salmon Co Ltd [2014] NZSC 38, [2014] NZRMA 19 at [8]-[16].

${ }^{15}$ Sections 30, 64, 104.

${ }^{16}$ Section 30.

${ }^{17}$ Sections 56-58, 67(3)(b). Compare the EEZ Act, which has a simpler structure whereby central government has wide scope to impose regulations.
} 
1 Purpose: sustainable management

Marine CCS falls within the broad purpose of the RMA. This is to promote the "sustainable management" of natural and physical resources, which is defined as: ${ }^{18}$

managing the use, development, and protection of natural and physical resources in a way, or at a rate, which enables people and communities to provide for their social, economic, and cultural well-being and for their health and safety while-

(a) sustaining the potential of natural and physical resources (excluding minerals) to meet the reasonably foreseeable needs of future generations; and

(b) safeguarding the life-supporting capacity of air, water, soil and ecosystems; and

(c) avoiding, remedying and mitigating any adverse effects of activities on the environment.

A subsurface storage site, and $\mathrm{CO}_{2}$ itself, is a "natural and physical resource" to be managed. ${ }^{19}$ The term has been deliberately left open-ended. ${ }^{20}$ Sustainable management is pertinent also because CCS operations could affect other natural and physical resources, ${ }^{21}$ including plants and animals, ${ }^{22}$ and change the condition of land, water and air. ${ }^{23}$ As Panckhurst J identified in Gebbie v Banks Peninsula District Council, 'the control and management of these issues is the very stuff of the Act'. ${ }^{24}$

\section{Regulatory restrictions on CCS}

Part 3 of the RMA contains a number of restrictions on marine activities, some of which would apply to marine CCS. Notable are restrictions on erecting structures, occupying seabed space, and dumping. I find below that is not immediately clear how pt 3, and associated restrictions in regional plans, apply to CCS. This infringes the certainty-flexibility principle and is therefore a barrier. In contrast, the EEZ Act is much clearer in restricting CCS as a form of dumping.

\footnotetext{
${ }^{18}$ Section 5. Compare EEZ Act, s 10, but note it is limited in scope to natural resources and economic wellbeing, and introduces a second purpose focusing on protection from pollution.

19 'Land' includes the general subsurface: Gebbie v Banks Peninsula District Council [2000] NZRMA 553 (HC)

at [26]. Compare EEZ Act, s 4.

${ }^{20}$ Section 2; New Zealand Rail Ltd v Marlborough District Council [1994] NZRMA 70 (HC).

${ }^{21}$ See ch I.

22 IPCC Carbon Capture and Storage (Cambridge University Press, New York, 2005) at 249.

23 See ch I.

${ }^{24}$ Gebbie, above n 19, at [25].
} 
In some ways, the application of the RMA is reasonably clear. A coastal permit (a type of resource consent) is required for disturbances of the seabed and deposits of substances likely to have an adverse environmental effect, ${ }^{25}$ the erection of structures, ${ }^{26}$ and the discharge of contaminants. ${ }^{27}$ The construction of CCS injection platforms would therefore be restricted, as would some exploration activities. For example, seismic surveying would amount to the discharge of a "contaminant" to the environment, which includes the release of energy. ${ }^{28}$

Section 12 of the RMA restricts the occupation of space in the coastal marine area. Occupation rights would be needed for the footprint of injection infrastructure. ${ }^{29}$ It is unlikely, however, that this would restrict the ongoing presence of $\mathrm{CO}_{2}$ in the subsurface. ${ }^{30}$ $\mathrm{CO}_{2}$ does not "occupy" the subsurface in the way envisaged by the Act; the basic purpose for which restrictions exist is to safeguard public access, not to authorise other activities, allocate subsurface space, or prevent discharges. ${ }^{31}$ In fact, the Act is clear that dumping and discharges of material do not require an additional permit to occupy the space into which the material is dumped or discharged. ${ }^{32}$ I conclude below that CCS is likely to amount to a dumping under the RMA, so additional consent for $\mathrm{CO}_{2}$ to occupy the subsurface would not be required. For the same reason, it is likely that the injection of $\mathrm{CO}_{2}$ is not restricted by the RMA as a "deposit" of matter beneath the seabed under s 12, or a general discharge under $\mathrm{s}$ $15 .^{33}$ Moreover, $\mathrm{CO}_{2}$ is unlikely to amount to a hazardous and toxic waste, and would thus escape prohibition under s $15 \mathrm{C}$ of the Act. ${ }^{34}$ These restrictions do not present any barriers to storage, because they do not apply to it.

In contrast, the storage of $\mathrm{CO}_{2}$ is likely a form of "dumping", and restricted under s $15 \mathrm{~A}$ of the Act where conducted from offshore installations. However, this may not be immediately

\footnotetext{
${ }^{25}$ Section 12(1)(c)-(d). Compare EEZ Act, s 20(2)(e)-(f).

${ }^{26}$ Section 12(1)(b). Compare EEZ Act, s 20(2)(a).

${ }^{27}$ Section 15B. Compare EEZ Act, s 20B, but note it applies only to "harmful" substances.

${ }^{28}$ Section 2. Compare EEZ Act, s 20(4)(b) restricting vibrations.

${ }^{29}$ Section 12(2). Contrast EEZ Act, s 20, where occupation is not expressly restricted.

${ }^{30}$ See Re Lyttelton Marina EnvC Christchurch C104/98, 4 September 1998 at [21].

${ }^{31}$ Sections 6(d), 2, 122(5); see also Hume v Auckland Regional Council [2002] NZRMA 422 (CA) at [11]-[16];

D Nolan "The Coastal Environment" in Nolan, above n 4.

${ }^{32}$ Section 12(6).

${ }^{33}$ Sections 12(6), 15(3). Compare EEZ Act, s 20(5).

${ }^{34}$ See Hazardous Substances (Minimum Degrees of Hazard) Regulations 2001, schs 4 and 6.
} 
obvious to a reader. "Dumping" is defined broadly as the "deliberate disposal" of waste or other matter. ${ }^{36}$ Injection would be "deliberate", and $\mathrm{CO}_{2}$ is a form of matter. As under the London Protocol, CCS is also likely to be a form of "disposal", given that there is an interpretive presumption that statutes are consistent with international law. ${ }^{37}$ The Act itself makes no exception for the deliberate disposal of $\mathrm{CO}_{2}$ associated with offshore petroleum activities, such as where $\mathrm{CO}_{2}$ is stripped from natural gas or deliberately disposed of as one purpose of a CCUS operation. These, too, amount to dumping. ${ }^{38}$

Some confusion arises because CCS also falls within the broad definition of a "discharge", 39 which is separately restricted under s $15 \mathrm{~B}$ of the Act. Section $15 \mathrm{~A}(3)$ provides that nothing in that section allows "any discharge of a harmful substance that would contravene section $15 \mathrm{~B} "$. It seems that even if a dumping complies with s $15 \mathrm{~A}$, it must also meet the separate requirements of $\mathrm{s} 15 \mathrm{~B}$. The latter requires authorisation for any discharge of harmful substance or contaminant in the coastal marine area. $\mathrm{CO}_{2}$ is a "contaminant". ${ }^{40}$ But while $\mathrm{s}$ 15B itself applies to the discharge of all contaminants into the coastal marine area, the implication of $\mathrm{s} 15 \mathrm{~A}(3)$ is that its applicability to dumping activities is limited to where the matter dumped is a harmful substance (such as sewage). ${ }^{41}$ It does not further restrict the dumping of matter that is not harmful. $\mathrm{CO}_{2}$ is not itself a harmful substance as defined in regulations. ${ }^{42}$ The result is that it would be restricted only under s $15 \mathrm{~A}$ as a form of dumping.

The above analysis highlights that there is a fair amount of uncertainty for CCS applicants and others in navigating pt 3 of the Act, which infringes the certainty-flexibility principle and is thus a barrier. For example, a reader may conclude that CCS is a discharge or storage of $\mathrm{CO}_{2}$, not the "disposal" of it.

The provisions of regional coastal plans may also exacerbate the uncertainty around how $\mathrm{CO}_{2}$ is classified, and therefore what restrictions apply to it. While I have not conducted an

\footnotetext{
${ }^{35}$ The definition of an offshore installation is focused on mineral exploration, but is not exhaustive: RMA, s 2; Maritime Transport Act 1994 (MTA), s 221(1). Compare EEZ Act, s 20G, but note it does not require dumping to be from an offshore installation.

${ }^{36}$ Section 2. Compare EEZ Act, s 4, where dumping also includes storage.

${ }^{37}$ See ch V.

38 Although they are exempted from most dumping requirements through regulations (see below).

39 Including to "emit, deposit, and allow to escape" under s 2.

${ }^{40}$ Which includes any substance that is likely to change the condition of a receiving environment: see $\mathrm{s} 2$.

${ }^{41}$ See s 15A(3); Resource Management (Marine Pollution) Regulations 1998 (Pollution Regulations), cls 4(2)(b), 2, 3(c), 11(2).

${ }^{42}$ See Pollution Regulations, reg 3.
} 
exhaustive review of all regional plans, in at least some cases a reader may come to different conclusions as to what rules apply. It appears that CCS has not yet been referred to specifically. Reading a plan in isolation, it may seem that the injection of $\mathrm{CO}_{2}$ triggers rules concerning the discharge of contaminants to coastal water, ${ }^{43}$ the deposit of substances under the seabed, ${ }^{44}$ or the storage of a contaminant. ${ }^{45}$ Greater certainty is needed in both pt 3 and regional plans as to how CCS is classified and which rules apply.

In contrast, the EEZ Act is much clearer that CCS is restricted as a form of dumping. Anything amounting to dumping, including CCS, is expressly excluded from the definition of a "discharge". ${ }^{46}$ Regulations now specifically refer to CCS as a discretionary form of dumping. ${ }^{47}$

\section{Barrier 1}

The ways in which restrictions in the RMA and regional plans apply to marine CCS are not sufficiently clear to reflect the certainty-flexibility principle

\section{Regulatory restrictions under regulations}

The Resource Management (Marine Pollution) Regulations 1998 (Pollution Regulations) restrict marine dumping activities, elaborating on s 15A of the RMA. They pose a significant barrier, because they likely prohibit pure CCS operations in the coastal marine area. This is inconsistent with the distributive principle. In contrast, CCS is facilitated as a discretionary activity under EEZ Act regulations, which present no comparable barriers.

The Pollution Regulations restrict dumping and discharges from offshore installations. They import the regulatory requirements of the London Protocol into domestic law by prohibiting all forms of marine dumping except for "white-listed" substances. However, they do not include the amendments made to the London Protocol in 2006, and as such $\mathrm{CO}_{2}$ is not a

\footnotetext{
${ }^{43}$ See, for example, Taranaki Regional Coastal Plan, rule G2.13.

${ }^{44}$ Ibid rules C3.7-C3.9.

${ }^{45}$ Ibid rules A1.7, B1.11.

${ }^{46}$ See s 4, definition of "discharge".

47 Exclusive Economic Zone and Continental Shelf (Environmental Effects - Discharges and Dumping) Regulations 2015 (EEZ Dumping Regulations), reg 33.
} 
substance for which a dumping permit can be obtained. ${ }^{48}$ Effectively, the Regulations deem pure CCS to be a prohibited activity in all regional coastal plans. ${ }^{49}$

There are some important exceptions to the prohibition. Where $\mathrm{CO}_{2}$ arises directly from or is related to the exploration, exploitation, and associated offshore processing of seabed mineral resources, CCS would not be prohibited. ${ }^{50}$ This would include CCUS and the offshore stripping of $\mathrm{CO}_{2}$ from natural gas, resulting in an inconsistent and arbitrary approach to prohibiting storage, based on the origin of $\mathrm{CO}_{2}$ and the existence of economic co-benefits of injection. ${ }^{51}$ The value of mining is thus assumed to be higher than the climate value of CCS, which is inconsistent with the distributive principle.

A second exception to the prohibition is where a discharge is separately authorised under $\mathrm{S}$ 15B of the RMA. ${ }^{52}$ This exception introduces significant uncertainty as to the meaning of the law. In contrast to the above discussion on s $15 \mathrm{~A}(3)$, it suggests that, as long as dumping falls within the definition of a discharge, it will escape regulation under dumping provisions entirely. Instead, it could be authorised under the (potentially) more lenient standards of $\mathrm{s}$ 15B. That could authorise the deliberate disposal of matter prohibited under the London Protocol, because regulations concerning discharges contain no blanket prohibitions nor specific parameters for $\mathrm{CO}_{2}$ storage that mirror those required by the Protocol. ${ }^{53}$

Therefore at present, two equally unacceptable interpretations are possible. The Regulations either entirely prohibit pure storage as a form of dumping, or potentially enable it (as a discharge) in variants that are inconsistent with international law. Both are barriers. The more persuasive legal interpretation is more likely to be the former. This is because regulations do not have the vires to reverse the relationship between dumping and discharges outlined (albeit not clearly) in s $15 \mathrm{~A}(3)$.

\footnotetext{
${ }^{48}$ Clause 4(2). Contrast EEZ Dumping Regulations, reg 33(d), where CCS is listed as a discretionary activity.

${ }^{49}$ RMA, s 104(3)(c)(iii).

${ }^{50}$ Pollution Regulations, reg 4(3)(a). Compare EEZ Act, s 4, where dumping excludes the disposal of matter relating to a mining activity.

${ }^{51}$ This approach also reflects inconsistent treatment in international law, although there other forms of CCS are no longer prohibited: see ch V and C Hendriks, MJ Mace and R Coenraads Impacts of EU and International Law on the Implementation of Carbon Capture and Geological Storage in the European Union (European Commission, 2005) at 37.

${ }_{53}^{52}$ Pollution Regulations, reg 4(3)(b).

${ }^{53}$ Ibid pt 3.
} 


\section{Barrier 2}

The prohibition on marine CCS in RMA Pollution Regulations fails to reflect the benefits of marine CCS under the distributive principle

\section{Barrier 3}

The ways in which restrictions in RMA Pollution Regulations apply to marine CCS are not sufficiently clear to reflect the certainty-flexibility principle

Aside from the above issues, the specific requirements of the Pollution Regulations do not pose barriers. These impose assessment criteria and record keeping obligations. ${ }^{54}$ Applicants for consent must provide specific kinds of information, consistent with the London Protocol, ${ }^{55}$ to enable a proper assessment of environmental impacts. ${ }^{56}$ They must also give consideration to the hierarchy of waste management options listed in the London Protocol, and undertake a comparative assessment of land disposal options. ${ }^{57}$ Decision-makers must have regard to the imposition of monitoring and reporting programmes, the avoidance, remedying or mitigation of environmental detriment and disturbance, and conditions concerning the types and sources of matter, dump-site location, and methods of dumping. ${ }^{58}$ Consent holders are obliged to record the source, type and quantity of matter dumped, the location of dump sites, and methods used. ${ }^{59}$ All are broadly appropriate for CCS.

Sections 107 and 138A of the RMA impose additional requirements on decision-makers when considering applications to dump matter (including $\mathrm{CO}_{2}$ ). These do not pose barriers to deployment. But they do present barriers in the sense that they are inconsistent with the certainty-flexibility principle, distributive principle and public-interest industries principle.

Under s 107, a permit cannot (in the absence of exceptional circumstances) allow dumping if it would, after reasonable mixing, be likely to cause (among other effects) any conspicuous

\footnotetext{
${ }^{54}$ Clause 7.

${ }^{55}$ Pollution Regulations, sch 3, pt 1.

${ }^{56}$ Pollution Regulations, sch 3, pt 1; RMA, s 88.

${ }^{57}$ See ch V.

${ }^{58}$ Schedule 3, pt 2.

${ }^{59}$ Clause 7; RMA s 138A(6).
} 
change in the colour or visual clarity of receiving water. ${ }^{60} \mathrm{CCS}$ streams may well do so where injected into subsurface brine, but would be largely irrelevant in a deep sub-seabed context and may prove impossible to measure. Under s 138A, a consent authority must have regard to potential alternative receiving environments. ${ }^{61}$ This does not necessarily require disposal to air or land to be preferred, but paints a picture in which, usually for good reason, dumping at sea is viewed with suspicion. For CCS, that characterisation is inconsistent with the distributive and public-interest industries principle. Similar kinds of provision are contained in the EEZ Act. ${ }^{62}$

\section{Barrier 4}

Consenting provisions under the RMA and EEZ Act assume CCS, as a form of dumping, is an undesirable activity, failing to reflect the benefits of marine CCS under the distributive principle

\section{Policy guidance under the RMA}

Policy guidance under the RMA does not prevent the deployment of CCS, but it may currently provide a balance of considerations that could fail to implement the distributive principle in practice. ${ }^{63}$ It may, therefore, present a significant barrier. Under the Act, when considering consent applications for a CCS operation under s 104, a consent authority must, and may, have regard to a variety of matters. ${ }^{64}$ This involves a contextual assessment of actual and potential effects, the content of subordinate instruments prepared under the RMA, and any other matter considered relevant and reasonably necessary to determine the application. ${ }^{65}$ Of crucial importance are policy provisions contained in the Act itself (primarily pt 2) and subordinate instruments, such as NPS, regional policy statements (RPS),

\footnotetext{
${ }^{60}$ Section $107(1)(d)$.

${ }^{61}$ Section $138 \mathrm{~A}(1)(\mathrm{b})$.

${ }^{62}$ See s 34A, where the Minister must consider alternative methods of disposal when making regulations on dumping, and $s 87 \mathrm{~F}(2)$, where consent must be refused if the matter to be dumped can be reused, recycled or treated without more than minor adverse effects or imposing unreasonable costs, or if it is considered not to be the "best" approach to disposal. Under s 34A, decision-makers are also directed not to consider the economic benefits of dumping. See also Barton and others, above n 2, at 38.

63 "Policy guidance" is used here to encompass provisions that guide the discretion of a consent authority, including pt 2 of the Act, objectives and policies in subordinate instruments, and other instruments relevant under s 104(1)(c).

${ }^{64}$ For convenience, a discretionary activity status is assumed.

${ }^{65}$ Section 104(1)(c). Compare EEZ Act, s 59(2).
} 
and regional plans. Consent authorities retain substantial discretion as to how they apply those provisions in context, but they are taken very seriously. They may not impose strict bottom lines, ${ }^{66}$ but placing unreasonably excessive or inadequate weight on a relevant policy provision may expose a decision to judicial review. ${ }^{67}$

The guidance provided in pt 2 of the RMA (ss 5-8) does not refer to CCS, and is not overtly hostile to it. ${ }^{68}$ But it also fails to recognise the kinds of benefits it has, and may tend towards the refusal of consent given its emphasis on protecting the marine environment. Part 2 provides for matters of national importance (s 6) which consent authorities must recognise and provide for, matters to which particular regard must be had (s 7), and the Treaty of Waitangi (s 8). The importance of efficient use and development of natural and physical resources is recognised, and general references to the "quality of the environment" and kaitiakitanga can be read at least partly in favour of CCS. However, on balance, pt 2 matters tend to focus on the protection of the local environment (such as the preservation of the natural character of the coastal environment, its protection from inappropriate use, the protection of habitats, the intrinsic value of ecosystems, and the enhancement of amenity values). ${ }^{69}$ This is not surprising, given that their initial conception was as biophysical bottom lines, rather than a complete set of positive and negative attributes of resource use. ${ }^{70}$ An emphasis on local protection does not prevent significant weight being given to the environmental (or other) benefits of resource use as a way to enable well-being under s $5,^{71}$ but a lack of recognition of CCS and climate change mitigation creates uncertainty as to their appropriate weighting. ${ }^{72}$ This could cause unpredictable outcomes, and the protective directions in pt 2 may prove more difficult for consent authorities to ignore than the general benefits of activities not contemplated in the Act at all. ${ }^{73}$

\footnotetext{
${ }^{66}$ See ch III.

${ }^{67}$ On judicial review in environmental matters, see T Daya Winterbottom "The Role of Administrative Law" in Salmon and Grinlinton, above $\mathrm{n} 12$.

${ }^{68}$ Contrast the purpose of the EEZ Act, in s $10(1)(\mathrm{b})$, which is more overtly hostile to activities amounting to dumping.

${ }^{69}$ See D Nolan "The Coastal Environment" in Nolan, above n 4, from 398.

${ }^{70}$ See Technical Advisory Group (TAG) Report of the Minister for the Environment's Resource Management Act 1991 Principles Technical Advisory Group (2012) at 8.

${ }^{71}$ Genesis Power Ltd v Franklin District Council [2005] NZRMA 541 (EnvC) at [61]-[66].

${ }^{72}$ See TAG, above $\mathrm{n} 70$, at 37 . The reference to climate change in $\mathrm{s} 7$ is limited to adaptation, not mitigation: see Greenpeace New Zealand Inc v Genesis Power Ltd [2008] NZSC 112, [2009] 1 NZLR 730 at [49]; West Coast ENT Inc v Buller Coal Ltd [2013] NZSC 87, [2014] 1 NZLR 32 at [130].

${ }^{73}$ See TAG, above n 70, at 38.
} 
5 Policy guidance under RMA subordinate instruments

Provisions in subordinate RMA instruments (NESs, NPSs, RPSs and regional plans) also impose a balance of considerations that is inconsistent with the distributive principle, and are thus a barrier. ${ }^{74}$ Again, this is not usually because their focus on the protection of the local marine environment is inappropriate. This is, in fact, generally demanded by the conservation-enhancement principle. It is rather because they do not actively emphasise the global climate benefits of CCS to a comparable extent. ${ }^{75}$

While NESs must be considered by a consent authority as a relevant matter under s 104(1)(b)(i), they are regulatory tools and do not themselves provide policy guidance. In contrast, NPSs do not have regulatory effect, but provide policy guidance - to steer a consent authority's discretion - once the need for consent is triggered. Lower level instruments must give effect to them. No NES or NPS in force directly concerns CCS, but two NPSs may be relevant matters in decision-making.

First, the NPS for Renewable Electricity Generation (Renewables NPS) emphasises the benefits to be derived from the use and development of renewable energy, both for climate reasons and for long-term energy security. ${ }^{76}$ While the deployment of CCS may have negative implications for renewable electricity (in that it could encourage the exploitation of fossil fuel based generation), the NPS does not require the development of non-renewable sources to be discouraged. ${ }^{77}$ Nor does the distributive principle or London Protocol support the deployment of CCS at the expense of longer-term measures like renewable generation. ${ }^{78}$ A barrier is thus presented not by the existence of the Renewables NPS, but rather by the relative lack of encouragement for CCS in a comparable instrument.

\footnotetext{
${ }^{74}$ Currently, there is no provision for policy guidance to be contained in subordinate instruments under the EEZ Act, although amendments are proposed to enable this.

75 Contrast Carbon Dioxide Capture and Geological Storage: Australian Regulatory Guiding Principles (MCMPR, 2005) at 11.

${ }^{76}$ See preamble; pol A, pol B(c). Compare NPS on Electricity Transmission 2008, pol 1(iii). See generally C Warnock "Global Atmospheric Pollution: Climate Change and Ozone" in Salmon and Grinlinton, above n 12, at 817-818; K Palmer and D Grinlinton "Developments in Renewable Energy Law and Policy in New Zealand" (2014) 32 Journal of Energy and Natural Resources Law 245.

${ }_{77}$ Greenpeace, above n 72, at [62].

${ }^{78}$ See chs 4,5 .
} 
Secondly, the New Zealand Coastal Policy Statement (NZCPS) contains policies that emphasise the relative importance of protecting the local marine environment. Under s 58 of the RMA, the NZCPS can include objectives and policies relating to (among other things) the Crown's interests in the coastal marine area and New Zealand's international obligations affecting the coastal environment. However, the contribution that the marine environment can make to climate change mitigation has not been included. Its focus remains on the protection of the local coastal environment and its ecosystems, natural character, the principles of the Treaty of Waitangi, and the importance of public access. Locally-focused objectives tend against the granting of consent for CCS injection. Injection presents a risk, not an opportunity, when measured against them; for example, injection platforms would have adverse effects on "natural" coastal character, and would to some extent also limit public access, ${ }^{79}$ (especially if safety zones were established under the Continental Shelf Act). ${ }^{80}$ Many locally protective provisions in the NZCPS are highly directive, leaving a consent authority with less discretion to weigh positive effects. ${ }^{81}$ The importance of the use and development of the coastal environment is also recognised, ${ }^{82}$ but policies only specifically recognise mineral extraction, the supply and transport of energy, and the provision of infrastructure. $^{83}$

The need for precaution is expressly recognised in policy 3 of the NZCPS, but it only directs decision makers to address the local adverse effects of activities. It does not cite precaution as a justification for action to achieve positive global effects. This narrow view of precaution is inconsistent with the spirit of the principle identified in chapter IV. In addition, policy $6(2)(d)$ provides that, where there is no functional need for an activity to be located in the coastal marine area, it should not generally be located there. Similar kinds of barriers may also be contained within RPSs and regional plans, although their extent will vary from region to region. These instruments must give effect to the NZCPS, ${ }^{84}$ which may demand strict prohibitions on industrial activities in some areas. ${ }^{85}$ Again, this fails to reflect the balance demanded by the distributive principle, particularly the principle of inter-generational equity.

\footnotetext{
${ }^{79}$ See pol 6(2)(b).

${ }^{80}$ Continental Shelf Act 1964, s 8(c).

81 See Environmental Defence Soc Inc v New Zealand King Salmon Co Ltd [2013] NZHC 1992, [2013] NZRMA 371 at [80], [122]-[127].

${ }^{82}$ Objective 6.

${ }^{83}$ Policy 6.

${ }^{84}$ RMA, ss 62(3), 67(3)(b).

${ }^{85}$ See King Salmon, above n 81.
} 
When making a decision, a consent authority is also directed to have regard to any other matter that is relevant and reasonably necessary to determine an application. ${ }^{86}$ Such matters can include instruments developed outside the RMA, and one stands out: the Energy Efficiency and Conservation Act 2000 (EECA). This aims to promote the use of renewable sources of electricity. ${ }^{87}$ The New Zealand Energy Strategy 2011-2021, developed under the Act, is more balanced in its view and recognises that the transition from fossil fuels to total reliance on renewable sources of energy will take a number of decades. ${ }^{88}$ In this time, the Strategy promotes diversity in energy sources, and the development of substantial oil and gas reserves. ${ }^{89}$ It introduces (among other things) broad aims of reducing energy-related greenhouse gas emissions, embracing new energy technologies, and ensuring energy security. ${ }^{90}$ Enabling marine CCS in the energy sector would assist in achieving these, and the Strategy expressly recognises the Government's participation in international CCS research initiatives. ${ }^{91}$ However, it also provides that emissions trading and renewable energy will be the focus of mitigation efforts. No specific reference is made to the value of CCS. EECA's focus on energy efficiency may also reduce the weight a consent authority places on the value of marine CCS, owing to the large energy penalties involved in capturing $\mathrm{CO}_{2}{ }^{92}$

When viewed holistically, the range of policy considerations to which a consent authority must or may have regard under s 104 of the RMA tend to weigh in favour of refusing consent for CCS, and do not reflect the balance of values demanded by the distributive principle. ${ }^{93}$ It is therefore a barrier. This is not because existing policies are themselves inappropriate. Most are necessary to implement the locally protective components of the conservationenhancement principle. It is rather because there is an absence of policy guidance that recognises the relative climate benefits of CCS and can be set against its risks. ${ }^{94}$ For now, it is hard to say whether the EEZ Act presents comparable barriers, because it does not yet provide for the development of subordinate policy documents.

\footnotetext{
${ }^{86}$ Section $104(1)(c)$

${ }^{87}$ Section 5.

${ }^{88}$ At 2.

${ }^{89}$ At 3 .

90 At 5.

${ }^{91}$ At 7.

92 IEA CCS Model Regulatory Framework (Paris, IEA, 2010) at 38.

${ }^{93}$ Compare TAG, above n 70, at 36-37.

${ }^{94}$ Contrast the United Kingdom's Marine Policy Statement: see B Milligan "Planning for Offshore $\mathrm{CO}_{2}$ Storage" (2014) 48 Marine Policy 162 at 166.
} 


\section{Barrier 5}

Policy provisions under the RMA provide a balance of considerations that does not reflect the global, atmospheric and long-term benefits of CCS under the distributive principle

6 Stocktake: why barriers arise under the RMA and EEZ Act

I have identified two broad kinds of barriers thus far in this chapter. First are those that arise from the absence of provisions targeted at storage. Greater clarity as to the meaning and applicability of provisions is needed to implement the certainty-flexibility principle (for example, whether CCS is a dumping, a discharge, or a deposit). The second is that existing law restricts CCS in arbitrary ways, and approaches it negatively, infringing the distributive principle. To overcome these barriers, we could amend particular provisions. For example, we could add $\mathrm{CO}_{2}$ storage to the "white list" in the RMA's Pollution Regulations. Yet to do so would address only the symptoms, not the cause.

The broader point is that negatively classifying CCS as a form of "dumping" is inconsistent with the distributive principle and public-interest industries principle. ${ }^{95}$ Dumping is a concept that is viewed as harmful for the environment, as synonymous with pollution, and as having little (or no) productive value. This explains the multitude of safeguards that apply to dumping activities under the RMA. While we must implement the London Protocol, this does not require storage to be characterised as dumping, as long as we adhere to its specific restrictions on CCS.

I therefore contend that CCS, where authorised under the RMA or EEZ Act, should be expressly excluded from the meaning of both "dumping" and "discharge", along with "pollution" and "deposit". It should be subject to its own definition and targeted restriction, which would avoid the need to rely on regulatory trigger points with a negative normative character. ${ }^{96}$ It would allow also for a targeted set of regulations to be promulgated that imposed specific prohibitions and restrictions in line with the London Protocol, some of

\footnotetext{
${ }^{95}$ See ch IV.

${ }^{96}$ For example, a more neutral approach to permitting CCS is taken in the OPGGSA(Vic), ss 1(b), 3.
} 
which would mirror existing dumping regulations. ${ }^{97}$ In this way, the barriers arising from the application of the dumping provisions of the RMA would be removed, and a clear and normatively defensible pathway created for the development of specific rules and policies in subordinate instruments. ${ }^{98}$

\section{Climate change considerations under the RMA and EEZ Act}

Removing CCS from the scope of dumping, and implementing bespoke restrictions, would not automatically overcome a third kind of barrier in existing law. Under the distributive principle and public-interest industries principle, we need to develop subordinate instruments that stress the climate benefits of CCS, to be set against numerous policies that seek to protect the local environment. But under current settings, this may not be possible in the coastal marine area. This is because, for the most part, considerations of climate change mitigation cannot be considered under the RMA. In the EEZ, this barrier is less acute.

In the early 2000s several cases were brought before the New Zealand courts in which parties requested that weight be placed on the adverse climate impacts of activities seeking resource consent. ${ }^{99}$ In short, it was accepted in these cases that global climate impacts fell comfortably within the broad definition of "effect" in the RMA. ${ }^{100}$ Yet the courts declined to place weight on effects that, in a global context, were infinitesimal, where causation was difficult to establish, and where no real policy guidance was available to guide the relative weight to be assigned to global issues. ${ }^{101}$ Regulatory restriction through the consenting process was considered to be inefficient, inappropriate and unreasonable. ${ }^{102}$ At the same time, these decisions recognised the importance of climate change, and called for a national response that would be applied consistently and coherently. ${ }^{103}$ This was delivered largely outside the RMA framework, in the form of an emissions trading scheme. ${ }^{104}$ Complementing these measures was a package of amendments to the RMA in 2004, which (generally speaking) removed

\footnotetext{
${ }^{97}$ For example, RMA, ss 15A(3), s 107(1)(g).

${ }^{98}$ On their content, see ch VII.

${ }^{99}$ Environmental Defence Soc Inc v Auckland Regional Council [2002] NZRMA 492 (EnvC); Environmental Defence Soc Inc v Taranaki Regional Council EnvC Auckland A184/02, 6 September 2002; Todd Energy Ltd v Taranaki Regional Council EnvC Wellington W101/05, 7 December 2005. See generally A Arthur-Young "Climate Change" in Nolan, above n 4, from 1150.

${ }^{100}$ See Auckland Regional Council, above n 99, at [59]-[65].

${ }^{101}$ See Taranaki Energy Watch v Taranaki Regional Council EnvC Wellington W039/03, 16 June 2003 at [86], [91] and [94]; Auckland Regional Council, above n 99, at [57], [88]; Todd Energy, above n 99, at [47].

${ }_{102}$ Auckland Regional Council, above n 99, at [88].

103 Ibid at [85]-[88].

${ }^{104}$ See Warnock, above n 76, at 800.
} 
jurisdiction to consider climate change from sub-national decision-makers. ${ }^{105}$ Economic measures have been embraced, and command and control mechanisms rejected. The rationale is that the market provides greater consistency, and additional regulatory tools would provide dual and overlapping policy responses. ${ }^{106}$

The 2004 amendments present a potentially significant barrier in the context of marine CCS, because they may prohibit planners and consent authorities from giving weight to the positive effects of the technology. In the consenting context, the key provisions of the 2004 amendments are ss 104E and 104F (these are largely mirrored in the plan-making context under ss 70A and 70B). Section 104E provides: ${ }^{107}$

When considering an application for a discharge permit or coastal permit to do something that would otherwise contravene section 15 or section $15 \mathrm{~B}$ relating to the discharge into air of greenhouse gases, a consent authority must not have regard to the effects of such a discharge on climate change, except to the extent that the use and development of renewable energy enables a reduction in the discharge into air of greenhouse gases, either-

(a) in absolute terms; or

(b) relative to the use and development of non-renewable energy.

While a literal interpretation would suggest that the prohibition on considering effects on climate change (the "prohibition") in the section is constrained in a number of ways, the courts have focused rather on the broad purpose of the 2004 Amendment Act to expand its scope. ${ }^{108}$ The Supreme Court held that: ${ }^{109}$

[t]he underlying policy of the Amendment Act was to require the negative effects of greenhouse gases causing climate change to be addressed not on a local but on a national basis while enabling the positive effects of the use of renewable energy to be assessed locally or regionally.

\footnotetext{
${ }^{105}$ Resource Management (Energy and Climate Change) Amendment Act 2004. See generally A Tal "Tried and True: Reducing Greenhouse Gas Emissions in New Zealand through Conventional Environmental Legislative Modalities" (2009) 12 Otago L Rev 149 at 160.

${ }^{106}$ Warnock, above n 76, at 800.

${ }^{107}$ See generally A Cao "Climate Change Considerations in Energy Decision-making" (2014) 18 NZJEL 111; A Arthur-Young and J Riddell "Climate Change and the RMA" [2014] NZLJ 82.

${ }^{108}$ In 3(b)(ii), "to require local authorities ... (ii) not to consider the effects on climate change of discharges into air of greenhouse gases".

${ }^{109}$ Greenpeace, above $\mathrm{n} 72$, at [55].
} 
The Court was silent as to the level at which the positive effects of other activities (like CCS) were to be assessed. Yet its broader comments reveal that the purpose has been seen as the almost wholesale transfer of jurisdiction over activities having climate impacts from local to national. ${ }^{110}$ This suggests that the prohibition applies to the consideration of activities having not only adverse effects, but also positive effects; ${ }^{111}$ the need for a specific exception to enable consent authorities to consider the positive climate effects of renewable energy supports such a view. ${ }^{112}$ So too does the Court's observation that the "commitment and the statutory and national mechanisms provided for in the [CCRA] left little - and arguably no scope for useful involvement by local authorities" in relation to the effects of activities on climate change. ${ }^{113}$

A purposive approach has also meant that the prohibition has been applied to applications for activities restricted under sections other than ss 15 or $15 \mathrm{~B} .{ }^{114}$ It is likely that jurisdiction for dumping under s 15A would be similarly constrained. Moreover, the prohibition applies to activities that do not themselves envisage, cause or propose the discharge of greenhouse gases to the air. ${ }^{115}$ It is enough that an application "relates to" a discharge into air. Effects of discharges that have not yet occurred, are not proposed to occur, or are purely hypothetical, can still "relate" to an application and are thus non-justiciable. ${ }^{116}$

Taking a purposive approach, the climate benefit of CCS is likely something that "relates" to a discharge of $\mathrm{CO}_{2}$ to air, and therefore cannot be considered. While the technology aims to prevent $\mathrm{CO}_{2}$ discharges to air, it still requires a decision-maker to consider them. This is because the benefit of storing $\mathrm{CO}_{2}$ can be meaningfully assessed only by comparing the effects of storage to the effects that would or may occur if the gas were instead emitted to the air. It is a purely hypothetical atmospheric discharge, designed as a reference point from which positive effects can be determined. The fact that an express exception for the climate benefits of renewable generation exists in s 104E indicates that such projects would otherwise

\footnotetext{
${ }^{110}$ Ibid at [58]-[62].

${ }^{111}$ See G Palmer "New Zealand's Defective Law on Climate Change" (2015) 13 NZJPIL115 at 128.

112 Greenpeace, above n 72, at [127].

${ }^{113}$ Ibid. Compare West Coast ENT, above n 72, at [173].

${ }^{114}$ West Coast ENT, above n 72, at [139], [173].

115 Ibid.

${ }^{116}$ Including a discharge from the end use of coal (a purely hypothetical discharge in the context of an application for land use consent to mine): see West Coast ENT, above n 72, at [175]-[176].
} 
be caught by the prohibition (that they also "relate" to the discharge of greenhouse gases to air). ${ }^{117}$ It suggests that similar activities not enjoying a specific exception (such as CCS) would remain subject to it.

An inability to consider climate benefits is a substantial barrier. The technology poses risks to the local environment but offers very few appreciable positive effects other than on the climate. This provides an artificial bias towards declining consent in an overall broad judgment. It would also be inefficient; a high carbon price under the emissions trading scheme may incentivise applications, only for those applications to be declined in practice.

This barrier cannot be removed entirely by using the mechanisms already contemplated by ss $70 \mathrm{~B}$ and 104F. Consistent with the purpose of transferring jurisdiction from local to national, those sections provide that decision-makers can consider effects on climate change when making rules and deciding consents, to the extent allowed in an NES. No NES currently exists, because - as some have suggested - it would be a "duality of response". ${ }^{118}$ Others have seen the lack of a climate NES as a policy failure. ${ }^{119}$ The RMA specifically allows for one to be developed. ${ }^{120}$

However, an NES is a regulatory tool that could not contain the positive policies described above. The vehicle required would be an NPS, which would recognise the national interest in the benefits of CCS under the principle of subsidiarity. In fact, the kinds of matters that must be considered in developing an NPS fit well with recognising the benefits of the technology (for example, New Zealand's interests and obligations in maintaining or enhancing aspects of the national or global environment). ${ }^{121}$ But the Act does not specifically state that an NPS is capable of overcoming the prohibition when deciding consents or making plans, leaving us in some doubt as to whether the barrier can be removed without legislative amendment.

It is most helpful to return to first principles. The courts' expansive interpretation of the purpose of the 2004 amendments likely means that regions would also be barred from developing their own climate mitigation policies. To enable the development of regional

\footnotetext{
${ }^{117}$ Implicitly accepted in Greenpeace, above n 72, at [62].

${ }^{118}$ See Warnock, above n 76, at 814. Contrast Cao, above n 107, at 146.

119 Palmer, above n 111, at 127.

120 Section 70B.

${ }^{121}$ Sections 45(2)(b)-(f).
} 
policy that could not then be considered at all at the consenting stage would be anomalous. One must also be cognisant of the High Court's direction that "given the unambiguous policy of the Amendment Act 2004... [one] must be slow to imply ... collateral jurisdiction". ${ }^{122}$ But the concern of the courts has been to shift jurisdiction from local to national level, not to remove it from the RMA entirely. A better reading of the law is, therefore, that national jurisdiction exists to the same extent that local jurisdiction has been removed. That would allow the development of an NPS that highlighted the climate benefits of CCS, which would then be given effect to in regional instruments and given weight in consenting decisions. These conclusions would not be at all obvious from a cursory reading of the RMA or case law, which infringes the certainty-flexibility principle, and legislative clarification is desirable.

The issue outlined above is less acute in the EEZ. This is because, when deciding applications for marine dumping consent, the EEZ Act does not prohibit decision-makers from considering the effects of activities on climate change. ${ }^{123}$

\section{Barrier 6}

The RMA's prohibition on consent authorities considering the impacts of activities on climate change fails to recognise the benefits of marine CCS required under the distributive principle

\section{Barrier 7}

The ability to provide national policy guidance on the climate benefits of marine CCS under the RMA is not sufficiently clear to reflect the certainty-flexibility principle

\section{Leakage under the RMA and EEZ Act}

The RMA would restrict not only injection and storage, but also any leakage of $\mathrm{CO}_{2}$ from a storage site. I contend that current settings concerning leakage under the Act are inconsistent with existing principle (primarily the public-interest industries principle), and are therefore

\footnotetext{
${ }^{122}$ Royal Forest and Bird Protection Society v Buller Coal Ltd [2012] NZHC 2156, [2012] NZRMA 552 at [41]; West Coast ENT, above n 72, at [176].

${ }^{123}$ Sections 87D and 59(5)(b).
} 
barriers, in three broad ways. First, consent conditions addressing the climate impacts of leakage may be ultra vires the Act. Secondly, the duration of conditions may be inappropriately short. Thirdly, conditions may not be sufficiently flexible. Some of these are also likely to be barriers under the EEZ Act.

Leakage to the water column would constitute a discharge of a contaminant to water, and thus be restricted by s 15(1)(a) of the RMA. An injector would likely have sufficient awareness and control over the stored gas to be held responsible for that discharge. ${ }^{124}$ However, to rely only on this restriction after a leak had occurred would be inconsistent with the precautionary principle. Rather, leakage needs to be monitored and managed pro-actively through the conditions of consent. In the EEZ, regulations may not be capable of restricting leaks of $\mathrm{CO}_{2}$ at all, so it would be even more important for robust conditions on leakage to be imposed when granting marine consent. ${ }^{125}$

However, the RMA and EEZ Act may present several barriers to doing so. First, under the RMA (although not under the EEZ Act), ${ }^{126}$ consent conditions addressing the climate impacts of leakage may be ultra vires the Act. This is for much the same reasons described earlier. If a decision-maker cannot have regard to the effects of leakage on the climate, it cannot then impose conditions or rules for that reason. Leakage can, of course, be restricted for reasons of its local impact. But it may be unreasonable in administrative law terms for conditions to take a strict approach to leakage, or subsurface migration, if risks to the local marine environment were extremely small. After all, the law takes a permissive approach to other forms of $\mathrm{CO}_{2}$ emissions that have negligible local risks. The obvious solution is the development of an NES. The RMA enables this instrument to allow climate considerations to be taken into account in decision-making, and would allow rules to be implemented in regional plans concerning leakage. This is desirable, but may not be sufficient, to ensure that all CCS consents contained site-specific conditions requiring secure storage (for reasons discussed in chapter VIII).

\footnotetext{
124 See McKnight v NZ Biogas Industries Ltd (1994) 1B ELRNZ 263 (CA) at 272-273; compare Works Infrastructure Ltd v Taranaki Regional Council [2002] NZRMA 517 (HC) at [27].

125 See EEZ Act, s 20B, where discharges are restricted only of "harmful substances", of which $\mathrm{CO}_{2}$ is not one, and from structures, of which a storage formation is not one. That means any restriction on leakage would have to be imposed directly through conditions of marine dumping consent to be effective.

${ }^{126}$ See s 34A, where there is no comparable prohibition when making regulations concerning discharges.
} 


\section{Barrier 8}

The RMA's prohibition on consent authorities considering the impacts of activities on climate change limits the ability to impose consent conditions restricting $\mathrm{CO}_{2}$ leakage

A second barrier under both the RMA and EEZ Act is that consents may be of insufficient duration to provide injectors sufficient certainty of rights under the certainty-flexibility principle. Coastal permits to dump matter under the RMA, and marine dumping consents under the EEZ Act, are limited to a maximum duration of 35 years (and may be granted for fewer), yet injection may need to occur for longer periods. ${ }^{127}$ Requiring a consent holder to renew a consent several times over the life of a project would provide additional costs and little investment certainty when making an initial business case. ${ }^{128}$

There is also a risk that conditions preventing leakage may cease to be enforceable after a period of time. Active measurement, modelling and verification may need to continue for decades following the cessation of injection, ${ }^{129}$ and the importance of preventing leakage under the public-interest industries principle means that someone must remain responsible for corrective measures and liability over the long life of a storage site. ${ }^{130}$ Current settings may therefore present a barrier. This is not to claim that conditions are rendered nugatory by the expiry of consent. Both the RMA and EEZ Act are explicit that bonds may be required to secure the performance of long-term remediation and monitoring obligations. ${ }^{131}$ The Environment Court has also held that, under the RMA, "continuing conditions of a consent are not avoided by the surrender or expiry of the consent. ${ }^{132}$ However, the period of such obligations must still be reasonable, ${ }^{133}$ and other decisions have considered that ongoing landscaping obligations fail this test. ${ }^{134}$ There remains some doubt as to whether post-closure monitoring requirements for a CCS site, over several decades, would be unreasonable. If so,

\footnotetext{
${ }^{127}$ RMA, s 123; EEZ Act, s 73(1).

${ }^{128}$ See Barton and others, above n 2, at 34. Compare Crest Energy Kaipara Ltd v Northland Regional Council [2011] NZEnvC 26, [2011] NZRMA 420 at [19]; Ministry for the Environment Freshwater Reform 2013 and Beyond (MfE, 2013) at 43.

${ }^{129}$ See Barton and others, above n 2, at 14.

${ }^{130}$ See IPCC, above n 22, at 36, 69.

${ }^{131}$ RMA, s 108A; EEZ Act, s 65.

${ }^{132}$ Bay of Plenty Regional Council v Waaka EnvC Auckland A080/09, 4 September 2009 at [24].

${ }^{133}$ Cookie Munchers Charitable Trust v Christchurch City Council EnvC Wellington W090/08, 22 December 2008 at [33].

${ }^{134}$ For example, see Munro v Manukau City Council EnvC Auckland A074/01, 16 August 2001 at [137].
} 
existing law would fail to achieve the long-term regulatory oversight needed to ensure secure storage under the public-interest industries principle. ${ }^{135}$

\section{Barrier 9}

Constraints on the duration of consent fail to provide sufficient certainty to injectors under the certainty-flexibility principle, and may fail to ensure that the long-term climate goals of CCS are achieved under the public-interest industries principle

A third barrier is that conditions may not be flexible enough to maximise climate outcomes (through advances in technology, methods, and risk models) ${ }^{136}$ required by the public-interest industries principle. The longevity of storage and extent of geological uncertainties mean that significant changes may be needed over a project's life-cycle. ${ }^{137}$ Facilitating such change is set against the participatory principle; a participatory process should not be undermined by the ability to change conditions at a later date without further public involvement. ${ }^{138}$ It is ultimately a question of balance, but one in which the public interest in climate outcomes seems to receive insufficient emphasis. ${ }^{139}$ Presently, conditions could not be varied without a full process of public participation akin to a new application for consent. ${ }^{140}$ Even the use of flexible management plans, instead of prescriptive conditions, only allows changes that are capable of objective certification and that do not require further value-judgments. ${ }^{141}$ CCS operations may need numerous alterations that go beyond this in order to maximise climate opportunities for the public good. Regulatory permission should still be obtained for such changes, ${ }^{142}$ and some community consultation conducted. ${ }^{143}$ But non-notified or limited-

\footnotetext{
${ }^{135}$ Compare Strategic Analysis of the Global Status of Carbon Capture and Storage: Report 3: Country Studies: New Zealand (GCCSI, 2009) at 19.

${ }^{136}$ On the importance of ongoing changes to risk management, see World Resources Institute (WRI) CCS Guidelines (WRI, Washington, DC, 2008) at 76; IEA, above n 92, at 87.

${ }^{137}$ See IEA, above n 92, at 62; Barton and others, above n 2, at 111.

${ }^{138}$ See ch III.

${ }^{139}$ Compare Barton and others, above n 2, at 35-36.

140 RMA, s 127(3). Compare EEZ Act, s 87J, but contrast the ability to make non-notified changes where "minor" under s 87(3)(b).

${ }^{141}$ See Mount Field Ltd v Queenstown Lakes District Council [2012] NZENVC 262 at [76]-[83]; Wood v West Coast Regional Council [2000] NZRMA 193 (EnvC) at 199; Royal Forest and Bird Protection Society v Gisborne District Council EnvC Wellington W26/2009, 7 April 2009 at [88].

${ }^{142}$ Compare Greenhouse Gas and Geological Sequestration Act 2008 (Vic) (GGGSA(Vic)), ss 160-162.

${ }^{143}$ Compare Ibid s 152.
} 
notified processes (and associated restrictions on appeal rights) would be justifiable if nonsignificant changes were necessary to achieve climate outcomes. ${ }^{144}$

\section{Barrier 10}

Consent conditions may not be sufficiently flexible to facilitate operational changes needed under the public-interest industries principle

\section{Climate Change Response Act 2002}

Three barriers are also presented by the CCRA (and the emissions trading scheme implemented under it). ${ }^{145}$ These arise primarily because the regime does not adequately implement the public-interest industries principle and the certainty-flexibility principle. First, it does not currently provide financial incentives to prevent leakage. Secondly, it provides little certainty as to when injection would amount to a "removal" for which payment (credits) can be received. Thirdly, it is uncertain when leakage would amount to an "emission" for which payment must be made (units surrendered).

The CCRA is one of very few legal instruments in New Zealand that specifically contemplates CCS. The storage of $\mathrm{CO}_{2}$ is specified as a removal activity, for which a person may choose to be a participant under the emissions trading scheme. ${ }^{146}$ In contrast to the EU CCS Directive (where captured $\mathrm{CO}_{2}$ is treated as an avoided emission), emissions would be accounted for at the point of capture and units would have to be surrendered (payment made) at that point. ${ }^{147}$ Credits would then be granted when $\mathrm{CO}_{2}$ were stored, providing an incentive to register as a participant. ${ }^{148}$ However, an order in council has not yet been made to bring this provision into force, ${ }^{149}$ which fails to provide an incentive both for CCS to occur (credits

\footnotetext{
${ }^{144}$ See Barton and others, above n 2, at 139. Compare Offshore Petroleum and Greenhouse Gas Storage (Environment) Regulations 2009 (Cth), cls 20A-21.

${ }^{145}$ On a comprehensive analysis of the scheme until 2011, see A Cameron (ed) Climate Change Law and Policy in New Zealand (LexisNexis, 2011). See also A Arthur-Young "Climate Change" in Nolan, above $\mathrm{n} 4$.

${ }^{146}$ Schedule 4, pt 2(2).

${ }^{147}$ CCRA, ss 63, 4. See Barton and others, above n 2, at 230-231; I Guddas, T Hohmuth and L Schafer "Crediting $\mathrm{CO}_{2}$ Sequestration" (2008) 4 CCLR 387; R Macrory and others Legal Status of $\mathrm{CO}_{2}$-Enhanced Oil Recovery (UCL Carbon Capture Legal Programme, 2013) at 17; Directive 2003/87/EC establishing a Scheme for Greenhouse Gas Emission Allowance Trading within the Community [2003] OJ L275/32, art 12(3).

${ }^{148}$ Barton and others, above $\mathrm{n} 2$, at 231; CCRA, ss 64-64A. Compare the treatment of CCS under the Kyoto Protocol's clean development mechanism: M Doelle and E Lukaweski "Carbon Capture and Storage in the CDM" (2012) 3 Climate Law 49 at 61.

${ }^{149}$ CCRA, sch 4, pt 2(2).
} 
would not currently be payable) and to prevent leakage if it were to occur (it is not a sector for which emitters must participate, and they may unilaterally elect to withdraw). ${ }^{150}$ The latter would infringe the public-interest industries principle.

\section{Barrier 11}

The emissions trading scheme does not provide the incentives to prevent leakage demanded by the public-interest industries principle

Furthermore, the points in time at which removal activities generate credits, and any subsequent leakages of $\mathrm{CO}_{2}$ amount to emissions, are clarified through sector-specific regulations. ${ }^{151}$ No regulations have yet been developed for CCS, so both of these points remain highly uncertain, infringing the certainty-flexibility principle. ${ }^{152}$ Such uncertainty is significant; only at the point of "removal" would credits be payable, and only at the point of "emission" would an injector be required to surrender units. ${ }^{153}$ An "emission" could conceivably be at different points (for example, the escape of $\mathrm{CO}_{2}$ from a storage site, to the water column, or to the atmosphere). Because thresholds for payment are closely related to the thresholds for regulatory action (discussed in chapter VIII), discussion of possible solutions is deferred until then.

\section{Barrier 12}

The points at which injection amounts to a "removal" and a leak amounts to an "emission" are insufficiently clear to reflect the certainty-flexibility principle

\footnotetext{
${ }^{150}$ Section 58(4). The separate specific reference to CCS in sch 4 suggests that it is not caught by the more general direction that "waste disposal" activities must be participants (sch 3, pt 6).

${ }^{151}$ Section 62(b).

152 See Climate Change (Other Removal Activities) Regulations 2009; IEA Carbon Capture and Storage: Legal and Regulatory Review ( $2^{\text {nd }}$ ed, IEA, Paris, 2011) at 41.

${ }^{153}$ Sections 63-64.
} 
The Marine and Coastal Area (Takutai Moana) Act 2011 (MCAA) is one mechanism by which the Crown has sought to implement its Treaty of Waitangi obligations. ${ }^{154}$ In allowing some culturally important activities (protected customary rights), ${ }^{155}$ and shifting some decision-making powers to Māori (permission rights in recognised customary marine title areas), ${ }^{156}$ it reflects Treaty principles. However, it may implement a balance of values that is inconsistent with the distributive principle, and thus pose a potential barrier, by allowing customary marine title groups to refuse permission for CCS on any grounds.

\section{Barrier 13}

The power for customary marine title groups to refuse permission for CCS on any grounds fails to reflect the importance of climate benefits under the distributive principle and public-interest industries principle

The Crown retains the right to pursue policies that are in the wider public interest. ${ }^{157}$ This has led to some exceptions to Māori rights of veto in customary marine title areas, where they relate to "accommodated activities" reasonably necessary for the social and economic wellbeing of New Zealanders. ${ }^{158}$ The absence of CCS on this list is inconsistent with the distributive and public-interest industries principles, because storage is equally important for long-term social, economic and environmental well-being. ${ }^{159}$ A solution may be to include authorised CCS operations as "accommodated infrastructure", by classifying it as a network utility operation under the RMA. ${ }^{160}$ Projects could not then be unilaterally prevented by title holders, but only if several safeguards in the MCAA were met. ${ }^{161}$ In practice, given the limited coverage of title areas, it is unlikely to present a significant barrier.

\footnotetext{
${ }^{154}$ Generally, see I Boisvert "Lifting the Looking Glass" (2011) 15 NZJEL 1; C Charters and A Erueti (eds) Māori Property Rights and the Foreshore and Seabed (Victoria University Press, Wellington, 2008); R Makgill "Feeling Left Out at Sea? Navigating No Ownership, Customary Rights and Resource Management" in R Boast and R Makgill Marine and Coastal Area Act - Demystifying the Hype (NZLS, Wellington, 2011); P Majurey and C Whata "Maori and Environmental Law" in Nolan, above n 4, from 976.

${ }_{155}$ Sections 51-57.

${ }^{156}$ Sections 66-70.

${ }^{157}$ See ch III.

158 Section 63.

159 See ch IV.

${ }^{160}$ MCAA, s 63; RMA, s 166.

${ }^{161}$ Section 65(1)(a).
} 


\section{F Maritime Transport Act 1994}

The Maritime Transport Act 1994 (MTA) poses one key barrier: a lack of certainty as to whether its provisions on civil liability for pollution, in pt 26A, apply to the leakage of $\mathrm{CO}_{2}$. Under s $385 \mathrm{C}$, the owner of a marine structure is liable for all pollution damage caused by any matter that is dumped from that structure. Pollution does not have to come from a "structure" directly (and may encompass a geological storage site). Liability extends to any clean-up costs incurred by the Crown, or preventative measures taken by the Crown where there is a grave and imminent threat of pollution damage. ${ }^{162}$ Pollution damage is defined widely as including "damage or loss of any kind", and includes the costs of any measures to prevent damage, reasonable measures to reinstate the environment and any loss of profit from the impairment of the environment. ${ }^{163}$ However, it does not include the wider costs of environmental damage, such as climate change, which are more difficult to quantify. It remains unclear whether likely leakage scenarios (which would have minimal risk to the local environment) would be caught. It seems unlikely. ${ }^{164}$

The public-interest industries principle, precautionary principle and polluter-pays principle demand that leakage be dis-incentivised, harm remediated, and the costs of leakage be internalised. Thus the law should clarify that pt 26A applies to leaking CCS operations where it causes local damage. While this clarification is necessary, it is not sufficient; liability under the emissions trading scheme for leakage would also be needed to compensate for climate harm (and for reasons of efficiency should not be duplicated under the MTA). In addition, targeted regulatory restrictions would be needed to prevent leakage before it occurred. ${ }^{165}$ Liability alone may not achieve this.

\section{Barrier 14}

The way in which the liability provisions of the MTA apply to CCS operations is unclear and infringes the certainty-flexibility principle

\footnotetext{
${ }^{162}$ Sections 385B-385C(1)(b).

${ }^{163}$ Section 385A.

${ }^{164}$ On pt 26A generally, see P David "Marine Pollution" in Nolan, above n 4, at 702-703.

${ }^{165}$ See chs 7-8.
} 


\section{G Hazardous Substances and New Organisms Act 1996}

The Hazardous Substances and New Organisms Act 1996 is of limited application to marine CCS and poses no significant barriers. ${ }^{166}$ It applies primarily to hazardous substances, ${ }^{167}$ of which $\mathrm{CO}_{2}$ is not one (although it may impact on substances incidental to the storage process). ${ }^{168}$ Carbon dioxide is not a hazardous substance under the Act, because it is not explosive, flammable, oxidising, corrosive or toxic, either by its intrinsic nature or when exposed to contact with water or air that is not artificially pressurised or heated. ${ }^{169}$ Compressing a substance that is not intrinsically hazardous does not render it hazardous at law. ${ }^{170}$ More guidance is found in regulations. There, $\mathrm{CO}_{2}$ is unlikely to meet the requirements for a substance with explosive, toxic, corrosive or eco-toxic properties; ${ }^{171}$ it is currently classified as a class 2.2 (non-flammable, non-toxic) gas, and is therefore not considered hazardous under the definition in the Act. ${ }^{172}$ This reflects the United Nations Model Regulations, ${ }^{173}$ in which division 2.2 relates to non-toxic, non-flammable gases and includes $\mathrm{CO}_{2}{ }^{174}$ This seems broadly appropriate as long as robust health and safety requirements applied to operations, although there may be a case for altering the classifications to treat $\mathrm{CO}_{2}$ as eco-toxic if it leaked from a storage site into the water column, given its potential impacts on marine life.

\section{H Legislation not Addressed}

Other legislation applicable to marine CCS in the coastal marine area has been considered, but is not addressed directly because it does not pose significant barriers. Various statutes concerned with the protection of specific areas and marine species are good examples; as in other jurisdictions, they seem likely to prohibit industrial activities like CCS in areas subject

\footnotetext{
${ }^{166}$ Barton and others, above n 2, at 56-57.

${ }_{167}$ And new organisms, which is not relevant to CCS.

${ }^{168}$ For example, chemicals used to fingerprint an injection stream or from the capture and transport process See IPCC, above n 22, at 69.

${ }^{169}$ Section 2. On the properties of $\mathrm{CO}_{2}$, see J Ennis King, K Pruess and N Spycher " $\mathrm{CO}_{2}-\mathrm{H}_{2} \mathrm{O}$ Mixtures in the Geological Sequestration of $\mathrm{CO}_{2}$ ” (2003) 67 Geochimica et Cosmochimica Acta 3015 at 3015.

${ }^{170}$ Section 2.

${ }^{171}$ Hazardous Substances (Minimum Degrees of Hazard) Regulations 2001, sch 1, cls 4-6.

${ }^{172}$ Environmental Protection Authority Thresholds and Classifications (2012) at 272; Hazardous Substances (Classification) Regulations 2001, reg 7(5).

${ }^{173}$ United Nations Recommendations on the Transport of Dangerous Goods Model Regulations (Geneva, 1999) at $74,198$.

${ }^{174}$ See Ministry of Transport Transporting Dangerous Goods Safely (2008) at 7.
} 
to conservation purposes or where there are impacts on sensitive species. ${ }^{175}$ Under the conservation-enhancement principle, such measures are justifiable, although confirmation of this approach would be desirable in management plans and strategies. Many other environmental laws are relevant only to terrestrial CCS. ${ }^{176}$

\section{Conclusion}

In this chapter I have considered how existing law applies to marine CCS, and concluded that barriers arise from just three general characteristics of that law. First, even law of a general, inclusive and effects-based nature is often uncertain when applied to the technology, because it was not drafted with it in mind. This is a significant barrier because it fails to reflect the certainty-flexibility principle, and is most noticeable under the RMA, the CCRA, and the MTA. Secondly, the RMA treats most forms of marine CCS as a kind of dumping, bringing with it inappropriately negative normative baggage that is inconsistent with its positive treatment under the distributive principle. Thirdly, the RMA prohibits most climate change mitigation considerations being taken into account when authorities are making regulatory decisions. This means that the global, atmospheric and future benefits of marine CCS, essential under the distributive principle, may receive no or little weight in the decisionmaking process. The 14 specific barriers to which these features give rise are summarised below.

\begin{tabular}{|ll|}
\hline Barrier 1 & The ways in which restrictions in the RMA and regional plans apply to marine \\
CCS are not sufficiently clear to reflect the certainty-flexibility principle. \\
The prohibition on marine CCS in RMA pollution regulations fails to reflect the \\
benefits of marine CCS under the distributive principle. \\
The ways in which restrictions in RMA pollution regulations apply to marine \\
CCS are not sufficiently clear to reflect the certainty-flexibility principle. \\
Barrier 4 & $\begin{array}{l}\text { Consenting provisions under the RMA and EEZ Act assume CCS, as a form of } \\
\text { dumping, is an undesirable activity, failing to reflect the benefits of marine CCS }\end{array}$ \\
under the distributive principle. & Policy provisions under the RMA provide a balance of considerations that does
\end{tabular}

\footnotetext{
${ }^{175}$ For example, Marine Reserves Act 1971, s 3; Wildlife Act 1953, ss 2B, 9, 14-14A; Marine Mammals Protection Act 1978, s 22; Sugar Loaf Islands Marine Protected Area Act 1991, s 3; Fiordland (Te Moana o Atawhenua) Marine Management Act 2005, s 7. Compare GGGSA(Vic), 192; CMA, sch 4. See generally Parliamentary Commissioner for the Environment Making Difficult Decisions: Mining the Conservation Estate (2010) at 31; Boisvert, above n 154, at 20.

${ }^{176}$ See Environment Act 1986, sch 1; Reserves Act 1977; National Parks Act 1980; Forests Act 1949, Waste Minimisation Act 2008.
} 


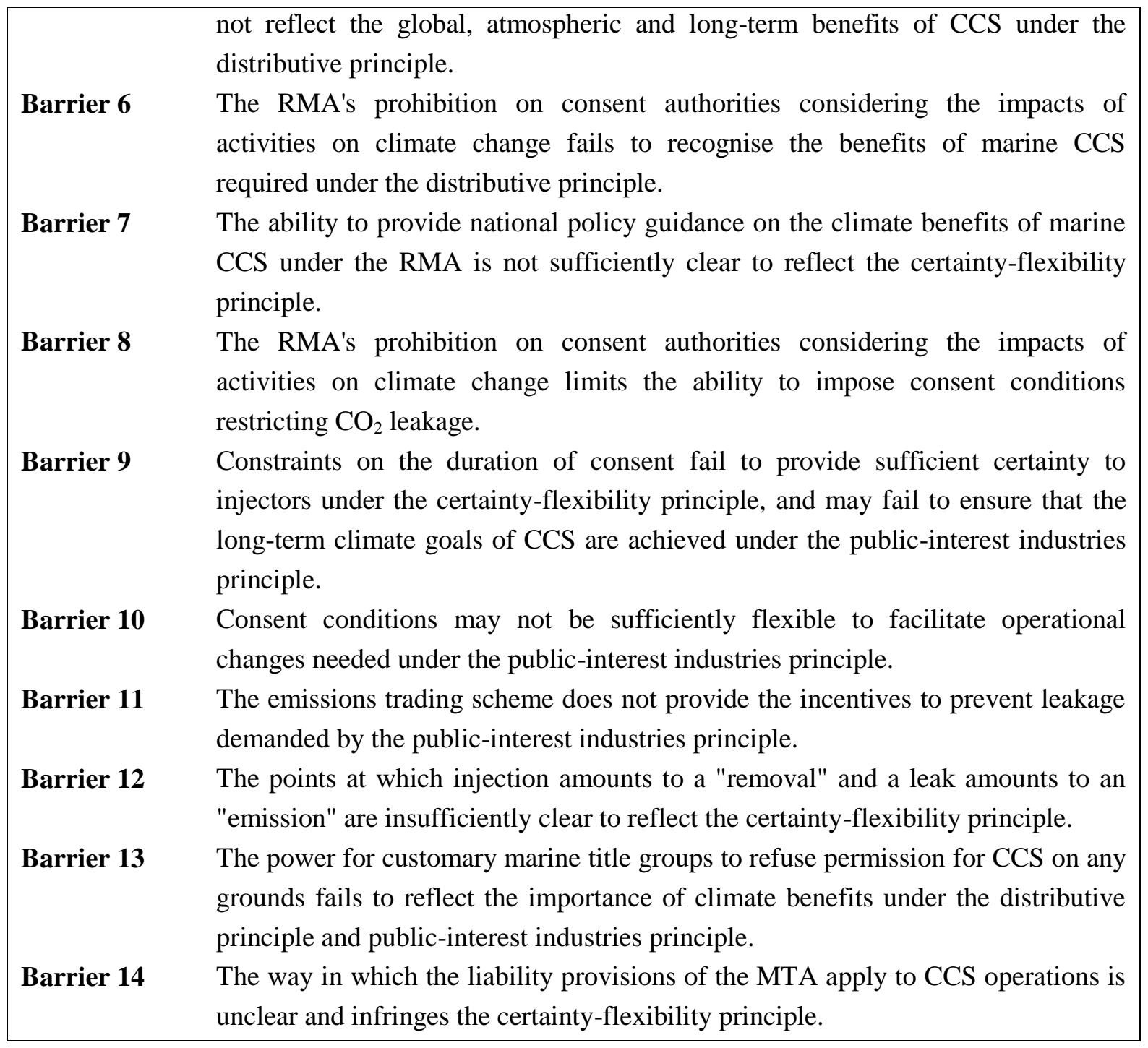

I have recommended that these barriers be removed through legislative amendments and the development of subordinate legislative instruments. Key among these recommendations is that CCS be removed from the RMA's dumping regime, and be subjected to its own, bespoke restriction under which targeted, climate-focused subordinate instruments could be developed. Specific regulations should also be developed under the CCRA to facilitate CCS under New Zealand's emissions trading scheme. 


\section{$\xi$}

\section{VII}

\section{Gaps within Legislation - Targeted Instruments}

\section{A Introduction}

In chapter VI I considered how New Zealand's existing environmental law would apply to marine CCS, and barriers it could pose. That analysis also provides a foundation to consider whether the law presents any gaps. A gap exists if existing provisions fail to realise the aims described in chapters 4 and 5 , even once barriers have been removed.

Three broad kinds of gap can be identified in New Zealand's environmental law. First are those that fail to achieve the certainty-flexibility principle. These arise because existing regimes fail to refer to marine CCS specifically. ${ }^{1}$ As identified in chapter VI, the absence of targeted provisions is a barrier. What those provisions ought to contain is a gap, and is the concern of this chapter. The second and third kinds of gaps, addressed in chapters VIII and IX, arise mainly because provisions needed for storage may be beyond the scope of existing regimes, and therefore require either new legislation or an extension of the scope of existing legislation. Chapter VIII asks whether existing regimes are capable of ensuring that secure storage is achieved. Chapter IX asks whether existing regimes are capable of effectively resolving conflicting interests in sub-surface resource use.

\footnotetext{
${ }^{1}$ New Zealand CCS Partnership CCS in New Zealand: Can Carbon Capture and Storage Deliver Value to New Zealand as we Head towards a Low Carbon Future? Summary Report (NZ CCS Partnership, 2011) at 14; On the importance of targeted laws, see GCCSI The Global Status of CCS: 2015 Summary Report (GCCSI, Melbourne, 2015) at 9; IPCC Carbon Capture and Storage (Cambridge University Press, Cambridge, 2005) at 255.
} 
I turn now to the question of what CCS-specific provisions under existing statutory frameworks should look like. Many of New Zealand's existing environmental regimes are broad in scope, highly inclusive, and effects-based (especially the RMA). ${ }^{2}$ Chapter VI has demonstrated that activities like storage are not left totally unregulated simply because they are new and different. Many aspects of the law already apply to the technology, and are already fit for purpose when measured against our aims. Our use of effects-based regimes mean that true gaps are actually few and far between.

In particular, we can observe that our framework laws, once barriers are removed, are largely adequate to address local environmental issues - to ensure that CCS is deployed in an "environmentally safe" way. ${ }^{3}$ The broad framing principle of sustainability, for example, is satisfied through the purposes of the RMA and EEZ Act. The precautionary principle is applied through their existing approaches to risk management. The strong focus on the preservation of the local marine environment in these Acts, and in conservation legislation, also satisfies the local dimensions of the distributive principle as well as the conservationenhancement principle. This is not surprising, considering that CCS involves local impacts that are already very familiar to decision-makers dealing with petroleum activities (such as seismic surveying, physical disturbance of the seabed, discharges, and the construction of offshore platforms). Treaty principles are recognised in the RMA, ${ }^{4}$ which also recognises substantive Māori values. ${ }^{5}$ Māori rights to manage resources are recognised in the Marine and Coastal Area (Takutai Moana) Act 2011 (MCAA) and specific settlement legislation. ${ }^{6}$

In terms of procedure, the participatory principle is largely satisfied by the substantial potential for public involvement in the planning and consenting processes of the RMA, including rights to submit, be heard, and appeal. ${ }^{7}$ Decisions under all environmental statutes are also at least capable of being made at a national level to reflect the national community of interest in storage, under the decision-making principle. ${ }^{8}$

\footnotetext{
${ }^{2}$ See ch III.

${ }^{3}$ Directive 2009/31/EC on the Geological Storage of Carbon Dioxide [2009] OJ L140/114 (CCS Directive) preamble at (9). See also the "sustainable development" principles in Victoria's Greenhouse Gas Geological Storage Act 2008 (Vic) (GGGSA(Vic)) ss 7(d), 8.

${ }^{4}$ RMA, s 8. Compare EEZ Act, s 12.

${ }^{5}$ For example, s 7(a).

6 Part 3; see also Waikato-Tanui Raupatu Claims (Waikato River) Settlement Act 2010.

${ }^{7}$ RMA, ss 89-121. See also International Energy Agency (IEA) Carbon Capture and Storage Model Regulatory Framework (IEA, Paris, 2010) at 48.

${ }^{8}$ For example, RMA pt 6AA, s 43. Compare GGGSA(Vic), s 191.
} 
Not all areas of the law are fit for purpose when applied to marine CCS, largely because they do not contemplate the technology specifically. Most environmental legislation in New Zealand provides a framework for decision making, within which specific controls and policies are developed in subordinate instruments. For example, the RMA has a broad purpose, principles and restrictive provisions, but provides for these to be operationalised through the development of rules, standards, objectives and policies in regulations, policy statements and plans. ${ }^{9}$ Although in much simpler form, the EEZ Act, conservation legislation and (to some extent) the MCAA operate in the same way. The purposes, principles and restrictive provisions of such legislation are sufficiently broad to encompass the regulation of almost all environmental aspects of marine CCS. ${ }^{10}$ Yet, given its novelty, the technology is not regulated specifically in legislation or in subordinate instruments. ${ }^{11}$

In chapter VI I recommended that storage be removed from the scope of dumping under the RMA and EEZ Act, and instead be subjected to bespoke restrictions while remaining subject to the Act's general purpose and processes. The thrust of that restriction would be that express authorisation is required to inject and store $\mathrm{CO}_{2}$ beneath the seabed for the purposes of permanent geological storage. Other forms of permanent $\mathrm{CO}_{2}$ storage, unless already exempted, ${ }^{12}$ would remain within the Acts' dumping regime and therefore continue to be prohibited.

Yet to create a new class of restriction for marine CCS would place the activity within a regulatory and policy limbo. It would be unclear which specific activities would trigger the need for consent, which activity statuses would be possible in plans, and the relative weight that would be given to the adverse and positive effects of storage (and leakage). To leave these issues unaddressed would encourage litigation and infringe the certainty-flexibility

\footnotetext{
${ }^{9}$ See Environmental Defence Society v New Zealand King Salmon Co Ltd [2014] NZSC 38, [2014] NZRMA 195 at [14].

${ }^{10}$ See exceptions in chs 8 and 9. Daya Winterbottom has observed that the RMA "may not be suitable" as the core framework for CCS: T Daya Winterbottom "Resource Management Act 1991 Issues" in B Barton, K Jordan and G Severinsen Carbon Capture and Storage: Designing the Legal and Regulatory Framework for New Zealand (University of Waikato Centre for Environmental, Resources and Energy Law, Hamilton, 2013) at $365,367$.

${ }^{11}$ Passing reference is made in the Climate Change Response Act 2002 (CCRA), s 168(1)(n), sch 4, pt 2.

${ }^{12}$ For example, storage as a result of enhanced petroleum recovery.
} 
principle and efficiency principle, ${ }^{13}$ as well as failing to specifically recognise the climate benefits of the technology under the distributive principle. Decision-makers would be unable to point to particular regulations or rules in regional plans, or be guided by directly relevant objectives and policies, and outcomes from the consenting process may be inconsistent across the country. ${ }^{14}$ It is therefore a gap that should be filled. That can be achieved through the development of subordinate instruments without major legislative change. ${ }^{15}$

The concept of subsidiarity suggests that it should be filled by the development of regulatory and policy instruments at the national level, to reflect the national community of interest in CCS. ${ }^{16}$ This would also ensure a consistent adherence to the requirements of international law in the coastal marine area, and facilitate an efficient process for ensuring consistency with regulation in the EEZ (which is already nationally determined). ${ }^{17}$ Under the RMA, this requires the use of an NES (for regulatory matters) and NPS (for policy matters). ${ }^{18}$ Similarly, in Australia, commentators have lamented the inconsistent and fragmented approaches taken by states. ${ }^{19}$

\section{Filling the Gaps in Regulatory Instruments}

Rules (under the RMA) and regulations (under the EEZ Act) on CCS must perform a number of functions. As explored below, they must impose standards concerning $\mathrm{CO}_{2}$ stream purity, injection activities, and leakage. The specific content of technical standards requires further work by scientists and policy makers, and is not a legal concern within the scope of this thesis. In fact, international experience has shown the value of tying specific standards to flexible and evolving documents representing current best-practice, rather than enshrining

\footnotetext{
${ }^{13}$ CCS specific regulation increases certainty, transparency and consistency: see Carbon Dioxide Capture and Geological Storage: Australian Regulatory Guiding Principles (MCMPR, 2005) at 45.

${ }^{14}$ On national consistency, see JJ Snyder "Obstacles to Carbon Capture and Sequestration by US States: Can they be Overcome?" in I Havercroft, R Macrory and RB Stewart Carbon Capture and Storage: Emerging Legal and Regulatory Issues (Hart, Oxford, 2011) at 199, 207.

${ }^{15}$ See ch VI. The Government has indicated that targeted regulations for CCS in the EEZ are unlikely to be made before 2022: see Regulatory Impact Statement: Regulations under the Exclusive Economic Zone and Continental Shelf (Environmental Effects) Act (December 2012).

${ }^{16}$ See ch IV; Barton and others, above n 10, at 365.

${ }^{17}$ On consistency in regulation across boundaries, see IEA, above n 7, at 30-31; I Boisvert "Lifting the Looking Glass" (2011) 15 NZJEL 1 at 37. Co-ordination between instruments under the RMA and EEZ Act would be important to harmonise considerations when deciding cross boundary activities under ss 88-100 of the EEZ Act.

${ }^{18}$ Daya Winterbottom, above n 10, at 368. Compare G Palmer "The Resource Management Act - How we got it and what Changes are being made to it" (2014) RM Theory\&Practice 22 at 35.

19 N Durrant "Carbon Capture and Storage Laws in Australia: Project Facilitation or a Precautionary Approach?" (2010) 18 Environmental Liability Journal 148 at [8]; Havercroft and others, above n 14, at 3.
} 
them in inflexible legal documents. ${ }^{20}$ The role of legal principle is in determining the general nature of their content.

First and foremost, standards are needed to assign appropriate activity status to injection and storage. This would trigger the need to apply for consent, and ensure that associated public notification occurred under the participatory principle. The London Protocol stipulates that no form of storage can be treated as a permitted activity. It should therefore be made clear in a new targeted restrictive provision that no person may engage in the injection of $\mathrm{CO}_{2}$ unless expressly authorised by a consent. The law would also need to impose some prohibited activity statuses, for which no consent could be applied or granted. The London Protocol demands that this be imposed where injection is to the water column, where streams are not "overwhelmingly" comprised of $\mathrm{CO}_{2},{ }^{21}$ or where streams contain other substances intended for disposal. ${ }^{22}$ Where prohibited activity status is not required under the London Protocol, marine CCS should not be broadly prohibited ex ante or treated as a non-complying activity under the RMA. ${ }^{23}$ To do so would be inconsistent with the balance of matters demanded by the distributive principle. A discretionary activity status would be most appropriate. This has already been implemented through EEZ regulations, albeit (inappropriately) as a form of dumping. ${ }^{24}$

\section{Standards for $\mathrm{CO}_{2}$-stream purity}

Under the London Protocol, streams must be "overwhelmingly" comprised of $\mathrm{CO}_{2} \cdot{ }^{25}$ The certainty-flexibility principle suggests that standards should provide clearer guidance as to what "overwhelming" means, ${ }^{26}$ and what kinds of incidental substances (or their effects) are acceptable or unacceptable. ${ }^{27}$ Doing so would set clear boundaries and expectations for potential applicants. Any proposal that did not meet these standards should be expressly

\footnotetext{
${ }^{20}$ For example, see GGGSA(Vic), s 301.

${ }^{21}$ Compare Greenhouse Gas and Geological Storage Act 2009 (Qld) (GGSA(Qld)), s 12; GGGSA(Vic), s 3; Offshore Petroleum and Greenhouse Gas Sequestration Act 2008 (Cth) (OPGGSA(Cth)), s 7.

${ }^{22}$ See ch V, compare Offshore Petroleum and Greenhouse Gas Sequestration Act 2010 (Vic) (OPGGSA(Vic)), s 488.

${ }^{23}$ Compare GGGSA(Vic), s 190.

${ }^{24}$ See ch VI.

${ }^{25}$ See ch V.

${ }^{26}$ See Alberta Government Carbon Capture and Storage: Summary Report of the Regulatory Framework Assessment (Energy Alberta, Edmonton, 2013) at 82. Even where CCS is referred to in EEZ Dumping Regulations (see ch VI), this does not refer to the purity requirements of the London Protocol.

${ }^{27}$ See GGSA(Qld), ss 83, 164. These will vary according to the storage scenario: IEA, above $\mathrm{n}$ 7, at 40.
} 
prohibited. The EU CCS Directive, for example, has stated that any incidental substances must not adversely affect the integrity of the site or pose a significant risk to the environment. $^{28}$

An initial "gateway" test for stream purity should be one of purpose. If it is not reasonably necessary for (or resulting from) the capture, transport and storage processes, we can surmise that the addition of other substances, no matter how innocuous, is for their disposal rather than incidental to climate aims. ${ }^{29}$ Marine CCS should not be used as a smokescreen for the disposal of other materials, as the latter lacks the normative basis upon which storage is positively perceived under existing principle. ${ }^{30}$ For example, the disposal of $\mathrm{CO}_{2}$ mixed with added $\mathrm{H}_{2} \mathrm{~S}$ (acid gas), a common onshore activity in Canada, ${ }^{31}$ should not be acceptable offshore.

Whether any given substance is reasonably necessary for (or resulting from) $\mathrm{CO}_{2}$ capture processes is a contextual question, given the wide variety of capture and storage scenarios possible. Under the certainty-flexibility principle, these should not be pre-determined. One exception that may be worth making explicitly, however, relates to substances that originated within the formation into which they are subsequently re-injected. Examples may be residual natural gas that is injected back into a formation together with the $\mathrm{CO}_{2}$ that had been stripped from it, or mixtures of gas and $\mathrm{CO}_{2}$ produced from a $\mathrm{CO}_{2}$-enhanced petroleum recovery operation and recycled. ${ }^{32}$ This would not offend the "mischief" the provision is designed to address - the disposal of anthropogenic wastes from elsewhere. ${ }^{33}$ Arguably it is not even a "waste" under the conservation-enhancement principle, because it already existed naturally in the formation. Nor would it be contrary to international dumping law. ${ }^{34}$ It would simply be returning a substance to where it came, after extracting the "useful" parts.

\footnotetext{
${ }^{28}$ Article 12(1); Implementation of Directive 2009/31/EC on the Geological Storage of Carbon Dioxide: Guidance Document 2 (European Commission, 2011) at 58-84.

${ }^{29}$ Compare OPGGSA(Vic), s 25(2); CCS Directive, art 12. See N Bankes "The Developing Regime for the Regulation of Carbon Capture and Storage Projects in Canada" in Barton and others, above n 10, at 326; Storage of Carbon Dioxide (Licensing etc.) Regulations 2010 (UK), sch 2(1.2); OPGGSA(Vic), s 488; OPGGSA(Cth), s 453; GGSA(Qld), s 83.

${ }^{30}$ See ch IV.

${ }^{31}$ IPCC, above $\mathrm{n} 1$, at 201.

${ }^{32} \mathrm{R}$ Macrory, and others Legal Status of $\mathrm{CO}_{2}$-Enhanced Oil Recovery (UCL Carbon Capture Legal Programme, 2013) at 16.

${ }^{33}$ Ibid at 15.

${ }^{34}$ See ch V.
} 
Where a substance were reasonably necessary for, or arose from, marine CCS processes, regulatory instruments should be realistic in setting specific purity requirements. A stream of $\mathrm{CO}_{2}$ is unlikely ever to be perfectly pure, but impurities will vary according to the capture process used and the substances present in the source of emissions. ${ }^{35}$ Under the sustainability principle, standards should be effects-based and not reflect an assumption that harm will result from their injection. But where it is known that substances in certain concentrations or quantities pose unacceptable risks to the subsurface or surface environment, they may justifiably be linked to prohibited activity status. In fact, the London Dumping Protocol specifically contemplates that states may still choose to prohibit outright forms of CCS that it allows, ${ }^{36}$ and the distributive principle does not require the climate benefits of storage to be achieved at any cost. ${ }^{37}$

We can add also that technical research should inform the development of specific standards concerning likely incidental substances, to increase regulatory certainty. For example, a review in Alberta has recommended that chemicals used in post-combustion capture be assessed for their environmental impacts. ${ }^{38}$ Investigation and classification of key impurities could be done at the national level under the aegis of the Hazardous Substances and New Organisms Act 1996, and given effect to in regulations/NES that referred to thresholds set under that Act.

A more likely scenario is that the acceptability of trace amounts of incidental substances will need to be assessed on a case by case basis according to a geological, geographical and chemical-specific assessments of environmental effects. ${ }^{39}$ The RMA and EEZ Act are already admirably suited to facilitating this kind of flexible, risk and effects-based assessment of projects. ${ }^{40}$ To ensure compliance, standards concerning stream composition should also be subject to stringent monitoring immediately prior to the point of injection, coupled with

\footnotetext{
${ }^{35}$ See C Armeni "Legal Developments for Carbon Capture and Storage under International and Regional Marine Legislation" in Havercroft and others, above n 14, at 151; London Dumping Protocol Risk Assessment and Management Framework for $\mathrm{CO}_{2}$ Sequestration in Sub-Seabed Geological Structures (CS SSGS, LC/SG-CO2 1/7) Annex 3 at 3.3. Macrory and others, above n 32, at 16.

361996 Protocol to the Convention on the Prevention of Marine Pollution by Dumping of Wastes and Other Matter 36 ILM 1 (signed 7 November 1996, entered into force 24 March 2006), art 4(2).

${ }^{37}$ See ch III.

${ }^{38}$ Alberta Government, above n 26, at 35.

${ }^{39}$ IEA, above n 7, at 41. On the importance of contextual assessment, see IPCC, above n 1, at 242.

${ }^{40}$ On the importance of flexibility, see IEA, above n 7, at 41.
} 
requirements to cease injection if standards are not met. ${ }^{41}$ Relying only on market mechanisms would be inconsistent with the precautionary principle, even though operators may also in practice have commercial incentives to remove many impurities. ${ }^{42}$

\section{Other standards for injection and storage}

Standards are important for matters other than $\mathrm{CO}_{2}$ stream purity. It may be desirable to link other specific performance standards to a prohibited activity status in regional plans, if it was known in advance that exceeding those standards would result in unacceptable local effects. For example, projects could be expressly prohibited where they were likely to exceed specific reservoir pressures, produce seismic effects, breach particular injection rates, or result in local harm from leakage.

To the extent that such standards could be generalised across all projects, the certaintyflexibility and efficiency principles encourage the development of specific regulatory requirements. If quantitative standards could not be generalised, it may be possible to do so for qualitative standards. For example, regulations/NES could specify that formation pressures must remain low enough so as not to fracture a primary geological seal. The use of qualitative standards, where possible, provides much greater transparency and certainty than an approach by which decision-makers have wide powers of veto on environmental grounds. ${ }^{43}$ The development of these standards is primarily a task for technical and policy experts. However, standards must at minimum reflect the requirements of Annex II of the London Protocol described in chapter V, and under the distributive principle not presuppose that increases in pressure, changes in subsurface chemistry, or the presence of $\mathrm{CO}_{2}$ under the seabed are automatically adverse.

As with stream composition, the reality is likely to be that there is limited room for the generalisation of other standards. ${ }^{44}$ Storage sites may vary hugely in terms of both surface and sub-surface characteristics. Careful measurement of site-specific baseline data in the marine environment is likely to be needed to understand the extent and acceptability of any given project's potential effects on the local environment, particularly in the deep offshore

\footnotetext{
${ }^{41}$ Ibid at 42 .

42 Ibid at 40.

${ }^{43}$ As under the GGGSA(Vic), ss 41, 97 and 136.

${ }^{44}$ IEA, above $n 7$, at 41 .
} 
context. ${ }^{45}$ Of course, this does not mean that the general acceptability of particular kinds of effects should be re-opened to full debate on a case by case basis. It simply suggests that the more appropriate mechanism is a contextual application of flexible policies (which can be highly directive where certain kinds of outcomes are particularly important) ${ }^{46}$ rather than prescriptive or proscriptive (and potentially arbitrary) regulatory controls. ${ }^{47}$ Moreover, the certainty-flexibility principle (and international experience) suggests that a degree of ongoing flexibility is required in consent conditions for many matters. This would not be achievable through the imposition of strict standards that are tied to prohibited activity status, because conditions do not have the power to allow prohibited activities. ${ }^{48}$

It would be possible for regulations/NES (as well as consent conditions) to incorporate by reference international standards concerning the local effects of marine CCS. ${ }^{49}$ These are currently in development. ${ }^{50}$ Doing so would provide regulatory certainty, prevent duplication of expert effort, and allow for best practice to evolve over time without needing to amend provisions through long and costly legislative or planning processes. ${ }^{51}$ However, providing external standards with blanket regulatory force may remove the ability of regulators to respond to important contextual environmental factors. Any international standards would need to be closely scrutinised with that in mind. Regulators could, instead, be encouraged to have particular regard to these documents in the planning process, and pick and choose which provisions can be generalised into binding standards in the New Zealand context. ${ }^{52}$

Under the distributive principle, the creation of specific controls on storage should occur under regulatory instruments not concerned with dumping or discharges. This is particularly important given that the nature of regulatory controls (rules and standards) are to be interpreted in light of the policies related to them. ${ }^{53}$ The current restriction on CCS under

\footnotetext{
${ }^{45}$ See World Resources Institute (WRI) CCS Guidelines (WRI, Washington, DC, 2008) at 68; Environmental Protection Authority Trans Tasman Resources Ltd Marine Consent Decision (June 2014) from [831].

${ }^{46}$ See Auckland Regional Council v North Shore City Council (1995) 1B ELRNZ 426 at 435; Environmental Defence Society Inc v New Zealand King Salmon Co Ltd [2014] NZSC 38, [2014] NZRMA 195 at [114]-[116].

${ }^{47}$ See Barton and others, above n 10, at 110.

${ }^{48}$ RMA, s 87A(6); EEZ Act, s 37(2).

${ }^{49}$ RMA, ss $46 \mathrm{~B}$ and $43 \mathrm{G}$, sch $1 \mathrm{AA}$.

${ }^{50}$ For example, see the work being produced by the International Standards Organisation in its technical committee 265, such as draft ISO 27917. Compare the Canadian standard CSA Z741.

${ }^{51}$ See RMA, sch 1AA(2)(1).

${ }^{52} \mathrm{P}$ Taylor "The Relevance of International Environmental Law for Domestic Law" in P Salmon and D Grinlinton (eds) Environmental Law in New Zealand (Thomson Reuters, Wellington, 2015) at 304.

${ }^{53}$ See Powell v Dunedin City Council [2004] 3 NZLR 721 (CA) at [35]. On the power of policies even where adverse effects are minor, see Stirling v Christchurch City Council (2011) 16 ELRNZ 798.
} 
EEZ dumping regulations is not itself inappropriate; it is simply sited incorrectly. ${ }^{54}$ Moreover, the participatory principle suggests that regulations/NES should explicitly require public notification for a storage consent application, which would bring with it an ability for all persons to submit, ${ }^{55}$ be heard, and appeal, ${ }^{56}$ and impose conditions that require a degree of community consultation. ${ }^{57}$

\section{Standards for leakage}

Provisions with regulatory force (enforceable against operators) are needed to restrict leakage of $\mathrm{CO}_{2}$ from storage sites, because leakage could have adverse impacts on the local marine environment. The primary role of such standards would be to require the imposition of conditions on consented activities to prevent subsequent leakage. ${ }^{58}$ Some minimum standards in conditions may be generalisable (for example, that there be no more than a certain percentage of total volume leaked over the course of a specified number of years). These are desirable to ensure consistency across the country and provide certainty to operators. As with debates in the 1990s over the effects of telecommunications towers, it would be inefficient to allow the same basic value-judgments around the acceptability of leakage to be re-litigated. At the same time, relying only on such standards ex ante would be insufficient, because leakage scenarios and specific thresholds would vary according to the site in question. Sitespecific conditions would be needed, guided by clear policies.

Under the public-interest industries principle, regulatory provisions (including conditions) are needed to prevent leakage not only for reasons of local environmental risk, but also climate risk. As explained in chapter VI, decision-makers under the RMA are currently prohibited from doing so, and an NES is required to overcome that barrier. Even so, questions remain as to whether this would be possible under the RMA and EEZ Act in all cases, and the issue is discussed in the following chapter. The kinds of standards needed for climate reasons will, in many cases, be valuable for addressing the risks of leakage to the local environment, and

\footnotetext{
54 Exclusive Economic Zone and Continental Shelf (Environmental Effects - Discharges and Dumping) Regulations 2015 (EEZ Dumping Regulations), reg 33(d).

${ }^{55}$ Compare Ibid reg 33(d), which already provides for CCS as a notified activity; GGGSA(Vic), ss 46-47, 102103.

${ }^{56}$ RMA, ss 96, 120.

${ }^{57}$ Compare GGGSA(Vic), ss 152-153.

${ }^{58}$ Under RMA, s 43A(2)(a)(i).
} 
could be incorporated by reference in conditions of resource consent. To avoid undue repetition, such standards are also discussed in the following chapter.

\section{Gap 1}

There are no national level legal standards that assign appropriate activity status to CCS, or that impose requirements (where generalisable) for $\mathrm{CO}_{2}$ purity, injection operations, and leakage

\section{Policy Provisions}

Regulatory provisions are only one tool in the toolkit of environmental law. Policy provisions, as contained in instruments like NPS, RPS, and regional plans, provide another. Policy provisions do not have direct binding effect like rules and consent conditions, but are important in guiding discretionary decisions once the need for consent has been triggered. Their wording is particularly important given the continued pre-eminence of the "overall broad judgment", rather than "bottom line" approach to consenting decisions under the RMA, ${ }^{59}$ where decision-maker discretion is wide. Just as targeted standards for marine CCS provide valuable certainty to regulators, applicants, and the public, so too do targeted policies. ${ }^{60}$ They are also important to ensure that the global, atmospheric and long-term benefits of storage are given appropriate weight under the distributive principle.

Currently, there is no provision for the development of policy under the EEZ Act. Change is urgently needed to allow this to happen, and is anticipated to be delivered through forthcoming amendments to the Act. ${ }^{61}$

\section{Leveraging off international standards}

Policy instruments should embrace international learnings. This chapter's earlier hesitation to embrace international standards as a blanket regulatory tool is not to say that such standards are inappropriate or irrelevant. The truth is quite the opposite. They are a valuable guide to

\footnotetext{
${ }^{59}$ See ch III.

${ }^{60}$ More than general references to "acceptable" impacts: see Offshore Petroleum and Greenhouse Gas Storage (Environment) Regulations 2009 (Cth), reg 10A.

${ }^{61}$ See Resource Legislation Amendment Bill 2015 (101-1), cl 188.
} 
best practice, and an important tool for countries to approach CCS consistently on a global basis. International standards are particularly valuable because knowledge and understanding of storage are growing much faster in those overseas jurisdictions that are informing their development than in New Zealand. ${ }^{62}$

This suggests two things. Decision-makers under the RMA and EEZ Act should have access to robust technical advice, and themselves be highly familiar with the technology. International standards and guidance should also be brought into the consenting process as a highly persuasive matter to which regard must be had, even if they do not have regulatory force. ${ }^{63}$ This would be consistent with the efficiency principle, since decision makers would not have to reinvent the wheel when considering what matters are potentially relevant and when imposing conditions. The certainty-flexibility principle also suggests that such standards should not simply be one of myriad unspecified matters to which consent authorities may already choose to have regard and give discretionary weight as "relevant and reasonably necessary to determine the application". ${ }^{64}$ To ensure consistency in the implementation of policy, they should be highly visible in national policy instruments as a matter to which substantial weight must be given. ${ }^{65}$

\section{Ensuring the provision of relevant information}

Policy instruments play a key role in ensuring that decision-makers are well-informed. They can increase certainty and efficiency in the consenting process by specifically requiring applicants to provide particular kinds of information. ${ }^{66}$ The RMA and EEZ Act already require applicants to provide an assessment of environmental effects (with a level of detail proportionate to a proposal's potential effects), ${ }^{67}$ and this framework is generally consistent with existing principle and international approaches to impact assessment. ${ }^{68}$ Consent authorities are also subject to a broad direction to take into account all actual and potential

\footnotetext{
${ }^{62}$ Such as Australia, the European Union, and Canada.

${ }^{63}$ For example, London Dumping Protocol Specific Guidelines for the Assessment of Carbon Dioxide for Disposal into Sub-Seabed Geological Formations (LC34/15, 2012), Annex 8; Risk Assessment and Management Framework, above n 35.

${ }^{64}$ RMA, s 104(1)(c); such decisions would ordinarily be a matter of discretion: Pinehaven Orchards Ltd v South Wairarapa District Council EnvC Wellington W054/06, 4 July 2006.

${ }^{65}$ On the meaning of "particular regard" see King Salmon, above n 9, at [25]-[26].

${ }^{66}$ RMA, sch 4, cl 6(2); New Zealand CCS Partnership, above n 1, at 14.

${ }^{67}$ RMA, sch 4, cl 2(3)(c); EEZ Act, s 39(2)(a). Compare OPGGSA(Cth) Regulations, above n 60, division 2.3.

${ }^{68}$ See IEA, above n 7, at 42-44; OSPAR Framework for Risk Assessment and Management of Storage of $\mathrm{CO}_{2}$ Streams in Geological Formations (2007-12) (OSPAR FRAM) at 4; Alberta Government, above n 26, at 77.
} 
effects of an activity. ${ }^{69}$ However, given that all storage projects generally give rise to comparable kinds of effects and risks, it would be more efficient and transparent if the law specifically required this kind of information to be tendered. Guidance under the London Protocol and recommendations of the International Energy Agency include extensive examples of information that would be useful to decision-makers. ${ }^{70}$

\section{Recognising the positive climate effects of marine CCS}

It is vital that policies under the RMA and EEZ Act recognise the positive impacts of storage on the climate. ${ }^{71}$ As discussed in chapter VI, in the coastal marine area this must be delivered through an NPS in order to overcome the RMA's prohibition on considering climate impacts. Exactly how much weight is accorded to climate benefits must be assessed on a case by case basis. The distributive principle does not translate into overwhelming emphasis on benefits over costs, or the automatic authorisation of specific projects. ${ }^{72}$ But it is also important to recall that, while the overall broad judgment of a consent authority is certainly not as simplistic as a mechanical "balancing" or "cost-benefit" exercise, the weight given to positive effects is relative to adverse effects. ${ }^{73}$ For example, an activity posing (even low) risks of significant adverse effects may not be consented if it enables only a modicum of socioeconomic (or environmental) well-being. ${ }^{74}$ The kinds of language used in policy provisions addressing both adverse and positive effects is therefore very significant, all the more so because other provisions in the relevant instrument are to be interpreted in light of them. ${ }^{75}$ We must place substantial weight on the global, atmospheric and long-term benefits of storage.

Moreover, while policies cannot provide the same certainty of outcome as specific regulatory controls, they should nevertheless be consistent with the certainty-flexibility principle. This suggests that policies should be clearly worded, targeted, effects-based and give some

\footnotetext{
${ }^{69}$ RMA, s 104(1)(a); EEZ Act, s 59(2).

${ }^{70}$ See IEA, above n 7, at 43; Risk Assessment and Management Framework, above n 35, Appendix 2. See also OSPAR FRAM document, above n 68, at 4.6; IEA, above n 7, at 44, 72; CCS Directive, art 7; Bankes, above n 29 , at 307.

${ }^{71}$ See ch VI.

${ }^{72}$ IPCC, above n 1, at 257.

${ }^{73}$ See JF Investments Ltd v Queenstown Lakes District Council EnvC Christchurch C48/06, 27 April 2006 at [23].

${ }^{74}$ See Te Aroha Air Quality Protection Appeal Group v Waikato Regional Council (1993) 1A ELRNZ 399 (PT) at 410 .

${ }^{75}$ Powell, above n 53, at [35].
} 
indication as to the relative importance that will be placed on the local and global matters they address. ${ }^{76}$ This is needed to avoid the confusion that characterised cases prior to the enactment of the RMA's climate prohibition. ${ }^{77}$ In the same spirit, in the United Kingdom, some commentators have emphasised the need for some kind of "policy steer" to be embedded in formal planning instruments. ${ }^{78}$ Presently, marine CCS would exist in a policy vacuum. $^{79}$

4 Targeting the adverse effects of marine CCS

Targeted policies concerning the adverse effects of the technology should be robust and protective. This accords with the high value placed on the natural character of the marine environment under the conservation-enhancement principle. Policy support for storage need not soften policies supporting stringent local protections. Many general policies of a protective character already exist under the RMA, ${ }^{80}$ and remain appropriate (such as those protecting the environment from the effects of drilling or the discharge of contaminants), but they should provide more certainty by referencing the specific kinds of effects that are to be avoided, remedied and mitigated from storage projects. This is primarily a policy rather than legal matter, and subsidiarity suggests that specific policies on adverse effects may legitimately vary from region to region. Yet there is substantial certainty and efficiency value in harmonising policies through the use of an NPS, which would recognise that there remains a substantial national interest in the marine environment under regional jurisdiction. ${ }^{81}$ An NPS should therefore outline key policies with which regional policy must be consistent, ${ }^{82}$ but not prevent the development of additional policies responding to regionally-specific circumstances. They should be more specific than a bare direction that there be no "significant environmental or health risk". ${ }^{83}$

Protective policies are not inappropriate unless they conceive of the presence of subsurface $\mathrm{CO}_{2}$ as an adverse effect in its own right. For example, the avoidance of the adverse effects

\footnotetext{
${ }^{76}$ IEA, above $\mathrm{n} 7$, at 41.

${ }^{77}$ See ch VI.

${ }^{78}$ M Lewis and N Westaway "Public Participation in UK CCS Planning and Consent Processes" in Havercroft and others, above n 14, at 286.

${ }^{79}$ Daya Winterbottom, above n 10, at 364.

${ }^{80}$ See ch VI.

${ }^{81}$ See ch III.

${ }^{82}$ For example, the protection of ecosystems and subsurface resources: see WRI, above n 45, at 3.

${ }^{83}$ See CCS Directive, art 4(4).
} 
of drilling, coastal occupation or injection in particularly sensitive ecosystems is fully consistent with the distributive principle. ${ }^{84}$ The principle simply requires the positive effects of storage to be emphasised as a nationally significant matter, ${ }^{85}$ to ensure that global, atmospheric and future effects are given appropriate weight in a consent authority's overall broad judgment. ${ }^{86}$ For example, a policy could "recognise," "acknowledge" or "support" the significant benefits that storage can have for the global climate ${ }^{87}$ while clarifying that this is not intended to undermine longer-term climate measures. Consent authorities are well-versed in resolving these tensions at the project level where policies are clearly expressed.

Policies broadly concerned with the inherent undesirability of dumping and the discharge of contaminants to the marine environment should not play a role in the refusal of consent. ${ }^{88}$ The fact that injection causes physical and chemical changes to the deep subsurface does not itself place it within the realm of an "adverse" effect when valued anthropocentrically. Where changes are limited to elements of the deep subsurface that people do not value, they are normatively neutral. ${ }^{89}$ Policies should instead focus on the importance of avoiding, remedying or mitigating specific risks to elements of the local environment that people do value or are likely to value in the future (for example, groundwater, petroleum resources, and marine life). In drafting such provisions, one may look to documents such as the Guidelines produced under the London Protocol ${ }^{90}$ and those produced under the OSPAR Convention. ${ }^{91}$ Generally speaking, international approaches and recommendations in the literature have sought to prevent "significant" risks to the local environment. ${ }^{92}$

\section{Gap 2}

There is no national level policy guidance that promotes the climate benefits of CCS, targets its specific risks, and ensures that relevant information is provided

\footnotetext{
${ }^{84}$ See WRI, above n 45, at 89; for example, see Taranaki Regional Coastal Plan, rules A1.5-A1.6.

${ }^{85}$ Consistent with Barton and others, above n 10, at 43.

${ }^{86}$ See ch IV.

${ }^{87}$ See Barton and others, above n 10, at 43.

${ }^{88}$ See also ch VIII re leakage.

${ }^{89}$ See ch IV.

${ }^{90}$ Above n 35, above n 63.

${ }^{91}$ Above n 68.

${ }^{92}$ See, for example, CCS Directive, art 4(4); IEA, above n 7, at 70.
} 
Most internal gaps arise under the RMA and EEZ Act, because they provide broad effectsbased frameworks within which targeted subordinate instruments are needed. Yet some gaps also arise under the Climate Change Response Act (CCRA). In chapter VI I concluded that, while the CCRA contemplates marine CCS as a removal activity, regulations are needed to clarify the method by which removal amounts are calculated. Similarly, they need to clarify the point at which units are payable for leakage as an "emission". Specific measurement, monitoring and verification requirements are also necessary to support an effective emissions trading scheme; we cannot know whether units are payable unless there is a robust system for quantifying and verifying leakage. ${ }^{93}$ Proper accounting and regulatory clarity are vital in ensuring market confidence in storage. ${ }^{94}$ But as Sir Geoffrey Palmer has opined, there is a "cloud of regulatory uncertainty" over aspects of the Act. ${ }^{95} \mathrm{CCS}$ is one of many examples of this.

Although the CCRA provides for regulations to be promulgated to impose particular calculation methods on a sector-specific basis, and provides no general guidance, ${ }^{96}$ several recommendations can be made as to what regulations should contain. Given that these, along with monitoring requirements, relate closely to regulatory provisions concerning the climate effects of leakage, they are discussed in following chapter.

\section{Gap 3}

There are no regulations under the CCRA that specify when storage amounts to a "removal" or when leakage amounts to an "emission"

\footnotetext{
${ }^{93}$ IEA, above $\mathrm{n} 7$, at 7.

${ }^{94}$ WRI, above $\mathrm{n} 45$, at 3 .

${ }^{95}$ G Palmer "New Zealand's Defective Law on Climate Change" (2015) 13 NZJPIL115 at 129.

${ }^{96}$ For example, see Climate Change (Other Removal Activities) Regulations 2009, reg 7 for the method by which removals are calculated for the production of methanol.
} 


\section{F $\quad$ Conclusion}

In this chapter I have identified gaps within existing legislation. These are summarised below.
Gap 1 There are no national level legal standards that assign appropriate activity status to CCS, or that impose requirements (where generalisable) for $\mathrm{CO}_{2}$ purity, injection operations, and leakage.

Gap 2 There is no national level policy guidance that promotes the climate benefits of CCS, targets its specific risks, and ensures that relevant information is provided.

Gap 3 There are no regulations under the CCRA that specify when storage amounts to a "removal" or when leakage amounts to an "emission".

Filling these gaps requires the development of targeted rules, standards, objectives and policies in subordinate legislation made under the RMA and EEZ Act, and the promulgation of regulations under the CCRA. These are necessary to promote certainty, transparency and efficiency, and to provide suitable guidance to decision makers as to how the positive and adverse effects of a storage project are to be weighed under the distributive principle. 


\section{$\xi$}

\section{VIII}

\section{Gaps outside Legislation - Security of Storage}

\section{A Introduction}

In this chapter I consider a legal gap that may require a solution outside - or an extension to New Zealand's environmental laws. This is to ensure that the secure storage of $\mathrm{CO}_{2}$ is achieved for climate reasons ("operational" success) ${ }^{1}$ not just that the local environment is protected. ${ }^{2}$ A large part of this is to ensure that leakage is prevented. Slow leaks or unauthorised subsurface migration may have de minimis local risks, yet contribute to climate change when extrapolated over many years and many sites. ${ }^{3}$ A decision maker who considered the local risks of leakage to be acceptable would not necessarily consider the cumulative global risk to be minor.

There is a gap because current law may not be able to require the climate benefits of CCS to be realised in all cases, as required by the public-interest industries principle. ${ }^{4}$ This is because secure storage may sometimes be treated as a positive effect (and thus not enforceable through conditions) rather than the prevention of an adverse effect. I conclude below that additional law is needed to ensure secure storage, including a requirement to obtain a storage permit and permit to transfer long-term liability and responsibility to the Crown.

\footnotetext{
${ }^{1}$ World Resources Institute (WRI) CCS Guidelines (WRI, Washington, DC, 2008) at 89.

2 IPCC Carbon Capture and Storage (Cambridge University Press, Cambridge, 2005) at 200.

${ }^{3} \mathrm{C}$ Hendriks, MJ Mace and R Coenraads Impacts of EU and International Law on the Implementation of Carbon Capture and Geological Storage in the European Union (European Commission, 2005) at 9; International Risk Governance Council Regulation of Carbon Capture and Storage (IRGC, Geneva, 2008) at 24.

${ }^{4}$ See also IEA CCS Model Regulatory Framework (Paris, IEA, 2010) at 14.
} 
The emissions trading scheme under the Climate Change Response Act 2002 (CCRA) is not sufficient by itself to ensure security of storage. The Act's normative focus is on the health of the global climate, ${ }^{5}$ it could provide financial incentives to retain $\mathrm{CO}_{2}$ below ground (payment must be made for leakage) ${ }^{6}$ and it allows the imposition of measurement, monitoring and verification obligations. ${ }^{7}$ But it does not provide for regulatory restrictions on $\mathrm{CO}_{2}$ emissions. Such regulatory responses - requiring preventative action to stop leaks occurring, and corrective measures to stop them if they do - are required to implement the public-interest industries principle and the precautionary principle. They have been common in CCS laws overseas. ${ }^{8}$ Because of the relatively high negative value of leaked $\mathrm{CO}_{2}$ compared to other kinds of $\mathrm{CO}_{2}$ emissions, ${ }^{9}$ our aim must be more than maintaining the economic integrity of the emissions trading scheme. ${ }^{10}$ We need to manage and prevent leakage right from the site selection stage, not only respond once it occurs. ${ }^{11}$

Relying only on emissions trading may also fail to implement the polluter-pays principle, if it were possible for responsibility for leakage to be evaded entirely. ${ }^{12}$ A CCS company may simply cease to exist, or not have the financial capacity to pay the total amount for which it is liable under the scheme. This is a real risk, especially if the price of carbon emissions became significantly higher at the point of leakage than the point of injection. ${ }^{13}$ Due to this uncertainty, some operations may even be uninsurable. ${ }^{14}$ Furthermore, it the carbon price were to fall relative to the costs of corrective measures, the financial incentive to prevent leakage could be weakened or disappear entirely, to the detriment of climate outcomes.

\footnotetext{
${ }^{5}$ Section 3 .

${ }^{6}$ See ch VI.

${ }^{7}$ Section 62.

${ }^{8}$ See also P Zakkour Choices for Regulating $\mathrm{CO}_{2}$ Capture and Storage in the EU (European Commission, Amsterdam, 2007) at 5, 6, 11; Directive 2009/31/EC on the Geological Storage of Carbon Dioxide [2009] OJ L140/114 (CCS Directive), preamble at (30).

${ }^{9}$ See ch IV; Hendriks and others, above n 3, at 49.

${ }^{10}$ Contrast P Marston and P Moore "From EOR to CCS" (2008) 29 Energy Law Journal 421 at 441.

${ }^{11}$ See I Havercroft and R Purdy "Carbon Capture and Storage - A Legal Perspective" <www.un.org> at 14.

12 See ch IV.

${ }^{13} \mathrm{C}$ Hendriks and others, above $\mathrm{n} 3$, at 49.

${ }^{14}$ See A Ingelson, A Kleffner and N Nielson "Long-term Liability for Carbon Capture and Storage in Depleted North American Oil and Gas Reservoirs" (2010) 31 Energy Law Journal 431 at 464, 469. Such risks may be uninsurable: see PK Freeman and H Kunreuther "The Roles of Insurance and Well-Specified Standards in Dealing with Environmental Risks" (1996) 17 Managerial \& Decision Econ 517.
} 
We face the opposite dilemma when we look at the RMA and EEZ Act. They provide for regulatory responses to environmental issues (rules, standards and conditions), but may have normative limitations in restricting the climate effects of leakage. This is not simply because the RMA imposes a prohibition on considering the effects of activities on climate change, which can, and should, be overcome through the use of national instruments. ${ }^{15}$ One could also argue that the eschewal of climate considerations reflects more systemic problems with the RMA's ability to address climate issues, hinted at in the failed climate change jurisprudence that preceded the 2004 prohibition. ${ }^{16}$ This is not a difficulty unique to New Zealand. Other countries have also seen a difference in character between effects usually regulated under environmental regimes and the climate impacts of leakage, and have felt compelled to regulate for the latter specifically. ${ }^{17}$

\section{Positive Effects, Adverse Effects, and Conditions under the RMA/EEZ Act}

A more significant gap in the RMA and EEZ Act is their inability to ensure that positive effects of activities are achieved. This means that in some cases they may not allow consent authorities to impose conditions to prevent leakage for climate reasons. Because each storage scenario would be unique, such site-specific leakage conditions (not just general standards in rules) would be needed to implement the public-interest industries principle effectively.

The RMA (and, by analogy, the EEZ Act) operates by enabling people to provide for their own well-being. ${ }^{18}$ In this sense it is permissive and market-led, and does not drive the deployment of particular activities that may better enable communities to achieve positive effects. Policies developed under the RMA may stress the benefits of some resource uses, but regulatory tools (rules and conditions) are designed to guard against adverse effects, not achieve or maximise benefits. As the Environment Court has pointed out, "the primary

\footnotetext{
${ }^{15}$ See ch VI.

${ }^{16}$ See Environmental Defence Soc Inc v Auckland Regional Council [2002] NZRMA 492 (EnvC) at [88]. See also Environmental Defence Society v Taranaki Regional Council EnvC A084/2002, 6 September 2002 at [45].

${ }^{17}$ See IPCC, above n 2, at 242; R Pritchard "Carbon Capture and Storage - A Review of the Australian Legal and Regulatory Regime" in B Barton, K Jordan and G Severinsen Carbon Capture and Storage: Designing the Legal and Regulatory Framework for New Zealand (University of Waikato Centre for Environmental, Resources and Energy Law, Hamilton, 2013) at 271; Zakkour, above n 8, at 2; C Hendriks and others, above $\mathrm{n} 3$, at 21; K Robertson, J Findsen, and S Messner International Carbon Capture and Storage Projects (DOE/NETL, 2006) at 13; Offshore Petroleum and Greenhouse Gas Sequestration Act 2010 (Vic) (OPGGSA(Vic)), s 64(1)(b).

${ }^{18}$ The basic structures of the EEZ Act's purpose and consenting provisions are very similar to the RMA, but there has been comparatively little case law on such points.
} 
emphasis of the RMA is on consent-holders avoiding or mitigating the effects ... caused by them", ${ }^{19}$ and the High Court has recognised that the general scheme of the RMA is that that only adverse effects "greater" than those already permitted are to be considered. ${ }^{20}$ What this means in practice is fourfold.

First, those with functions under the Act are called upon in a general sense to improve the environment (provide benefits). ${ }^{21}$ Secondly, the need to obtain consent for private activities, like CCS, under planning instruments is triggered by their adverse effects. ${ }^{22}$ Thirdly, as a generalisation, consent authorities must weigh both the positive and adverse effects of a proposal within the matrix of sustainable management (an "overall broad judgment"), ${ }^{23}$ having regard to various policy provisions. Policies may emphasise the relative importance of adverse and positive effects. ${ }^{24}$ Fourthly, a consent may be granted or refused, and, if granted, be subject to conditions with which a consent holder must comply. ${ }^{25}$ Conditions cannot generally require that positive effects be realised.

Thus regulators themselves are directed to achieve positive environmental effects, ${ }^{26}$ and when making decisions must consider a wide range of benefits and give weight to policies that stress their value. ${ }^{27}$ But they are then practically constrained in the ways they can require those to be achieved. Generally speaking, they can control private activities through rules and conditions only on the basis of their potential for adverse effects. ${ }^{28}$ For example, whether an activity is financially viable (whether its expected economic benefits are actually forthcoming) has been seen as a matter "for the boardroom". ${ }^{29}$ As the language of the Act's purpose suggests, "enabling" people to provide for their own well-being is a passive part of

\footnotetext{
${ }^{19}$ JF Investments Ltd v Queenstown Lakes District Council EnvC Christchurch C48/06, 27 April 2006 at [40].

${ }^{20}$ See Nash v Queenstown Lakes District Council [2015] NZHC 1041 at [92].

${ }^{21}$ See ch III.

${ }^{22}$ RMA, s 68(3).

${ }^{23}$ See ch III.

${ }^{24}$ See Queenstown Central v Queenstown Lakes District Council [2013] NZHC 815 at [32]; RMA, s 104(1).

${ }^{25}$ Sections 104A-104C, 108.

${ }^{26}$ Sections 30(1)(a), 31(1)(a).

${ }^{27}$ See Royal Forest and Bird Protection Society v Buller District Council [2013] NZHC 1346, [2013] NZRMA 293 at [60]; JF Investments, above n 19, at [36], [40].

${ }^{28}$ See Gisborne District Council v Eldamos Investments Ltd HC Gisborne CIV-2005-485-1241, 26 October 2005 at [44]-[46]; Flavell v Western Bay of Plenty District Council EnvC Auckland A016/05, 3 February 2005 at [97].

${ }^{29}$ New Zealand Rail Ltd v Marlborough District Council [1994] NZRMA 70 (HC) at 92; compare Lower Waitaki River Management Society Inc v Canterbury Regional Council EnvC Christchurch C080/09, 21 September 2009 at [202]; Environmental Defence Soc Inc v Taranaki Regional Council EnvC Auckland A184/02, 6 September 2002 at [19].
} 
the sustainability equation, not one to be enforced. Whether an impact amounts to a positive or adverse effect is therefore of some significance. In some cases, leakage of $\mathrm{CO}_{2}$ from a storage site may be treated not as an adverse effect, but rather as a failure to obtain a positive effect.

Case law supports this conclusion. The courts have held that a condition of consent must relate to a resource management purpose ${ }^{30}$ fairly and reasonably relate to the activity consented (rather than ulterior concerns), ${ }^{31}$ be intra-vires the powers of the consent authority, and not be unreasonable. ${ }^{32}$ Effectively, powers are constrained by the administrative law principles first set out in Newbury $v$ Secretary of State for the Environment. ${ }^{33}$

The Supreme Court in Waitakere City Council $v$ Estate Homes Ltd has since taken a relatively expansive view of lawful conditions, stating that administrative law does not constrain conditions to "circumstances where they would ameliorate the effects of the proposed development". ${ }^{34}$ All that is required is a logical connection and reasonableness. Yet it is not clear that this general conclusion of administrative law displaces a large body of case law that has developed around the meaning of what is, in fact, "reasonable". Many decisions have held that, apart from conditions requiring financial contributions (which are not so constrained), unreasonable and therefore ultra vires conditions include those that impose measures above and beyond what is required to mitigate the adverse effects of an activity. ${ }^{35}$ This is the case even where a consent authority has, in making its discretionary judgment, given substantial weight to the projects' potential benefits. In fact, post-Estate Homes jurisprudence suggests that the practical impact of that case may not be as significant as it appears. The courts have continued to link "reasonableness" with the mitigation of the broad adverse effects of proposals. ${ }^{36}$ Moreover, proposed amendments to the RMA in the Resource

\footnotetext{
${ }^{30}$ Housing New Zealand v Waitakere City Council [2001] NZRMA 202 (CA); Waitakere City Council v Estate Homes Ltd [2006] NZSC 112, [2007] 2 NZLR 149 at [20], [61].

${ }^{31}$ Estate Homes, at [66].

${ }^{32}$ Estate Homes, at [66]; Cookie Munchers Charitable Trust v Christchurch City Council EnvC Wellington W090/08, 22 December 2008 at [33].

${ }^{33}$ Newbury $v$ Secretary of State for the Environment [1981] AC 578.

${ }^{34}$ Estate Homes at [64]; Housing New Zealand Ltd v Waitakere City Council [2001] 1 NZLR 340 (HC) at [24], [31].

${ }^{35}$ For example, see Sampson v Waikato Regional Council EnvC Auckland A178/02, 2 September 2002 at [84]; Alexander v Auckland City Council (1999) 5 ELRNZ 411 (EnvC) at 414.

${ }^{36}$ See, for example, Reuters Homes Ltd $v$ Wanganui District Council [2011] 16 ELRNZ 493 (HC) at [42]-[44]; Morgan v Whangarei District Council [2008] NZRMA 113 (HC) at [33]-[34]; Queenstown Central v Queenstown Lakes District Council [2013] NZHC 815 at [79]; Infinity Investment Group Holdings Ltd v Queenstown Lakes District Council [2011] NZRMA 321 (HC) at [42].
} 
Legislation Amendment Bill specifically state that conditions cannot be imposed unless "directly connected" to an adverse effect of the activity on the environment or an applicable rule. ${ }^{37}$ This would narrow the scope of lawful conditions envisaged in Estate Homes. Ultimately, the position under the RMA is not abundantly clear since the Supreme Court's decision, and the degree of connection between a condition and a development, and thus its reasonableness, must be determined in context. ${ }^{38}$ The EEZ Act is more explicit that conditions can be imposed only to "deal with adverse effects of the activity ... on the environment or existing interests". 39

\section{Secure Storage as a Positive Effect}

Where a storage project posed only de minimis risks of local adverse effects, secure storage is (in some cases) likely to be treated as a positive effect on the climate (and leakage as the failure to obtain that positive effect) and thus unenforceable through conditions. The contexts in which this is likely to be the case depends on the point in time against which impacts are measured. If we compare the effect of leakage with the secure storage that existed immediately prior to the leakage, ${ }^{40}$ it is as an adverse effect. It would make a negative contribution to the climate that would not have existed had the leakage not occurred. In contrast, if we compare the state of the climate that could lawfully have existed prior to the emissions being captured, leakage is a failure to achieve a positive effect. The alternative to storage would have been an unrestricted release of $\mathrm{CO}_{2}$ by the original emitter to the atmosphere (there would simply have been an obligation to pay under the emissions trading scheme).

Both points of view are conceptually valid. Yet the courts have developed a relatively precise point of reference under the RMA, and there is little reason to imagine the situation would be different under the comparable EEZ regime. Effects are measured against a reference-point commonly described as the "existing environment". Under the leading authority of Queenstown Lakes District Council v Hawthorn, this is the environment as it exists at the time of application, and the environment that could potentially exist in the future if non-

\footnotetext{
${ }^{37}$ Resource Legislation Amendment Bill 2015, cl 64.

${ }^{38}$ See Morgan, above n 36, at [48].

${ }^{39}$ Sections 63(1), 87F(4).

${ }^{40}$ A consent to discharge into a controlled area does not confer the right to discharge beyond that area: see McKnight v NZ Biogas Industries Ltd (1994) 1B ELRNZ 263 (CA) at 272-273; Barton and others, above n 17, at 29 .
} 
fanciful permitted activities or already-consented activities (which are more likely than not to be implemented) occurred. ${ }^{41}$ That environment does not assume the existence of consents for which a person may apply in the future. ${ }^{42}$

The fairly dogmatic test in Hawthorn has been softened by subsequent case law, which has recognised that its underlying concern is finding a realistic or non-artificial description of the environment in which an activity would occur. ${ }^{43}$ A decision-maker has substantial discretion to determine whether consents or permitted rights are, in fact, "more likely than not" to be implemented, ${ }^{44}$ but the existing environment test itself is not optional. ${ }^{45}$ This is different from the "permitted baseline" test. ${ }^{46}$ There, consent authorities can choose whether or not to disregard any permitted adverse effects of a proposal once the existing environment has been determined. ${ }^{47}$ But there is no scope to artificially exclude matters when describing a factually-determined, realistic, environment in which the proposed activity would occur and to which the permitted baseline may then be applied. ${ }^{48}$

While most arguments have revolved around the measurement of adverse effects, there is no reason to doubt that this conception of the existing environment also forms the reference point from which positive effects are measured. Recent case law, including from the Supreme Court, supports this view. ${ }^{49}$

If looked at as a whole process chain, CCS operations that involved a voluntary retrofit of emitting activities (such as a fertiliser plant) with capture facilities would improve upon the

${ }^{41}$ Queenstown Lakes District Council v Hawthorn [2006] NZRMA 424 (CA) at [84]; see also Far North District Council v Te Runanga-a-Iwi O Ngati Kahu [2013] NZCA 221 and Royal Forest and Bird Protection Society v Buller District Council [2013] NZCA 496, (2013) 17 ELRNZ 616 at [23]; Save Kapiti Inc v New Zealand Transport Agency [2013] NZHC 2104 at [78], Burgess v Selwyn District Council [2014] NZEnvC 11 at [74], [79].

${ }^{42}$ Hawthorn at [80].

${ }^{43}$ See Royal Forest and Bird v Buller District Council [2013] NZHC 1324, [2013] NZRMA 275 at [59]; Queenstown Central v Queenstown Lakes District Council [2013] NZHC 815 at [64]-[66], [84]; Save Kapiti, above n 41, at [70]; Rive "Update on Case Law" in Environmental Law Intensive (NZLS, 2014) at 1-16.

${ }^{44}$ See Calveley v Kaipara District Council [2014] NZEnvC 182 at [19].

${ }^{45}$ See Rive, above n 43, at 15.

${ }^{46}$ See Ngati Kahu, above n 41, at [88]-[91]; Save Kapiti, above n 41, at [70]; Royal Forest and Bird, above n 41, at [23]-[25].

${ }^{47}$ RMA, s 104(2). On the permitted baseline, see Hawthorn at [65], Smith Chilcott Ltd v Auckland City Council [2001] 3 NZLR 473 (CA), Arrigato Investments Ltd v Auckland Regional Council [2002] 1 NZLR 323 (CA); M Casey "Land Use" in P Salmon and D Grinlinton (eds) Environmental Law in New Zealand (Thomson Reuters, Wellington, 2015) at 622.

${ }^{48}$ See Ngati Kahu, above n 41, at [94]; Nash, above n 20, at [64], [97].

49 Save Kapiti Inc v New Zealand Transport Agency [2013] NZSC 123 at [4]; Save Kapiti, above n 41, at [70], [77]. 
existing environment - where that environment is defined as one in which non-fanciful permitted activities, consented activities likely to be implemented, and general kinds of activities signalled clearly in planning instruments, are assumed to occur. ${ }^{50}$ The fertiliser plant would already be authorised, and an operator would already be lawfully entitled to emit $\mathrm{CO}_{2}$ with no regulatory restriction. ${ }^{51}$ The presence of emitted $\mathrm{CO}_{2}$ in the air would be a nonfanciful description of the environment as it could exist if permitted or consented effects ( $\mathrm{CO}_{2}$ emissions) occurred. In the words of the Court of Appeal in Hawthorn, "the task of predicting the likely future state of the environment ... [would not be] difficult": ${ }^{52} \mathrm{CO}_{2}$ would likely be in the atmosphere. Even if our focus is only on the storage phase rather than the whole process chain, and the emitter and CCS operator were separate persons (as seems likely), secure storage would amount to a positive effect. Consents must operate exclusively between an applicant (an injector) and a consent authority, and conditions can be imposed only to address the adverse effects of one's own activity on the environment, not another's. ${ }^{53}$ The adverse effect would stem from the emitter's already authorised activity, which an injector would then be mitigating.

A second scenario in which secure storage would be a positive effect is where a project involves bio-energy CCS (BECCS). ${ }^{54}$ When viewed holistically, BECCS projects do not mitigate the adverse effects of an emitting activity. Rather they provide a net benefit to the climate by removing pre-existing $\mathrm{CO}_{2}$ from the atmosphere. The non-fanciful "existing environment" against which its effects would be measured has higher concentrations of atmospheric $\mathrm{CO}_{2}$ than if the BECCS project occurred. ${ }^{55}$

\section{E Exceptions for the Enforcement of Positive Effects: Offsetting}

There are limited cases in which positive effects are enforceable through conditions, but the mechanisms for doing so do not provide sufficient assurance of secure storage in cases involving retrofits and BECCS. Sometimes an applicant may wish to undertake environmentally beneficial measures that are not sufficiently connected to a project's adverse

\footnotetext{
${ }^{50}$ Voluntary measures would be incentivised by the emissions trading scheme.

${ }^{51}$ As long as payment were made under the emissions trading scheme.

${ }^{52}$ Hawthorn at [61].

${ }^{53}$ See JF Investments, above n 19, at [35]. Compare EEZ Act, s 63(1).

${ }^{54}$ See ch I.

${ }^{55}$ In this sense, BECCS is similar to a forestry proposal.
} 
effects to amount to "mitigation" of those effects. ${ }^{56}$ This is generally referred to as "offsetting" or "environmental compensation". ${ }^{57}$ Despite significant judicial confusion in the past as to what these terms mean, ${ }^{58}$ it is now reasonably clear that such measures are positive effects, not a separate class of "mitigation" measures. Despite earlier judicial conclusions to the contrary, ${ }^{59}$ a measure must now relate fairly directly to, and at the point of impact of, an adverse effect for it to fall within the concept of mitigation. ${ }^{60}$ Otherwise, the harm remains in existence so is not, in fact, mitigated. ${ }^{61}$ Because the climate benefits of secure storage would not be related to the local risks of a storage project, it would be a form of offset, and treated no different to any other positive effect justiciable under the RMA. It would be weighed under s 104 of the Act, ${ }^{62}$ but could not be enforced through conditions.

The exception comes when offsetting measures are volunteered freely by an application through a clear and unequivocal undertaking. ${ }^{63}$ In such cases, the law accepts that an applicant should be estopped from ignoring specific promises of positive effects where it would cause detriment to those relying on them; to do so would be inequitable. ${ }^{64}$ These "Augier" conditions can be imposed and enforced. ${ }^{65}$

However, relying on case-specific voluntary measures to achieve secure storage is not a solid foundation for its regulation. It would lack certainty, transparency and consistency (they would not appear in plans, and applicants may choose to volunteer very different kinds of conditions in different cases). Furthermore, a consent authority may not be able to refuse consent (to do so may be unreasonable) if the risk of local effects of leakage would be de

\footnotetext{
${ }^{56}$ See G Severinsen "Glass half Empty or Glass half Full?" (2016) 11 BRMB 110.

57 Forest and Bird, above n 27, at [49].

${ }^{58}$ Contrast JF Investments, above $\mathrm{n} 19$, with Forest and Bird, above $\mathrm{n} 27$ at [72]. See also A Memon and P Skelton "The Practice of Environmental Compensation under the Resource Management Act 1991" (2004) 8 NZJEL 177.

${ }^{59}$ For example, JF Investments, above n 19, at [42]; Director General of Conservation $v$ Wairoa District Council NZEnvC Wellington W081/07, 19 September 2007 at [32]; Royal Forest and Bird v Gisborne District Council NZEnvC Wellington W26/2009, 7 April 2009 at [68]; Mainpower NZ v Hurunui DC [2011] NZEnvC 384 at [461]-[463].

${ }^{60}$ Forest and Bird, above n 27, at [74]-[76].

${ }^{61}$ Ibid at [54], [72], [122].

${ }^{6}$ Ibid at [15].

${ }^{63}$ See Frasers Papamoa v Tauranga City Council [2010] 2 NZLR 202 (HC) at [34].

64 Springs Promotions Ltd v Springs Stadium Residents Assn Inc [2006] 1 NZLR 846 (HC); Re Transit New Zealand EnvC Auckland A183/2003, 24 October 2003 at [31]-[34].

65 See Kirton v Napier City Council [2013] NZEnvC 66 at [57]; Re Whitewater New Zealand Inc [2013] NZEnvC 131, [2013] NZRMA 357 at [184]-[186]; Warren v Gisborne District Council [2011] NZEnvC 103 at [13]; Crest Energy Kaipara Ltd v Northland Regional Council [2011] NZEnvC 26, [2011] NZRMA 420 at [19]; Smith v Muldoon [2013] NZEnvC 161 from [16]; Augier v Secretary of State for the Environment (1978) 38 P \& CR 219 (QBD); Mora v Te Kohanga Reo Trust [1996] NZRMA 556.
} 
minimis and an applicant chose not to volunteer secure storage conditions. The courts have also pointed out that Augier conditions are valid only where promises are clear and very specific. ${ }^{66}$ It is questionable whether the kinds of detailed, extensive, flexible and ongoing standards needed for secure storage could be encapsulated in an undertaking. Finally, it is difficult to see the global impacts of climate change as the kind of "detriment" to identifiable persons contemplated by the concept. ${ }^{67}$

\section{F $\quad$ Other Limitations of the RMA and EEZ Act}

In some cases the RMA and EEZ Act would treat leakage as having an adverse effect on the climate. This would be the case where an applicant sought consent for a new emitting activity (such as a fertiliser plant) at the same time as consent for a CCS operation. No emissions from the plant would have been consented, ${ }^{68}$ so storage would mitigate an adverse effect on the "existing environment" rather than provide an unrelated positive effect. However, this is only a small saving grace. The aim of the public-interest industries principle is to deliver climate outcomes more broadly, not only to mitigate adverse effects. To allow leakage conditions in some operations but not others would be confusing and inconsistent with an effects-based approach to sustainability.

Furthermore, even where leakage were an adverse effect, using the acts to achieve secure storage may be problematic for two other reasons. First, even where there is no prohibition on considering climate effects, conditions imposing mitigation measures may prove to be unreasonable in administrative law terms. This was the experience in case law concerning reforestation conditions that pre-dated the climate prohibition. ${ }^{69}$ It may also be unlawful for conditions to require mitigation measures outside the region in question, which may arbitrarily prevent secure storage where pipelines crossed regional boundaries. ${ }^{70}$ In short, the legislation is simply not geared towards global issues like climate change. ${ }^{71}$

\footnotetext{
${ }^{66}$ See Frasers Papamoa, above n 63, at [32], [44].

${ }^{67}$ See, for example, Re Transit, above n 64, at [113]-[114]; Redvale Lime Co Ltd v Rodney District Council EnvC Auckland A16/06, 15 February 206 at [4]; Alexander, above n 35, at 413; Re Meridian Energy Ltd EnvC Christchurch C125/2003, 12 September 2003 at [20].

${ }_{68}^{68}$ Assuming an NES on $\mathrm{CO}_{2}$ emissions were in force.

${ }^{69}$ Environmental Defence Soc, above n 16, at [88].

${ }^{70}$ Ibid at [89].

${ }^{71}$ A Arthur-Young and J Riddell "Climate Change and the RMA" [2014] NZLJ 82 at 83-84.
} 
Secondly, the public-interest industries principle demands that the climate benefits of storage be maximised even where they are unrelated to risks of leakage. Other jurisdictions provide for such measures to be taken (for example, requiring the rate of injection to increase, to maximise total volumes stored, or to make use of the latest technologies). ${ }^{72}$ These are more clearly about achieving positive effects, not the mitigation of adverse effects, and are therefore likely to be unlawful for the reasons described earlier.

In sum, the RMA and EEZ Act provide only a weak - or, at best, uncertain and untargeted normative foundation for achieving secure storage. ${ }^{73}$ It is not sufficient to implement the public-interest industries principle. To adopt a phrase used by Nigel Bankes to describe the Albertan regulatory experience, the "statutory 'hook' on which regulation hangs would be quite slender" in pursuing our climate goals. ${ }^{74}$

\section{Gap 4}

The RMA, EEZ Act and CCRA do not provide adequate assurance that the climate benefits of all CCS operations would be achieved

\section{G Filling the Gap}

We require a targeted legal framework, ${ }^{75}$ applicable to a wide range of storage scenarios, ${ }^{76}$ to ensure that secure storage is achieved under the public-interest industries principle. For convenience, this is labelled "storage law". It does not require the replacement of the legal framework relating to local impacts, ${ }^{77}$ which has been addressed in chapter VII, although the kinds of measures described in this chapter may be usefully replicated in regulatory and policy instruments (and consent conditions) under the RMA and EEZ Act to the extent they are required for safeguarding the local environment from leakage. Other jurisdictions have

\footnotetext{
${ }^{72}$ See Greenhouse Gas Geological Sequestration Act 2008 (Vic) (GGGSA(Vic)), ss 89, 90, 91; Greenhous Gas Storage Act 2009 (Qld) (GGSA(Qld)), ss 154(2)(c), 156(3), 266; CCS Directive, art 11(3)(d).

${ }^{73}$ See also B Barton "Carbon Capture and Storage Law for New Zealand: A Comparative Study" (2009) 13 NZJEL 1 at 9.

${ }^{74}$ N Bankes "The Developing Regime for the Regulation of Carbon Capture and Storage Projects in Canada" in

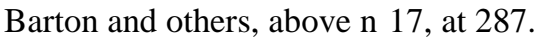

${ }^{75}$ IEA, above n 4, at 59. See also Barton and others, above n 17, at 110.

${ }^{76}$ IEA, above $n$, at 59.

${ }^{77}$ For example, see OPGGSA(Vic), s 64(1)(b).
} 
tended to enact climate-focused laws for CCS above and beyond those concerned with local environmental protection. ${ }^{78}$

The narrow normative driver for storage law has been identified already: secure storage, and the prevention of leakage, to achieve climate outcomes. ${ }^{79}$ This is required by the publicinterest industries principle, the distributive principle, and Treaty of Waitangi obligations. ${ }^{80}$ We should be satisfied that a proposal will result in the permanent sequestration or containment of an injection stream within a geologically-defined area of the sub-seabed. ${ }^{81}$ Unlike sustainable management and the RMA/EEZ Act issues described in chapter VII, the aim of storage law does not require the weighing of multiple values. ${ }^{82}$ Under the decisionmaking principle, this suggests that complex and duplicative participatory processes (including merits appeals) are not needed, and that decision-making power can shift from the value-laden political sphere to the technical sphere. The risk of leakage from a project can be determined by a body of independent experts. ${ }^{83}$ Most suitable would be an arms-length Crown entity, reflecting the national community of interest in CCS under the concept of subsidiarity (for simplicity, that decision-maker is henceforth referred to as the Crown). Māori are partners in government, so should be consulted and have a strong voice in making decisions on storage permits.

Leakage prevention must be our aim, but excessively dogmatic thresholds for leakage may be counter-productive to that aim. It is not technically possible or commercially realistic to anticipate or monitor every small leak, ${ }^{84}$ which may need to be estimated rather than measured. Harsh regulatory responses may prevent the uptake of CCS. Something less than

\footnotetext{
78 IEA, above n 4, at 75; Parliament of the Commonwealth of Australia Offshore Petroleum Amendment (Greenhouse Gas Storage) Bill 2008: Revised Explanatory Memorandum (2008), Attachment A, at 15; Guidelines for Injection and Storage of Greenhouse Gas Substances in Offshore Areas (Australian Department of Resources, Energy and Tourism, 2011) at 37; M Montini and E Orlando "Balancing Climate Change Mitigation and Environmental Protection Interests in the EU Directive on Carbon Capture and Storage" (2012) 3 Climate Law 165 at 173 .

${ }^{79}$ Compare GGSA(Qld), s 3.

${ }^{80} \mathrm{See}$ ch IV.

${ }^{81}$ Compare CCS Directive, art 1(2); Offshore Petroleum and Greenhouse Gas Sequestration Act 2006 (Cth) (OPGGSA(Cth)), s 312 .

${ }^{82}$ See chs 3-4.

${ }^{83}$ See Marston and Moore, above n 10, at 483.

${ }^{84}$ Bannister and others Opportunities for Underground Geological Storage of $\mathrm{CO}_{2}$ in New Zealand: Monitoring and Verification Methodologies (GNS Science, Report 2009/64 CCS 08/11, 2009) at 15.
} 
perfect containment may be contemplated in practice if it does not undermine the climate aims of the technology. ${ }^{85}$

\section{H Authorisation of Storage}

The public-interest industries principle, and international experience, suggest that there are two milestones that warrant regulatory oversight through a permitting process: the storage phase, to allow an operator to inject, and the post-closure phase, to allow responsibility and liability to be transferred from an operator to the Crown. ${ }^{86}$ In this section, we are concerned with the former.

A precautionary approach to secure storage demands that express authorisation be obtained, to provide assurance that a project will achieve its climate aims, before injection occurs. ${ }^{87}$ Although a variety of terminology for such authorisations is used overseas, some based on a dual system of regulatory "permits" and proprietary "licenses" (reflecting traditional models for petroleum regulation), ${ }^{88}$ it is simpler in New Zealand to refer to this simply as a "storage permit". ${ }^{89}$

When deciding whether to grant a permit, it is important to consider multiple points over a project's life-cycle that can impact on secure storage: from suitable site selection, to methods of injection, through to site closure and ongoing stewardship responsibilities. ${ }^{90}$ If any of these are deficient, the outcome may be storage that is not secure. Some rules or standards may be capable of generalisation across all storage scenarios, and the certainty-flexibility principle suggests that these should be outlined in regulations rather than relying on the discretion of a decision-maker at the project level. ${ }^{91}$ As Elias CJ has noted, excessive discretion "opens the door for arbitrariness and inequality of treatment". ${ }^{92}$ A close technical assessment is needed

\footnotetext{
${ }^{85}$ B van der Zwaan and R Gerlagh "Offshore CCS and Ocean Acidification” (2016) 137 Climatic Change 157 at 167.

${ }^{86}$ On exploration permits, see ch IX.

${ }^{87}$ Barton and others, above n 17 at 109. OPGGSA(Cth), s 361; GGSA(Qld), s 147(1)(c).

${ }^{88}$ Barton, above n 73, at 25, 28; Alberta Government Carbon Capture and Storage: Summary Report of the Regulatory Framework Assessment (Energy Alberta, Edmonton, 2013) at 54. For example, see OPGGSA(Vic), s 372; OPGGSA, pt 3.4; GGSA(Qld), s 113.

${ }^{89}$ See also B Milligan "Planning for Offshore $\mathrm{CO}_{2}$ Storage" (2014) 48 Marine Policy 162 at 168.

${ }^{90}$ IEA, above $\mathrm{n} 4$, at 55.

${ }^{91}$ See IEA, above n 4, at 71; Alberta Government, above n 88, at 84.

92 Elias CJ "Righting Environmental Justice" (12 ${ }^{\text {th }}$ Annual Salmon Lecture, Auckland, 25 July 2013$)$ at 12.
} 
of all international standards concerning the climate impacts of $\mathrm{CCS},{ }^{93}$ to determine the extent to which they are appropriate to be imposed ex ante in New Zealand, or instead are left as matters of guidance to which regard must be had in deciding a storage permit. ${ }^{94}$

1 Standards for site selection, injection, and site closure

The site selection stage has been described as the most crucial component of a CCS project's regulatory life cycle. ${ }^{95}$ It is the lynchpin of a precautionary approach to leakage, because the natural characteristics of a storage site are the most influential factor in preventing potential leakage before it occurs. ${ }^{96}$ Substantial variation in sites means that quantitative standards can seldom be generalised, ${ }^{97}$ but some directions may be possible through a national level, industry-specific strategic environmental assessment. ${ }^{98}$ Some have characterised these as "fundamental suitability requirements". ${ }^{99}$ Open ended discretion in approving storage sites is undesirable, and some consistency is needed. ${ }^{100}$

In particular, a site should have the capacity to store the $\mathrm{CO}_{2}$ permanently within a defined sub-surface area, ${ }^{101}$ and have no faults, fractures or other features (like poorly closed legacy wells) that are likely to allow unintended subsurface migration or leakage. ${ }^{102}$ Decision makers should also have confidence in the models proposed to simulate the migration of $\mathrm{CO}_{2}$ plumes. ${ }^{103}$ In practice, this is likely to mean that a site is sufficiently deep, have thick accumulations of sediment, low porosity caprocks, and structural simplicity. ${ }^{104}$ A relatively stable geological setting is also required, and the Intergovernmental Panel on Climate Change

\footnotetext{
${ }^{93}$ For example, see the work of the International Standards Organisation on TC265.

${ }^{94}$ For example, see GGGSA(Vic), s 301.

${ }^{95}$ IEA, above n 4, at 70; London Dumping Protocol Specific Guidelines for the Assessment of Carbon Dioxide for Disposal into Sub-Seabed Geological Formations (LC34/15, 2012), Annex 8 at 6.1; London Dumping Protocol Risk Assessment and Management Framework for $\mathrm{CO}_{2}$ Sequestration in Sub-Seabed Geological Structures (CS SSGS, LC/SG-CO2 1/7), Annex 3 at 5.5.

${ }^{96}$ Ingleson and others, above n 14, at 437.

${ }^{97}$ WRI, above n 1 , at 55.

${ }^{98}$ See generally I Boisvert "Lifting the Looking Glass" (2011) 15 NZJEL 1 at 6; International Risk Governance Council Regulation of Carbon Capture and Storage (IRGC, Geneva, 2008) at 23.

${ }^{99}$ OPGGSA(Vic), s 374(2), 380(2); OPGGSA(Cth), s 358(4).

${ }^{100}$ Zakkour, above n 8, at 8; Barton and others, above n 17 at 119. See Implementation of Directive 2009/31/EC on the Geological Storage of Carbon Dioxide: Guidance Document 2 (European Commission, 2011) at 27-46.

101 For example, see GGGSA(Vic), ss 82(2)(c)-(d), 83(1)(b) 94(d); OPGGSA(Vic), s 382(1)(b)(ii); OPGGSA(Cth), ss 357(1)(b), 362(1)(b)(ii); IEA, above n 4, at 73.

102 IEA, above n 4, at 70; OPGGSA(Cth), ss 312 and 21(1); Offshore Petroleum and Greenhouse Gas Storage (Greenhouse Gas Injection and Storage) Regulations 2011 (Cth) (Storage Regulations (Cth)), reg 3.3; IPCC, above n 2, at 208, 228.

${ }^{103}$ See IPCC, above n 2, ch 5; WRI, above n 1, at 64.

${ }^{104}$ IPCC, above n 2, at 200; WRI, above n 1, at 86.
} 
(IPCC) has pointed out that storage sites around the Pacific rim must be selected with particular care. ${ }^{105}$ However, effective storage does not always require physical lateral barriers. An expert decision-maker should be given appropriate discretion to assess the actual potential for leakage across a wide range of geological scenarios, even in seismically active areas. $^{106}$

The way that the injection process and well design interact with the features of a storage site is also crucial to achieving secure storage. Comprehensive information concerning this relationship should be required. ${ }^{107}$ In particular, the location, pressures, rate and volume of injection must be matched to the capacity and injectivity of a site, ${ }^{108}$ as well as the specifications of injection infrastructure. ${ }^{109}$ It would be important to require a wellbore to be concreted at least to beyond a confining zone to prevent migration up the well itself. ${ }^{110}$ Maximum pressures and close monitoring are required especially at the point of injection, as this is where the pressure gradient and risk of leakage is greatest and where catastrophic escapes are possible. ${ }^{111}$ Overall formation pressures must also remain low enough to avoid fracturing a caprock or "fault valving", ${ }^{112}$ although some controlled fracturing tests may be necessary to characterise a site. ${ }^{113}$ Moreover, the composition of a $\mathrm{CO}_{2}$ stream is important; restrictions are needed on impurities that could reduce the effectiveness of storage by threatening the integrity of infrastructure and inhibiting the flow and geologic trapping of $\mathrm{CO}_{2}{ }^{114}$ Standards for the construction of offshore injection facilities are also important, but existing health and safety regulations appear to be transferable. ${ }^{115}$

\footnotetext{
${ }^{105}$ IPCC, above n 2, at 213, 214.

106 IPCC, above n 2, at 209; Barton, above n 73, at 4; M Gerstenberger and others Opportunities for Underground Geological Storage of $\mathrm{CO}_{2}$ in New Zealand: Risk Assessment Methodologies (GNS Science, Report CCS 08/10 2009/63, 2009) at 30-31.

${ }^{107}$ IEA, above n 4, at 75. See GGGSA(Vic), s 94; GGSA(Qld), s 142; Barrow Island Act 2003 (WA), s 13(2).

${ }^{108}$ See GGGSA(Vic), ss 86, 94(e), CCS Directive, art 9; OPGGSA(Vic), ss 374(1)(i)-(j); OPGGSA(Cth), s 358; IPCC, above n 2, at 232; WRI, above n 1, at 73, 88, .

${ }^{109}$ IPCC, above n 2, at 231; WRI, above n 1, at 95, 97; C Hendriks and others, above n 3, at 52; Marston and Moore, above n 10, at 448-449; Alberta Government, above n 88, at 9.

${ }^{110}$ WRI, above $\mathrm{n} 1$, at 95; C Hendriks and others, above $\mathrm{n} 3$, at 15.

111 IEA $\mathrm{CO}_{2}$ Capture and Storage: A Key Carbon Abatement Option (IEA, Paris, 2008), at 125; IPCC, above n 2, at 233; C Hendriks and others, above n 3, at 15.

${ }_{112}$ IPCC, above n 2, at 210, 232; WRI, above n 1, at 73; Marston and Moore, above n 10, at 468.

${ }^{113}$ WRI, above $\mathrm{n} 1$, at 95 .

${ }^{114}$ IPCC, above n 2, at 228.

115 See G Severinsen "Constructing a Legal Framework for Carbon Capture and Storage in New Zealand" (2014) 63 EGYPRO 6629 at 6654; Health and Safety in Employment (Petroleum Exploration and Extraction) Regulations 2013.
} 
A crucial consideration in determining whether to grant a storage permit is the adequacy of plans that govern a site once injection has ceased. ${ }^{116}$ The principle of precaution requires that injection should not commence without a thorough understanding of, and plan for, the whole project life-cycle. ${ }^{117}$ In particular, wells need to be properly plugged and abandoned to prevent later leakage. ${ }^{118}$ Given similarities with the closure/abandonment of petroleum wells, it may be possible to build upon practice developed under the Crown Minerals Act 1991, with specific attention paid to the need for $\mathrm{CO}_{2}$ resistant materials. ${ }^{119}$

\section{Risk assessment and the exercise of discretion}

Given the substantial variation in possible storage scenarios, blanket standards are unlikely to be possible in many cases. ${ }^{120}$ Secure storage may be achievable only through a close contextual assessment of a specific application, and the imposition of bespoke conditions. ${ }^{121}$ In this section I contend that, where there is a discretion to grant or decline a storage permit, it should be granted only where there is a very low risk of leakage.

Such discretion would not be exercised by weighing competing values, but rather by determining whether the technical features of a proposal would result in secure storage. ${ }^{122}$ In doing so, some have embraced both the flexibility and the stringency of a general test like "permanent" storage. ${ }^{123}$ However, as well as there being little agreement among technical experts as to how stringent limits on volumes or rates of leakage should be, ${ }^{124}$ such simple normative statements (that we ought to pursue permanent storage) remain marred by questions of risk and uncertainty. We will seldom be able to say in practice that secure storage will result. More likely is that the Crown will be faced with multiple, complex, and

\footnotetext{
${ }^{116}$ IEA, above $\mathrm{n} 4$, at 75 .

${ }^{117}$ IPCC, above n 2, at 226; Storage Regulations (Cth), pt 12.

${ }^{118}$ IEA, above n 4, at 96; IPCC, above n 2, at 231; WRI, above n 1, at 98; Alberta Government, above n 88, at 9; GGSA(Qld), s 267.

${ }^{119}$ Risk Assessment and Management Framework, above n 95, Annex 3 at 6.14.

${ }^{120}$ WRI, above n 1, at 55; Pritchard, above n 17, at 273; IEA, above n 4, at 70; Barton and others, above n 17 at 137.

${ }^{121}$ Bankes, above n 74, at 287; Alberta Government, above n 88, at 8; Australian Parliament, above n 78, Attachment A, at 19.

${ }^{122}$ See IPCC, above $\mathrm{n} 2$, at 225.

${ }^{123}$ H Bolscher and others Report for European Commission: Support to the Review of Directive 2009/31/EC on the Geological Storage of Carbon Dioxide (Task 2) (CLIMA.A4/FRA/2011/0027, 2014) at 81; OPGGSA(Vic), s 23(1)(a),

${ }^{124}$ IPCC, above n 2, at 14, 67.
} 
potentially conflicting probabilistic models of leakage, and be forced to decide - according to some standard of proof - whether these predictions are sufficient.

Risk assessment is therefore an essential component of a legal regime for CCS. ${ }^{125}$ It is not the role of this thesis to speculate as to the specific risks a CCS operation might pose or the merits of scientific risk assessment methodologies. ${ }^{126}$ A robust assessment of the site-specific risks of leakage would be expected in an assessment of environmental effects upon application for a storage permit, and the law should afford an applicant flexibility to do so in accordance with best industry practice. ${ }^{127}$ Guidelines may be useful here, to leverage off international best practice in risk-assessment ${ }^{128}$ and require the provision of particular kinds of information and decision-making considerations that are common to all storage scenarios. ${ }^{129}$ Risk assessment should also be transparent, accessible to the public, iterative and ongoing, ${ }^{130}$ and based on robust modelling. ${ }^{131}$

The key question from a legal perspective is what an unacceptable level of risk is when deciding a storage permit application. ${ }^{132}$ Technical reports tend to leave this question open, conceding that it is not one that can be made by scientific experts. ${ }^{133}$ Generally speaking, the key features of the RMA's process for risk assessment are transferable to storage law, in that they provide a robust approach to identifying, assessing and managing a range of risks (including low probability effects). ${ }^{134}$ The core difference, however, is that we must be more specific as to what degree climate risk is acceptable for CCS. For the same reasons that the public-interest industries principle demands the prevention of leakage, it also requires a clear statement that only very low risks of leakage are acceptable.

\footnotetext{
${ }^{125}$ IPCC, above n 2, at 250; Ingelson and others, above n 14, at 437; Gerstenberger and others, above n 106, at 24.

${ }^{126}$ See, IPCC, above n 2, at 250; C Hendriks and others, above n 3, at 18.

${ }^{127}$ Alberta Government, above n 88, at 83. For common risks, see WRI, above n 1, from 72.

${ }^{128}$ See Risk Assessment and Management Framework, above n 95, Annex 3 at 5.13; CCS Directive, Annex I; Implementation of Directive 2009/31/EC on the Geological Storage of Carbon Dioxide: Guidance Document 1 (European Commission, 2011).

${ }^{129}$ See Barton and others, above n 17 at 110; CCS Directive, art 7; WRI, above n 1, at 92; IEA, above n 4, from 72; IPCC, above n 2, at 225, 227; RM Cueller-Franca and A Azapagic "Carbon Capture, Storage and Utilisation" (2015) 9 Journal of $\mathrm{CO}_{2}$ Utilization 82 at 86; Storage Regulations (Cth), above n 102, schs 1-2.

${ }^{130}$ Gerstenberger and others, above n 106, at 59.

${ }^{131}$ Ibid at 8 .

${ }^{132}$ Ibid at 16.

${ }^{133}$ Ibid at 31, 56.

${ }^{134}$ See chs 3, 6.
} 
This conclusion colours our approach both to "risk" (the product of an effect's magnitude and probability), and "uncertainty" (uncertainty in factual information upon which risk assessments rely). In terms of risk, we must treat the cumulative and long-term impacts on the climate of even small leaks as significant, and entertain only low probabilities of it occurring. Our risk horizons should therefore be extensive. ${ }^{135}$ Overseas, this has produced relatively robust (yet realistic) ${ }^{136}$ and qualitative thresholds for acceptable risk in regulatory instruments. For example, Victorian legislation requires that $\mathrm{CO}_{2}$ is "likely" to be permanently contained, ${ }^{137}$ while the International Energy Agency (based on the CCS Directive) has suggested that formations are not suitable if there is "significant" risk of unintended migration or leakage. ${ }^{138}$ They recognise that there is little value in trying to clothe what are inherently qualitative thresholds in quantitative language, ${ }^{139}$ especially given that there is little long-term empirical data to feed into risk models and that quantitative risks may only be presentable as probability distributions (which are not well-suited to concise regulatory thresholds). ${ }^{140}$ We would be wise to express thresholds in terms of "significant", 141 "appreciable" or "more than minor" probability of "significant" leakage over the life of the site. Risks to secure storage may also need to consider an applicant's capability, financial security, compliance history, ${ }^{142}$ and ability to source $\mathrm{CO}_{2}$ streams. ${ }^{143}$

Our approach to uncertainty in information (the degree to which the Crown must be satisfied that information is sufficient and correct) must also be precautionary. There may be different assumptions and uncertainties underlying experts' risk assessments that are produced from different models. ${ }^{144}$ At its most basic, we would have no assurance of secure storage where large uncertainties in information meant risks remained largely unknown. An ordinary civil standard of proof (the balance of probabilities) would be insufficient to reflect the publicinterest industries principle, but a criminal standard (beyond reasonable doubt) would likely

\footnotetext{
${ }^{135}$ Gerstenberger and others, above n 106, at 16, 22.

136 N Swayne and A Phillips "Legal Liability for Carbon Capture and Storage in Australia" (2012) 29 Environmental and Planning Law Journal 189.

${ }^{137}$ GGGSA(Vic), s 83(1)(c). See WRI, above n 1, at 98.

${ }^{138}$ IEA, above n 4, at 70; CCS Directive, arts 4(4) and 8. Compare Storage of Carbon Dioxide (Licensing etc.) Regulations 2010 (UK), reg 7.

${ }^{139}$ Gerstenberger and others, above n 106, at 9, 12; WRI, above n 1, at 92.

${ }^{140} \mathrm{C}$ Hendriks and others, above n 3, at 14; Gerstenberger and others, above n 106, at 52.

${ }^{141}$ CCS Directive, art 3(18).

142 IEA, above n 4, at 75; N Bankes "Developing a Legal Regime for Carbon Capture and Storage in Canada" (ISEE Research Paper, December 2009) at 15.

${ }^{143}$ WRI, above n 1, at 56; GGSA(Qld), ss 115, 118; OPGGSA(Vic), s 380(3)(c); OPGGSA(Cth), s 361(10)(c); GGGSA(Vic), s 75, 83(1)(a).

${ }^{144}$ Gerstenberger and others, above n 106, at 16.
} 
pose insuperable barriers to applicants (the future has inherent uncertainty). I contend that there is greatest value in relying not on inflexible standards of proof, but rather on informed and expert evaluation, guided by a firm, but not absolute, qualitative directive that the Crown be (for example) "satisfied", 145 "convinced", or "very sure" of the accuracy and sufficiency of information tendered.

\section{Conditions and management plans}

Conditions on storage permits are necessary to ensure that remaining risks of leakage are managed, and that secure storage is actually achieved under the public-interest industries principle. They need to provide for the measurement, monitoring and verification of secure storage, and provide for corrective measures where storage fails to be secure. They also need to be measurable, reviewable, enforceable and enduring. ${ }^{146}$ At least some monitoring and corrective measures must continue over the life of the site (although they may decrease in frequency, intensity and scope as risks of leakage decline). ${ }^{147}$ Thus an injector's ability to surrender injection rights should not affect the enforceability of associated obligations. ${ }^{148}$

I do not speculate as to the appropriate wording of site-specific conditions, because they will need to be determined in the context of a particular application. But many will relate to those general matters for which an applicant must provide information, so broad powers to impose conditions for the purposes of a storage permit are appropriate. ${ }^{149}$ Under the certaintyflexibility principle, detailed requirements could be provided for in site-specific management plans. Under the RMA model, these would need to be capable of certification against the clear outcomes provided for in conditions. ${ }^{150}$ This approach would provide the flexibility in storage operations that has been recognised as crucial for the success of a CCS industry where knowledge and best practice is developing rapidly, ${ }^{151}$ because change would not

\footnotetext{
${ }^{145}$ See Storage Regulations (Cth), sch 1, 1.3(1); GGGSA(Vic), s 83(1).

${ }^{146}$ IPCC, above n 2 , at 252.

${ }^{147}$ WRI, above n 1, at 66-69; S McCoy Carbon Capture and Storage: Legal and Regulatory Review $\left(4^{\text {th }}\right.$ ed, IEA, Paris, 2014) at 24; Barton and others, above n 17, at 125; OPGGSA(Cth), s 359(1); IPCC Guidelines for National Greenhouse Gas Inventories (2006) at 5.14-5.17.

${ }^{148}$ See GGGSA(Vic), ss 88, 92(2), 168(2); OPGGSA(Vic), ss 474(3), 476, 643; OPGGSA(Cth), ss 359, 442; Barton and others, above n 17, at 60 .

${ }^{149}$ See CCS Directive, art 8; GGGSA(Vic), ss 94 and 157; OPGGSA(Vic), s 374; Storage of Carbon Dioxide (Licensing etc.) Regulations 2010 (UK), reg 8.

${ }^{150}$ WRI, above n 1, at 92; Barton and others, above n 17, at 137.

${ }^{151}$ Barton, above n 73, at 35; OPGGSA(Vic), s 493, OPGGSA(Cth), s 436.
} 
require the formal and participatory processes that accompany changes to conditions. ${ }^{152}$ These kinds of plans are a key tool used under Australian legislation ${ }^{153}$ and the EU CCS Directive. ${ }^{154}$ They would be particularly valuable to provide to the public and a regulator clear expectations of long-term events like site management following the cessation of injection, while allowing operational detail to be crystallised when a future context and specific site is more well-known (in a site closure plan). ${ }^{155}$ Changes to management plans would generally be capable of certification by a regulator (rather than requiring the exercise of discretion), because the outcomes embedded in conditions (secure storage) would be clear. They would therefore not require extensive formal participatory processes.

Measurement, monitoring and verification conditions (and management plans) are especially important in achieving a precautionary approach to secure storage. ${ }^{156} \mathrm{We}$ need to be able to anticipate leaks and respond accordingly. ${ }^{157}$ Thus a storage permit should not be granted without an assurance that risk assessment will be ongoing and fed into continuously evolving and updated monitoring plans. ${ }^{158}$ Two tasks are crucial here: requiring the measurement, monitoring and verification of secure storage (to a degree proportionate to any risks and based on extensive baseline measurements), ${ }^{159}$ and providing for corrective measures where storage fails to be secure. ${ }^{160}$ Their significance can be seen internationally; ${ }^{161}$ for example, Nigel Bankes has pointed out that 21 of the 23 conditions imposed on one large Albertan storage operation related to these kinds of obligation. ${ }^{162}$

\footnotetext{
${ }^{152}$ Compare OPGGSA(Vic), s 399 and OPGGSA(Cth), s 374.

153 See GGGSA(Vic), Division 6, ss 209-212; GGSA(Qld), from s 139; OPGGSA(Vic), ss 380(3)(a), 492; OPGGSA(Cth), ss 361(10)(a), 357; Storage Regulations (Cth), pt 3; Australian Parliament, above n 78, at [23].

154 CCS Directive, art 7, Annex II; see also OPGGSA(Cth), ss 361, 362; GGSA(Qld), ss 141-142; GGGSA(Vic), ss 94-95; CCS Directive, art 7, Annex II; Mines and Minerals Act 2000 (Alb), s 115-116.

${ }^{155}$ See Alberta Government, above n 88, at 99; C Clarke "Long-Term Liability for CCS: Some Thoughts About Specific Risks, Multiple Regimes and the EU Directive" in I Havercroft, R Macrory and RB Stewart Carbon Capture and Storage: Emerging Legal and Regulatory Issues (2011, Hart, Oxford) at 185; Australian Parliament, above n 78, at [367]; GGSA(Qld), from s 152.

${ }^{156}$ IEA, above n 4, at 75; GGGSA(Vic) s 94(j). On available monitoring techniques, see IPCC, above n 2, from 235.

${ }^{157}$ WRI, above n 1 , at 67.

${ }^{158}$ Ibid at 57, 64; Specific Guidelines, above n 95, Annex 8 at 8.10; CCS Directive, arts 13-14, Annex II at 1.2; Storage Regulations (Cth), above n 102, reg 3.11(4).

${ }^{159}$ See Bankes, above n 74, at 307, 327; Alberta Government, above n 88, at 86; WRI, above n 1, at 68.

${ }^{160}$ See CCS Directive, art 16.

${ }^{161}$ WRI, above n 1, at 57, 65; Bannister and others, above n 84, at 9.

${ }^{162}$ Bankes, above n 74, at 307.
} 
Detailed monitoring requirements must be site-specific to respond to particular risks. ${ }^{163}$ Regulation should not be too prescriptive, given potentially large variation in storage site characteristics ${ }^{164}$ and evolving technologies. ${ }^{165} \mathrm{~A}$ better tool may be the use of best practice documents to shape conditions (and management plans), and obligations to use best available technology. ${ }^{166}$ Under the certainty-flexibility principle and efficiency principle, it would be important to align the requirements of a storage permit with CCRA (emissions trading) regulations. ${ }^{167}$

Guidance on monitoring under the London Protocol has emphasised the need to monitor plume movements, geological strata above it, the seafloor and water column, and benthic communities. ${ }^{168}$ Conditions or management plans should specify the locations, scope, and frequency of monitoring, ${ }^{169}$ key metrics, ${ }^{170}$ and a range of suitable methods and technologies (without prescribing ineffective, irrelevant or impossible measures). ${ }^{171}$ A package of methods will likely be needed. ${ }^{172}$ Through monitoring we should seek actively to understand and map plume movements and behaviour (including wider pressure fronts and fluid displacement), ${ }^{173}$ not just detect surface leakage. Some metrics (such as formation pressure) may be highly predictable and require minimal monitoring. ${ }^{174}$

To be effective, monitoring requirements must go hand in hand with regular reporting obligations, ${ }^{175}$ verification requirements, ${ }^{176}$ obligations to notify a regulator of any irregularities and powers of inspection. ${ }^{177}$ Yet they should also reflect operational reality. Marginal costs of detecting extremely small scale or diffuse surface leakage would be

\footnotetext{
${ }^{163}$ See Barton and others, above n 17 at 137, 143; CCS Directive, art 13; Bannister and others, above n 84.

${ }^{164}$ IEA, above n 4, at 83-84; IPCC, above n 2, at 235.

${ }^{165}$ WRI, above $\mathrm{n} 1$, at 68 ; IPCC, above n 147, at 5.13.

${ }^{166}$ See WRI, above n 1, at 65; Robertson and others, above n 17, at 11; Specific Guidelines, above n 95, Annex 8 at 8.

${ }^{167}$ On consistency, see I Havercroft and R Macrory Legal Liability and Carbon Capture and Storage: A Comparative Perspective (GCCSI, 2014) at 26.

${ }^{168}$ Risk Assessment and Management Framework, above n 95, Annex 3 at 6.21.

${ }^{169}$ IEA, above $\mathrm{n} 4$, at 82 .

${ }^{170}$ WRI, above n 1, at 70; CCS Directive, Annex II at 1.1; Bannister and others, above n 84, from 39.

${ }^{171}$ IPCC, above n 2, at 202, 236-237, 263.

${ }^{172}$ IPCC, above n 147, from 5.24. See generally Storage of Carbon Dioxide (Licensing etc.) Regulations 2010 (UK), sch 2(2); M McCormick A Greenhouse Gas Accounting Framework for CCS Projects (C2ES, 2012) at 45-46.

${ }^{173}$ IEA, above n 4, at 83-85; Bankes, above n 74, at 307.

${ }^{174}$ WRI, above $\mathrm{n} 1$, at 66.

${ }^{175}$ See CCS Directive, art 14; Bankes, above n 74, at 328; Alberta Government, above n 88, at 92; Storage Regulations (Cth), above n 102, pt 4.

${ }^{176}$ See Barton and others, above n 17, at 128, 144; CCS Directive, art 14; Pritchard, above n 17, at 274.

${ }^{177}$ IEA, above n 4, at 79; CCS Directive, arts 15-16; OPGGSA(Vic), s 655; GGGSA(Vic), pt 15.
} 
prohibitively high, particularly in an offshore context, ${ }^{178}$ and must be balanced against the climate benefit this would provide. There should be no expectation of perfect leakage detection. For example, the WRI has suggested that margins of error should not be stricter than plus or minus one percent. ${ }^{179}$

Monitoring conditions will also be ineffective unless they are tied to requirements for corrective action. ${ }^{180}$ Under the public-interest industries principle, corrective measures are needed when storage is no longer secure. Because measures may involve substantial costs for operators, clear thresholds for their application are important. Further, the precautionary principle suggests that action is warranted not only where monitoring shows $\mathrm{CO}_{2}$ reaching the atmosphere or water column (leakage), but also in any scenario in which geological sequestration is no longer verifiable and thus poses a heightened risk to the climate. This could include unanticipated migration into other, uncharacterised or unmapped, areas of the subsurface. $^{181}$

Some certainty could be provided to operators by defining a geological formation outside of which storage is no longer secure. ${ }^{182}$ For example, as in the EU, the law could provide that if a plume migrated beyond a storage "complex", security could no longer be presumed. A storage complex is the area of containment within which migration poses no climate risk. ${ }^{183}$ It can be defined, in geological terms, by predictions of how a plume's boundaries and associated pressure waves are expected to disperse and stabilise, which will vary according to the site and may change over time. ${ }^{184}$

Under the precautionary principle, any corrective measures should be proportionate to the risk. For example, extreme action need not be taken in response to unauthorised subsurface migration where storage can, in practice, be verified as secure. ${ }^{185}$ Such migration could simply trigger a requirement that an applicant provide verification. The law should be flexible

\footnotetext{
${ }^{178}$ IPCC, above n 2, at 259.

${ }^{179}$ WRI, above n 1 , at 68,71 .

${ }^{180}$ See Specific Guidelines, above n 95, Annex 8 at 8.1

${ }^{181}$ WRI, above $\mathrm{n} 1$, at 57.

182 IEA, above n 4, at 59; C Philibert, J Ellis and J Podkanski Carbon Capture and Storage in the CDM (IEA, Paris, 2007) at 5.

${ }^{183}$ See Guidance Document 2, above n 100, at 25-26.

${ }^{184}$ WRI, above n 1, at 68; Risk Assessment and Management Framework, above n 95, Annex 3 at 6.8; IEA, above n 4, at 59-60; OPGGSA(Vic), s 23(3); Storage Regulations (Cth), above n 102, reg 3.4; GGGSA(Vic), s 84(2).

${ }^{185}$ On the importance of constraining Crown powers of intervention, see Barton and others, above n 17, at 140.
} 
enough to allow the adjustment of storage site boundaries over time as models become more accurate, ${ }^{186}$ with an onus on an operator to satisfy a regulator that risks of leakage remain acceptable (for example, if risks were "not significant"). ${ }^{187}$ The true geological boundaries of a storage site cannot be measured with certainty until injection commences, ${ }^{188}$ and we should not respond excessively to an unexpected event simply because a technology is new and in the spotlight. ${ }^{189}$

Where secure storage could not be verified (or where surface leakage were measurable), this could justifiably be treated as leakage (pollution) and subject to wide Crown powers to require corrective measures. Precaution suggests that powers should also be available where there are significant irregularities (for example, where plumes fail to behave as expected or where there is an enhanced or significant risk of leakage), ${ }^{190}$ or a breach of other conditions. $^{191}$ The particular measures required would be context-dependent, ${ }^{192}$ and international experience suggests that substantial (although not absolute) ${ }^{193}$ discretion should be granted to a regulator in determining them. ${ }^{194}$ Guidance documents may be useful. Any given response would need to be reasonable and applied consistently across similar sites. ${ }^{195}$ In some cases corrective measures may simply mean additional monitoring and modelling, ${ }^{196}$ a reduction of the rate or volumes of injection, or (in extreme cases of leakage, recalcitrant breaches, or evidence that the site is fundamentally unsuitable for storage) the temporary ${ }^{197}$ or permanent cessation of injection and/or the removal of injected $\mathrm{CO}_{2} \cdot{ }^{198}$ There is a strong case for key terms - such as "significant irregularity" - to be carefully and precisely defined, and

\footnotetext{
${ }^{186}$ Barton and others, above n 17, at 129; WRI, above n 1, at 68.

${ }^{187}$ IEA, above n 4, at 61-62.

${ }^{188}$ Ibid at 61 .

${ }^{189}$ Clarke, above n 155, at 184.

190 IEA, above n 4, at 89, 76; Barton and others, above n 17, at 127; Bankes, above n 74, at 307; OPGGSA(Cth), ss 379-380. But on concerns over using risk as a regulatory trigger, see N Durrant "Carbon Capture and Storage Laws in Australia: Project Facilitation or a Precautionary Approach?" (2010) 18 Environmental Liability Journal 148 at 164; Havercroft and Macrory, above n 167, at 25.

${ }^{191}$ IEA, above $\mathrm{n} 4$, at 63 .

${ }^{192}$ Australian Parliament, above n 78, at [342].

${ }^{193}$ Havercroft and Macrory, above n 167, at 25. For wide discretion, see OPGGSA(Cth), s 438; OPGGSA(Vic), s 470.

${ }^{194}$ See CCS Directive, arts 16(2) and (3); GGSA(Qld), s 364; OPGGSA(Cth), from s 376; OPGGSA(Vic), s 406; GGGSA(Vic), s 182; Energy Act 2008 (UK), s 24.

${ }^{195}$ GGGSA(Vic), s 182(a); OPGGSA(Vic), s 406(1)(a); OPGGSA(Cth), s 380(a); Durrant, above n 190, at 154; Bankes, above n 74, at 331; M Gibbs "The Regulation of Geological Storage of Greenhouse Gases in Australia" in Havercroft and others, above n 155, at 164.

${ }^{196}$ Bankes, above n 74, at 326.

${ }^{197}$ IPCC, above n 2, at 230; OPGGSA(Cth), s 380(1)(c).

${ }^{198}$ GGSA(Qld), ss 175, 364-366; OPGGSA(Vic), ss 406(1)(c), 481; CCS Directive, art 11(3); IEA, above n 4, at 76; Barton and others, above n 17, at 129; IEA, above n 4, at 89; OPGGSA(Cth), ss 380-382; GGGSA(Vic), ss $182-183$.
} 
for directions to be reviewable by a specialist administrative tribunal on questions of law, reasonableness and proportionality. ${ }^{199}$ Furthermore, it may be necessary under the publicinterest industries principle to provide powers (and duties) for the Crown to take emergency corrective measures itself, and recoup costs from an operator, if an operator failed to do so in a timely way. ${ }^{200}$

\section{Liability for leakage}

The question of who is responsible under a storage permit for monitoring and correcting leakage is closely related to the question of who is liable for the harm it causes. A clear assignation of regulatory liability is required, before a storage permit is granted, under the certainty-flexibility principle. $^{201}$ Internationally, this has been seen as a key element of a regulatory regime for storage. ${ }^{202}$ In this section my key argument is that liability for leakage under the emissions trading scheme should be incurred when $\mathrm{CO}_{2}$ can no longer be verified as being contained below ground.

For local harm, liability is provided for already under the RMA and EEZ Act through mechanisms like abatement notices, enforcement orders and prosecutions. ${ }^{203}$ The law must also provide for comparable kinds of liability and enforcement mechanisms where there is a failure by an operator to comply with conditions and directions under the storage law described above (for example, a failure to take corrective measures). ${ }^{204}$ This should include provision for cost recovery where the Crown is obliged to do so, ${ }^{205}$ the ability to withdraw or suspend a storage permit where proportionate to the seriousness of the failure, ${ }^{206}$ and fines for punitive and deterrent purposes where there is no reasonable excuse for non-compliance. ${ }^{207}$ Leakage itself need not immediately attract such heavy-handed responses.

\footnotetext{
${ }^{199}$ Havercroft and Macrory, above n 167, at 26.

${ }^{200}$ See CCS Directive, arts 16(4)-(5); IEA, above n 4, at 79, 89.

${ }^{201}$ This thesis is limited to consideration of regulatory liability.

${ }^{202}$ See IEA, above $\mathrm{n} 4$, at 91-105.

${ }^{203}$ RMA, ss 314-325B; 341; EEZ Act, ss 115-141. Compare Environment Protection Act 1970 (Vic), ss 31A and $62 \mathrm{~A}$.

${ }^{204}$ IEA, above n 4, at 92.

${ }^{205}$ Havercroft and Macrory, above n 167, at 25; compare OPGGSA(Vic), s 632; OPGGSA(Cth), s 583.

${ }^{206}$ CCS Directive, art 3(17).

207 See OPGGSA(Vic), ss 367, 404, 409, 633; OPGGSA(Cth), ss 317, 378, 584; GGGSA(Vic), s 183; GGSA(Qld), s 366. Compare Machinery Movers Ltd v ARC [1994] 1 NZLR 492 (HC) and $R$ v Conway [2005] NZRMA 274 (CA).
} 
Liability for the climate impacts of $\mathrm{CO}_{2}$ emissions is provided under the CCRA. However, as noted in chapter VI, this is not currently satisfactory. ${ }^{208}$ Clarification is needed as to when storage amounts to a "removal" (when credits are payable) and when leakage amounts to an "emission" (when units must be surrendered).

It would be best for an injector to be credited periodically throughout the injection phase for $\mathrm{CO}_{2}$ stored, measured at the point of injection, after independent verification. A "removal" would thus occur at the point of injection. ${ }^{209}$ Although the greatest assurance that $\mathrm{CO}_{2}$ had been permanently removed from the atmosphere would be after a site had been closed for several years (as Havercroft and Macrory have described it, at this point the storage "cheque" is unlikely to bounce $)^{210}$ this would provide insufficient certainty to injectors (the carbon price may change over time). Crediting throughout injection would also involve leakage being accounted for (estimated) periodically, ${ }^{211}$ and subtracted from total removals in that period. The IPCC has recommended that leakage be accounted for on an annual basis, and this is the approach the New Zealand emissions trading scheme takes to most activities. ${ }^{212}$

Leakage may occur after a site has been closed and credits are no longer payable. But the exact point at which the movement of $\mathrm{CO}_{2}$ should amount to an "emission" under the CCRA is debatable. For example, it could be when plumes move beyond a storage site, or when they enter the water column. The latter seems the most appropriate. The fairly low thresholds for corrective measures - described earlier as including migration of $\mathrm{CO}_{2}$ beyond a site, and irregularities in the behaviour of plumes - are not necessarily appropriate for imposing liability under the CCRA. Corrective measures are precautionary, and designed to prevent leakage before it occurs. Liability under the CCRA would also have this deterrent value, but is primarily designed to be compensatory. Under the polluter-pays principle, it ensures that an injector pays for leakage (which would otherwise be an externality) where climate harm has occurred. Unauthorised subsurface migration should not automatically be treated as an emission where it can be shown that $\mathrm{CO}_{2}$ in fact remains below ground. This approach is consistent with the IPCC's definition of "leakage" as the movement of $\mathrm{CO}_{2}$ to the ocean or

\footnotetext{
${ }^{208}$ Barton, above $\mathrm{n} 73$, at 33 .

${ }^{209}$ The prevention of an emission under the CCRA, s 4.

${ }^{210}$ Havercroft and Macrory, above n 167, at 34.

${ }^{211}$ On calculation methodologies for leakage, see McCormick, above n 172, at 30-31.

212 IPCC, above n 147, at 5.16; C Warnock "Global Atmospheric Pollution: Climate Change and Ozone" in Salmon and Grinlinton, above n 47, at 805; CCRA, s 65.
} 
atmosphere. ${ }^{213}$ In practice, leakage volumes may need to be estimated and verified on a case by case basis through modelling, rather than direct measurement. ${ }^{214}$ As Barton and others have observed, such approaches to accounting would require the operator of storage site (for which credits had already been issued) to remain a mandatory participant under the emissions trading scheme until liability were transferred to the Crown. ${ }^{215}$

There may be a case to limit the quantum of liability for leakage under the CCRA. It is possible that the price of emissions will change dramatically between the moment of injection and leakage. Not only could this expose operators to unpredictable and potentially large increases in costs if the price of units rose (with associated insurability risks), it could also provide a financial disincentive to achieve secure storage if the price of units decreased. ${ }^{216} \mathrm{~A}$ potential solution would be to freeze the price of emissions at (or as a proportion of) the value of credits generated by storage. ${ }^{217}$ To do so would guard against perverse incentives. If carbon prices rose, it would effectively shift some of the future costs of leakage to society at large. This may be justified under the concept of beneficiary-pays, although some have suggested it may not be politically realistic. ${ }^{218}$

\section{Financial security and orphaned projects}

The potential for leakage to occur in the future, after injection ceases, means that some financial security is necessary, before injection commences, ${ }^{219}$ to cover the potential liabilities of "orphaned" projects. ${ }^{220}$ Without security, there may be no assurance that an applicant could fund such measures. It is a common feature of CCS regimes overseas, ${ }^{221}$ and implements a precautionary approach to leakage. Financial security would need to cover any Crown costs from taking corrective measures, ${ }^{222}$ liability under the emissions trading scheme

\footnotetext{
${ }^{213}$ IPCC, above n 147, at 5.11, 5.16; compare CCS Directive, art 3(5)-(6).

${ }^{214}$ Benham and others, above n 112, at 5; IPCC, above n 147, at 5.19. See also Guidance Document 2, above n 100 , at $122-123$

${ }^{215}$ Barton and others, above n 17, at 237.

${ }^{216}$ Havercroft and Macrory, above n 167, at 35; Clarke, above n 155, at 181, 189; Bolscher and others, above n 123, at 82; Carbon Capture Legal Programme Dedicated CCS Legislation (UCL).

${ }^{217} \mathrm{C}$ Hendriks and others, above n 3 , at 49.

${ }^{218}$ Clarke, above n 155 , at 189.

${ }^{219}$ CCS Directive, art 19.

${ }^{220}$ McCoy, above n 147, at 21; Ingelson and others, above n 14, at 456.

${ }^{221}$ See GGGSA(Vic), ss 218-220; GGSA(Qld), from s 270.

${ }^{222}$ Barton and others, above n 17 at 130; CCS Directive, art 19; GGGSA(Vic), ss 222, 275.
} 
and the cost of monitoring. ${ }^{223}$ It would also include site closure activities. ${ }^{224}$ There are many potential mechanisms that could be used, ${ }^{225}$ including compulsory insurance, ${ }^{226}$ corporate guarantees, the provision of a refundable bond, ${ }^{227}$ the charging of fees or levies, ${ }^{228}$ or a pooled fund to which all operators contribute. ${ }^{229}$ The exact mechanism, and quantum of security required, would be a policy choice. Certainty is important. ${ }^{230}$ However, we also need to balance the need for security against the imperative not to dis-incentivise projects, ${ }^{231} \mathrm{a}$ realistic approach to the actual risks of leakage and the prospects of insurability. ${ }^{232}$

The most important outcome of a CCS project is that storage is secure. Therefore if an operator ceased to exist and its financial security proved inadequate to achieve that outcome, the Crown is best placed to assume liability for orphaned projects. ${ }^{233}$ It may justifiably do so under the beneficiary-pays principle, given the public interest in storage. This is consistent with other scenarios overseas in which the public interest is so great as to justify the state operating as the last resort recipient of liability (such as where harm results from terrorist activity or nuclear incidents). ${ }^{234}$

\footnotetext{
${ }^{223}$ See generally CCS Directive, art 19.

${ }^{224}$ IEA, above n 4, at 76; CCS Directive, art 19; GGSA(Qld), s 270; GGGSA(Vic), ss 112, 218, 224; Alberta Government, above $\mathrm{n} 88$, at 9.

${ }^{225}$ See European Commission Implementation of Directive 2009/31/EC on the Geological Storage of Carbon Dioxide: Guidance Document 4 (2011); Ingelson and others, above n 14, at 442; C Bidlack "Regulating the Inevitable" (2010) 30 J Land Resources \& Envtl L 199 at 224; A Klass and E Wilson "Climate Change and Carbon Sequestration" (2008-2009) 58 Emory LJ 103 from 158.

${ }^{226}$ GGGSA(Vic), s 218.

${ }^{227}$ See Alberta Government, above n 88, at 96; s McCoy, above n 147, at 22; OPGGSA(Cth), s 220; GGGSA(Vic), s 218.

${ }^{228} \mathrm{IEA}$, above n 4, at 31; OPGGSA(Vic), s 694; GGGSA(Vic), s 224. For a critique, see Gibbs, above n 195, at 165.

${ }^{229}$ IEA, above n 4, at 106; E Wilson, A Klass and S Bergan "Assessing a Liability Regime for Carbon Capture and Storage" (2009) 1 EGYPRO 4575 at 4580-4581; Interstate Oil and Gas Compact Commission Storage of Carbon Dioxide in Geological Structures: Model Statute (2007), s 6. Contrast Barton and others, above n 17, at 131.

${ }^{230}$ Carbon Capture Legal Programme CCS Liability Legislation (UCL).

${ }^{231}$ WRI, above $\mathrm{n} 1$, at 79 .

${ }^{232}$ European Commission, above n 225, at 17; Havercroft and Macrory, above n 167, at 47; Clarke, above n 155 , at 197.

${ }^{233}$ See OPGGSA(Cth), s 401; Mines and Minerals Act 2000 (Alb), s 121(3); G Severinsen "Towards an Effective Legal Framework for the Geo-Sequestration of Carbon Dioxide in New Zealand" [2010] Canterbury Law Review 331 at 367.

${ }^{234}$ See Ingelson and others, above n 14, at 461 .
} 
In this section I contend that the law should provide for long-term liability and responsibility for a CCS operation to pass from an operator to the Crown. A transfer permit should be granted where a minimum time has elapsed and clear performance criteria have been met.

The way in which an operation is closed has implications for its long-term security of storage. Closure involves the cessation of injection, sealing of a well, and remediation of a site. ${ }^{235}$ Under the precautionary principle and certainty-flexibility principle, management plans concerning closure need to be contemplated at the point of granting a storage permit, ${ }^{236}$ and constantly updated over a project's life-cycle to respond to changes in operations and a site's unique risk profile. They must predict the migration of $\mathrm{CO}_{2}$ streams and its likely consequences. ${ }^{237}$ But if there were scope for a regulator to certify such closure plans prior to the cessation of injection, there is little reason to require an additional point of regulatory intervention (a specific permit for closure). ${ }^{238}$ Closure requirements for the site would already be clear and enforceable. Providing discretion to refuse permission would present uncertainty for operators and would require additional (and potentially costly) regulatory processes. ${ }^{239}$

In contrast, I contend that it would be desirable to allow an applicant to obtain a different kind of permit, at a point in time well after injection has been ceased and a site has been closed. The purpose of this permit would be to transfer regulatory liability and responsibility from an injector to a competent public authority (in New Zealand, the Crown). ${ }^{240}$ Here, I call this a "transfer" permit, although the concept is known by various labels elsewhere. ${ }^{241}$ This kind of transfer is fairly unusual in environmental law, but has proved a common measure in CCS law overseas, and its absence is frequently discussed in the literature as a legal gap. ${ }^{242}$ Ordinarily, those conducting an activity are expected to remain responsible for its

\footnotetext{
${ }^{235}$ GGGSA(Vic), s 92.

236 See Barton and others, above n 17, at 118. Compare Mines and Minerals Act 2000 (Alb), s 116(3)(e); Storage of Carbon Dioxide (Licensing etc.) Regulations 2010 (UK), reg 6.

${ }^{237}$ See OPGGSA(Vic), s 414(2); OPGGSA(Cth), s 386(2); GGSA(Qld), s 177(2).

${ }^{238}$ For example, see GGGSA(Vic), s 92.

${ }^{239}$ Contrast OPGGSA(Vic), ss 414, 422, and 433; OPGGSA(Cth), ss 386-392.

240 Including under the emissions trading scheme, pt 26A of the Maritime Transport Act, any long-term obligations under RMA and EEZ Act consent conditions, and storage permit conditions. Compare CCS Directive, art 18; OPGGSA(Cth), s 400; Havercroft and Macrory, above n 167, at 42.

${ }^{241}$ See OPGGSA(Cth), ss 391-395.

${ }^{242}$ IPCC, above n 2, at 15, 36; Strategic Analysis of the Global Status of Carbon Capture and Storage: Report 3: Policies and Legislation Framing Carbon Capture and Storage Globally (GCCSI, 2009) at 68; Gibbs, above n 195, at 167; GCCSI The Global Status of CCS: 2015 Summary Report (GCCSI, Melbourne, 2015) at 9-10.
} 
environmental consequences under the polluter-pays principle. The basic rationale for a different approach to CCS is that private injectors cannot reasonably be expected to bear the risks of storage in perpetuity, ${ }^{243}$ and to do so may unduly discourage investment in which the public has a strong interest.

A number of jurisdictions have embraced transfer, including Alberta, ${ }^{244}$ the European Union, ${ }^{245}$ several states of the United States, ${ }^{246}$ and Australia in Commonwealth waters. ${ }^{247}$ Others, such as Victoria, Queensland, South Australia and others in the United States, simply remain silent as to whether transfer of liability can occur, with the implication being that it will not. ${ }^{248}$ The latter approach can be criticised on the grounds it provides little certainty. ${ }^{249}$

There is a strong case that New Zealand law should provide for a transfer of long-term responsibility and liability to the Crown. While an unfettered ability to offload liability in the future may incentivise risk-taking by operators, ${ }^{250}$ and is bound to be politically sensitive, ${ }^{251}$ existing principle supports a transfer if safeguards are in place. Practically speaking, a private injector does not endure forever, ${ }^{252}$ and may have limited financial resources. ${ }^{253}$ Even financial security posted by an applicant may not be sufficient to address potential problems a century or more after injection ceases. Under the public-interest industries principle, someone must remain responsible for leakage from a site, or the climate costs of leakage will be passed on to the wider community. ${ }^{254}$ In contrast, the state has greater permanence, legal continuity, and more substantial resources. ${ }^{255}$ It can spread risk over a long period of time as, effectively, an insurer of last resort. ${ }^{256}$ Moreover, the prospect of permanent and therefore uncertain regulatory liability may unduly dis-incentivise deployment and fail to reflect the distributive

\footnotetext{
${ }^{243}$ See Havercroft and Macrory, above n 167, at 36; Alberta Government, above n 88, at 94.

${ }^{244}$ Mines and Minerals Act 2000 (Alb), s 121.

${ }^{245}$ CCS Directive, art 18.

${ }^{246}$ IEA Carbon Capture and Storage: Legal and Regulatory Review (2 ${ }^{\text {nd }}$ ed, IEA, Paris, 2011) at 10.

247 OPGGSA ss 399-401. Compare Barrow Island Act 2003 (WA), ss 14B-14D.

248 Compare Carbon Dioxide Capture and Geological Storage: Australian Regulatory Guiding Principles (MCMPR, 2005) at 46. There is usually still a point after which an injector no longer has active obligations, even if liability is not specifically transferred: see GGGSA(Vic), ss 168-170; GGSA(Qld), ss 177(2)(f), 269(3); IEA, above n 4, at 100; Ingelson and others, above n 14, at 443.

${ }^{249}$ See Gibbs, above n 195, at 169; IEA, above n 4, at 54 .

${ }^{250}$ Gibbs, above n 195, at 171.

${ }^{251}$ Ibid at 171; see also Clarke, above n 155, at 181.

${ }^{252}$ IPCC, above n 2, at 257; Strategic Analysis, above n 242, at 68; Gibbs, above n 195, at 170.

${ }^{253}$ IEA, above $\mathrm{n} 4$, at 100.

${ }^{254}$ Australian Parliament, above n 78, Attachment A, at 29.

${ }^{255}$ Robertson and others, above n 17 , at 14 .

${ }^{256}$ Ingelson and others, above n 14, at 464.
} 
principle, ${ }^{257}$ especially if potential profit margins under carbon markets were slim. While some have argued that Crown assumption of some liability offends the polluter-pays principle and is a subsidy in disguise, ${ }^{258}$ it is important to recall that in New Zealand the principle does not seek to internalise all costs. Transfer is consistent with the beneficiary-pays principle, given the benefits that permanent storage has for society as a whole. ${ }^{259}$ It is best seen as the ongoing provision of a vital public (and inter-generational) good, rather than the prevention of private harm. ${ }^{260}$ This goes some way to countering criticism that CCS is no different to other private activities having long-term effects (such as landfills), where liability remains with an operator. ${ }^{261}$ That said, injectors benefit disproportionately to society (by gaining carbon credits). They should also be incentivised to manage sites properly. The bulk of risk should therefore remain with an injector, with transfer to the Crown occurring only when remaining risks of climate harm are low. ${ }^{262}$

Taking a similar risk-averse perspective, ${ }^{263}$ other jurisdictions that provide for transfer have generally required three pre-requisites for it to occur. ${ }^{264}$ This approach would provide adequate certainty under the certainty-flexibility principle, ${ }^{265}$ while also ensuring that wider society (through the Crown) is not exposed to more than minimal risk under the beneficiarypays principle. ${ }^{266}$ First, closure obligations (such as the plugging of wells) must have been fulfilled. ${ }^{267}$ Conditions in a storage permit therefore need to be able to endure until the point of transfer. ${ }^{268}$ Secondly, a minimum period of time must have elapsed. ${ }^{269}$ Specific minimum timeframes require a policy choice, although internationally risks have been considered

\footnotetext{
${ }^{257}$ IEA, above n 4, at 63, 100; WRI, above n 1, at 104 .

${ }^{258}$ Barton and others, above n 17, at 226; Barton, above n 73, at 31; Strategic Analysis, above n 242, at 77-79. See generally C Hendriks and others, above n 3 at 32; Australian Parliament, above n 78, Attachment A, at 29.

${ }_{259}$ See generally Severinsen, above n 233, at 367; N Bankes, J Poschwatta and EM Shier "The Legal Framework for Carbon Capture and Storage in Alberta" (2008) 45 Alta L Rev 585 at 623.

${ }^{260}$ See Ingelson and others, above n 14, at 460, 465. Contrast C Armeni, 'Carbon Capture and Storage in the Sub-Seabed and Sustainable Development: Please Mind the Gap' (2013) 27 Ocean Yearbook 1 at 18.

${ }^{261}$ See IEA, above $\mathrm{n}$ 4, at 101.

262 Compare J McLaren and J Fahey "Key Legal and Regulatory Considerations for the Geosequestration of Carbon Dioxide in Australia" (2005) 24 ARELJ 46 at 73.

${ }^{263}$ See Pritchard, above n 17, at 281; Havercroft and Macrory, above n 167, at 46.

${ }^{264}$ Along with jurisdictions that provide for an end point for active site closure obligations.

${ }^{265}$ On the importance of certainty as to transfer, see Clarke, above n 155, at 188 .

${ }^{266}$ Compare Regulatory Guiding Principles, above n 248, at 5.

267 See CCS Directive, art 18; Mines and Minerals Act 2000 (Alb), s 120(3); OPGGSA(Vic), s 423; OPGGSA(Cth), s 388(6).

${ }^{268}$ Barton and others, above n 17, at 123; compare OPGGSA(Cth), s 359; OPGGSA(Vic), s 377.

${ }^{269}$ Ingelson and others, above n 14 , at 448. Such timeframes are not always inflexible.
} 
sufficiently low between 10 and 30 years following the cessation of injection. ${ }^{270}$ Risks of leakage decline steadily over time, so would be borne mostly by an injector. ${ }^{271}$ Thirdly, the ultimate criterion for transfer should be performance-based, and therefore involve a degree of Crown discretion. ${ }^{272}$ Relying only on time-based criteria (for example, automatic transfer after 10 years) may encourage an operator to take unnecessary and unacceptable risks and fail to work to long-term risk horizons. ${ }^{273}$

Performance-based criteria have been expressed in various ways, but there has been recognition that they should not be overly prescriptive. ${ }^{274}$ They should also be practically obtainable. ${ }^{275}$ Their thrust is that the Crown should be satisfied that risks of leakage and irregularities are low, not significant or have been reduced as far as reasonably practicable, ${ }^{276}$ the site and plume are behaving in a stable or predictable manner, ${ }^{277}$ and there is agreement between measured and modelled plume behaviour. ${ }^{278}$ The World Resources Institute has used language of "non-endangerment" and demonstrable containment in a confining zone, ${ }^{279}$ while in the EU there must be no detectable leakage, all available evidence must indicate complete and permanent containment, ${ }^{280}$ and the site must be "evolving towards a situation of longterm stability". ${ }^{281}$ The Alberta Regulatory Framework Assessment has recommended that there be a requirement of decreasing risk. ${ }^{282}$ Some have also required there to be a low level of risk to other subsurface resources and the environment, ${ }^{283}$ although in New Zealand these

\footnotetext{
${ }^{270}$ OPGGSA(Cth), ss 399-401; CCS Directive, art 18(1)(b); Alberta Government, above n 88, at 103; Ingelson and others, above $\mathrm{n} 14$, at 446 .

${ }^{271} \mathrm{C}$ Hendriks and others, above n 3, at 19.

${ }^{272}$ Barton and others, above n 17, at 80; Severinsen, above n 233, at 364. Contrast M Granger Morgan and S McCoy Carbon Capture and Sequestration: Removing the Legal and Regulatory Barriers (RFF Press, New York, 2012) at 128.

${ }^{273}$ IEA, above n 4, at 100; Department of Primary Industries A Regulatory Framework for the Long-term Underground Geological Storage of Carbon Dioxide in Victoria (2008) at 62.

${ }^{274}$ WRI, above n 1, at 102; Havercroft and Macrory, above n 167, at 37. See also Implementation of Directive 2009/31/EC on the Geological Storage of Carbon Dioxide: Guidance Document 3 (European Commission, 2011).

${ }^{275}$ Clarke, above n 155 , at 193.

${ }^{276}$ WRI, above n 1, at 100; Mines and Minerals Act 2000 (Alb), ss 120(3), 121; IEA, above n 4, at 95; GGGSA(Vic), s 168; OPGGSA(Cth), ss 399-401; Louisiana Geologic Sequestration of Carbon Dioxide Act 2009, s 1109; GGSA(Qld), s 179(1)(c).

${ }^{277}$ IEA, above n 4, at 94, 99; Mines and Minerals Act 2000 (Alb), s 120(3); GGGSA(Vic), s 170(1).

${ }^{278}$ WRI, above n 1, at 100; CCS Directive, art 18.

${ }^{279}$ WRI, above $\mathrm{n} 1$, at 98 .

${ }^{280}$ See also Storage of Carbon Dioxide (Termination of Licence) Regulations 2011 (UK), reg 9(2).

${ }^{281}$ CCS Directive, arts 18-19; Guidance Document 3, above n 274. Compare Alberta Government, above n 88, at 104.

${ }^{282}$ Alberta Government, above n 88, at 104.

${ }^{283}$ See OPGGSA(Cth), s 399; OPGGSA(Vic), s 422; Alberta Government, above n 88, at 104.
} 
would already have been addressed through RMA resource consent conditions concerning site closure.

Because of a site's relatively low post-transfer risk profile, an effects-based approach means that the Crown's monitoring obligations may justifiably reduce in scope, intensity and frequency. ${ }^{284}$ To reduce the burden on the Crown, an operator could also be required to furnish a post-closure monitoring and maintenance plan, ${ }^{285}$ to retain in good working order and transfer monitoring infrastructure, ${ }^{286}$ and to provide some form of financial contribution towards the long-term management of the site and future regulatory liabilities. ${ }^{287}$

Finally, there may be a need to extend the duration of consents under the RMA and EEZ Act that authorise the activities necessary to ensure secure storage over the long-term. Consent may be required, for example, to operate monitoring wells, conduct seismic surveying, and engage in corrective measures if leakage occurred. ${ }^{288}$ Since a storage permit would mandate these activities, it would be anomalous, inefficient and inconsistent with the public-interest industries principle if the Crown were then obliged constantly to renew consent, or potentially be refused consent, to do so. Thus I recommend that these activities, once initially authorised, should be exempted from the need to renew consent.

\section{J Conclusion}

In this chapter I have considered the legal framework that is required to ensure that $\mathrm{CO}_{2}$ storage is secure for climate reasons. This outcome is required by the public-interest industries principle. I have concluded that there is a gap in the current law, largely because it does not provide for comprehensive, consistent or precautionary regulatory measures to achieve positive effects on the climate.

Gap 4 The RMA, EEZ Act and CCRA do not provide adequate assurance that the climate benefits of all CCS operations would be achieved.

\footnotetext{
${ }^{284}$ WRI, above n 1, at 101; CCS Directive, preamble at (35), art 18(6); Ingelson and others, above n 14 , at 459.

${ }^{285}$ See GGGSA(Vic), s 170; GGSA(Q1d), s 177.

${ }^{286}$ IEA, above n 4, at 96.

${ }^{287}$ See CCS Directive, art 20; GGGSA(Vic), ss 112, 174; OPGGSA(Vic), s 426; Mines and Minerals Act 2000 (Alb), s 122; Clarke, above n 155, at 197; Barton and others, above n 17, at 228; IEA, above n 4, at 96; S McCoy, above n 147, at 21-22; Alberta Government, above n 88, at 94-95.

${ }^{288}$ Strategic Analysis, above n 242, at 57.
} 
New provisions are needed to ensure that leakage is prevented and that the law is certain. A key part of this is to require an operator to obtain a storage permit from the Crown before injecting $\mathrm{CO}_{2}$. This must contemplate the impacts on secure storage of all stages of the project life-cycle, from site-selection to post-closure monitoring and corrective measures. Where standards concerning site selection, injection and post-injection stewardship are generalisable, they should be imposed ex ante within regulations, and translated to permit conditions. To the extent that generalisation is not possible and contextualisation is required, discretionary permit decisions should be guided by a risk-averse approach to leakage.

A permitting process should also be implemented to allow an operator to transfer regulatory responsibility and liability to the Crown. This is necessary to ensure that climate risks are actively managed in the long-term but also provide assurance to operators that their liability will not be permanent. Under the beneficiary-pays principle, society - through the Crown can justifiably bear some costs of activities that are in the public interest.

In practice, the measures recommended in this chapter to achieve climate aims may to some extent also prevent or mitigate the local risks of leakage managed already under the RMA (discussed in chapter VII). Preventing leakage will usually be good for both the local and global environment. It may therefore be most efficient for a resource consent to incorporate by reference aspects of a storage permit. Whether these two permitting systems are actually integrated is an important question of legislative design, but beyond the scope of the thesis. The key point is that the law - wherever it is sited - needs both a clear normative basis for achieving positive climate effects and the kinds of machinery capable of doing so. 


\section{IX}

\section{Other Gaps - the Relationship between Marine CCS and Petroleum Mining}

\section{A Introduction}

The relationship between marine CCS and petroleum mining activities is complex. ${ }^{1}$ In some cases the activities can be compatible (or even mutually beneficial). In others, they may be incompatible. They can impact upon each other where they occur in close proximity.

In this chapter I conclude that there are gaps in New Zealand's existing law, because it fails to govern the relationship in a way that is consistent with existing principle. This is for three reasons, which I address in turn. First, our current methods for allocating subsurface space to different users fail to reflect the importance of CCS under the distributive principle. They are also inefficient, because choices are made after substantial effort may have been expended on exploration activities. We require a new, targeted, and comparative process for determining uses that best reflect the public interest. Secondly, the law does not provide adequate certainty or protection for existing subsurface operations, including CCS, under the publicinterest industries principle and certainty-flexibility principle. New law is required to provide clearer expectations. Thirdly, the point at which a petroleum operation becomes a storage

\footnotetext{
${ }^{1}$ I exclude specific consideration of the relationship between marine CCS and other potential offshore subsurface activities (such as geothermal generation, coal bed methane and aquifer minerals), as these are less likely to be significant offshore in the short-term. On these kinds of relationship, see Alberta Government Carbon Capture and Storage: Summary Report of the Regulatory Framework Assessment (Energy Alberta, Edmonton, 2013) at 65; B Field and others Interaction of $\mathrm{CO}_{2}$ Storage with Subsurface Resources (IEA, Paris, 2013).
} 
operation (and thus subject to storage law) is not always clear, especially in cases of carbon capture, utilisation and storage (CCUS). This infringes the certainty-flexibility principle, and requires new law for clarification.

\section{B $\quad$ Allocating Unused Subsurface Space}

My proposition in this section is that the law does not provide an effective framework for allocating rights to use subsurface space. It fails to make considered choices between petroleum mining and CCS in a way that reflects the distributive principle. Mechanisms for making choices between those uses are also inefficient, because they apply only after substantial effort may have been expended on exploration activities. New law is needed to fill this gap.

As explained in chapter IV, the law currently treats both CCS and petroleum mining as industries in which there is a substantial public interest. Yet areas of the subsurface may be usable for either activity, and applicants may compete directly for rights to use the space. The question of which should be preferred is of practical concern, because an emergent CCS industry may threaten an established petroleum industry that has thus far enjoyed an effective monopoly on the use of the deep subsurface offshore. ${ }^{2}$

New Zealand's laissez faire take on the distributive principle means that the law usually avoids determining the specific use to which resources are put (how their benefits are allocated). ${ }^{3}$ Such questions are generally separated from those concerning the regulation of activities' adverse effects. ${ }^{4}$ A narrow range of "public-interest" resources (like minerals and fisheries) are allocated more pro-actively under specific legislation, but those acts do not allocate subsurface space itself. ${ }^{5}$ The RMA and EEZ Act, which in practice facilitate the allocation of rights to use the subsurface, rely mainly on market forces to do so - as long as their adverse effects on the environment are acceptable. ${ }^{6}$ As Grinlinton has observed, these

\footnotetext{
${ }^{2}$ IEA CCS Model Regulatory Framework (Paris, IEA, 2010) at 17.

${ }^{3}$ See ch III.

${ }^{4}$ M Bramley "Institutional and Governance Structures of Environmental Law" in P Salmon and D Grinlinton (eds) Environmental Law in New Zealand (Thomson Reuters, Wellington, 2015) at 416.

${ }^{5}$ See Crown Minerals Act 1991 (CMA), Forests Act 1949, Fisheries Act 1996; see D Grinlinton "Sustainability in New Zealand Law and Policy" in Salmon and Grinlinton, above n 4, at 126-127. For exceptions for allocating freshwater and energy, see RMA, s 39(1)(fa)-(fb).

${ }^{6}$ See Royal Forest and Bird v Buller District Council [2013] NZHC 1324, [2013] NZRMA 275 at [50]-[53].
} 
dual economic (free-market) and environmental (sustainability) platforms on which the RMA was founded can produce conceptual tensions. ${ }^{7}$ For example, we may feel legitimate unease if one resource use would have been more sustainable than the one authorised.

This ethos means that CCS and petroleum applicants who wished to use the same area of the subsurface would be prioritised on a first-in-time basis under the acts. ${ }^{8}$ Once an application were made, a consent authority could not speculate as to whether a subsequent or alternative proposal would be preferable. ${ }^{9}$ There may be little wrong with that in a world of abundant resources. But where public resources (such as marine space, ${ }^{10}$ viable storage formations, or freshwater) ${ }^{11}$ are scarce, the public interest may not be served by blindly granting exclusive, long-term, rights to activities determined by the market. ${ }^{12}$ The issue of allocation has been described by some as "the antithesis of a sustainable and efficient use of public resources"13 and "an urgent and important question". ${ }^{14}$

In the context of CCS, a first in time approach to allocating rights is particularly undesirable. ${ }^{15}$ Passively allocating rights to use subsurface space for mining, without even considering whether storage would better provide for the basic needs of future people, would be inconsistent with inter-generational equity. ${ }^{16}$ The law must provide some form of comparative mechanism under which the public interest - not market forces - determines the use of subsurface space. ${ }^{17}$ This would reduce the risk of "misallocating valuable public resources". ${ }^{18}$

\footnotetext{
${ }^{7}$ Grinlinton, above n 5, at 111 .

${ }^{8}$ See Fleetwing Farms Ltd v Marlborough District Council [1997] 3 NZLR 257 (CA) at 264.

${ }^{9}$ Ibid.

${ }^{10}$ See I Boisvert "Lifting the Looking Glass" (2011) 15 NZJEL 1 at 16.

11 See G Severinsen "Variation 6: A Fresh Approach to Water Allocation" (April 2012) RMJ 17; T Daya Winterbottom "Water Management" in Salmon and Grinlinton, above n 4, at 667-670; Land and Water Forum $A$ Fresh Start for Freshwater (Land and Water Forum, 2010).

${ }^{12}$ K Bosselmann and V Tava "Introduction: Water in Context" in K Bosselmann and V Tava (eds) Water Rights and Sustainability (New Zealand Centre for Environmental Law, Auckland, 2011) 1 at 9.

${ }^{13}$ B Brunette "Freshwater Management and Allocation under the Resource Management Act 1991" (2006) 10 NZJEL 169 at 204.

${ }^{14}$ B Barton "The Nature of Resource Consents" in Environmental Law: National Issues Intensive (NZLS, 2009) at 52 .

${ }^{15}$ B Barton, K Jordan and G Severinsen Carbon Capture and Storage: Designing the Legal and Regulatory Framework for New Zealand (University of Waikato Centre for Environmental, Resources and Energy Law, Hamilton, 2013) at 152.

16 See also K Bosselmann The Principle of Sustainability: Transforming Law and Governance (Ashgate, Aldershot, 2008 at 84; J Sinner and J Scherzer "The Public Interest in Resource Rent" (2007) 11 NZJEL 279 at 288.

${ }^{17}$ M Gibbs "The Regulation of Geological Storage of Greenhouse Gases in Australia" in I Havercroft, R Macrory and RB Stewart Carbon Capture and Storage: Emerging Legal and Regulatory Issues (Hart, Oxford,
} 
1 Existing allocative mechanisms

There are four tools that could be used under existing law to avoid relying entirely on market forces to allocate subsurface rights, ${ }^{19}$ but they all have shortcomings. Ultimately, the law's effects and market-based ethos remains too strong, failing to integrate allocative questions to the extent needed. ${ }^{20}$

First is the use of controlled activity status under the RMA, to make applications easier for activities that are "preferred" in any given area. ${ }^{21}$ It is easier because consent for controlled activities cannot be refused. However, this mechanism fails to recognise that in some cases consent may need to be declined for both CCS and petroleum operations. Both demand close consideration through a discretionary status because of their potential for adverse effects. Imposing controlled status would also not enable the best use of a particular site to be determined on a case by case basis. Proposals for storage and mining could not be compared, and it may be difficult to decide in advance which use would better serve the public interest. Controlled status is also not available under the simpler EEZ regime.

A second possible allocative tool is the strategic use of a prohibited activity status. Areas could be earmarked in advance for storage, in which petroleum mining would not be allowed (and vice versa). ${ }^{22}$ Case law has confirmed that prohibited status can be used in a strategic way, such as to stagger the availability of resources. ${ }^{23}$ If sufficient information were available

2011) at 173; IEA, above n 2, at 100. On deficiencies in the RMA's allocative regime, see Barton and others, above $\mathrm{n} 15$, at 33,110 .

${ }^{18}$ GCCSI The Global Status of CCS: 2015 Summary Report (GCCSI, Melbourne, 2015) at 9; Parliament of the Commonwealth of Australia Offshore Petroleum Amendment (Greenhouse Gas Storage) Bill 2008: Revised Explanatory Memorandum (2008), Attachment A, at 34; Sinner and Scherzer, above n 16, at 286.

19 Judge Sheppard has concluded that no amendment is needed to dispense with a dogmatic first in time approach: DF Sheppard "Reaching Sustainable Management of Fresh Water" [2011] RM Theory \& Practice 85 at 101-102.

${ }^{20}$ D Grinlinton "The Context of Environmental Law" in Salmon and Grinlinton, above n 4, at 68; Questions of resource "regulation" and "disposition" have been distinguished overseas: see N Bankes "Developing a Legal Regime for Carbon Capture and Storage in Canada" (ISEE Research Paper, December 2009) at 17.

${ }^{21}$ For example, the Waikato regional plan imposes controlled activity status on existing freshwater takes for drinking purposes: see Severinsen, above n 11.

${ }^{22}$ Blocks can be "reserved" under the Offshore Petroleum and Greenhouse Gas Sequestration Act 2010 (Vic) (OPGGSA(Vic)), s 495; Offshore Petroleum and Greenhouse Gas Sequestration Act 2006 (Cth) (OPGGSA(Cth)), s 459. See generally UK Department of Energy and Climate Change CCS Roadmap (2012) at 38.

${ }^{23}$ See Coromandel Watchdog of Hauraki Inc v Ministry of Economic Development [2007] NZCA 473, [2008] 1 NZLR 562 at [34]-[36]. 
(if public screening studies were conducted in advance) to identify areas clearly suited to one or the other industry, this may be a feasible mechanism. ${ }^{24}$ However, some commentators have described "the power to lock up areas for one single use" as "neither equitable nor efficient", and noted that councils may not have the expertise to make such sweeping decisions. ${ }^{25}$ Presently, it is not the role of regional coastal plans to allocate space to specified groups or give preference to some over others, only to identify the space for allocation. ${ }^{26}$ In many cases we may also need to rely on and compare information provided by applicants to determine the suitability of an area for different activities.

A third existing tool is a decision-maker's (apparent) ability, at least under the RMA, to give weight to an activity's opportunity cost. Case law has recently suggested that using a resource in one way (such as land for commercial purposes) that could otherwise be used for other, more valuable, purposes (industrial use) can be regarded as having an "adverse effect" on the environment. $^{27}$ Professor Sax has seen this as a useful factor in deciding competing applications. ${ }^{28}$ Both the Court of Appeal and Supreme Court have also recently hinted that applications close in time may sometimes be compared, on the understanding that one of them might better promote sustainable management. ${ }^{29}$ They suggest that the "first in time" priority rule under RMA and, by extension, the Act's underlying market-led ethos, may require rethinking. ${ }^{30}$ It is consistent with recent attempts in planning instruments to allocate resources more proactively to different uses, albeit by using the language of preventing adverse effects on existing resource interests. ${ }^{31}$

\footnotetext{
${ }^{24}$ On such studies overseas, see GCCSI, above n 18 , at 10.

${ }^{25}$ Boisvert, above n 10, at 21. Compare Barton and others, above n 15, at 152.

${ }^{26}$ Carter Holt Harvey Ltd v Waikato Regional Council [2011] NZEnvC 380 from [435].

${ }^{27}$ See Queenstown Central v Queenstown Lakes District Council [2013] NZHC 815 at [91]. On the need to think about the more valuable use, see E Hudspith "Freshwater Management in New Zealand" (2013) 16 NZJEL 277 at 295.

${ }^{28}$ J Sax "Our Precious Water Resources" [2009] RM Theory \& Practice 30 at 42-43.

${ }^{29}$ See Central Plains Water Trust v Synlait Ltd [2009] NZCA 609, [2010] 2 NZLR 363 (CA) at [89]; Synlait Ltd $v$ Central Plains Water Trust [2010] NZSC 32, [2010] NZRMA 257; Forest and Bird, above n 6, at [52]; Ngai Tahu Property Ltd v Central Plains Water Trust [2009] NZSC 24; Sheppard, above n 19, at 100.

${ }^{30}$ Central Plains Water Trust v Ngai Tahu Properties Ltd [2008] NZCA 71, [2008] NZRMA 200 (CA) at [90][91]. For the more traditional view that alternative uses usually need not be considered (and where they are, it is for the purpose of better protecting the environment rather than using the resource for a better purpose) see Lower Waitaki River Management Society Inc v Meridian Energy Ltd NZEnvC Christchurch C80/09, 21 September 2009 at [201]; Maniototo Environmental Society Inc v Central Otago District Council EnvC Christchurch C103/2009, 28 October 2009 from [702].

${ }^{31}$ See generally Severinsen, above n 11; S Foster "Redirecting the Flow" (2007) 7 BRMB 27.
} 
If we embrace the idea, we could say that the inability to use a formation for storage is an unacceptable adverse effect of, and therefore a reason to decline, a mining proposal. However, the approach has flaws. We may question whether there is really an "adverse effect" in the sense envisaged by the RMA if the market is selecting a particular use, over another, for a scarce resource. ${ }^{32}$ It is really a question of which has the greater benefit. More tangibly, relying on consent authority discretion would fail to provide a nationally consistent or transparent approach to allocation, and would require a speculative comparison with a hypothetical storage scenario. It would be difficult to gauge whether a CCS proposal would better serve the public interest, because there would be no such proposal in existence (and it may never occur at all).

A fourth tool is the alternative (and optional) mechanisms under Part 7A of the RMA for allocating coastal occupation rights in regional coastal plans. One mechanism is for a regional council to consider competing applications to occupy the same or proximate space (as well as "related" coastal permits) together. ${ }^{33}$ Competing mining and CCS proposals could be compared. The downside of this is that it relies on having two or more applications ready to be made at the same or similar times, and effectively remains a version of "first in time".

More promising is a power under pt 7A of the RMA to include rules in a regional plan requiring a structured, competitive process for allocating "authorisations" (including by tender). ${ }^{34}$ Authorisations are exclusive rights to apply for a coastal occupation permit, but do not themselves confer a right to a permit. ${ }^{35}$ This mechanism would enable a consent authority to compare directly the relative merits of the occupation of space by a storage proposal and a petroleum mining proposal.

However, it has drawbacks and uncertainties. It is unclear if a competitive process must be governed by financial considerations only, ${ }^{36}$ or if a successful bid could be determined by the broader "public interest" (especially if this were a different concept to the "sustainable management" purpose of the Act). If so, it would be a bold move beyond the market-led ethos of the RMA. More significantly, the main concern of the pt 7A process is the allocation

\footnotetext{
${ }^{32}$ See Queenstown Central, above n 27, at [159]-[160].

${ }^{33}$ RMA, s $165 \mathrm{~F}(1)$.

${ }^{34}$ RMA, from $\mathrm{s} 165 \mathrm{G}$.

${ }^{35}$ RMA, s 165R.

${ }^{36}$ RMA, s $165 \mathrm{H}$.
} 
of rights to occupy the seabed surface, not how to determine the best use of sub-seabed space or the relative merits of extraction and storage. ${ }^{37} \mathrm{~A}$ mining and CCS operation could both obtain authorisation for their minimal surface occupation needs through a pt 7A process, without resolving underlying competition for subsurface space, because neither would involve "occupation" of that space. ${ }^{38}$ Conflict may well simply resurface elsewhere, such as when consent applications were made to inject or to extract. There, the first application in time would likely be preferred, because no equivalent competitive process exists for determining those kinds of consent application.

As Barton and others have observed, there is simply "no general process for the management of conflicts over subsurface resources in New Zealand". ${ }^{39}$ Part 7A is not targeted at the kind of distributive question we are asking. Occupation restrictions are primarily about ensuring public access to the coastal marine area and managing the surface spatial demands of activities like aquaculture, ${ }^{40}$ whereas restricting subsurface use is about making choices between the relative public benefits of different activities like petroleum mining and CCS. A framework for such choices would be equally important on land and in the exclusive economic zone, yet neither of those has an equivalent of pt $7 \mathrm{~A} .{ }^{41}$ Relying on the competitive allocation of surface occupation rights in the coastal marine area would therefore provide multiple, inconsistent, ${ }^{42}$ and therefore confusing processes across New Zealand for securing subsurface rights.

Perhaps the most significant objection to relying on pt 7A is that it would be inefficient to allocate subsurface space only at the stage where coastal permits for occupation were being considered. Bids for authorisations would only be considered where the modest surface occupation needs of projects were known, because exploration activities (such as seismic surveying) would not necessarily have triggered the need for an occupation permit. ${ }^{43}$ By then, substantial costs and time may have already been expended by multiple competing parties on

\footnotetext{
${ }^{37}$ RMA, s 2 definition of "occupy".

${ }^{38}$ See ch VI.

${ }^{39}$ Barton and others, above n 15 , at 159 .

${ }^{40}$ See T Daya Winterbottom "Protection of the Coastal and Marine Environment" in Salmon and Grinlinton, above n 4, at 730; Thomas v Marlborough District Council PT Wellington W16/95, 21 February 1995 at 17.

41 On land, the RMA relies on private property rights in land (and therefore market forces) to allocate occupation rights Under the EEZ Act, occupation is not an activity that is restricted.

${ }^{42}$ On the importance of consistency and coordination in CCS law, see Strategic Analysis of the Global Status of Carbon Capture and Storage: Report 3: Policies and Legislation Framing Carbon Capture and Storage Globally (GCCSI, 2009) at 66.

${ }^{43} \mathrm{Or}$, potentially, any kind of permit, if those activities were permitted in a regional coastal plan.
} 
exploration activities, because only once a target has been explored can an applicant know what (and where) surface rights will be required. ${ }^{44}$ Exploration permits are already required to explore for petroleum under the Crown Minerals Act 1991 (CMA), even if no resource consent is required - but there is no equivalent for exploring for CCS storage space. ${ }^{45}$ Thus exploration proposals cannot be directly compared under current settings.

\section{Gap 5}

The law does not provide an efficient framework for allocating rights to use subsurface space to CCS and petroleum operators in a way that reflects the distributive principle

\section{Filling the gap}

To fill the gap described above, we require a targeted and transparent framework, guided by the public interest, for the Crown to allocate sub-seabed acreage at the exploration stage. The law should at least enable the Crown to use a comparative and competitive process of allocation for unused acreage, so that direct choices can be made between the merits of mining and storage.

The efficiency principle suggests that direct choices for sub-seabed use should be made at the point of granting exploration rights, by allowing CCS proposals to be integrated into the single block offer process currently run under the CMA. ${ }^{46}$ Acreage could still be released for competitive bidding by only mining or CCS bidders (and the other excluded), ${ }^{47}$ if it were known in advance that one were not suitable or was particularly suitable (direct spatial allocation). ${ }^{48}$ It might also be necessary to release acreage only for CCS where exclusive

\footnotetext{
${ }^{44}$ See Gibbs, above n 17, at 175; World Resources Institute (WRI) CCS Guidelines (WRI, Washington, DC, $2008)$ at 85.

${ }^{45}$ Crown Minerals Act 1991 (CMA), s 8.

${ }^{46}$ On the importance of coordinating questions of exploration and exploitation, see IEA, above $\mathrm{n} 2$, at 67 ; S McCoy Carbon Capture and Storage: Legal and Regulatory Review ( $4^{\text {th }}$ ed, IEA/OECD, Paris, 2014) at 19; B Barton "Carbon Capture and Storage Law for New Zealand: A Comparative Study" (2009) 13 NZJEL 1 at 35.

${ }^{47}$ See generally B Milligan "Planning for Offshore $\mathrm{CO}_{2}$ Storage" (2014) 48 Marine Policy 162 at 169; Barton and others, above n 15, at 153-154.

${ }^{48}$ See Strategic Analysis, above n 42, at 44. Some jurisdictions have also provided for exploration rights to be granted for particular vertical strata: for example Greenhouse Gas Geological Sequestration Act 2008 (Vic) (GGGSA(Vic)), s 29. See also Alberta Government, above n 1, at 66-67.
} 
petroleum exploration rights had already been granted over most offshore space. ${ }^{49}$ This is a common approach overseas. ${ }^{50}$ It may also allow the direct application by a single person, if demand for rights is likely to be so low as to make a structured process inefficient. ${ }^{51}$

However, I contend that the law should enable acreage to be released for competitive work programme bidding by both miners and injectors, if an area had legitimate potential for either. ${ }^{52}$ That would enable the merits of multiple mining and storage work programmes (and applicants) to be compared against each other early in the process chain according to the public interest. While making stark choices at the exploration stage has downsides (at that point there may be incomplete geological information on which to make an informed decision as to a preferable use $)^{53}$ they are outweighed by the practical need to provide investment certainty to an explorer. The power to decline a storage application once significant cost had been incurred in exploration activities, on the grounds that mining would be preferable, would provide insufficient certainty to private applicants. The risk of incomplete information could be mitigated to some extent by pre-competitive and publicly funded prospecting or "screening studies", 54 to provide basic information on an area to inform the release of acreage and against which competing exploration bids could then be assessed.

To implement the above approach, we need a basic restriction on the exploration of subsurface space (a requirement that a permit be obtained to explore) ${ }^{55}$ not just a restriction on exploration for minerals as under the CMA. Restrictions on exploration have been common in CCS regimes overseas, ${ }^{56}$ above and beyond those needed to address any local

\footnotetext{
${ }^{49}$ Australian Parliament, above n 18, Attachment A, at 32. The location of such acreage should be determined according to the public interest: see Down Under: Greenhouse Gas Storage (Parliament of the Commonwealth of Australia, Canberra, 2008) at 26. On impacts on existing mining operations, see below.

${ }^{50}$ Most regimes internationally provide for separate block offers for CCS and mining, rather than combining them into one process: see OPGGSA(Vic), ss 86 and 297; OPGGSA(Cth), ss 125 and 296; Greenhouse Gas Storage Act 2009 (Qld) (GGSA(Qld)), ss 22, 33.

${ }^{51}$ Participation in Australia has thus far proved to be low.

${ }^{52}$ On the value of competition, see IEA, above $\mathrm{n} 2$, at 67.

${ }_{53}$ Barton and others, above n 15, at 152; Barton, above n 46, at 22; GCCSI, above n 18, at 10.

${ }^{54}$ See generally S McCoy, above n 46, at 7, 18, 26, 34; Australian Parliament, above n 18, Attachment A, at 13; IEA Methods to Assess Geologic $\mathrm{CO}_{2}$ Storage Capacity (IEA, Paris, 2013).

${ }^{55}$ Compare OPGGSA(Vic), s 285, GGGSA(Vic), s 17.

56 See N Bankes and J Poschwatta, "Australian Legislation on Carbon Capture and Storage: A Canadian Perspective" (University of Calgary ISEEE Research Paper, June 2008) at 64-70; Barton, above n 46, at 22; OPGGSA s 289.
} 
environmental impacts of exploration. ${ }^{57}$ But in doing so, we cannot rely on the same normative justifications as under CMA, despite technical similarities between mining and $\mathrm{CCS}^{58}$ and the largely unexamined tendency overseas to replicate the dual explorationexploitation frameworks of petroleum laws. ${ }^{59}$ Under the CMA, the Crown restricts exploration due to its proprietary interest in minerals. In contrast to some other jurisdictions, ${ }^{60}$ in New Zealand the Crown cannot restrict exploration based on ownership of $\mathrm{CO}_{2}$ or the subsurface generally. ${ }^{61}$ Nor can we restrict exploration on the grounds that it will affect security of storage, because injection (and therefore the risk of leakage) cannot occur until a storage permit is granted.

We must look primarily to the efficiency principle - a need to align decision-making with the CMA block offer process - to justify a wider restriction on subsurface exploration. Other justifications are also possible. We can go further than the EU CCS Directive, where restrictions have been rather baldly justified by a statement that the state has the right to determine storage areas. ${ }^{62}$ Even though not Crown-owned, deep sub-seabed space is a "public" resource in which future people, under the principle of inter-generational equity, have a sufficient interest to warrant regulatory intervention based only on an intention to exploit. ${ }^{63}$ The Crown is best seen as a trustee, rather than owner, of this resource. It would thus be sensible for the Crown to make such choices (in partnership with iwi), ${ }^{64}$ given the national community of interest in both the success of mining and CCS, the fact that choices may impact on the Crown's proprietary rights in petroleum, and the Crown's role as custodian of the public good. ${ }^{65}$

\footnotetext{
${ }^{57}$ IEA, above n 2, at 63, 64; OPGGSA(Cth), s 249AC; Strategic Analysis, above n 42, at 40; Gibbs, above n 17, at 163.

${ }^{58}$ IEA, above n 2, at 65 .

${ }^{59}$ Ibid at 54; Gibbs above n 17, at 162; WRI, above n 44, at 59; Barton and others, above n 15, at 111.

${ }^{60}$ For example, OPGGSA(Vic), ss 65(1), 67; GGGSA(Vic) ss 14, 16; GGGSA(Vic), s 17; GGSA(Qld), s 27; Barrow Island Act 2003 (WA), s 13; Mines and Minerals Act 2000 (Alb), 15.1.

${ }^{61}$ Marine and Coastal Area (Takutai Moana) Act 2011, s 11(2). Vesting of the seabed would likely prove politically impossible. See generally G Severinsen "Towards an Effective Legal Framework for the GeoSequestration of Carbon Dioxide in New Zealand" [2010] Canterbury Law Review 331 at 359.

${ }^{62}$ Directive 2009/31/EC on the Geological Storage of Carbon Dioxide [2009] OJ L140/114 (CCS Directive), art 4(1).

${ }^{63}$ See Barton and others, above n 15, at 110; OPGGSA, (Vic), ss 21(1)(b), 21(2)(b), 285.

${ }^{64}$ See P Beverley "The Mechanisms for the Protection of Māori Interests under pt II of the Resource Management Act 1991" (1998) 2 NZJEL 121 at 131; Barton and others, above n 15, at 113.

${ }^{65}$ See Barton and others, above n 15 , at 81,133 .
} 
The normative guidance currently provided under the $\mathrm{CMA}^{66}$ when granting exploration rights is not appropriate to guide a competitive process involving CCS. It is by no means simple to make choices between CCS and mining operations, ${ }^{67}$ but the distributive principle demands that the climate benefits of CCS be recognised and emphasised more than under the narrow considerations that currently dominate bidding under the CMA. ${ }^{68}$ An emergent storage industry should not be stunted by a blanket preference for petroleum interests. ${ }^{69}$ The ultimate consideration in considering alternative work programmes must be the public interest at any given point in time. ${ }^{70}$ Clarity as to what this means is desirable, ${ }^{71}$ but should be provided through policy instruments and guidance to allow it to shift over time. ${ }^{72}$ The public interest should also be linked to the relative suitability of an area for each activity. For example, the efficiency principle suggests that shallow reservoirs may be better suited to extraction than storage, since $\mathrm{CO}_{2}$ streams would be less dense and therefore a less efficient use of space (and potentially at higher risk of leakage). ${ }^{73}$ Another important consideration would be the likelihood of work going ahead, including (in the case of storage) whether there were suitable and economically viable sources of emissions available for injection in the near future. ${ }^{74}$ Choices would also depend on the relative merits of applicants and their work programmes, ${ }^{75}$ which could reduce risks to the Crown as the eventual recipient of long-term responsibility for storage sites. ${ }^{76}$ Cash-bidding, ${ }^{77}$ a narrow economic approach to the public interest, would be an inappropriate mechanism for comparing CCS and mining proposals.

Overall, the law should emphasise that the climate benefits of storage receive substantial weight in decision-making. ${ }^{78}$ For example, the mining-centric Albertan approach, in which neither exploration nor storage rights for CCS can be granted where injection would

\footnotetext{
${ }^{66}$ And, in the EEZ, the Continental Shelf Act 1964 (which incorporates large parts of the CMA by reference).

${ }^{67}$ See IEA, above n 2, from 29.

${ }^{68}$ For example, see NZ Petroleum\&Minerals New Zealand Block Offer: Invitation for Bids (2016) at 8-9, sch 5.

${ }^{69}$ Barton, above n 46, at 35; Milligan, above n 47, at 167.

${ }^{70}$ For example, see GGGSA(Vic), s 76. Compare OPGGSA(Vic), s 301; OPGGSA(Cth), s 299(5). See also Barton and others, above n 15, at 153.

${ }_{71}$ As Barton has pointed out, "unconstrained discretionary powers do not promote the rule of law": Barton, above n 46, at 35. See, for example, the general "public interest" test in s 66 of the CMA.

72 See Alberta Government, above n 1, at 65. Under the OPGGSA(Cth) and the OPGGSA(Vic), the public interest is left to be defined by regulation: see Gibbs, above n 17, at 176 .

${ }_{73}^{7}$ IPCC Carbon Capture and Storage (Cambridge University Press, New York, 2005) at 215.

${ }^{74}$ See ibid at 224.

75 For example, GGGSA(Vic), ss 22-24; OPGGSA(Cth), s 296; OPGGSA(Vic), s 297; GGGSA(Vic), s 23; GGSA(Q1d), s 42.

${ }^{76}$ Crown Minerals Act 1991, s 29A(2).

${ }^{77}$ See OPGGSA(Cth), s 303.

${ }^{78}$ See McCoy, above n 46, at 19; GGGSA(Vic), ss 3 (definition of “public interest”), 7(a).
} 
"interfere with" the recovery of a petroleum resource, ${ }^{79}$ would fail to reflect the distributive principle in New Zealand. ${ }^{80}$ Some have made similar criticisms of the Australian Commonwealth regime. ${ }^{81} \mathrm{We}$ can even dispute the suggestion of the IPCC, that the potential existence of hydrocarbon reserves is a reason not to use otherwise suitable storage space. ${ }^{82}$

Once granted, an exploration permit needs to authorise a wide and non-exhaustive range of activities necessary to determine whether a storage site is viable. ${ }^{83}$ This would provide an adequate information base for a storage permit to be assessed. ${ }^{84}$ As under the CMA, it should not dispense with the need to obtain other environmental authorisations (such as under the RMA). These are necessary to protect the local environment from activities like exploratory drilling, in order to implement the conservation-enhancement principle. Conditions should outline a clear work programme,${ }^{85}$ and the permit should make clear what activities cannot be done without a storage permit. In particular, under the public-interest industries principle, exploration activities should not undermine the ability of the site to store $\mathrm{CO}_{2}$ securely, ${ }^{86}$ and in this sense there may be a case to require additional approvals - or certification - for activities like exploratory drilling. ${ }^{87}$

Another key lesson that can be drawn from the minerals framework, and one that is consistent with the efficiency principle and certainty-flexibility principle, ${ }^{88}$ is that those investing time and resources into exploration should then have some security of tenure to exploit the explored sites. ${ }^{89}$ It does not mean that a storage permit should follow as of right. ${ }^{90}$ That would still need to be assessed against the matters described in chapter VIII. Nor does it mean that an exploration permit should always be a pre-requisite to the grant of a storage permit. In some cases, such as where a partially depleted petroleum reservoir was already adequately

\footnotetext{
${ }^{79}$ Oil and Gas Conservation Act 2000 (Alb), s 39(1.1); Alberta Government, above n 1, at 49.

${ }^{80} \mathrm{~N}$ Bankes "The Developing Regime for the Regulation of Carbon Capture and Storage Projects in Canada" in Barton and others, above n 15, at 304.

${ }^{81}$ On such criticisms, see Gibbs above n 17, at 177; S Barrymore and A Mathison, "Update: Offshore Petroleum Amendment (Greenhouse Gas Storage) Bill 2008 (Cth)" (2008) 27 ARELJ 469.

${ }^{82}$ IPCC, above n 73 , at 215.

${ }^{83}$ WRI, above n 44, at 56; see OPGGSA(Vic), s 286, OPGGSA(Cth), s 290, GGGSA(Vic), ss 19(1)(b), 19(2).

${ }^{84}$ See ch IX; Barton and others, above n 15, at 111.

${ }^{85}$ IEA, above $\mathrm{n} 2$, at 65.

${ }^{86}$ GGGSA(Vic) s 21.

${ }^{87}$ For example, under ss $291-292$ of the OPGGSA, additional approval is needed for "key greenhouse gas operations". Compare GGGSA(Vic), s 39; GGSA(Qld), s 80.

${ }^{88}$ IEA, above n 2, at 29; Barton and others, above n 15, at 34, 111. See more generally Foster, above n 31, at 27.

${ }^{89}$ Barton, above n 46, at 22; GGGSA(Vic), ss 7(b), 19(2) and 72.

${ }^{90}$ See ch IX. Compare CMA, s 32.
} 
characterised, the law could provide for a process to obtain a storage permit directly. ${ }^{91}$ But it does suggest that any conflicting uses that would undermine the rights envisaged in an exploration permit (for example, petroleum mining) should be restricted in the area during the exploration phase, ${ }^{92}$ and that rights to apply for a storage permit should be exclusive to an exploration permit holder. ${ }^{93}$ Many jurisdictions have taken this approach. ${ }^{94}$

That said, exploration and storage permits should lapse after a certain time period if adequate progress has not been made. We need to ensure that the climate benefits of using the resource are actually realised, under the public-interest industries principle. ${ }^{95}$ Rights to explore subsurface space for a public purpose should not be the subject of financial speculation. In Australia, for example, Commonwealth legislation has implemented a "holding lease" to allow explorers to retain this exclusive right for a limited period of time. ${ }^{96}$ Furthermore, the efficiency principle suggests that any co-operative agreement made between multiple parties should be facilitated by the law. ${ }^{97}$ If they were willing, multiple explorers and injectors with pooled resources may make more efficient use underground storage space. ${ }^{98}$

While the RMA's approach to allocating surface occupation rights is insufficient to resolve competition for subsurface resources, it is important for reasons of efficiency to align the two. Otherwise, surface occupation rights (a coastal permit) could be granted for one use, and subsurface right (a storage or mining permit) to another. Where suitable surface space for drilling were limited, ${ }^{99}$ this could in theory prevent both activities proceeding, failing to achieve the public interest in either and threatening the efficiency of resource use. ${ }^{100}$ If this issue arose in the future, it may be useful to allow the holder of subsurface rights to acquire

\footnotetext{
${ }^{91}$ For example, see OPGGSA(Vic), ss 392-393; OPGGSA(Cth), ss 369-370; GGGSA(Vic), s 74; GGSA(Qld), from s 124. See H Bolscher and others Report for European Commission: Support to the Review of Directive 2009/31/EC on the Geological Storage of Carbon Dioxide (Task 2) (CLIMA.A4/FRA/2011/0027, 2014) at 83; CCS Directive, art 5(1); GCCSI, above n 18, at 11. In such cases, there may need to be flexibility to implement a competitive bidding process for exploitation rights directly.

${ }^{92}$ Strategic Analysis, above n 42, at 41. CCS Directive, preamble at (23).

${ }^{93}$ Compare RMA, pt 7; CMA, s 32; GGSA(Qld), s 113.

${ }^{94}$ For example, see GGGSA(Vic), ss 28, 19(2); IEA, above n 2, at 65; CCS Directive, art 6(3), preamble (23)(24).

${ }^{95}$ For example, see CCS Directive, preamble at (23); IEA, above n 2, at 65; GGGSA(Vic), ss 30, 57, 70, 176; OPGGSA(Vic), ss 294-296, 378; OPGGSA(Cth), ss 293, 360; GGSA(Qld), ss 107, 167; GGSA(Qld), s 167; Storage of Carbon Dioxide (Licensing etc.) Regulations 2010 (UK), reg 4. Compare CMA, s 35.

${ }^{96}$ WRI, above n 44, at 59. See OPGGSA(Cth), pt 3.3. Compare OPGGSA(Vic), pt 3.3; GGGSA(Vic), pt 4.

${ }^{97}$ Compare GGSA(Q1d), s 186.

${ }^{98}$ Alberta Government, above n 1, at 64.

${ }^{99}$ Barton and others, above n 15, at 85-86.

${ }^{100}$ RMA, s 7(b); CMA, s 1A(2)(a).
} 
associated surface occupation rights compulsorily, or arbitrated access rights, in a similar way that private network utility operators can access powers to compulsorily acquire land ${ }^{101}$ and petroleum miners can obtain access rights to private property. ${ }^{102}$ The RMA does not currently provide a means for a CCS operator to acquire coastal occupation rights or forced access rights to occupied areas, ${ }^{103}$ but without them, a conscious decision to authorise one subsurface activity over another for reasons of public interest may be frustrated. The concept of non-derogation already envisages that existing grants can be removed in favour of an alternative resource uses where the public interest is at stake, safeguards are imposed, and where compensation is forthcoming. ${ }^{104}$ Barton and others, for example, have seen CCS as justifying compulsory acquisition on land. ${ }^{105}$ A compromise position may be for the Crown, where possible, to reserve surface occupation rights in areas known to be suitable for CCS, to prevent the need to acquire another's rights later on. ${ }^{106}$

The ability to acquire or access areas of the seabed for authorised CCS operations should not remove an injector's obligation to obtain its own occupation permit. The permitting process for coastal occupation rights is important not only to confer on a private person a defensible right to occupy (akin to the role of private property rights on land), ${ }^{107}$ but also to allow the refusal of consent where an occupation would have adverse environmental effects. Such effects, which do not exist in relation to privately held land, ${ }^{108}$ would include any diminution in public and Māori access to the marine environment. ${ }^{109}$

Finally, when considering applications for exploration rights, an additional process of public participation would not necessarily be required by the participatory principle. It would be

\footnotetext{
${ }^{101}$ See RMA, s 186; P Marston and P Moore "From EOR to CCS" (2008) 29 Energy Law Journal 421 at 485 ; Barton and others, above n 15, at 95.

102 CMA, ss 53; compare GGSA(Qld), s 289. See generally M van Kampen and B Matheson "Minerals and Petroleum" in D Nolan (ed) Environmental and Resource Management Law $\left(5^{\text {th }}\right.$ ed, LexisNexis, Wellington, 2015) from 538.

${ }^{103}$ Sections 52(1)(b) and 30 of the Public Works Act 1981 allow areas of the common marine and coastal area to be "set apart" for a public work, and for subsisting "permits" to be acquired (and compensation paid), but it is not clear that requiring authorities can access the latter power (see RMA, s 186). In any case, neither CCS operators nor petroleum miners are requiring authorities (see RMA, ss 166-167).

${ }^{104}$ Under the Public Works Act 1981. See generally Waitakere City Council v Brunel [2007] NZRMA 235 (HC). Compare GGGSA(Vic), s 201.

105 Barton and others, above n 15, at 95; A Regulatory Framework for the Long-term Underground Geological Storage of Carbon Dioxide in Victoria (Victoria Department of Primary Industries, Melbourne, 2008) at 39.

${ }^{106}$ RMA, s 165K; Public Works Act, s 52.

${ }^{107}$ Barton and others, above n 15, at 110; Boisvert, above n 10, at 14-15.

${ }^{108}$ See G Hewison "The Resource Management Act 1991" in Salmon and Grinlinton, above n 4, at 566.

${ }^{109}$ RMA, s 122(5).
} 
duplicative of the existing rights of submission and appeal conferred under the RMA and EEZ Act for the same activity. Public involvement at the exploration stage would also be less useful, because there would be no concrete storage proposal on which to comment (it would be "chasing a mirage"). ${ }^{110}$

\section{Resolving Conflict between New and Existing Interests}

In some situations a CCS operator or a petroleum miner may wish to use the subsurface in a way that would impact on an existing, authorised, use. The law must resolve such conflicts by determining the point at which impacts warrant a refusal of the new activity. This presents a gap, because there are currently no provisions that require a sufficiently risk-averse approach to be taken to protecting existing CCS operations, in a way that would reflect the publicinterest industries principle. Where an existing petroleum operation is potentially impacted by a proposed CCS operation, I contend that a relatively risk-averse approach is also appropriate. If we grant exclusive rights to a user, we should not grant new rights in a way that would derogate from or frustrate those rights.

\section{Gap 6}

The law does not contain provisions that adopt a sufficiently risk-averse and public interest focused approach to protecting existing CCS and, to a lesser extent, petroleum operations

1 Conflict where no adverse effects arise

The efficiency principle suggests that existing rights to explore and exploit the sub-seabed should not prevent alternative uses of resources that a person does not intend to exploit. The ability to "bank" storage or petroleum rights without actually using them would fail to achieve the public interest for which the activity were authorised. ${ }^{111}$ Removing those rights would not frustrate the reason for the grant, or derogate from it, if, before a permit were obtained, the law explicitly and transparently required those rights to be relinquished. ${ }^{112}$

\footnotetext{
${ }^{110}$ Barton and others, above $\mathrm{n} 15$, at 76.

${ }_{111}$ See Barton and others, above n 15, at 117; Alberta Government, above n 1, at 76; GGGSA(Vic), s 180(1).

112 See GGGSA(Vic), s 35(2)(b).
} 
A sensible solution would be to require any subsurface discoveries (whether by a CCS or petroleum operator) during exploration to be notified to the Crown, ${ }^{113}$ and that those not required for exploitation be relinquished and released for alternative uses after a certain period had expired. ${ }^{114}$ Here, the public interest in using public resources must override purely speculative private interests in retaining exclusive rights for their own sake. Further, the law should facilitate the co-existence of mining and storage where agreement can be reached between users.

A complementary solution would be for a petroleum reservoir to be compulsorily designated for storage (if it was technically suitable) once an authorised mining operation had ceased. In fact, the IPCC has assumed that waiting for the commercial depletion of petroleum reserves (or joint use through CCUS) is the only feasible way to deploy storage in petroleum reservoirs. ${ }^{115}$ Here, the efficiency and distributive principles suggest that mining activities should not be allowed to occur in a way that would adversely affect the integrity of the reservoir for subsequent $\mathrm{CO}_{2}$ storage, ${ }^{116}$ but also that miners be given the right of first refusal to transition a site to storage ${ }^{117}$ (and to explore in the permitted area for additional storage space). ${ }^{118}$

2 Risks of adverse effects on existing operations

More difficult is a scenario in which one operation is already occurring or authorised, and another wishes to conduct another activity in a way that might materially affect it. ${ }^{119}$ The degree to which existing operations should be protected from the impacts of subsequent activities is not a question that is beyond the scope of existing law. The RMA and EEZ Act

\footnotetext{
${ }^{113}$ OPGGSA(Cth), s 452.

${ }^{114}$ See European Commission Report on Review of Directive 2009/31/EC on the Geological Storage of Carbon Dioxide (Brussels, 2015) at 5. Compare CMA, ss 35B-35C; GGSA(Qld), from s 72; Barton and others, above n 15 , at 158.

115 IPCC, above n 73, at 221.

116 See Barton, above n 46, at 29; Alberta Government, above n 1, at 66; IEA, above n 2, at 76; Barton and others, above n 15, at 154-155.

${ }^{117}$ See Down Under: Greenhouse Gas Storage, above n 49, at 67-71.

118 IPCC, above n 73, at 215; OPGGSA(Cth), ss 98(3); 161(3), 297; OPGGSA(Vic), ss 298, 315, 357, $392-393$.

${ }^{119}$ On what these effects could be, see ch I.
} 
already treat impacts on existing operations as justiciable environmental effects, ${ }^{120}$ not as a question of resource allocation.

However, we can still perceive a gap in the law, because the acts do not specify the degree of adverse impact on an existing operation that is acceptable. It is usually a discretionary matter that is considered on a case-by-case basis. This approach remains broadly acceptable to the extent a storage operation had potential impacts on surface activities like strip-mining, navigation and fishing. ${ }^{121}$ But the certainty-flexibility principle suggests that a more directive approach is required for marine CCS and petroleum mining that present potential subsurface conflict. There needs to be clarity as to whether, and on what terms, later subsurface uses could occur, particularly where no agreement could been reached between existing and proposed operators. $^{122}$

The importance of exclusive exploitation rights would probably require that any later application be refused where it proposed the use of the same sub-seabed site in a way that was technically incompatible with an existing one. ${ }^{123}$ This could include where a second application were made for storage. Granting such an application would frustrate an existing grant or, if it were worded in exclusive terms, unlawfully derogate from it. ${ }^{124}$ By comparison, in practice, marine CCS licenses in the United Kingdom are refused where they threaten the integrity of other lawful activities in the area. ${ }^{125}$

However, this does not mean that existing operations should be accorded absolute protection. ${ }^{126}$ Already, large tracts of the seabed have been allocated to petroleum explorers, ${ }^{127}$ and an over-zealous approach to other activities in those areas could stifle the deployment of CCS in a way that fails to reflect the distributive principle. ${ }^{128}$ So too could a blanket prohibition on later CCS operators who wished to store $\mathrm{CO}_{2}$ in hydraulically connected formations.

\footnotetext{
${ }^{120}$ RMA, s 2 definition of "environment"; EEZ Act, ss 2 definition of "existing interest", 59(2)(a).

${ }^{121}$ Strategic Analysis, above n 42, at 44; OPGGSA(Cth), s 460; OPGGSA(Vic), s 496.

${ }^{122}$ On cooperative agreements, see GGSA(Qld), ss 187-212.

${ }^{123}$ Compare CCS Directive, art 6(3); I Walker and others "Regulating Carbon Dioxide Storage Operations near Oil and Gas Fields" (2013) 37 EGYPRO 7766.

${ }^{124}$ See ch III. Compare CMA, s 30(7).

${ }^{125}$ Milligan, above n 47, at 166.

${ }^{126}$ See ch I.

127 New Zealand CCS Partnership CCS in New Zealand: Can Carbon Capture and Storage Deliver Value to New Zealand as we Head towards a Low Carbon Future? Summary Report (NZ CCS Partnership, 2011$)$ at 14.

${ }^{128}$ See Barton, above n 46, at 35; Milligan, above n 47, at 167.
} 
An effects-based approach suggests that integrated "basin management" should be the focus. It is important to remember that some subsurface uses can co-exist. ${ }^{129}$ Barton has pointed out that exclusivity "discourages sharing and co-operative solutions" ${ }^{, 130}$ and Australian legislation explicitly recognises that petroleum and CCS license areas can overlap. ${ }^{131}$ More generally, New Zealand's environmental law already recognises that some potential adverse effects on existing interests are acceptable. ${ }^{132}$ For example, some district plans actively encourage the densification of residential dwellings despite potential amenity impacts on adjacent landowners. Our tolerance for adverse impacts depends largely on the relative value society places on the existing and new uses. Public authorisations like resource consents and storage permits do not confer rights that are accorded absolute protection.

\section{Risks to an existing storage operation}

Where a mining proposal (or a subsequent storage proposal) had potential effects on an existing storage operation, ${ }^{133}$ the public-interest industries principle demands that a highly risk-averse approach be taken. The prevention of leakage is a clear normative goal, which does not contemplate the balancing of various interests (such as the economic benefits of extraction). ${ }^{134}$ That said, it would be unrealistic to eliminate all risk, as subsurface interactions are difficult to predict in advance. Whether an activity is acceptable is a question that must be answered on a case by case basis according to technical advice, but should be accompanied by a general direction that only (for example) "low" probabilities of "minimal" or "insignificant" effects on storage are appropriate. ${ }^{135}$ Similarly, Barton and others have considered that "unauthorised interference" should be prohibited. ${ }^{136}$

\footnotetext{
${ }^{129}$ R Pritchard "Carbon Capture and Storage - A Review of the Australian Legal and Regulatory Regime" in Barton and others, above n 15, at 270; IEA, above n 2, at 29.

${ }^{130}$ Barton, above n 14, at 76.

${ }^{131}$ OPGGSA(Vic), s 494; OPGGSA(Cth), s 458; GGSA(Qld), from s 196.

${ }^{132}$ See Southern Alps Air Ltd v Queenstown Lakes District Council [2008] NZRMA 47 (HC) at [48]-[52].

${ }^{133}$ For example, if new wells posed risks to storage: Barton, above n 46, at 23.

${ }^{134}$ See ch IV. Contrast OPGGSA(Vic), s 28(2)(c); OPGGSA(Cth), s 26(5); Offshore Petroleum and Greenhouse Gas Storage (Greenhouse Gas Injection and Storage) Regulations 2011, reg 1.5, which consider relative economic value in determining the significance of risk.

${ }^{135}$ See Strategic Analysis, above n 42, at 57.

${ }^{136}$ Barton and others, above n 15, at 106. See also A Ingelson, A Kleffner and N Nielson "Long-term Liability for Carbon Capture and Storage in Depleted North American Oil and Gas Reservoirs" (2010) 31 Energy Law Journal 431 at 438.
} 
Activities that clearly threatened secure storage should be strictly prohibited, either through nationally consistent standards under the RMA and EEZ Act, or through specific legislative provisions governing protected areas (as under the Submarine Cables and Pipelines Protection Act 1996). ${ }^{137}$ For example, the EU CCS Directive prevents any "conflicting uses". ${ }^{138}$ Similar kinds of protections are found in the RMA concerning designations. ${ }^{139}$ For CCS, any subsequent drilling activities around a storage complex would be of particular concern. ${ }^{140}$

Whether this approach would always prevent later access to a storage site for additional recovery of residual petroleum is unclear. Some jurisdictions have at least implied that petroleum recovery will not be entertained once a site has transitioned to storage. ${ }^{141}$ If not an absolute prohibition, strong risk-averse directions are needed. The general Australian approach, where regard must be had to the public interest when considering new mining proposals, seems too uncertain. ${ }^{142}$ The public interest should never demand that the integrity of storage, on which climate health may depend, be sacrificed to the economic benefits of subsequent petroleum extraction. ${ }^{143}$

\section{Risks to an existing mining operation}

Where a later storage proposal presented risks to an authorised mining operation, significant risks to the latter should be avoided. There should be no uncertainty as to whose interests will prevail, ${ }^{144}$ and the International Energy Agency has stressed the need to recognise existing mining interests. ${ }^{145}$ Frustrating them would infringe the public-interest industries principle (since, for now, achieving the economic benefits of extraction is deemed to be in the public interest).

\footnotetext{
${ }^{137}$ Daya Winterbottom, above n 40, at 746.

${ }^{138}$ CCS Directive, art 6(3).

${ }^{139}$ RMA, s 176.

${ }^{140}$ See C Hendriks, MJ Mace and R Coenraads Impacts of EU and International Law on the Implementation of Carbon Capture and Geological Storage in the European Union (European Commission, 2005) at 16, 21.

${ }^{141}$ For example, in Wyoming: see Marston and Moore, above n 101, at 483.

${ }^{142}$ Gibbs, above n 17, at 174; OPGGSA(Cth), ss 163, 26.

${ }^{143}$ OPGGSA(Cth), s 26(2)(c).

144 Ibid at 23.

${ }^{145}$ IEA, above n 2, at 29, 76.
} 
Internationally, jurisdictions have adopted various degrees of protection for existing petroleum operations. In most cases they recognise that, while risk should not be eliminated, an aversion to risk is generally appropriate to preserve investment certainty. ${ }^{146}$ In Victoria, for example, storage is not allowed where it poses a significant risk of sterilising or contaminating other resources, unless required by the public interest. ${ }^{147}$ The offshore Australian Commonwealth regime has taken a very protective approach to established petroleum operations; where rights that existed before CCS legislation came into effect would be subject to a "significant risk of a significant adverse impact", the holder of those rights effectively enjoys a right to veto new storage operations. ${ }^{148}$ The same is true of offshore Victorian legislation. ${ }^{149}$ In the United Kingdom, current policy is to refuse $\mathrm{CO}_{2}$ storage authorisation where it would threaten the security and integrity of other existing activities, including petroleum mining. ${ }^{150}$

That said, in Commonwealth Australian waters, existing petroleum rights are not always absolute. Where a CCS proposal does not pose a significant risk of a significant adverse impact on existing petroleum rights, impacts are not a reason to refuse an injection license. ${ }^{151}$ Even where there is such a risk, but petroleum rights (other than actual production licenses) were granted after the CCS legislation came into force (miners were, essentially, put on notice), the Minister may still grant a license if it is in the public interest. ${ }^{152}$ This highlights the need for the protection of mining rights to be balanced against the importance of facilitating storage for climate reasons, ${ }^{153}$ which is demanded by the distributive principle.

Again, one sees value in linking acceptable risk thresholds with terms such as "significant", as in the Australian legislation. This would confer some discretion on consent authorities to determine what a significant risk to a mining operation means in context, ${ }^{154}$ while making clear the need for a risk-averse approach. Whether a risk to petroleum interests is "significant" could also usefully be determined in light of the current relative public interest

\footnotetext{
146 See definitions of "significant risk" in OPGGSA(Vic), s 29(2)-(5), 30(2)-(5); OPGGSA, ss 25-29.

${ }^{147}$ GGGSA(Vic), ss 42, 96(1)(b), 98(2)(b).

${ }^{148}$ Barton, above n 46, at 23; OPGGSA s 292(11); Gibbs, above n 17, at 173-174. Compare GGSA(Qld), s 220.

149 OPGGSA(Vic), s 293.

${ }^{150}$ Milligan, above n 47, at 169.

${ }^{151}$ OPGGSA(Vic), s 382(1)(f); OPGGSA(Cth), s 362(1)(f).

152 Gibbs, above n 17, at 174. Compare OPGGSA(Vic), s 382(1)(c); OPGGSA(Cth), ss 292-293, 362(1)(c); GGSA(Qld), ss 202-203.

${ }^{153}$ IEA, above n 2, at 29; see also Barton and others, above n 15, at 121.

${ }^{154}$ In Victoria, the meaning of a "significant risk of a significant impact" can be determined in regulations: OPGGSA(Vic), ss 28-29.
} 
in having storage and extraction occur, ${ }^{155}$ reflecting the need to place weight on long-term, atmospheric and global effects under the distributive principle. This is much more than an assessment of their relative economic value. ${ }^{156}$

A general risk-averse approach to existing petroleum operations should flow through into conditions of a storage permit, coupled with Crown powers to direct measures where risks become too great. ${ }^{157}$

$5 \quad$ Responding to adverse effects on existing operations

If we accept that entirely eliminating risks to existing operations is neither realistic nor desirable when authorising later projects, we are also accepting that adverse effects may in practice occur. For example, a petroleum operation may cause unexpected movements of $\mathrm{CO}_{2}$ plumes, while CCS may impact on the movement, composition and recoverability of petroleum. Yet authorising an activity does not mean that adverse effects deserve no response. Under the certainty-flexibility principle, permits should make it clear what rights are conferred on each activity, and therefore when they are infringed. ${ }^{158}$ Rights could be defined according to geological criteria, such as defining a storage complex within which migration is authorised, ${ }^{159}$ or according to the kinds of effect on other sub-seabed operations. ${ }^{160}$ Site-specific conditions should provide clear expectations of the kinds of remedial or compensatory action required as a result of a breach, or at least trigger the need for dispute resolution according to clear principles. ${ }^{161}$ In Australia, wide ministerial powers exist to issue directions to mitigate risks to petroleum interests (even if authorised under an injection license), including cancelling an injection license. ${ }^{162}$ More specific guidelines as to when powers would be exercised - based on the public interest - would be desirable to provide CCS operators greater certainty.

\footnotetext{
${ }^{155}$ See Severinsen, above n 61, at 359.

${ }^{156}$ Contrast OPGGSA(Vic), s 29(2); Guidelines for Injection and Storage of Greenhouse Gas Substances in Offshore Areas (Australian Department of Resources, Energy and Tourism, 2011) at 17-19.

${ }^{157}$ Barton, above n 46, at 24.

158 Compare Carbon Dioxide Capture and Geological Storage: Australian Regulatory Guiding Principles (MCMPR, 2005) at 4.

${ }^{159}$ IEA, above n 2, at 59-60.

${ }^{160}$ Ibid at 67.

${ }^{161}$ Ibid at 48; GGSA(Qld), s 186; GGGSA(Vic), ss 48-49. See also Barton and others, above n 15, at 156-158.

162 OPGGSA(Vic), ss 322, 401-402, 410; OPGGSA(Cth), ss 316, 351, 376, 383(1)(i).
} 
6 Third party access to storage formations

A different kind of conflict may arise if a third party wished to store $\mathrm{CO}_{2}$ streams in an area where a CCS operation was already occurring. The question is whether we should allow that to happen, or whether we instead protect the rights of an existing operator. This is usually described as an issue of third party access to storage sites, rather than one of conflicting resource uses.

The issue is largely one of policy rather than legal principle. The concept of non-derogation does not itself require that rights to inject $\mathrm{CO}_{2}$ be exclusive, only that rights that are exclusive then be upheld. ${ }^{163}$ The public-interest industries principle and efficiency principle tell us that storage in any given formation should be maximised for the benefit of the climate, ${ }^{164}$ suggesting that subsequent injectors should be allowed to use the same formation. ${ }^{165}$ Doing so, and potentially forcing "unitisation" ${ }^{166}$ to ensure joint basin management, may increase the total rate or volume of injection and therefore a formation's overall climate contribution. ${ }^{167}$ The same could be said of subsequent access to a specific storage site within a formation. But whether that would be the result in practice is unclear. Granting exclusive rights to one injector to control and inject into a site may enhance its investment certainty. Operators may be unwilling to invest if others could subsequently use it. In the EU, storage rights over a storage "site" are exclusive to one injector, but a site may not encompass the entirety of a geological formation or hydraulic unit. ${ }^{168}$ Later rights can be granted to inject elsewhere in a formation.

However, exclusive rights to storage sites should not necessarily be absolute. In the EU, for example, there are provisions that force existing injectors to accept and store $\mathrm{CO}_{2}$ streams from others on reasonable terms (albeit with some fairly wide exceptions) even though they

\footnotetext{
163 Southern Alps Air, above n 132, at [52]; L Fraser "Property Rights in Environmental Management" (2008) 12 NZJEL 145 at 169.

${ }^{164}$ See Alberta Government, above n 1, at 64; compare A Haan-Kamminga, MM Roggenkamp and E Woerdman "Legal Uncertainties of Carbon Capture and Storage in the EU" (2010) 3 CCLR 240 at 247.

${ }^{165}$ See Regulatory Guiding Principles, above n 158, at 4.

${ }^{166}$ Whereby multiple injectors are required to cooperate to manage a reservoir as a single unit: see Marston and Moore, above n 101, at 477; K Abend "Geological Sequestration of Carbon Dioxide" (2010-2011) 5 Appalachian Nat Res LJ 1 at 17.

${ }^{167}$ Forced unitisation agreements are provided for under GGGSA(Vic), s 119.

${ }^{168}$ See CCS Directive, arts 6(1), 8; compare GGGSA(Vic), s 119; Guidelines for Injection and Storage, above n 156 , at 11 .
} 
are not required to relinquish exclusive control over a storage site. ${ }^{169}$ Similarly, in Alberta, a recent review has recommended that access to a site be left in the first instance to private negotiations, because the market will generally produce efficient results. ${ }^{170}$ If the market failed, access could be forced (by requiring an operator to accept $\mathrm{CO}_{2}$ streams), together with appropriate compensation. ${ }^{171}$

\section{Enhanced Petroleum Recovery and Carbon Capture, Utilisation and Storage}

In this section I consider the point at which enhanced petroleum recovery, which involves the injection of $\mathrm{CO}_{2}$ into the sub-seabed, should become subject to storage law and require a storage permit. This presents a gap, because there are no provisions that govern that relationship, and I contend that storage law should apply when an injector seeks to obtain credits for a removal activity under New Zealand's emissions trading scheme.

The relationship between marine CCS and petroleum mining is not always one that is defined by conflict. In some cases, they can be compatible, and even mutually beneficial. ${ }^{172}$ Most notable is where $\mathrm{CO}_{2}$ that is injected to enhance the recovery of petroleum is then securely stored as a form of carbon capture, utilisation and storage (CCUS). ${ }^{173}$ The distributive principle, public-interest industries principle and efficiency principle support the use of CCUS, because it is a low-conflict way of using one resource to achieve multiple outcomes in which the public and future generations have an interest. Practically speaking, it may also provide a low-cost entry point for early $\mathrm{CO}_{2}$ storage. ${ }^{174}$

The relationship presents unique legal challenges. The normative bases upon which mining (including enhanced petroleum recovery) and storage are regulated are very different. ${ }^{175}$ In the case of CCUS, they collide. Both the socio-economic benefits of petroleum and the

\footnotetext{
${ }^{169}$ CCS Directive, art 21. See also OPGGSA(Vic), ss 375(2)-(3); OPGGSA(Cth), s 358(13); GGGSA(Vic), s 114; Storage of Carbon Dioxide (Access to Infrastructure) Regulations 2011 (UK). See generally Strategic Analysis, above n 42, at 52; MM Roggenkamp "The Concept of Third Party Access Applied to CCS" in MM Roggenkamp and E Woerdman (eds) Legal Design of Carbon Capture and Storage (Intersentia, Antwerp, 2009) from 273.

${ }^{170}$ Alberta Government, above n 1, at 70.

${ }^{171}$ Ibid at 70; GGGSA s 118 .

${ }^{172}$ In others, they may be incompatible: see NETL Carbon Dioxide Enhanced Oil Recovery (2010) at 5.

173 See ch I.

${ }^{174}$ McCoy, above n 46, at 8.

${ }^{175}$ See ch IV; R Macrory "Legal Aspects of $\mathrm{CO}_{2}$-enhanced Oil Recovery" in SCCS $\mathrm{CO}_{2}$ Storage and Enhanced Oil Recovery in the North Sea (University of Edinburgh, 2015) at 67.
} 
climate benefits of CCS are central to the one activity. Prima facie, this suggests that both mining and CCS laws should apply to it.

This apparent simplicity hides a difficult question. It is not clear exactly when an enhanced petroleum recovery operation becomes a CCUS operation, and thus should require a storage permit. Other jurisdictions have also faced this difficulty. ${ }^{176}$ Internationally, targeted regimes for CCUS are underdeveloped, ${ }^{177}$ and the Albertan review has called on the provincial government to justify more fully differences in regulating storage and enhanced petroleum recovery. ${ }^{178}$ We may ask: at what point in time should the need for a storage permit be triggered by the injection of $\mathrm{CO}_{2}$ ? The same kind of question arises where a purely extractive operation wishes to transition to a pure storage operation, to the extent that injection occurs concurrently with extraction. ${ }^{179}$ These boundaries need to be managed with care to provide certainty to participants, ${ }^{180}$ to prevent unintended consequences for the petroleum sector, ${ }^{181}$ and to ensure that any regulation that is imposed has a sound normative foundation.

\section{Gap 7}

The law contains no provisions that clarify the point at which enhanced petroleum recovery becomes subject to storage law

1 Enhanced petroleum recovery as a form of CCS

It would be possible - although, ultimately undesirable - for all enhanced petroleum recovery projects to require a storage permit. To do so might appear to further the public interest in secure storage, because injectors would be required to prevent leakage. In this vein, it has been recommended that lawmakers in Alberta look into how pure enhanced petroleum recovery could be made to contribute towards climate aims. ${ }^{182}$ Similarly, Marston has pointed out that enhanced petroleum recovery operators could be required to maximise the amount of

\footnotetext{
${ }^{176}$ Alberta Government, above n 1, at 114.

${ }^{177}$ Barton and others, above n 15, at 161.

${ }^{178}$ Alberta Government, above n 1, at 114.

${ }^{179}$ Ibid at 115; see also P Marston Bridging the Gap - An Analysis and Comparison of Legal and Regulatory Frameworks for CO2-EOR and CO2-CCS (Global Carbon Capture Storage Institute, 2013).

${ }^{180}$ IEA, above n 2, at 114; Alberta Government, above n 1, at 114.

${ }^{181}$ IEA, above n 2, at 23.

${ }^{182}$ See McCoy, above n 46, at 23. HC Bugge "An Overview of CCS Law and Regulation in Norway” in Barton and others, above $\mathrm{n} 15$, at 351 .
} 
$\mathrm{CO}_{2}$ stored to the extent consistent with hydrocarbon recovery. ${ }^{183}$ However, the practical effect of subjecting all enhanced recovery operations to CCS restrictions may actually be to undermine the climate outcomes sought by the distributive principle. A low carbon price may mean that ongoing monitoring requirements and liability under storage law would make an enhanced recovery operation financially unviable for a miner. This could dis-incentivise the use of $\mathrm{CO}_{2}$ floods and lead miners to focus only on secondary recovery methods such as water flooding (which would not have any incidental climate benefits). ${ }^{184}$

A blanket requirement to comply with storage law would also prevent the use of enhanced petroleum recovery where a reservoir would not be secure enough to allow a storage permit to be granted. We must recall that permanent storage in a petroleum reservoir is not always geologically possible. ${ }^{185}$ Moreover, petroleum extraction has its own benefits, which should not be abandoned simply because it cannot always achieve incidental storage benefits for the climate. ${ }^{186}$ This explains why enhanced petroleum recovery has been expressly excluded from the scope of the EU CCS Directive. ${ }^{187}$ In the United Kingdom, in contrast to pure CCS, enhanced petroleum recovery remains largely unregulated in terms of its climate effects. ${ }^{188}$ The OSPAR Group of Jurists and Linguists also recommended that $\mathrm{CO}_{2}$-enhanced petroleum recovery not be subjected to storage law. ${ }^{189}$

\section{Thresholds for the application of storage law}

Pure enhanced petroleum recovery is not the same thing as $\mathrm{CO}_{2}$ storage, and should not be regulated as such. But the existence of incidental benefits for petroleum recovery should also not allow what is, effectively, a storage project to escape its obligations to deliver climate outcomes under the public-interest industries principle. ${ }^{190}$ It has been recommended in Alberta, for example, that the regulation of enhanced petroleum recovery projects

\footnotetext{
${ }^{183}$ Marston, above n 179 , at 144.

${ }^{184}$ On the co-benefits of enhanced recovery see Barton and others, above n 15, at 159; IEA $\mathrm{CO}_{2}$ Capture and Storage: A Key Carbon Abatement Option (IEA, Paris, 2008), at 92; RM Cueller-Franca and A Azapagic "Carbon Capture, Storage and Utilisation Technologies" (2015) 9 Journal of $\mathrm{CO}_{2}$ Utilization 82 at 99; Marston and Moore, above n 101, at 425.

${ }^{185}$ Bugge, above n 182, at 351.

${ }^{186}$ See ch IV.

${ }^{187}$ Preamble, at 20.

${ }^{188}$ Milligan, above n 47, at 167.

${ }^{189}$ OSPAR Commission Report from the Group of Jurists and Linguists on Placement of Carbon Dioxide in the OSPAR Maritime Area (2004) at [22].

${ }^{190}$ Alberta Government, above n 1, at 115.
} 
transitioning to $\mathrm{CO}_{2}$ storage be consistent with those governing pure storage operations, ${ }^{191}$ and the EU CCS Directive applies to enhanced petroleum recovery where it is combined with permanent storage of $\mathrm{CO}_{2}{ }^{192}$ Of course, these observations do not answer our question. They simply rephrase it. When does the injection of $\mathrm{CO}_{2}$ effectively become a storage project rather than enhanced petroleum recovery? When does an operation become one of pure or permanent storage rather than one that is exempted as a mining-related activity? These aims may co-exist to varying degrees in a single project.

If we accept that pure enhanced petroleum recovery should be excluded from the application of storage law, thresholds for it to apply cannot be determined only by the act of injection. Nor can they be determined by the result (the permanent storage of $\mathrm{CO}_{2}$ ) because both of these also occur in pure enhanced recovery projects. Ultimately, a storage project exists only when the law imposes on it a suite of restrictions to prevent leakage and verify secure storage. ${ }^{193}$ Yet the law should only impose those restrictions where injection also amounts to a storage project (where storage is part of the project's purpose). This circular reasoning can be overcome only by recognising that the key difference is one of intention, not action or result. This has been recognised in the United Kingdom, where storage law is triggered by operations "with a view" to permanent disposal. ${ }^{194}$

We then face the further challenge of determining what the intention of a corporate injector actually is. On its own, it presents a highly uncertain regulatory trigger point. Fortunately, as Barton and others have observed, in most cases this intention would be clearly observable and definable in New Zealand: through the act of registering as a participant under the emissions trading scheme to undertake CCS as a removal activity. The generation of carbon credits would be the commercial driver for permanent storage to occur, ${ }^{195}$ so compliance with storage law should be a pre-requisite to receiving credits for any form of $\mathrm{CO}_{2}$ injection. ${ }^{196}$

\footnotetext{
${ }^{191}$ Ibid at 115, Appendix D4; McCoy, above n 46, at 23.

${ }^{192}$ See preamble at 20.

${ }^{193}$ IEA, above $\mathrm{n} 2$, at 114 .

${ }^{194} \mathrm{R}$ Macrory and others Legal Status of $\mathrm{CO}_{2}$-Enhanced Oil Recovery (UCL Carbon Capture Legal Programme, 2013) at 14; Energy Act 2008 (UK), s 17.

195 CCUS operators could register under the New Zealand emissions trading scheme: see Climate Change Response Act 2002, s 168(1)(n)(ii).

${ }^{196}$ Compare Barton and others, above n 15, at 164. Maintaining the integrity of emissions trading is a key reason for imposing storage laws on pure storage and CCUS operations: see IEA, above n 2, at 115.
} 
However, we may require storage law to apply even where an operator chose not register under the emissions trading scheme. There are two reasons for this. First, it is possible that, in the future, regulatory tools could be used to require emitters to capture and store $\mathrm{CO}_{2}$ as a condition of consent, ${ }^{197}$ rather than providing financial incentives to do so under the scheme. Secondly, suitable sub-seabed storage space is a public resource that may prove to be scarce. ${ }^{198}$ Under the precautionary and efficiency principles, it should not be permanently and irreversibly used by injecting $\mathrm{CO}_{2}$ unless authorities were satisfied it would actually achieve a public benefit, irrespective of whether an injector chose to receive carbon credits. ${ }^{199}$ In the United Kingdom, the Government is simply able to impose CCS regulation on a $\mathrm{CO}_{2}$ injection operation if it chooses, and has signalled it will do so if an operator seeks to obtain carbon credits. ${ }^{200}$ But others have pointed out that the power is not constrained in this way. ${ }^{201}$ It is therefore appropriate that the RMA and EEZ Act continue to prohibit any sub-surface injection of $\mathrm{CO}_{2}$ where not specifically authorised under storage law (for permanent storage), mining law (for enhanced recovery), or both (where credits are sought for enhanced recovery (CCUS operations)). ${ }^{202}$

\section{E Conclusion}

In chapter IX I have considered three key aspects of the relationship between marine CCS and petroleum mining. These present legal gaps, because new law is required to clarify them. They are summarised below.

Gap 5 The law does not provide an efficient framework for allocating rights to use subsurface space to CCS and petroleum operators in a way that reflects the distributive principle.

Gap 6 The law does not contain provisions that adopt a sufficiently risk-averse and public interest focused approach to protecting existing CCS and, to a lesser extent, petroleum operations.

Gap 7 The law contains no provisions that clarify the point at which enhanced petroleum recovery becomes subject to storage law.

\footnotetext{
${ }^{197}$ A national environmental standard under the RMA could do so: see ch VI.

198 Alberta Government, above n 1, at 49; GCCSI, above n 18, at 11.

${ }^{199}$ See IPCC, above n 73, at 224.

${ }^{200}$ Energy Act 2008 (UK), s 33, Explanatory Notes <www.legislation. gov.uk>.

${ }^{201}$ Macrory and others, above n 194, at 24.

${ }^{202}$ See OPGGSA(Vic), s 371; OPGGSA(Cth), s 356; GGGSA(Vic), s 18.
} 
We require a new structured process through which, where appropriate, we can make comparative, competitive and transparent choices between storage and mining early on when allocating rights to unused subsurface space. This should be guided by a public interest that emphasises climate risks, but can shift over time. In addition, the law needs to be more explicit that a highly risk-averse approach will be taken to protecting the security of existing storage operations once established. An enhanced petroleum recovery operation should also need to comply with storage law before credits are payable under the emissions trading scheme. 


\section{$\xi$ \\ $\mathbf{X}$ \\ Conclusion}

Our world is facing an acute climate problem. Globally, there continues to be little political will in the short-term to abandon or significantly scale down the carbon-intensive industries on which socio-economic well-being is perceived to depend. CCS offers temporary, but crucial, technological assistance in our transition to a more sustainable low-carbon society. ${ }^{1}$ It allows the continuation of key industries while softening or eliminating their impact on the climate, and opportunities to remove $\mathrm{CO}_{2}$ from the atmosphere through bio-energy CCS.

Internationally, the development of CCS continues to be seen as being extremely important. The Intergovernmental Panel on Climate Change has assumed the use of the technology in its models that allow for a meaningful degree of change, and a recent report in the UK has emphasised that the costs of addressing climate change will increase significantly if we do not start deploying CCS now. ${ }^{2}$ The need for the technology is urgent. The laws applicable to CCS play an important part in achieving its benefits, as well as protecting the environment from its risks. ${ }^{3}$ Law reform for CCS is therefore a topic that deserves close attention.

CCS has yet to occur in New Zealand. It is a small, but still potentially significant, part of a portfolio of climate measures, notably in the industrial sector. If the cost of emitting $\mathrm{CO}_{2}$ were to increase, it may well become a viable industry. We must be prepared for that day, by

\footnotetext{
${ }^{1}$ IEA World Energy Outlook: Executive Summary (IEA, Paris, 2014) at 3; International Risk Governance Council Regulation of Carbon Capture and Storage (IRGC, Geneva, 2008) at 4; IEA Energy Technology Perspectives 2015 (IEA, 2015).

${ }^{2}<$ www.theguardian.com/environment/2016/sep/12/uk-must-move-now-on-carbon-capture-to-save-consumers billions says report>; Parliamentary Advisory Group on CCS Lowest Cost Decarbonsation for the UK (2016) at 4.

${ }^{3}$ IEA Technology Roadmap: Carbon Capture and Storage (IEA, Paris, 2013) from 25.
} 
ensuring that applications are governed by a framework of public environmental law that is normatively defensible, contains minimal uncertainty, and is compliant with our international obligations.

In this thesis I have considered the law that is required to produce an appropriate regulatory framework for CCS in New Zealand's offshore waters. The "appropriate" framework I recommend is one that contains no legal barriers or gaps. I conclude that, currently, New Zealand's environmental law applies in a way that presents a range of barriers and gaps. Provisions would not currently apply to CCS in a way that reflects the fundamental principles on which our environmental law rests. Many of these are supportive of climate action. In the context of the imminent threat posed by climate change, the increasing global recognition of the technology's importance, and the potential for CCS to assist in meeting New Zealand's climate obligations, barriers and gaps are significant.

I contend that numerous legal barriers exist (summarised below), but that they arise primarily from three features of New Zealand's law: its uncertainty when existing provisions are applied to the technology; its negative treatment of the technology as a form of marine dumping; and its tendency to reject regulatory responses to mitigate climate change.

\begin{tabular}{|c|c|}
\hline Barrier 1 & $\begin{array}{l}\text { The ways in which restrictions in the RMA and regional plans apply to marine CCS are } \\
\text { not sufficiently clear to reflect the certainty-flexibility principle. }\end{array}$ \\
\hline Barrier 2 & $\begin{array}{l}\text { The prohibition on marine CCS in RMA pollution regulations fails to reflect the benefits } \\
\text { of marine CCS under the distributive principle. }\end{array}$ \\
\hline Barrier 3 & $\begin{array}{l}\text { The ways in which restrictions in RMA pollution regulations apply to marine CCS are } \\
\text { not sufficiently clear to reflect the certainty-flexibility principle. }\end{array}$ \\
\hline Barrier 4 & $\begin{array}{l}\text { Consenting provisions under the RMA and EEZ Act assume CCS, as a form of dumping, } \\
\text { is an undesirable activity, failing to reflect the benefits of marine CCS under the } \\
\text { distributive principle }\end{array}$ \\
\hline Barrier 5 & $\begin{array}{l}\text { Policy provisions under the RMA provide a balance of considerations that does not } \\
\text { reflect the global, atmospheric and long-term benefits of CCS under the distributive } \\
\text { principle. }\end{array}$ \\
\hline Barrier 6 & $\begin{array}{l}\text { The RMA's prohibition on consent authorities considering the impacts of activities on } \\
\text { climate change fails to recognise the benefits of marine CCS required under the } \\
\text { distributive principle. }\end{array}$ \\
\hline Barrier 7 & $\begin{array}{l}\text { The ability to provide national policy guidance on the climate benefits of marine CCS } \\
\text { under the RMA is not sufficiently clear to reflect the certainty-flexibility principle. }\end{array}$ \\
\hline Barrier 8 & $\begin{array}{l}\text { The RMA's prohibition on consent authorities considering the impacts of activities on } \\
\text { climate change limits the ability to impose consent conditions restricting } \mathrm{CO}_{2} \text { leakage. }\end{array}$ \\
\hline Barrier 9 & Constraints on the duration of consent fail to provide sufficient certainty to injectors \\
\hline
\end{tabular}




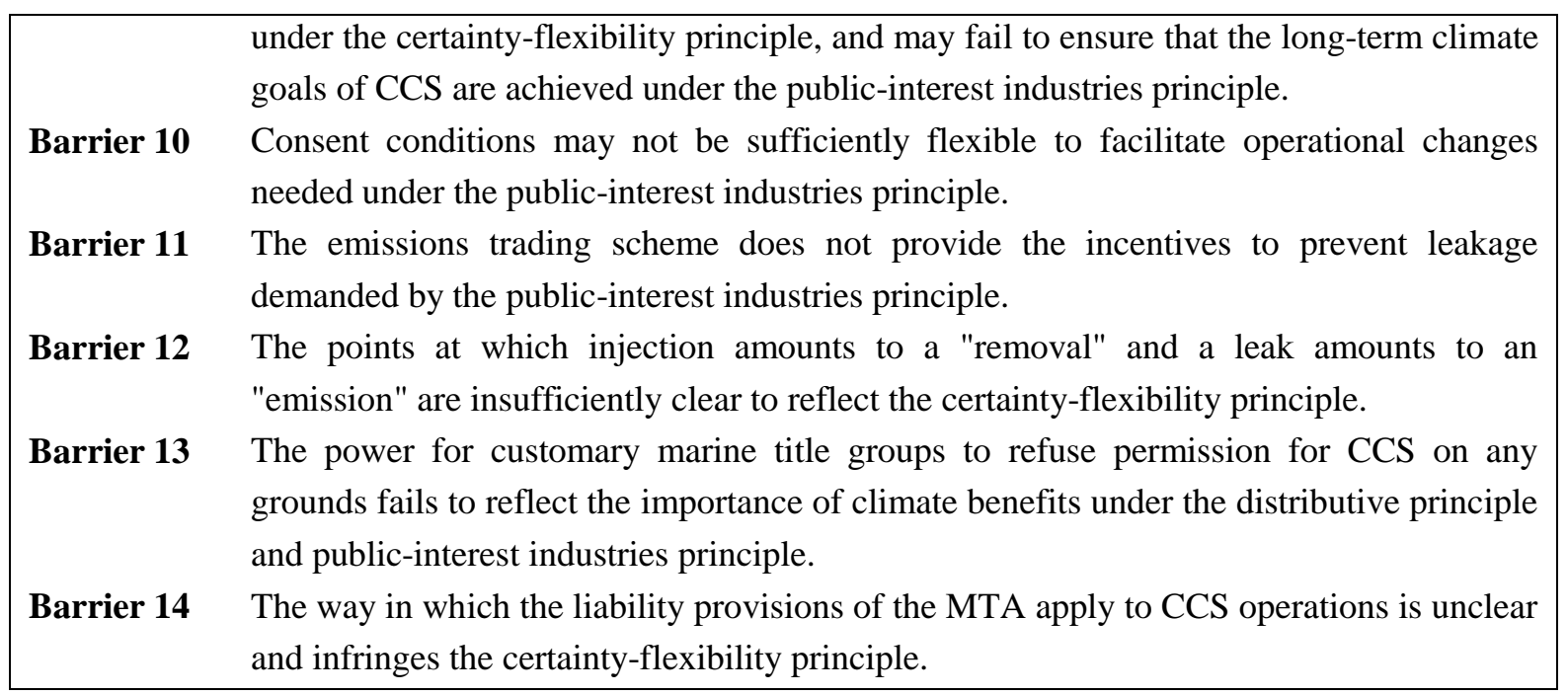

Legal gaps (summarised below) generally arise due to three limitations of the law: its lack of CCS-specific regulatory and policy provisions; its reluctance to regulate activities to achieve their positive effects; and the absence of a targeted, comparative and public interest focused decision-making process that is capable of resolving multiple interests in subsurface resources.

\begin{tabular}{|ll}
\hline Gap 1 & There are no national level legal standards that assign appropriate activity status to CCS, \\
or that impose requirements for $\mathrm{CO}_{2}$ purity, injection operations, and leakage. \\
There is no national level policy guidance that promotes the climate benefits of CCS, \\
Gap 3 \\
targets its specific risks, and ensures that relevant information is provided. \\
There are no regulations under the CCRA that specify when storage amounts to a \\
"removal" or when leakage amounts to an "emission". \\
The RMA, EEZ Act and CCRA do not provide adequate assurance that the climate \\
benefits of all CCS operations would be achieved. \\
The law does not provide an efficient framework for allocating rights to use subsurface \\
space to CCS and petroleum operators in a way that reflects the distributive principle. \\
The law does not contain provisions that adopt a sufficiently risk-averse and public \\
interest focused approach to protecting existing CCS and, to a lesser extent, petroleum \\
operations. \\
The law contains no provisions that clarify the point at which enhanced petroleum \\
recovery becomes subject to storage law.
\end{tabular}

Barriers need to be removed, and gaps need to be filled, in the ways described in chapters 6 to 9. But before recommending any significant law reform in any field, it is crucial that we understand exactly why we are embarking upon change, and if it is truly needed. As Sir Geoffrey Palmer has pointed out, we need to break free from New Zealand's culture of 
constantly fiddling with legislative schemes. ${ }^{4}$ The law needs to be driven by clear and coherent normative positions, avoiding knee-jerk reactions to social and technological change. All too often in the literature on CCS we encounter normative assertions that we ought to be pursuing certain kinds of change (for example, utilising existing regimes on petroleum extraction, or targeting the elusive and narrow idea of clean-coal). These sometimes fail to be justified by anything other than pure pragmatism or assumptions of nationally important resource agendas, and do not arise from the inherent features of CCS or legal principle. That approach can lead down a dangerous path, shaping subsequent perceptions and decisions on CCS in unexpected, and unprincipled, ways. In our understandable rush to respond to the urgency of climate change, we seem to wearing a normative blindfold of our own making.

As a first step for law reform in New Zealand, we need to think harder about how we see the environment, our place within it, and the role CCS plays in that relationship. The problem with environmental law, however, is that many valid normative positions are possible. One person might believe that our role is to protect the natural world from human or technological intervention. Another might believe that social welfare is the primary measure of our actions. Neither is wrong, but the point is that choices are based on ethical positions that lie beyond the realms of the law per se. The solution is to be transparent about the assumptions we make. In this thesis I have chosen to adopt a normative framework that has been characterised as inclusive and anthropocentric. It is a pluralist and human-centred approach to the environment that is rooted primarily in the broad concept of the public interest. This is not to dismiss other theories, particularly eco-centric approaches, as having no merit. Yet the choice has not been random or mindless. To produce workable recommendations, I considered it important for a normative approach to align well with the highly pluralist principles of New Zealand's existing law. An inclusive anthropocentric approach does so best (albeit not perfectly), for the reasons described in chapter II.

Broad ethical assumptions provide the background against which we can develop, in more detail, the normative drivers of law reform on CCS. We need to move beyond the abstract notion of inclusive anthropocentrism to generate principles that can produce concrete recommendations for reform. An inclusive anthropocentric approach has been chosen for its

\footnotetext{
${ }^{4}$ G Palmer "The Resource Management Act - How we got it and what Changes are being made to it" (2014) RM Theory\&Practice 22 at 38.
} 
power to account for New Zealand's existing environmental legal principles, which means it can also be developed further with reference to them. Ten key principles of our environmental law, identified in chapter III and translated to aims for marine CCS in chapter IV, form the normative lynchpin of my argument. They determine what an "appropriate" framework for the technology looks like. This is because existing law only presents legal barriers to the extent it hinders the achievement of those principles, and contains gaps only if our corpus of law fails to achieve them. An appropriate framework in one country may therefore not be appropriate in another. New Zealand requires a bespoke solution.

Many principles of our environmental law produce clear aims for marine CCS. For example, a desire for the law to be certain and predictable needs little translation. In other cases, the exercise is less straightforward. For example, it is not immediately clear whether injected $\mathrm{CO}_{2}$ should be seen as a waste or pollution, or whether a precautionary approach encourages or discourages deployment. My key normative arguments are that the law should place relatively substantial weight on positive atmospheric effects than on changes to the deep subsurface, and that the future global environment should at least be capable of equal or higher valuation than the present local (especially sub-surface) environment. Moreover, marine CCS should be seen as an industry in which the public has a substantial interest, justifying regulatory intervention not only to address adverse local effects but also to ensure the achievement of positive climate effects.

The technology should also not be classified in an inherently negative way as waste, pollution or dumping. Its role is much more unique and complex than that. Equally, we must not be tempted to see CCS as a permanent technological solution. It is part of a portfolio of measures, within which our emphasis may legitimately change over time. Legal classifications are driven not by the intrinsic features of substances or processes, but rather by the outcomes we wish to achieve. In the short-term, those outcomes are primarily the mitigation (and reversal) of anthropogenic climate change in a way that softens the impact of a sharp transition to a low-carbon society. CCS can help to achieve that. New Zealand's international legal obligations in relation to marine CCS are also important, notably under the London Dumping regime. I identified these in chapter $\mathrm{V}$, completing the normative framework for CCS (Part 1). 
The normative evaluation (Part 2 of the thesis) contains my recommendations for reform. There, I assessed existing laws against the normative framework developed in Part 1. When applied to a novel technology like CCS, we cannot assume that existing legal provisions are consistent with legal principles. In many cases they are not. That is the case even under broad, effects-based legislation like the RMA, which has not been drafted with CCS in mind. As such, I have argued that a number of barriers and gaps exist.

I acknowledge that the idea of barriers and gaps is a fluid and interconnected one. For example, the barrier produced by an inability to make climate regulation and policy under the RMA leads to a gap - the need for such targeted regulatory and policy instruments on CCS to be made. However, I have seen merit in treating them separately. Barriers can be removed by assessing and amending existing provisions that produce them, whereas gaps require a more conceptual analysis of the scope of our legislative frameworks, the ways that they operate together, and the new suite of provisions that are required.

The specific barriers presented by existing law have been summarised earlier in this chapter, and need not be outlined in detail again. My key conclusion is that barriers arise from three key features of existing law. First, it often applies in unclear ways, infringing the need for certainty and predictability in the law. For example, it would not be immediately clear to someone reading pt 2 of the RMA, or a regional plan, what restrictions applied and what consents were needed. Secondly, marine pollution law treats CCS negatively as a form of dumping, imposing provisions that presume, and focus heavily on the prevention of, adverse local effects. However, CCS is unlike other forms of dumping, in that it actively seeks to obtain climate benefits for the public good. It should be regulated in this light. Thirdly, the law may currently prevent decision-makers from giving appropriate weight to the technology's climate benefits. A policy choice has been made in New Zealand to remove regulatory responses to climate issues, which could in practice lead to an inappropriately narrow focus on adverse effects when considering consent applications under the RMA. Fortunately, these barriers can be removed relatively simply through minor legislative amendments and additions, and the development of subordinate legislative instruments.

The identification of gaps is more conceptually challenging, but equally important. Removing barriers still leaves a dearth of law that is needed to achieve key outcomes. We need regulation targeted at the specific adverse effects of CCS, policies emphasising the benefits of 
the technology and the relative weight to be given to positive and negative impacts, a framework that ensures positive climate effects are actually achieved and enforced, and laws clarifying the relationship between CCS and petroleum mining activities. The first two outcomes can be secured through the development of national level subordinate instruments under the RMA and EEZ Act, as explored in chapter VII. The second two outcomes require new legal frameworks (whether developed within or outside existing legislation).

I have argued in chapter VIII that our existing law may fail to ensure, for climate reasons, that storage remains secure. Partly because of its origins in the neo-liberal economic rationalism of the late 1980s, resource management legislation focuses on addressing adverse effects. This spirit has been continued in the market-led approach to greenhouse gas emissions under New Zealand's emissions trading scheme, under which $\mathrm{CO}_{2}$ emissions are permitted as long as they are paid for. As a whole, the system is ill-equipped to impose strict regulatory controls for the purposes of obtaining positive effects. Yet that is exactly what existing principle demands for CCS. Overseas, we observe that legal regimes for CCS are also much more focused on what the technology needs to achieve (secure storage), which is wider than New Zealand's traditional focus on the management of adverse effects or the internalisation of environmental externalities. The time has come to accept explicitly that the proper role of regulation is more than the correction of market failures. Our concern for the climate stems from a moral and social desire to improve our situation (the public interest) not our economic interests as consumers of natural resources.

As such, I have argued that we require a new framework targeted at the achievement of secure storage. Core to this is a two-step permitting system. First, a storage permit should be required to authorise the injection of $\mathrm{CO}_{2}$. Storage into the "public" sub-seabed should not occur unless the public has a robust assurance that its benefits will actually be achieved. Existing principle demands that leakage be prevented, and key to this is the selection of a suitable site, tailored plans for injection, and consideration of closure and post-closure activities. Generalised standards may be possible, but it is likely that most permits will need to be granted based on site-specific information combined with a robust risk assessment, leading to bespoke conditions. Complementary powers to require corrective measures are desirable to implement a precautionary approach, as are targeted regulations under the emissions trading scheme to ensure that payment is made for any leakage. Secondly, I have argued that a permit should be required to transfer long-term liability and responsibility from 
an injector to the Crown. This is not only for practical reasons (private investment may be unlikely if an operator's liability exists in perpetuity). It also recognises that the public, through the person of the Crown, has a legitimate role in bearing part of the burden of a project's long-term climate benefits. But because an operator benefits disproportionately to the public, transfer should only occur where risks are low.

The relationship between CCS and petroleum mining presents another key gap in the law, and has been explored in chapter IX. The industries may interact in complex ways that the law does not currently contemplate. They can compete for unused subsurface space, in which case choices need to be made as to which activity (or both) should proceed. In a future where offshore resources are likely to be increasingly constrained, and where both the energy and climate concerns of future generations are crucial, we can no longer rely on the market or case-by-case ministerial discretion in making such choices. We need a more sophisticated strategy, and the law is important in facilitating that. The tools under current law are limited. I have argued that principle requires a new competitive approach as an option when releasing unused acreage, in order to compare the merits of CCS and mining proposals. In doing so, a constantly evolving understanding of the public interest is paramount in making choices. We must also consider the efficiency of choice-making. As under existing petroleum law, exclusivity of tenure for those exploring the sub-surface (and to progress to exploitation rights) is desirable. This suggests that comparative choices should be made early, when assigning exploration rights. As has occurred overseas, a new framework is needed by which more general subsurface exploration activities (not just for mining purposes) require an exploration permit.

The grant of mining or storage rights should not necessarily prevent subsequent uses of the subsurface. To impose strict spatial separation would be inefficient, and we observe that, in other contexts, existing principle does not protect resource privileges absolutely. In many cases, CCS and mining could co-exist without threatening the viability of either. They may, for example, target different vertical strata. What the law needs is a more transparent position on the degree of risk that is acceptable to existing operations. The importance of preventing leakage from a storage site means a highly risk-averse approach is needed when considering subsequent mining operations. It is also important to guard the rights of existing miners from significant risk, but that need not be absolute. Again, an appropriate reference point is the 
public interest. The law should facilitate co-existence where possible, especially if rights holders can reach agreement.

The relationship between petroleum mining and storage is particularly complex because they can be (although are not always) mutually beneficial. $\mathrm{CO}_{2}$ can be injected to enhance petroleum recovery, and retained underground. The law plays a key role in clarifying the point at which an enhanced recovery operation requires a storage permit, which would entail additional obligations. An "intention" to store $\mathrm{CO}_{2}$ permanently appears to be the most defensible threshold for an enhanced recovery operation to become subject to storage law, and the most obvious evidence for this intention is where an injector registers as a voluntary participant under the emissions trading scheme.

The treatment of marine CCS under environmental law will be one crucial determinant of its success in New Zealand. In this thesis I have identified and addressed key legal barriers and gaps, in an effort to place law reform on a solid platform of principles. Faced with the perils of anthropogenic climate change on the one hand, and the social and economic ramifications of sharply reducing greenhouse gas emissions on the other, we must be proactive in reforming the law. 


\section{$\xi$}

\section{Bibliography}

A International Treaties and Related Instruments

Convention for the Protection of Natural Resources and Environment of the South Pacific Region [1986] PITSE 15 (signed 24 November 1986, entered into force 22 August 1990) (Noumea Convention).

Protocol for the Prevention of Pollution of the South Pacific Region by Dumping [1986] PITSE 16 (signed 24 November 1986, entered into force 22 August 1990).

Eleventh Meeting of the Noumea Convention Working Paper: Status as at July 2012 of the Noumea Conventions and Protocols (11NC/WP.8.4/Att.1).

Eleventh Meeting of the Noumea Convention: Agenda Item 8.4 (11NC /WP.8.4 30 August 2012).

Convention on the Control of Transboundary Movements of Hazardous Wastes and their Disposal 1673 UNTS 57 (opened for signature 22 March-1989, entered into force 5 May 1992).

Convention on the Prevention of Marine Pollution by Dumping of Wastes and Other Matter 1046 UNTS 120 (signed 29 December 1972, entered into force 30 August 1975) (London Convention).

1996 Protocol to the Convention on the Prevention of Marine Pollution by Dumping of Wastes and Other Matter 36 ILM 1 (signed 7 November 1996, entered into force 24 March-2006) (London Protocol). 
Risk Assessment and Management Framework for $\mathrm{CO}_{2}$ Sequestration in SubSeabed Geological Structures (CS-SSGS, LC/SG-CO2 1/7).

Specific Guidelines for the Assessment of Carbon Dioxide for Disposal into Sub-Seabed Geological Formations (LC34/15, 2012).

OSPAR Framework for Risk Assessment and Management of Storage of $\mathrm{CO}_{2}$ Streams in Geological Formations (2007-12).

United Nations Convention on the Law of the Sea 1833 UNTS 3 (opened for signature 10 December 1982, entered into force 16 November 1994).

United Nations Framework Convention on Climate Change 1771 UNTS 107 (signed 9 May 1992, entered into force 21 March-1994).

Protocol to the United Nations Framework Convention on Climate Change 37 ILM 22 (signed 11 December 1997, entered into force 16 February 2005).

Paris Agreement (signed 12 December 2015).

B Legislation

1 New Zealand

Animal Welfare Act 1999.

Biosecurity Act 1993.

Civil Defence Emergency Management Act 2002.

Climate Change Response Act 2002.

Conservation Act 1987.

Continental Shelf Act 1964.

Crown Minerals Act 1991.

Electricity Act 1992.

Electricity Industry Act 2010. 
Energy Efficiency and Conservation Act 2000.

Environmental Reporting Act 2015.

Exclusive Economic Zone and Continental Shelf (Environmental Effects) Act 2012.

Fiordland (Te Moana o Atawhenua) Marine Management Act 2005.

Fisheries Act 1996.

Forests Act 1949.

Gas Act 1992.

Hauraki Gulf Marine Park Act 2000.

Hazardous Substances and New Organisms Act 1996.

Health and Safety at Work Act 2015.

Housing Accords and Special Housing Areas Act 2013.

Judicature Amendment Act 1972.

Land Transport Management Act 2003.

Local Government Act 2002.

Local Government Official Information and Meetings Act 1987.

Maori Fisheries Act 2004.

Marine and Coastal Area (Takutai Moana) Act 2011.

Marine Mammals Protection Act 1978.

Marine Reserves Act 1971.

Maritime Transport Act 1994.

National Parks Act 1980.

Official Information Act 1982.

Public Works Act 1981.

Reserves Act 1977.

Resource Management Act 1991.

Resource Management (Energy and Climate Change) Amendment Act 2004. 
Sugar Loaf Islands Marine Protected Area Act 1991.

Te Uruwera Act 2014.

Telecommunications Act 2001.

Waikato-Tainui Raupatu Claims (Waikato River) Settlement Act 2010.

Waste Minimisation Act 2008.

Wildlife Act 1953.

Climate Change (Other Removal Activities) Regulations 2009.

Crown Minerals (Petroleum) Regulations 2007.

Hazardous Substances (Classification) Regulations 2001.

Hazardous Substances (Minimum Degrees of Hazard) Regulations 2001.

Minerals Programme for Petroleum (2013).

National Policy Statement for Renewable Electricity Generation 2011.

National Policy Statement on Electricity Transmission 2008.

New Zealand Coastal Policy Statement 2010.

Resource Management (Pollution Regulations) 1998.

Taranaki Regional Coastal Plan.

Resource Legislation Amendment Bill 2015.

2 Australia

Barrow Island Act 2003.

Environment Protection Act 1970 (Vic).

Greenhouse Gas Geological Sequestration Act 2008 (Vic).

Greenhouse Gas Storage Act 2009 (Qld).

Offshore Petroleum and Greenhouse Gas Storage Act 2006 (Cth).

Offshore Petroleum and Greenhouse Gas Storage Act 2010 (Vic). 
Offshore Petroleum and Greenhouse Gas Storage (Environment) Regulations 2009 (Cth).

Offshore Petroleum and Greenhouse Gas Storage (Greenhouse Gas Injection and Storage) Regulations 2011 (Cth).

Petroleum and Geothermal Energy Act 2000 (SA).

\section{Canada}

Mines and Minerals Act 2000 (Alb).

Oil and Gas Conservation Act 2000 (Alb).

\section{Europe}

Directive 2003/87/EC establishing a Scheme for Greenhouse Gas Emission Allowance Trading within the Community [2003] OJ L275/32.

Directive 2009/31/EC on the Geological Storage of Carbon Dioxide [2009] OJ L140/114. Energy Act 2008 (UK).

Storage of Carbon Dioxide (Access to Infrastructure) Regulations 2011 (UK).

Storage of Carbon Dioxide (Licensing etc) Regulations 2010 (UK).

C Cases

1 New Zealand

Affco v Far North District Council (No 2) (1994) 1B ELRNZ 101 (PT).

Alexander v Auckland City Council (1999) 5 ELRNZ 411 (EnvC).

Aoraki Water Trust v Meridian Energy Ltd [2005] 2 NZLR 268 (HC).

Arrigato Investments Ltd v Auckland Regional Council [2002] 1 NZLR 323 (CA). 
Ashby v Minister of Immigration [1981] 1 NZLR 222 (CA).

Auckland Regional Council v Auckland City Council [1997] NZRMA 205 (EnvC).

Auckland Regional Council v North Shore City Council (1995) 1B ELRNZ 426 (CA).

Batchelor v Tauranga District Council (No 2) (1992) 1A ELRNZ 221(HC).

Bay of Plenty Regional Council v Waaka EnvC Auckland A080/09, 4 September 2009.

Bleakley v Environmental Risk Management Authority [2001] 3 NZLR 213 (HC)

Board of Inquiry Final Report and Decision of the Board of Inquiry into the Basin Bridge Proposal (29 August 2014).

Board of Inquiry decision on applications for designation and resource consents by the New Zealand Transport Agency for the Mackays to Peka Expressway, Final Report.

Campbell v Southland District Council PT Wellington W114/94, 14 December 1994.

Canterbury Regional Council v Christchurch City Council EnvC Christchurch C217/2001, 6 December 2001.

Canterbury Regional Council v Apple Fields Ltd [2003] NZRMA 508 (HC).

Canterbury Regional Council v Selwyn District Council (1996) 2 ELRNZ 395 (EnvC).

Carter Holt Harvey v North Shore City Council [2006] 2 NZLR 787 (HC).

Carter Holt Harvey v North Shore City Council [2007] NZCA 420, [2008] 1 NZLR 744.

Carter Holt Harvey Ltd v Te Runanga o Tuwharetoa ki Kawerau [2003] 2 NZLR 349 (HC).

Carter Holt Harvey Ltd v Waikato Regional Council [2011] NZEnvC 380.

Central Plains Water Trust v Ngai Tahu Properties Ltd [2008] NZCA 71, [2008] NZRMA 200.

Central Plains Water Trust v Synlait Ltd [2009] NZCA 609, [2010] 2 NZLR 363.

Christchurch International Airport Ltd v Christchurch City Council (1996) 3 ELRNZ 96 (HC).

Colonial Homes Ltd v Queenstown Lakes District Council PT Wellington W104/95, 28 August 1995.

Cook Island Community Centre Soc (HB) Inc v Hastings District Council (1993) 1B ELRNZ $205(\mathrm{PT})$. 
Cookie Munchers Charitable Trust v Christchurch City Council EnvC Wellington W090/08, 22 December 2008.

Contact Energy Ltd v Manawatu-Wanganui Regional Council [2010] NZEnvC 406, [2011] NZRMA 155.

Coromandel Watchdog of Hauraki Inc v Ministry of Economic Development [2007] NZCA 473, [2008] 1 NZLR 562.

Crest Energy Kaipara Ltd v Northland Regional Council [2011] NZEnvC 26, [2011] NZRMA 420.

Cullen v Kaipara District Council EnvC Auckland A015/99, 17 February 1999.

Dart River Safaris Ltd v Kemp [2000] NZRMA 440 (HC).

Director General of Conservation v Marlborough District Council EnvC Christchurch C113/2004, 17 August 2004.

Director General of Conservation v Wairoa District Council NZEnvC Wellington W081/07, 19 September 2007.

Fleetwing Farms Ltd v Marlborough District Council [1997] 3 NZLR 257 (CA).

Environmental Defence Soc Inc v Auckland Regional Council [2002] NZRMA 492 (EnvC).

Environmental Defence Soc Inc v Taranaki Regional Council EnvC Auckland A184/02, 6 September 2002.

Environmental Defence Society Inc v New Zealand King Salmon Co Ltd [2014] NZSC 38, [2014] NZRMA 195.

Environmental Protection Authority Decision on Marine Consent Application: Chatham Rock Phosphate Limited (February 2015).

Environmental Protection Authority Trans-Tasman Resources Ltd Marine Consent Decision (June 2014).

Falkner v Gisborne District Council [1995] 3 NLZR 622 (HC).

Ferguson v Far North District Council [1999] NZRMA 238 (EnvC).

Far North District Council v Te Runanga-a-Iwi O Ngati Kahu [2013] NZCA 221.

Flavell v Western Bay of Plenty District Council EnvC Auckland A016/05, 3 February 2005. 
Frasers Papamoa v Tauranga City Council [2010] 2 NZLR 202 (HC).

Friends and Community of Ngawha Inc v Minister of Corrections [2002] NZRMA 401 (HC).

Friends and Community of Ngawha Inc v Minister of Corrections [2003] NZRMA 272 (CA).

Genesis Power Ltd v Franklin District Council [2005] NZRMA 541 (EnvC).

Geotherm Group Ltd v Waikato Regional Council EnvC Auckland A151/06, 19 November 2006.

Gisborne District Council v Eldamos Investments Ltd HC Gisborne CIV-2005-485-1241, 26 October 2005.

Greenpeace New Zealand Inc v Genesis Power Ltd [2008] NZSC 112, [2009] 1 NZLR 730.

Greenpeace New Zealand Inc v Minister of Energy and Resources [2012] NZHC 1422.

Haddon v Auckland Regional Council [1994] NZRMA 49 (PT).

Harrison v Tasman District Council [1994] NZRMA 193 (PT).

Helmbright v Environment Court [2005] NZRMA 118 (HC).

Housing New Zealand Ltd v Waitakere City Council [2001] 1 NZLR 340 (HC).

Housing New Zealand v Waitakere City Council [2001] NZRMA 202 (CA).

Huakina Development Trust v Waikato Valley Authority [1987] 2 NZLR 188 (HC).

Hume v Auckland Regional Council [2002] NZRMA 422 (CA).

Hurunui Water Project Ltd v Canterbury Regional Council [2015] NZHC 3098, [2016] NZRMA 71.

Infinity Investment Group Holdings Ltd v Queenstown Lakes District Council [2011] NZRMA 321 (HC).

JF Investments Ltd v Queenstown Lakes District Council EnvC Christchurch C48/06, 27 April 2006.

Kirton v Napier City Council [2013] NZEnvC 66.

KPF Investments Ltd v Marlborough District Council [2014] NZEnvC 152, (2014) 18 ELRNZ 367.

Long Bay-Okura Great Park Soc Inc v North Shore City Council EnvC Auckland A078/08, 16 July 2008. 
Lower Waitaki River Management Society Inc v Canterbury Regional Council EnvC Christchurch C080/09, 21 September 2009.

Re Lyttelton Marina EnvC Christchurch C104/98, 4 September 1998.

Machinery Movers Ltd v Auckland Regional Council (1993) 1A ELRNZ 411 (HC).

Mainpower NZ v Hurunui DC [2011] NZEnvC 384.

Mangakahia Maori Komiti v Northland Regional Council [1996] NZRMA 193 (PT).

Maniototo Environmental Society Inc v Central Otago District Council EnvC Christchurch C103/2009, 28 October 2009.

Mason-Riseborough v Matamata-Piako District Council EnvC Auckland A143/97, 11 December 1997.

McGuire v Hastings District Council [2000] UKPC 43, [2002] 2 NZLR 577.

McIntyre v Christchurch City Council (1996) 2 ELRNZ 84 (PT).

McKnight v NZ Biogas Industries Ltd (1994) 1B ELRNZ 263 (CA).

Re Meridian Energy Ltd [2013] NZEnvC 59.

Re Meridian Energy Ltd EnvC Christchurch C125/2003, 12 September 2003.

Meridian Energy Ltd v Central Otago District Council [2010] NZRMA 477 (HC).

Meridian Energy Limited v Central Otago District Council [2011] 1 NZLR 482 (HC).

Meridian Energy Ltd v Wellington City Council EnvC Wellington W31/07, 14 May 2007.

Mora v Te Kohanga Reo Trust [1996] NZRMA 556.

Morgan v Whangarei District Council [2008] NZRMA 113 (HC).

Mount Field Ltd v Queenstown Lakes District Council [2012] NZEnvC 262.

Munro v Manukau City Council EnvC Auckland A074/01, 16 August 2001.

Nash v Queenstown Lakes District Council [2015] NZHC 1041.

New Zealand Maori Council v Attorney-General [1987] 1 NZLR 641 (CA).

New Zealand Maori Council v Attorney-General [1994] 1 NZLR 513 (PC).

New Zealand Rail Ltd v Marlborough District Council [1994] NZRMA 70 (HC). 
New Zealand Recreational Fishing Council Inc v Sanford Ltd [2009] NZSC 54, [2009] 3 NZLR 438.

Ngai Tahu Property Ltd v Central Plains Water Trust [2009] NZSC 24.

North Shore City Council v Auckland Regional Council [1997] NZRMA 59 (EnvC).

Pigeon Bay Aquaculture Ltd v Canterbury Regional Council [1999] NZRMA 209 (EnvC).

Pigeon Bay Aquaculture v Canterbury Regional Council EnvC Christchurch C179/2003, 17 June 2004.

Pinehaven Orchards Ltd v South Wairarapa District Council EnvC Wellington W054/06, 4 July 2006.

Police v Teddy [2013] NZHC 432, [2013] NZAR 299.

Powell v Dunedin City Council [2004] 3 NZLR 721 (CA).

Queenstown Central v Queenstown Lakes District Council [2013] NZHC 815.

Queenstown Lakes District Council v Hawthorn [2006] NZRMA 424 (CA).

$R v$ Conway [2005] NZRMA 274 (CA).

Redvale Lime Co Ltd v Rodney District Council EnvC Auckland A16/06, 15 February 2006.

Reith v Ashburton District Council [1994] NZRMA 241 (PT).

Reuters Homes Ltd v Wanganui District Council [2011] 16 ELRNZ 493 (HC).

Royal Forest and Bird Protection Society v Buller District Council [2013] NZHC 1324, [2013] NZRMA 275.

Royal Forest and Bird Protection Society v Buller District Council [2013] NZHC 1346, [2013] NZRMA 293.

Royal Forest and Bird Protection Society v Buller District Council [2013] NZCA 496, (2013) 17 ELRNZ 616.

Royal Forest and Bird Protection Society v Buller Coal Ltd [2012] NZHC 2156, [2012] NZRMA 552.

Royal Forest and Bird Protection Society v Gisborne District Council EnvC Wellington W26/2009, 7 April 2009.

Sampson v Waikato Regional Council EnvC Auckland A178/02, 2 September 2002. 
Save Kapiti Inc v New Zealand Transport Agency [2013] NZHC 2104.

Shirley Primary School v Christchurch City Council [1999] NZRMA 66 (EnvC).

Smith v Muldoon [2013] NZEnvC 161.

Smith Chilcott Ltd v Auckland City Council [2001] 3 NZLR 473 (CA).

Southern Alps Air v Queenstown Lakes District Council [2008] NZRMA 47 (HC).

Springs Promotions Ltd v Springs Stadium Residents Assn Inc [2006] 1 NZLR 846 (HC).

St Columba's Environmental House Group v Hawkes Bay Regional Council [1994] NZRMA $560(\mathrm{PT})$.

Sustain our Sounds Inc v The New Zealand King Salmon Co Ltd [2014] NZSC 40, [2014] 1 NZLR 673.

Sutton v Moule (1992) 2 NZRMA 41 (CA).

Synlait Ltd v Central Plains Water Trust [2010] NZSC 32, [2010] NZRMA 257.

Taranaki Energy Watch v Taranaki Regional Council EnvC Wellington W039/03, 16 June 2003.

Te Aroha Air Quality Protection Appeal Group v Waikato Regional Council (1993) 1A ELRNZ 399 (PT).

Te Runanga-a-Iwi O Ngati Kahu v Far North District Council [2013] NZSC 134.

Te Runanga-a-Iwi O Ngati Kahu v Far North District Council (2011) 16 ELRNZ 708 (HC).

Te Runanga-a-Iwi O Ngati Kahu v Far North District Council [2013] NZEnvC 372, (2010) 16 ELRNZ 259.

Te Runanga O Taumarere v Northland Regional Council (1996) 2 ELRNZ 41 (PT).

Telecom v Christchurch City Council EnvC Wellington W165/96, 15 November 1996.

Todd Energy Ltd v Taranaki Regional Council EnvC Wellington W101/05, 7 December 2005.

Re Transit New Zealand EnvC Auckland A183/2003, 24 October 2003.

Treaty Tribes Coalition v Urban Maori Authorities [1997] 1 NZLR 513 (PC).

Trio Holdings Ltd v Marlborough District Council [1997] NZRMA 97 (PT). 
Waitakere City Council v Brunel [2007] NZRMA 235 (HC).

Waitakere City Council v Estate Homes Ltd [2006] NZSC 112, [2007] 2 NZLR 149.

Wakatipu Environmental Society Inc v Queenstown Lakes District Council [2000] NZRMA 59 (EnvC).

Warren v Gisborne District Council [2011] NZEnvC 103.

Watercare Services Ltd v Minhinnick (1997) 3 ELRNZ 511 (CA).

Wellington International Airport Ltd v Air New Zealand [1993] 1 NZLR 671 (CA).

West Coast ENT Inc v Buller Coal Ltd [2013] NZSC 87, [2014] 1 NZLR 32.

West Coast Regional Council v Royal Forest and Bird Protection Soc Inc [2007] NZMRA 32 $(\mathrm{HC})$.

Westfield (New Zealand) Ltd v North Shore City Council [2005] NZSC 17, [2005] NZRMA 337.

Re Whitewater New Zealand Inc [2013] NZEnvC 131, [2013] NZRMA 357.

Winstone Aggregates Ltd v Franklin District Council EnvC Auckland A080/02, 17 April 2002.

Wood v West Coast Regional Council [2000] NZRMA 193 (EnvC).

Works Infrastructure Ltd v Taranaki Regional Council [2002] NZRMA 517 (HC).

Zdrahal v Wellington City Council [1995] 1 NZLR 700 (HC).

\section{United Kingdom}

Associated Provincial Picture Houses Ltd v Wednesbury Corporation [1948] 1 KB 223 (CA). Attorney-General's Reference (No 5 of 2000) [2001] Env LR 129.

Augier v Secretary of State for the Environment (1978) 38 P \& CR 219 (QBD).

Newbury $v$ Secretary of State for the Environment [1981] AC 578 (HL).

Shire of Wannon v Riordan [1955] VLR 413. 
D Books and Reports

A Regulatory Framework for the Long-term Underground Geological Storage of Carbon Dioxide in Victoria (Victoria Department of Primary Industries, Melbourne, 2008).

Alberta Carbon Capture Storage and Development Council Accelerating Carbon Capture and Storage Implementation in Alberta (Interim Report, September 2008).

Alberta Government Carbon Capture and Storage: Summary Report of the Regulatory Framework Assessment (Energy Alberta, Edmonton, 2013).

SM Al-Fattah and others Carbon Capture and Storage (CRC Press, 2011).

N Bankes "Developing a Legal Regime for Carbon Capture and Storage in Canada" (ISEE Research Paper, December 2009).

Bannister and others Opportunities for Underground Geological Storage of $\mathrm{CO}_{2}$ in New Zealand: Monitoring and Verification Methodologies (GNS Science, Report 2009/64 CCS08/11, 2009).

B Barton, K Jordan and G Severinsen Carbon Capture and Storage: Designing the Legal and Regulatory Framework for New Zealand (University of Waikato Centre for Environmental, Resources and Energy Law, Hamilton, 2013).

Bellona Brief IPCC $5^{\text {th }}$ Climate Assessment Report (2015).

Between a Rock and a Hard Place (Commonwealth of Australia, Canberra, 2007).

U Beyerlin and T Marauhn International Environmental Law (Hart, Oxford, 2011).

P Birnie, A Boyle and C Redgwell International Law and the Environment $\left(3^{\text {nd }}\right.$ ed, OUP, Oxford, 2009).

R Boast and R Makgill Marine and Coastal Area Act - Demystifying the Hype (NZLS, Wellington, 2011). 
$\mathrm{H}$ Bolscher and others Report for European Commission: Support to the Review of Directive 2009/31/EC on the Geological Storage of Carbon Dioxide (Task 2) (CLIMA.A4/FRA/2011/0027, 2014).

K Bosselman and others Climate Change in New Zealand (NZCEL, Auckland, 2002).

K Bosselmann The Principle of Sustainability: Transforming Law and Governance (Ashgate, Aldershot, 2008).

K Bosselmann, D Grinlinton and P Taylor (eds) Environmental Law for a Sustainable Society $\left(2^{\text {nd }}\right.$ ed, New Zealand Centre for Environmental Law, Auckland, 2013).

K Bosselmann and V Tava (eds) Water Rights and Sustainability (New Zealand Centre for Environmental Law, Auckland, 2011).

A Boyle and D Freestone (eds) International Law and Sustainable Development (OUP, Oxford, 1999).

E Brown Weiss In Fairness to Future Generations (Tokyo, United Nations University Press, 1989).

HC Bugge and C Voigt (eds) Sustainable Development in International and National Law (Europe Law Publishing, Amsterdam, 2008).

S Busuttil and others (eds) Our Responsibilities to Future Generations (1990).

A Cameron (ed) Climate Change Law and Policy in New Zealand (LexisNexis, 2011).

Carbon Capture and Storage: Where are we now? (Proceedings of the International CCS Seminar, 2009).

Carbon Capture Legal Programme Emissions Trading Legislation and CCS (UCL).

Carbon Capture Legal Programme CCS Liability Legislation (UCL).

Carbon Capture Legal Programme CCS Offshore $\mathrm{CO}_{2}$ Storage (UCL).

Carbon Dioxide Capture and Geological Storage: Australian Regulatory Guiding Principles (MCMPR, 2005).

R Carson Silent Spring (Houghton Mifflin, 1962).

C Charters and A Erueti (eds) Māori Property Rights and the Foreshore and Seabed (Victoria University Press, Wellington, 2008). 
D Collard, D Pearce and D Ulph (eds) Economics, Growth and Sustainable Environments (Springer, 1988).

FJ Coyle Tackling Climate Change (Cooperative Research Centre for Greenhouse Gas Technologies, Canberra, 2014).

S Coyle and K Morrow The Philosophical Foundations of Environmental Law (Hart, Oxford, 2004).

T Daya Winterbottom (ed) Frontiers of Resource Management Law (Thomson Reuters, Wellington, 2012).

MA De Figueiredo The Liability of Carbon Dioxide Storage (MIT, Cambridge, 2007).

Department of Primary Industries (Vic) A Regulatory Framework for the Long-term Underground Geological Storage of Carbon Dioxide in Victoria (2008).

J Desbarats (ed) Review of the Public Participation Practices for CCS and non-CCS Projects in Europe (Institute for European Environmental Policy, 2010).

BJ Doody, JS Becker and FJ Coyle What should we do about $\mathrm{CO}_{2}$ ? (GNS Science, Report 2012/27, 2012).

Down Under: Greenhouse Gas Storage (Parliament of the Commonwealth of Australia, Canberra, 2008).

R Dworkin Taking Rights Seriously (Harvard University Press, Cambridge, 1977).

R Eckersley The Green State (MIT Press, Cambridge, 2004).

S Elias, Chief Justice of New Zealand "Righting Environmental Justice" (12 ${ }^{\text {th }}$ Annual Salmon Lecture, Auckland, 25 July 2013).

ENGO Network on CCS Moving CCS Forward in Europe (GCCSI, 2013).

Environmental Law: National Issues Intensive (NZLS, 2009).

Environmental Law Intensive (NZLS, 2014).

Environmental Protection Authority Thresholds and Classifications (2012).

European Commission Energy Roadmap 2050 (EU, Luxembourg, 2012).

European Commission Report on Review of Directive 2009/31/EC on the Geological Storage of Carbon Dioxide (Brussels, 2015). 
DJ Evans and RA Chadwick (eds) Underground Gas Storage (London, Geological Society, 2009).

Executive Office of the President of the United States The Cost of Delaying Action to Stem Climate Change (2014).

J Fahey and R Lyster Geosequestration in Australia: Existing and Proposed Regulatory Mechanisms (Legal Studies Research Paper 08/41, University of Sydney, 2008).

F Ferré Philosophy of Technology (University of Georgia Press, New Jersey, 1995).

B Field and others Interaction of $\mathrm{CO}_{2}$ Storage with Subsurface Resources (IEAGHG, Report 2013-08, April 2013).

B Field and others Interaction of $\mathrm{CO}_{2}$ Storage with Subsurface Resources (IEA, Paris, 2013).

B Field and others New Zealand Carbon Dioxide Storage Site Assessment: Phase 2 (Canberra, Cooperative Research Centre for Greenhouse Gas Technologies, 2009).

M Freeman Lloyd's Introduction to Jurisprudence (Sweet and Maxwell, 2014).

German Advisory Council on Global Change The Future Oceans-Warming up, Rising High, Turning Sour (Special Report, 2006).

M Gerstenberger and others Opportunities for Underground Geological Storage of $\mathrm{CO}_{2}$ in New Zealand: Risk Assessment Methodologies (GNS Science, Report CCS-08/10 2009/63, 2009).

A Gillespie International Environmental Law, Policy and Ethics $\left(2^{\text {nd }}\right.$ ed, OUP, Oxford, 2014).

J Glazewski, A Gilder and E Swanepoel Carbon Capture and Storage: Towards a Regulatory and Legal Regime in South Africa (IMEL, Cape Town, 2012).

B Gleeson and N Low (eds) Governing for the Environment (Basingstoke, Palgrave, 2001).

Global CCS Institute Open CCS: Storage (GCCSI, 2013).

Global CCS Institute CCS Legal and Regulatory Indicator (GCCSI, Melbourne, 2015)

Global CCS Institute The Global Status of CCS: 2015 Summary Report (GCCSI, Melbourne, 2015).

Global CCS Institute The Global Status of CCS: 2014 (GCCSI, Melbourne, 2014). 
M Granger Morgan and S McCoy Carbon Capture and Sequestration: Removing the Legal and Regulatory Barriers (RFF Press, New York, 2012).

Greenpeace False Hope: Why Carbon Capture and Storage won't Save the Climate (Greenpeace International, Amsterdam, 2008).

M Groves (ed) Legitimate Expectation in the Common Law World (Hart, Oxford, 2016).

Guidelines for Injection and Storage of Greenhouse Gas Substances in Offshore Areas (Australian Department of Resources, Energy and Tourism, 2011).

J Habermas Between Facts and Norms: Contributions to a Discourse Theory of Law and Democracy (Cambridge, Polity Press, 1996).

E Hargrove Foundations of Environmental Ethics (Prentice Hall, New Jersey, 1989).

JW Harris Legal Philosophies (Butterworths, London, 1980).

R Harris (ed) Handbook of Environmental Law (Royal Forest and Bird Protection Society of New Zealand, Wellington, 2004).

HLA Hart The Concept of Law ( $3^{\text {rd }}$ ed, OUP, Oxford, 2012).

I Havercroft, R Macrory and RB Stewart (eds) Carbon Capture and Storage: Emerging Legal and Regulatory Issues (Hart, Oxford, 2011).

I Havercroft and $\mathrm{R}$ Macrory Legal Liability and Carbon Capture and Storage: A Comparative Perspective (Global CCS Institute, 2014).

T Hayward Constitutional Environmental Rights (OUP, Oxford, 2004).

J Heinrich Legal Implications of $\mathrm{CO}_{2}$ Ocean Storage (MIT, Cambridge, 2002).

E Heiskanen Snohvit $\mathrm{CO}_{2}$ Capture and Storage Project (2006).

$\mathrm{C}$ Hendriks, MJ Mace and R Coenraads Impacts of EU and International Law on the Implementation of Carbon Capture and Geological Storage in the European Union (European Commission, 2005).

$\mathrm{R}$ von Ihering Law as a Means to an End (Macmillan, New York, 1924).

Implementation of Directive 2009/31/EC on the Geological Storage of Carbon Dioxide: Guidance Documents (European Commission, 2011).

IPCC Carbon Capture and Storage (Cambridge University Press, New York, 2005). 
IPCC Guidelines for National Greenhouse Gas Inventories (IPCC, 2006).

IPCC Synthesis Report: Fifth Assessment Report of the IPCC (IPCC, Geneva, 2014).

IPCC "Summary for Policymakers" in Climate Change 2013: The Physical Science Basis (IPCC, Geneva, 2013).

IEA CCS Model Regulatory Framework (Paris, IEA, 2010).

IEA CCS Roadmap (IEA, Paris, 2009).

IEA $\mathrm{CO}_{2}$ Capture and Storage: A Key Carbon Abatement Option (IEA, Paris, 2008).

IEA Carbon Capture and Storage: Legal and Regulatory Review ( $1^{\text {st }}$ ed, IEA, Paris, 2010).

IEA Carbon Capture and Storage: Legal and Regulatory Review (2 ${ }^{\text {nd }}$ ed, IEA, Paris, 2011).

IEA Carbon Capture and Storage Legal and Regulatory Review ( ${ }^{\text {rd }}$ ed, IEA, 2012).

IEA Carbon Capture and Storage and the London Protocol (IEA, Paris, 2011).

IEA Combining Bioenergy with CCS (IEA, Paris, 2011).

IEA Energy Technology Perspectives 2010 (IEA, Paris, 2010).

IEA Energy Technology Perspectives 2014 (IEA, Paris, 2014).

IEA Energy Technology Perspectives 2015 (IEA, 2015).

IEA Fourth IEA International CCS Regulatory Network Meeting (IEA, Paris, 2012).

IEA Legal Aspects of Storing $\mathrm{CO}_{2}$ (IEA, Paris, 2007).

IEA Methods to Assess Geologic $\mathrm{CO}_{2}$ Storage Capacity (IEA, Paris, 2013).

IEA Tracking Progress in Carbon Capture and Storage (2002).

IEA World Energy Outlook (IEA, Paris, 2014).

International ENGO Network on CCS Environmental Non-Government Organisation Perspectives on Carbon Capture and Storage (GCCSI, 2012).

International Risk Governance Council Regulation of Carbon Capture and Storage (IRGC, Geneva, 2008).

Interstate Oil and Gas Compact Commission Storage of Carbon Dioxide in Geological Structures: Model Statute (2007).

L Kaplow and S Shavell Fairness versus Welfare (Harvard University Press, 2009). 
DR Keller (ed) Environmental Ethics: the Big Questions (Wiley Blackwell, West Sussex, 2010).

H Kelsen Pure Theory of Law (University of California Press, 1978).

J Kelsey The New Zealand Experiment - A World Model for Structural Adjustment? (Auckland University Press, Auckland, 1995).

PR King and others Opportunities for Underground Storage of $\mathrm{CO}_{2}$ in New Zealand: Onshore Taranaki Basin Overview (GNS Science, Report CCS-08/5 2009/58, 2008).

A Kiss and D Shelton International Environmental Law $\left(3^{\text {rd }}\right.$ ed, New York, Transnational Publishers, 2004).

Y Le Bouthillier and others (eds) Poverty Alleviation and Environmental Law (Edward Elgar, Cheltenham, 2012).

Land and Water Forum A Fresh Start for Freshwater (Land and Water Forum, 2010).

FM Lehman Offshore Carbon Dioxide Capture and Storage (PL Academic, Frankfurt, 2011).

W Lippman Essays on the Public Philosophy (Hamish Hamilton, London, 1955).

E Louka International Environmental Law (Cambridge University Press, Cambridge, 2006).

P McAuslan The Ideologies of Planning Law (Pergamon Press, Oxford, 1980).

McCormick A Greenhouse Gas Accounting Framework for CCS Projects (C2ES, 2012).

S McCoy Carbon Capture and Storage: Legal and Regulatory Review (4 ${ }^{\text {th }}$ ed, IEA/OECD, Paris, 2014).

R MacDonald and D Johnston (eds) Towards World Constitutionalism (Martinus Nijhoff, 2007).

McKinsey \& Co Carbon Capture \& Storage: Assessing the Economics (McKinsey, 2008).

R Macrory and M Woods Modernising Environmental Justice (UCL, 2003).

R Macrory (ed) Principles of European Environmental Law (Groningen, Europa Law Publishing, 2004).

R Macrory and others Legal Status of $\mathrm{CO}_{2}$-Enhanced Oil Recovery (UCL Carbon Capture Legal Programme, 2013). 
P Marston Bridging the Gap - An Analysis and Comparison of Legal and Regulatory Frameworks for $\mathrm{CO}_{2}-\mathrm{EOR}$ and $\mathrm{CO}_{2}-\mathrm{CCS}$ (Global Carbon Capture Storage Institute, 2013).

P Martin and others (eds) In Search of Environmental Justice (Edward Elgar, 2015).

Ministry for the Environment Freshwater Reform 2013 and Beyond (MfE, 2013).

Ministry for the Environment Resource Management Act: Survey of Local Authorities 2010/2011 (2011).

Ministry for the Environment New Zealand's Sixth National Communication under the UNFCCC (MfE, Wellington 2013).

Ministry of Transport Transporting Dangerous Goods Safely (2008).

C Morris, J Boston and P Butler (eds) Reconstituting the Constitution (Springer, New York, 2011).

NETL Carbon Dioxide Enhanced Oil Recovery (2010).

New Zealand CCS Partnership CCS in New Zealand: Can Carbon Capture and Storage Deliver Value to New Zealand as we Head towards a Low Carbon Future? Summary Report (NZ CCS Partnership, 2011).

New Zealand Energy Strategy 2011-2021 (Ministry of Economic Development, 2011).

New Zealand Law Commission A New Zealand Guide to International Law and its Sources (NZLC R34, 1996).

D Nolan (ed) Environmental and Resource Management Law (5 $5^{\text {th }}$ ed, LexisNexis, Wellington, 2015).

NZ Petroleum\&Minerals New Zealand Block Offer: Invitation for Bids (2016).

OSPAR Commission Report from the Group of Jurists and Linguists on Placement of Carbon Dioxide in the OSPAR Maritime Area (2004).

G Palmer Constitutional and Administrative Law in New Zealand (Victoria University Press, Wellington, 2002).

G Palmer Environment - The International Challenge (Victoria University Press, Wellington, 1995).

M Palmer The Treaty of Waitangi in New Zealand's Law and Constitution (Victoria University Press, Wellington, 2008). 
Parliament of the Commonwealth of Australia Offshore Petroleum Amendment (Greenhouse Gas Storage) Bill 2008: Revised Explanatory Memorandum (2008).

Parliamentary Commissioner for the Environment Evaluating the Environmental Impacts of Fracking in New Zealand (2012).

Parliamentary Commissioner for the Environment Lignite and Climate Change (Wellington, 2010).

Parliamentary Commissioner for the Environment Making Difficult Decisions: Mining the Conservation Estate (Wellington, 2010).

Parliamentary Commissioner for the Environment Towards Sustainable Development: The Role of the Resource Management Act 1991 (Wellington, 1998).

C Philibert, J Ellis and J Podkanski Carbon Capture and Storage in the CDM (IEA, Paris, 2007).

Prospects for Carbon Capture and Storage in South East Asia (Asian Development Bank, 2013).

J Raz The Authority of Law (2 ${ }^{\text {nd }}$ ed, OUP, Oxford, 2009).

RL Revesz Foundations of Environmental Law and Policy (OUP, New York, 1997).

Report of the Review Group on the Resource Management Bill (MfE, Wellington, 1991).

K Robertson, J Findsen, and S Messner International Carbon Capture and Storage Projects (DOE/NETL, 2006).

MM Roggenkamp and E Woerdman (eds) Legal Design of Carbon Capture and Storage (Intersentia, Antwerp, 2009).

HA Rolston A New Environmental Ethics (Routledge, 2012).

Royal Society of New Zealand Climate Change Implications for New Zealand (2016).

Royal Society of New Zealand Transition to a Low Carbon Economy for New Zealand (2016).

N de Sadeleer Environmental Principles (OUP, Oxford, 2002).

M Sagoff The Economy of the Earth (Cambridge University Press, Cambridge, 2008).

P Salmon and D Grinlinton (eds) Environmental Law in New Zealand (Thomson Reuters, Wellington, 2015). 
P Sands and others Principles of International Environmental Law $\left(3^{\text {rd }}\right.$ ed, Cambridge University Press, Cambridge, 2012).

SCCS $\mathrm{CO}_{2}$ Storage and Enhanced Oil Recovery in the North Sea (University of Edinburgh, 2015).

MN Shaw International Law (6 $6^{\text {th }}$ ed, Cambridge University Press, Cambridge, 2008).

C Smith An Insight into why Environmental Groups Support CCS (2014).

L Smith "Carbon Capture and Storage" in Key Issues for the New Parliament 2010 (House of Commons Library Research).

V Stagpoole, H Bushe and M Milner Opportunities for Underground Geological Storage of $\mathrm{CO}_{2}$ in New Zealand: Offshore Waikato Region (GNS Science, Report CCS-08/4 2009/57, 2009).

C Stone Earth and Other Ethics (Harper and Row, New York, 1987).

Strategic Analysis of the Global Status of Carbon Capture and Storage: Report 3: Country Studies: New Zealand (GCCSI, 2009).

Strategic Analysis of the Global Status of Carbon Capture and Storage: Report 3: Policies and Legislation Framing Carbon Capture and Storage Globally (Global CCS Institute, 2009).

P Taylor Respect for Nature (Princeton University Press, 1986).

P Taylor and J Kleinig Valuing Life (Princeton University Press, 1991).

Technical Advisory Group Report of the Minister for the Environment's Resource Management Act 1991 Principles Technical Advisory Group (2012).

Transfield Worley Carbon Dioxide Transport and Pipelines (July 2013).

NZCCS Partnership CCS in New Zealand: Case Studies for Commercial Scale Plant (2010).

UK Department of Energy and Climate Change CCS Roadmap (2012).

United Nations Recommendations on the Transport of Dangerous Goods Model Regulations (Geneva, 1999).

Waitangi Tribunal Radio Spectrum Management and Development (Brookers, Wellington, 1999).

Waitangi Tribunal Te Maunga Railways Land Report (Brookers, Wellington, 1994). 
Waitangi Tribunal The Ngai Tahu Report (Brookers, Wellington, 1991).

C Warnock and M Baker-Galloway Focus on Resource Management Law (LexisNexis, Wellington, 2015).

A Watson Legal Transplants (University of Georgia Press, 1974).

World Commission on Environment and Development Our Common Future (OUP, Oxford, 1987).

World Resources Institute CCS Guidelines (WRI, Washington, DC, 2008).

World Resources Institute CCS and Community Engagement (WRI, 2010).

D Young Keeper of the Long View (PCE, Wellington, 2007).

D Young Values as Law (VUW Institute of Policy Studies, Wellington, 2001).

$\mathrm{P}$ Zakkour Choices for Regulating $\mathrm{CO}_{2}$ Capture and Storage in the EU (European Commission, Amsterdam, 2007).

D Zillman and others (eds) Beyond the Carbon Economy (OUP, Oxford, 2008).

D Zillman, A Lucas and G Pring (eds) Human Rights in Natural Resources Development (OUP, Oxford, 2002).

E Journal Articles

A Aarnio "Taking Rules Seriously" (1990) 42 ARSP 180.

K Abend "Geological Sequestration of Carbon Dioxide" (2010-2011) 5 Appalachian Nat Res LJ 1.

D Adelman and I Duncan "The Limits of Liability in Promoting Safe Geologic Sequestration of $\mathrm{CO}_{2} "$ (2011) 22 Duke Envtl L and Pol Forum 1.

C Armeni, 'Carbon Capture and Storage in the Sub-Seabed and Sustainable Development: Please Mind the Gap' (2013) 27 Ocean Yearbook 1.

B Armstrong "Time for a More Eco-Centric Approach to Resource Management in New Zealand" (August 2014) RMJ 7. 
AM Arranz "Carbon Capture and Storage: Frames and Blind Spots" (2015) 82 Energy Policy 249.

A Arthur-Young and J Riddell "Climate Change and the RMA" [2014] NZLJ 82.

A Baghaki "The Inequitable Connections between Environmental Degradation, Climate Change and Poverty" (2014) 18 NZJEL 1.

N Bankes, J Poschwatta, and EM Shier "The Legal Framework for Carbon Capture and Storage in Alberta" (2008) 45 Alberta Law Review 585.

S Barrymore and A Mathison, "Update: Offshore Petroleum Amendment (Greenhouse Gas Storage) Bill 2008 (Cth)” (2008) 27 ARELJ 469.

B Barton "Carbon Capture and Storage Law for New Zealand: A Comparative Study" (2009) 13 NZJEL.

S Beder "Costing the Earth" (2000) 4 NZJEL 227.

V Been “What’s Fairness Got to Do with it?” (1993) 78 Cornell Law Review 1001.

P Beverley "The Mechanisms for the Protection of Maori Interests under Part II of the Resource Management Act 1991" (1998) 2 NZJEL 121.

R Beverley "The Incorporation of the Principles of the Treaty of Waitangi into the Resource Management Act 1991" (1997) 1 NZJEL 125.

C Bidlack "Regulating the Inevitable" (2010) 30 J Land Resources \& Envtl L 199.

I Boisvert "Lifting the Looking Glass" (2011) 15 NZJEL 1.

F Bowen "Carbon Capture and Storage as a Corporate Technology Strategy Challenge" (2011) 39 Energy Policy 2256.

A Brennan "Moral Pluralism and the Environment" (1992) 1 Environmental Values 15.

A Brower "The ECan Act, Parliamentary Sovereignty and Environmental Law" (2010) 8 BRMB 144.

B Brunette "Freshwater Management and Allocation under the Resource Management Act 1991" (2006) 10 NZJEL 169.

P Burdon "Wild Law: A Proposal for Radical Social Change" (2015) 13 NZPIL 157.

SJ Burton "Normative Legal Theories: The Case for Pluralism and Balancing" (2012-2013)

98 Iowa L Rev 535. 
JB Callicott "The Case against Moral Pluralism" (1990) 12 Environmental Ethics 99.

TA Campbell, RA James and J Hutchings "Carbon Capture and Storage Project Development" (2007-2008) 38 Tex Envtl LJ 169.

A Cao "Climate Change Considerations in Energy Decision-making" (2014) 18 NZJEL 111.

I Carlman "The Resource Management Act 1991 through External Eyes" (2007) 11 NZJEL 181.

M Christensen "Valuation of Natural Assets under the Resource Management Act" (2013) 17 NZJEL 291.

R H Coase "The Problem of Social Cost" (1960) 3 Journal of Law and Economics 1.

RM Cueller-Franca and A Azapagic "Carbon Capture, Storage and Utilisation Technologies" (2015) 9 Journal of $\mathrm{CO}_{2}$ Utilization 82.

T Dixon, J Garrett and E Kleverlaan "Update on the London Protocol” (2014) 63 EGYPRO 6623.

A Dobson (ed) Fairness and Futurity (OUP, Oxford, 1999).

M Doelle and E Lukaweski "Carbon Capture and Storage in the CDM" (2012) 3 Climate Law 49.

Y Downing "Hydraulic Fracturing and Protection in Law from Negative Effects in New Zealand" (2012) 16 NZJEL 243.

N Durrant "Carbon Capture and Storage Laws in Australia: Project Facilitation or a Precautionary Approach?" (2010) 18 Environmental Liability Journal 148.

P Ekanayake, P Moriarty and D Honnery "Equity and Energy in Global Solutions to Climate Change" (2015) 26 Energy for Sustainable Development 72.

TR Elliot and MA Celia "Potential Restrictions for $\mathrm{CO}_{2}$ Sequestration Sites due to Shale and Tight Gas Production” (2012) 46 Environ Sci Technol 4223.

J Ennis-King, K Pruess and N Spycher " $\mathrm{CO}_{2}-\mathrm{H}_{2} \mathrm{O}$ Mixtures in the Geological Sequestration of $\mathrm{CO}_{2} "$ (2003) 67 Geochimica et Cosmochimica Acta 3015.

B Evar “Conditional Inevitability” (2011) 39 Energy Policy 3414.

M Faber "How to be an Ecological Economist" (2008) 66 Ecological Economics 1.

S Foster "Redirecting the Flow" (2007) 7 BRMB 27. 
L Fraser "Property Rights in Environmental Management" (2008) 12 NZJEL 145.

PK Freeman and H Kunreuther "The Roles of Insurance and Well-Specified Standards in Dealing with Environmental Risks" (1996) 17 Managerial \& Decision Econ 517.

B Freifeld and others "Geothermal Energy Production Coupled with CCS" (2013) 37 EGYPRO 6595.

J Friedrich "Carbon Capture and Storage: A New Challenge for International Environmental Law” 67 Zeitschrift fur auslandisches offentliches Recht und Volkerrecht (2007).

A Gillespie "Precautionary New Zealand" (2011) 24 NZULR 364.

S Glazebrook "Human Rights and the Environment" (2009) 40 VUWLR 293.

W Grey "Anthropocentrism and Deep Ecology" (1993) 71(4) Australasian Journal of Philosophy 463.

D Grinlinton "Access to Environmental Justice in New Zealand" [1999] Acta Juridica 80.

D Grinlinton "Does the RMA Need More Reform?" [1997] 2 BRMB 49.

D Grinlinton "Integrated Resource Management - A Model for the Future"(1992) 9 EPLJ 4.

D Grinlinton "Natural Resources Law Reform in New Zealand - Integrating Law, Policy and Sustainability" (1995) AJNRLP 1.

D Grinlinton 'Property Rights, the 'Public Interest' and Global Considerations" (2007) 7 BRMB 62.

D Grinlinton "The Nature of Property Rights in Resource Consents" (2007) 7 BRMB 37.

I Guddas, T Hohmuth and L Schafer "Crediting $\mathrm{CO}_{2}$ Sequestration" (2008) 4 CCLR 387.

B Gussen "Subsidiarity as a Constitutional Principle in New Zealand” (2014) 12 NZJPIL 123.

A Haan-Kamminga, MM Roggenkamp and E Woerdman "Legal Uncertainties of Carbon Capture and Storage in the EU" (2010) 3 CCLR 240.

G Hardin "The Tragedy of the Commons" (1968) 162 Science 1243.

B Harris "Sustainable Management as an Express Purpose of Environmental Legislation" (1993) 8 Otago Law Review 51. 
G Haver and HC Bugge "Transboundary Chains for CCS" (2007) 4 Journal for European Environmental and Planning Law 367.

I Havercroft and R Purdy "Carbon Capture and Storage - A Legal Perspective" <www.un.org>.

A Hayward "Freshwater Management: Water Markets and Novel Pricing Regimes" (2006) 10 NZJEL 215.

H Herzog "What Future for Carbon Capture and Sequestration?" (2001) Environmental Science and Technology 35.

NR Hoffman "The Emergence of Carbon Sequestration" (2011-2012) 29 Pace Envtl LR 218.

NR Hoffman "The Feasibility of Applying Strict Liability Principles to Carbon Capture and Storage" (2009-2010) 49 Washburn LJ 527.

E Hudspith "Freshwater Management in New Zealand" (2013) 16 NZJEL 277.

A Ingelson, A Kleffner and N Nielson "Long-term Liability for Carbon Capture and Storage in Depleted North American Oil and Gas Reservoirs" (2010) 31 Energy Law Journal 431.

C Iorns and G Severinsen "Diving in the Deep End" (2015) 13 NZJPIL 201.

S Hayes "Defining Kaitikaitanga and the Resource Management Act 1991" (1998) 8 Auckland U L Rev 893.

JR Jackson "The Role of Economics in the RMA" (1999) 3 NZJEL 19.

K Johnston “The Treaty of Waitangi” (2008) NZ L Rev 609.

J Jones "Regulatory Design for Scientific Uncertainty" (2007) 19 J Environmental Law 347.

K Keith "The Treaty of Waitangi in the Courts" (1990)1 4 NZULR 37.

A Klass and E Wilson "Climate Change and Carbon Sequestration" (2008-2009) 58 Emory LJ 103.

U Klein "Belief Views on Nature" (2000) 4 NZJEL 81.

U Klein “Integrated Resource Management in New Zealand” (2001) 5 NZJEL 1.

D Langlet "Exporting $\mathrm{CO}_{2}$ for Sub-Seabed Storage" (2015) 30 International Journal of Marine and Coastal Law 395.

D Langlet “Safe Return to the Underground?” (2009) 18 RECIEL 286. 
M Lassen "Sub-seabed Storage in the Maritime Zones of the 1982 Law of the Sea Convention” (2014) 29 International Journal of Marine and Coastal Law 381.

I Leersnyder “Free for All or User Pays?” (2008) 12 NZJEL 65.

L Mabon and others "Perceptions of Sub-seabed Carbon Dioxide Storage in Scotland and Implications for Policy" (2014) 45 Marine Policy 9.

MJ Mace, C Hendriks and R Coenraads "Regulatory Challenges to the Implementation of Carbon Capture and Geological Storage within the European Union under EU and International Law" (2007) 1 International Journal of Greenhouse Gas Control 253.

P Marston and P Moore "From EOR to CCS" (2008) 29 Energy Law Journal 21.

B Marten "Limitation of Liability in Maritime Law and Vessel-source Pollution" (2013) 9 NZ Law Review 199.

MG Massicotte, AL Ross and CB Thompson "The Changing Legislation and Regulation of Carbon Capture and Storage" (2011-2012) 49 Alta L Rev 305.

J McLaren and J Fahey "Key Legal and Regulatory Considerations for the Geosequestration of Carbon Dioxide in Australia" (2005) 24 ARELJ 46.

J McLean "New Zealand's Resource Management Act 1991: Process with Purpose?" (1992) 7 Otago LR 538.

A Memon and P Skelton "The Practice of Environmental Compensation under the Resource Management Act 1991”(2004) 8 NZJEL 177.

J Milligan "Equity in the Resource Management Act” (2000) 4 NZJEL 245.

B Milligan "Planning for Offshore $\mathrm{CO}_{2}$ Storage" (2014) 48 Marine Policy 162.

M Montini and E Orlando "Balancing Climate Change Mitigation and Environmental Protection Interests in the EU Directive on Carbon Capture and Storage" (2012) 3 Climate Law 165.

A Nollkaemper "Transboundary Movement of Hazardous Waste for the Purpose of Dumping at Sea" (1991) 22 Marine Pollution Bulletin 377.

G Palmer "New Zealand's Defective Law on Climate Change" (2015) 13 NZJPIL115.

G Palmer "The Resource Management Act - How we got it and what Changes are being made to it" (2014) RM Theory\&Practice 22. 
K Palmer and D Grinlinton "Developments in Renewable Energy Law and Policy in New Zealand" (2014) 32 Journal of Energy and Natural Resources Law 245.

M Pickford "Economic Efficiency and the Resource Management Act" (2014) 18 NZJEL 149 at 153 .

J Pike, "Waste Not Want Not" (2002) 14 Journal of Environmental Law 197.

B Praetorious and K Schumacher "Greenouse Gas Mitigation in a Carbon Constrained World" (2009) 37 Energy Policy 5081.

R Purdy "The Legal Implications of Carbon Capture and Storage under the Sea" (2006) Sustainable Development Law \& Policy 22.

R Purdy and I Havercroft "Carbon Capture and Storage: Developments under European Union and International Law" (2007) 5 JEEP 353.

F Orr "Storage of Carbon Dioxide in Geological Formations" (2004) 56 Journal of Petroleum Technology 90.

H Rolston "Rights and Responsibilities on the Home Planet" (1993) 18 Yale Journal of International Law 251.

J Ruru "Managing our Treasured Home" (2004) 8 NZJEL 243.

P Salmon "Access to Environmental Justice" (1998) 2 NZJEL 1.

PH Sands "Sovereignty Bounded" (2004) 4 Global Envtl Pol 47.

J Sax "Our Precious Water Resources" [2009] RM Theory \& Practice 30.

J Sax "The Public Trust Doctrine in Natural Resources Law" (1970) 68 Michigan Law Review 471.

S Schofield "Waste Management Law in New Zealand" (2010) 14 NZJEL 223.

L Sheehan "Implementing Rights of Nature through Sustainability Bills of Rights" (2015) 13 NZJPIL 89.

D Shelton "Human Rights, Environmental Rights, and the Right to Environment" (1991) 28 Stanford Journal of International Law 103.

G Severinsen "Variation 6: A Fresh Approach to Water Allocation" (April 2012) RMJ 17.

G Severinsen "Bearing the Weight of the World" (2014) 26 NZULR 375. 
G Severinsen "Consenting to a Bottom Line in the RMA?" (2014) 10 BRMB 192.

G Severinsen "Constructing a Legal Framework for Carbon Capture and Storage in New Zealand" (2014) 63 EGYPRO 6629.

G Severinsen "Glass half Empty or Glass half Full?" (2016) 11 BRMB 110.

G Severinsen “Letting our Standards Slip?” (2014) 18 NZJEL 173.

G Severinsen "The Role of Environmental Risk in Sentencing under the RMA" (2015) 11 BRMB 3.

G Severinsen "Towards an Effective Legal Framework for the Geo-Sequestration of Carbon Dioxide in New Zealand" (2010) 16 Canta LR 330.

J Sinner and J Scherzer “The Public Interest in Resource Rent” (2007) 11 NZJEL 279.

C Stone "Should Trees have Standing?" (1972) 45 S Cal LR 450.

N Swayne and A Phillips "Legal Liability for Carbon Capture and Storage in Australia" (2012) 29 Environmental and Planning Law Journal 189.

A Tal "Tried and True: Reducing Greenhouse Gas Emissions in New Zealand through Conventional Environmental Legislative Modalities" (2009) 12 Otago L Rev 149.

P Taylor "Heads in the Sand as the Tide Rises" (2000) 19 UCLA Journal of Environmental Law and Policy 247.

P Taylor "The Business of Climate Change: What's Ethics got to do with it?" (2007) 20 Pacific McGeorge Global Business and Development Law Journal 161.

D Tladi "Of Course for Humans: A Contextual Defence of Intergenerational Equity" (2007) 9 South African Journal of Environmental Law and Policy 177.

L Toomey "Public Participation in Resource Management" (2012) 16 NZJEL 117.

R Treumann "Global Problems, Globalization and Predictability" (1991) 31 World Futures 14.

A Tunks "Tangata Whenua Ethics and Climate Change" [1997] 1 NZJEL 67.

SD Upton "Purpose and Principle in the Resource Management Act" (1995) 3 Wai L Rev 17.

B van der Zwaan and R Gerlagh "Offshore CCS and Ocean Acidification" (2016) 137 Climatic Change 157. 
J Vince "Maori Consultation under the Resource Management Act and the 2005 Amendments" (2006) 10 NZJEL 295.

H Wagener "The Waste Minimisation Act 2008 and the Ability of Territorial Authorities to Manage Solid Waste" (2009) 13 NZJEL 295.

I Walker and others "Regulating Carbon Dioxide Storage Operations near Oil and Gas Fields" (2013) 37 EGYPRO 7766.

P Wallace "Integrated Conservation Management" (2011) 15 NZJEL 185.

C Warnock "The Climate Change Regime" (2004) 8 NZJEL 88.

C Whata "Environmental Rights in Times of Crisis" [2013] RM Theory \& Practice 42.

L White "The Historical Roots of our Ecological Crisis" (1967) 155 (3767) Science 1203.

E Wilson and A Gibbons "Deploying Carbon Capture and Storage in Europe and the United States" (2007) 5 JEEP 343.

E Wilson, A Klass and S Bergan "Assessing a Liability Regime for Carbon Capture and Storage" (2009) 1 EGYPRO 4575.

\section{F $\quad$ Other Sources}

International Standards Organisation, TC265, ISO 27917.

Ministry of Business, Innovation and Employment (January 2016) "CCS in New Zealand" <www.mbie.govt.nz>.

$<w w w . e p a . g o v>$. 